\title{
Transitional Societies, Democratic Accountability and Policy Responses: The Formulation of the Truth Commission-Approach to a Transitional Justice Policy (South Africa, Nigeria, Ghana)
}

by

Franklin Oduro, BA, Mphil.

A thesis submitted to the Faculty of Graduate and Post Doctoral Affairs in partial fulfillment of the requirements for the degree of

Doctor of Philosophy

in

Political Science

Carleton University

Ottawa, Ontario

(C) 2012

Franklin Oduro 
Library and Archives

Canada

Published Heritage

Branch

395 Wellington Street

Ottawa ON K1A ON4

Canada
Bibliothèque et

Archives Canada

Direction du

Patrimoine de l'édition

395 , rue Wellington

Ottawa ON K1A ON4

Canada
Your file Votre référence

ISBN: 978-0-494-89343-2

Our file Notre référence

ISBN: $978-0-494-89343-2$

\section{NOTICE:}

The author has granted a nonexclusive license allowing Library and Archives Canada to reproduce, publish, archive, preserve, conserve, communicate to the public by telecommunication or on the Internet, loan, distrbute and sell theses worldwide, for commercial or noncommercial purposes, in microform, paper, electronic and/or any other formats.

The author retains copyright ownership and moral rights in this thesis. Neither the thesis nor substantial extracts from it may be printed or otherwise reproduced without the author's permission.
AVIS:

L'auteur a accordé une licence non exclusive permettant à la Bibliothèque et Archives Canada de reproduire, publier, archiver, sauvegarder, conserver, transmettre au public par télécommunication ou par l'Internet, prêter, distribuer et vendre des thèses partout dans le monde, à des fins commerciales ou autres, sur support microforme, papier, électronique et/ou autres formats.

L'auteur conserve la propriété du droit d'auteur et des droits moraux qui protege cette thèse. $\mathrm{Ni}$ la thèse ni des extraits substantiels de celle-ci ne doivent être imprimés ou autrement reproduits sans son autorisation.
In compliance with the Canadian Privacy Act some supporting forms may have been removed from this thesis.

While these forms may be included in the document page count, their removal does not represent any loss of content from the thesis.
Conformément à la loi canadienne sur la protection de la vie privée, quelques formulaires secondaires ont été enlevés de cette thèse.

Bien que ces formulaires aient inclus dans la pagination, il n'y aura aucun contenu manquant. 


\begin{abstract}
This dissertation is a comparative study on policy formulation processes of the Truth and Reconciliation Commission (TRC) approach of three cases in Africa. At the centre of this inquiry are the issues of the replication of the TRC-approach across borders, and the policy formulation process of TRCs in the domestic politics of certain countries in Africa. Two main research questions are asked: what explains the reproduction of the TRC-approach across borders in Africa; and what factors and/or forces determine the policy establishment of the TRC-approach, shape its mandate and condition its success or failure? Featuring the 'most similar systems' in investigating the cases of South Africa, Nigeria and Ghana, the study demonstrates that in each instance the development of a policy on the TRC-approach has involved an act of policy transfer that has been the mechanism for its reproduction across Africa; and that the domestic policy formulation processes of the TRC-approach result from the interplay of policy actors, both domestic and transnational, with the domestic structures on the notion of restorative justice that underpins TRCs. The policy formulation process of the TRCapproach in the domestic political environment is thus both constitutive and contextual.

The study clearly makes obvious that a social constructivist framework elucidates the policy transfer and the associated domestic formulation processes of recent TRC-approaches to transitional justice in Africa. This study thus departs from the prevailing theoretical paradigms for explaining the policy formulation of the TRC-approach to transitional justice programs. Rather, it suggests that the policy formulation processes of the TRC-approach in Africa are characterized by a social constructivist account of policy transfers. Subsequently, the study corroborates the usefulness of policy transfer models in Africa, and posits, to a large extent, that African states are increasingly making good efforts to institutionalize public policy-making. By extending the policy lens through which to interrogate TRC policy formulation process, this study liberates the transitional justice discourse from the dominance of legal perspectives. It is imperative that researchers look at the domain of policy analysis to examine, at least in Africa, the recent discourse on transitional justice.
\end{abstract}




\section{Acknowledgement}

I have benefited immeasurably throughout the writing of this dissertation. From the start to the completion of this dissertation, I received gracious support from several people and organizations. It is proper that I acknowledge them. First, I would like to recognize the members of my supervisory committee in the persons of Professor Chris Brown, Professor Scott Bennett, both at Carleton University, and Professor Rosemary Nagy of Nipissing University. I sincerely thank them for their supervision, continuous counsel, and support throughout the writing of this dissertation. To Professor Chris Brown, my principal supervisor, I wish to express my profound appreciation for his patience and the generosity with his time to me. I also want to acknowledge Professor Joanna Quinn of University of Western Ontario and Professor David Mendeloff of Carleton University, both of whom, respectively, served as the external and internal examiners for this dissertation. I remain grateful to all of them.

Second, I would like to acknowledge my former lecturers at the department of political science at the University of Ghana, Legon, who have all contributed to my accomplishment of this level of academia. To this end, I cannot for a moment forget the late Professor Edward Osei Kwadwo Prempeh. As my academic adviser when I enrolled at Carleton University, I could not have reached this stage without his guidance, particularly during the early years of studies in Canada. Equally, Professor E. Gyimah-Boadi and Dr. Baffour Agyeman-Duah, both founding directors of the Ghana Center for Democratic Development (CDD-Ghana), deserve my appreciation for their encouragement and mentoring throughout my doctoral studies. My relationship with them began in 1997 and I have benefitted from their counsel. I am also grateful to my friends, school mates and colleagues resident in Canada, Ghana, Nigeria, South Africa and the United States who have been supportive in one way or another during this period of studies.

Third, I want to acknowledge the Centre for the Study of Violence and Reconciliation (CSVR) in South Africa, the Centre for Public Policy Research (CPPR) in Nigeria, and the CDD-Ghana for providing me with a base to conduct my field research during 2008 and 2009. To Nahla Valji of CSVR, Dr. Sam Amadi of CPPR, and Professor Gyimah-Boadi of CDD-Ghana, I thank you sincerely for hosting me. I am also grateful to Dr. Louis Bickford, then at the International Centre for Transitional Justice (ICTJ) and Dr. Dorina Bekoe, formerly with the United States Institute of Peace (USIP) for facilitating my research work in these institutions. To all my field research interview respondents, I thank you for spending your time and sharing your views with me. I will forever be grateful.

Fourth, my deep appreciation goes to my parents, John Osei-Kofi and Elizabeth Osei Adiyiah, for providing me with love and supporting my education. To my father, in particular, who did not live to read this dissertation, I will always be indebted to you. To all my siblings I am thankful for your words of encouragement and prayers. I must, in particular mention my elder brother, Paul Osei Williams (aka C.O) for his financial assistance throughout my education. As for Millicent, you endured and you understood. And for that, I am thankful to you.

Finally, for everything and for the strength to complete this dissertation, I give thanks and acknowledgment to the Almighty God.

iii 
This work was carried out with the aid of a grant from the International Development Research Center, Ottawa, Canada. Information on the Centre is available on the web at www.idrc.ca. To the Center, I acknowledge the generous financial support.

In the end, I am solely responsible for any shortcomings associated with this dissertation. 


\section{Acronyms}

\begin{tabular}{|c|c|}
\hline AFRC & - $\quad$ Armed Forces Revolutionary Council \\
\hline AMM & - Ahmadiyya Muslim Mission \\
\hline ANC & - African National Congress \\
\hline ATJRN & - African Transitional Justice Research Network \\
\hline $\mathrm{AU}$ & - African Union \\
\hline AZAPO & - Azania Peoples Organization \\
\hline $\mathrm{BC}$ & - Black Consciousness \\
\hline $\mathrm{CDD}$ & - Center for Democracy and Development \\
\hline CDD-Ghana & - Ghana Center for Democratic Development \\
\hline CDHR & - Committee for the Defence of Human Rights \\
\hline CLO & - Civil Liberty Organization \\
\hline CLPA & - Constitutional, Legal and Parliamentary Affairs \\
\hline CODESA & - Convention for a Democratic South Africa \\
\hline CPMRD & - Conflict Prevention, Management and Resolution Department \\
\hline CPPR & - Center for Public Policy Research \\
\hline CSO & - Civil Society Organization \\
\hline CSVR & - Center for the Study of Violence and Reconciliation \\
\hline DDR & - Demilitarization, Demobilization and Reintegration \\
\hline FF & - Freedom Front \\
\hline HRVC & - Human Rights Violation Committee \\
\hline HRVIC & - Human Rights Violations Investigation Commission \\
\hline ICC & - International Criminal Court \\
\hline
\end{tabular}




\begin{tabular}{|c|c|}
\hline ICTR & - International Criminal Tribunal for Rwanda \\
\hline ICTJ & International Center for Transitional Justice \\
\hline ICTY & - International Criminal Court of Yugoslavia \\
\hline IFI & - $\quad$ International Financial Institution \\
\hline IFP & - Inkatha Freedom Party \\
\hline IJR & - Institute of Justice and Reconciliation \\
\hline IMF & - International Monetary Fund \\
\hline IDASA & - Institute of Democracy for South Africa \\
\hline INGO & - International Non-Governmental Organization \\
\hline ISA & - International Studies Association \\
\hline KAIPTC & Kofi Annan International Peacekeeping Training Centre \\
\hline $\mathrm{KNC}$ & - $\quad$ Ken Nnamani Center for Leadership and Development \\
\hline KTJRC & - Kenyan Truth, Justice and Reconciliation Commission \\
\hline LEDAP & - Legal Defence and Assistance Project \\
\hline LRC & - Legal Resource Consortium \\
\hline LRC & Legal Resource Center \\
\hline MNC & - Multi-national Corporation \\
\hline NCC & - National Commission on Culture \\
\hline NEC & - National Executive Committee \\
\hline NDC & - National Democratic Congress \\
\hline NDI & - National Democratic Institute \\
\hline NEPAD & - New Partnership for African Development \\
\hline NGO & - Non-Governmental Organization \\
\hline
\end{tabular}




\begin{tabular}{|c|c|}
\hline NP & - National Party \\
\hline NPM & - $\quad$ New Public Management (NPM) \\
\hline NPP & New Patriotic Party \\
\hline NRC & - National Reconciliation Commission \\
\hline OECD & - Organization for Economic Cooperation and Development \\
\hline OHCHR & - Office of the High Commissioner for Human Rights \\
\hline OSI & - Open Society International \\
\hline OSIWA & - Open Society for West Africa \\
\hline OSJI & Open Society Justice Initiative \\
\hline PAC & - Pan Africanist Congress \\
\hline PDP & - Peoples Democratic Party \\
\hline PNDC & - Provisional National Defence Council \\
\hline PRS & - Poverty Reduction Strategy \\
\hline RRC & - Reparations and Rehabilitation Committee \\
\hline $\mathrm{SABC}$ & South African Broadcasting Corporation \\
\hline SACC & - South African Council of Churches \\
\hline SADF & - $\quad$ South African Defence Force \\
\hline SAP & - Structural Adjustment Program \\
\hline SATRC & - South African Truth and Reconciliation Commission \\
\hline SPO & - Special Prosecutor Office \\
\hline SSC & State Secret Council \\
\hline TJI & - Transitional Justice Institute \\
\hline TNC & - Trans-national Corporation \\
\hline
\end{tabular}




$\begin{array}{lll}\text { TRC } & - & \text { Truth and Reconciliation Commission } \\ \text { UDHR } & - & \text { Universal Declaration of Human Rights } \\ \text { UGCC } & - & \text { United Gold Coast Convention } \\ \text { UN } & - & \text { United Nations } \\ \text { USA } & - & \text { United States of America } \\ \text { USIP } & - & \text { United States Institute of Peace } \\ \text { WANEP } & - & \text { West African Network for Peacebuilding }\end{array}$




\section{Table of Contents}

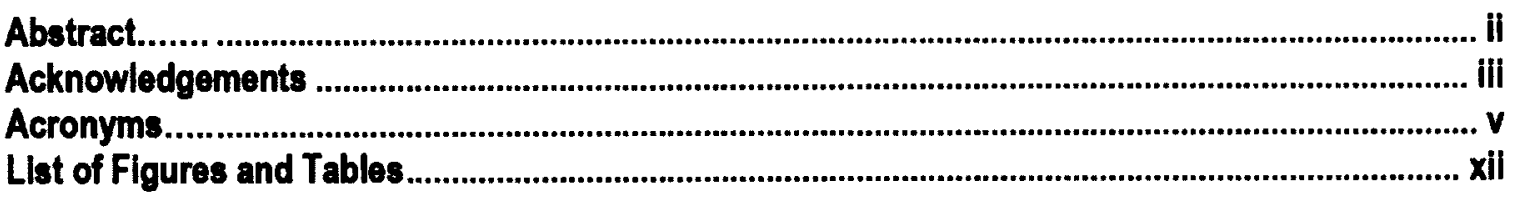

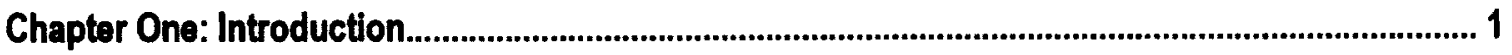

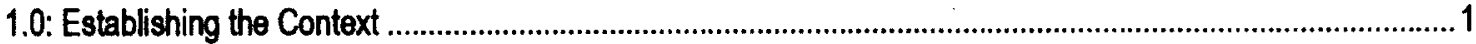

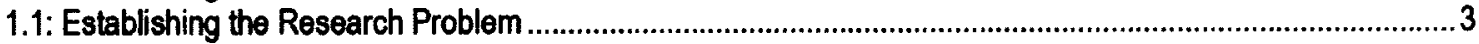

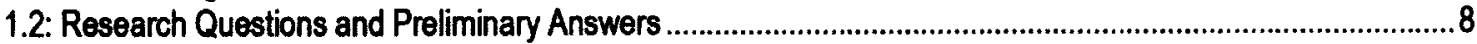

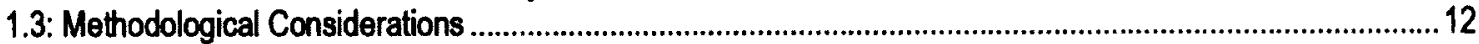

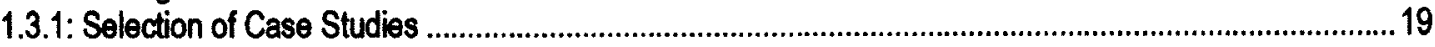

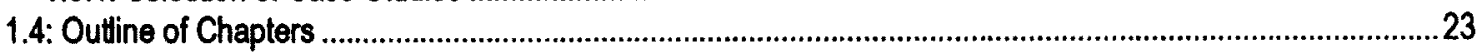

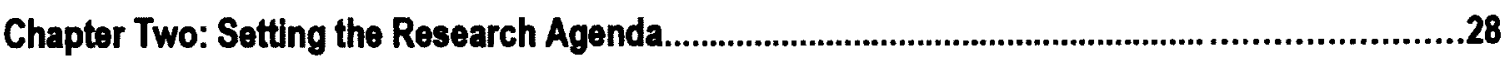

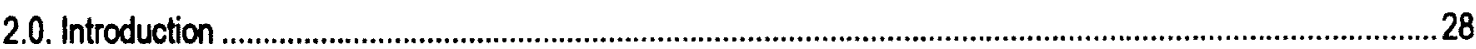

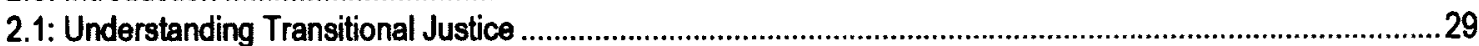

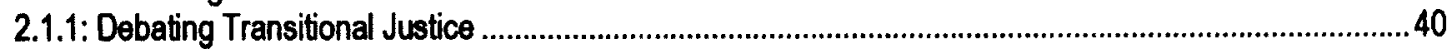

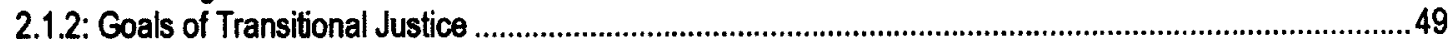

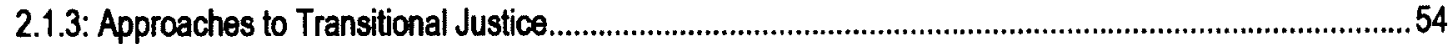

2.1.4: Understanding of Transitional Justice Policy Formulation Theory .....................................................6

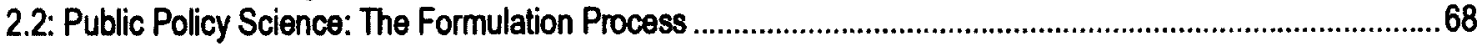

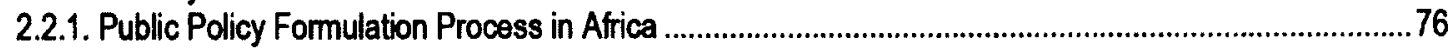

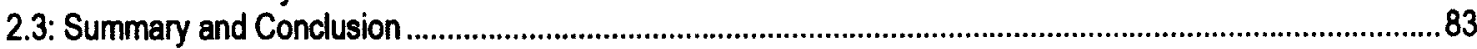

Chapter Three: Theoretical Model for TRC Policy Formulation ......................................................... 85

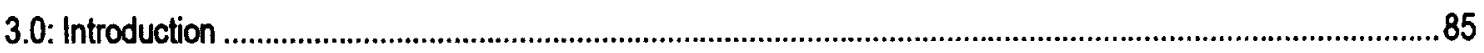

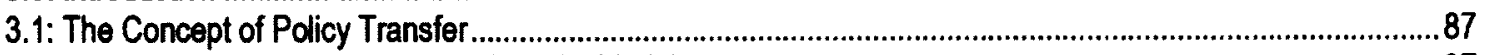

3.1.1: Dolowitz and Marsh Policy Transfer Model ......................................................................................... 97

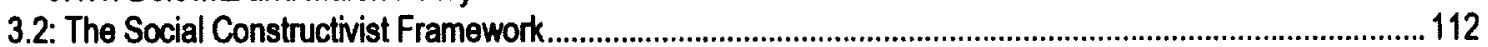

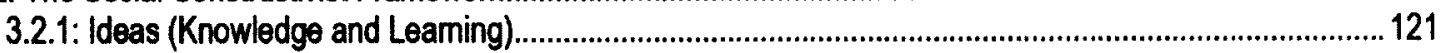

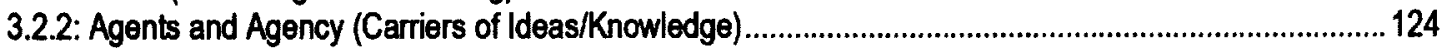

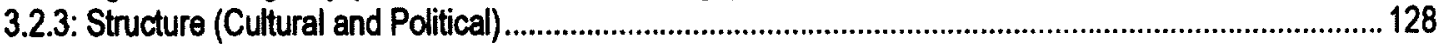

3.3: The Theoretical Model: Social Constructivist Account of Policy Transfers.................................................... 134

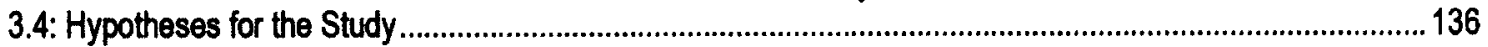

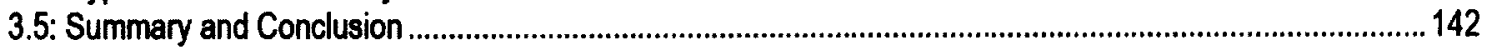

Chapter 4: The Policy Transfer of the Truth and Reconciliation Commission (TRC)-Approach... 143

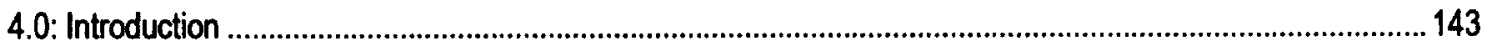

4.1: The TRC-Approach: Concept, Features and Origins ........................................................................ 146

4.1.1: The Notion of Restorative Justice and the TRC-Approach............................................................. 149

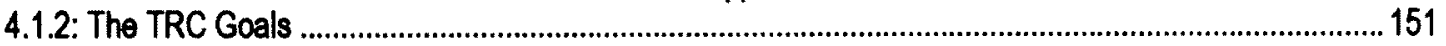

ix 


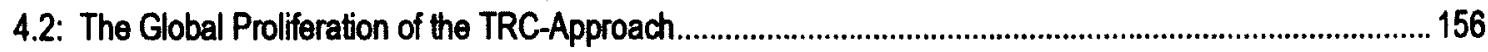

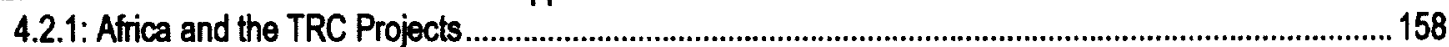

4.3: Conceptualizing and Defining TRC Policy Transfer Success or Failure..................................................... 165

4.4: Policy Transfer of TRCs in South Africa, Nigeria, and Ghana ............................................................... 174

4.4.1: The South African TRC (1995-2003): Establishment and Work .................................................... 174

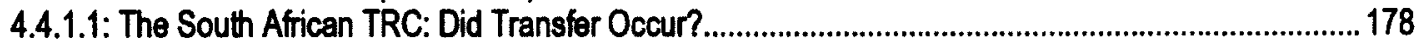

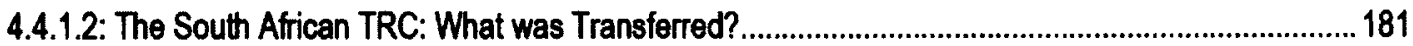

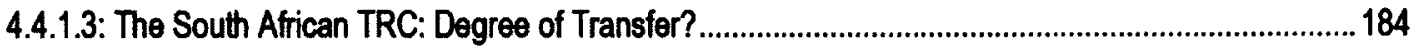

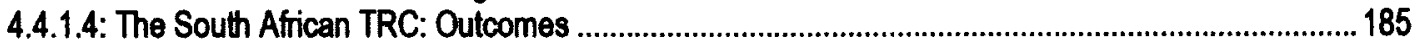

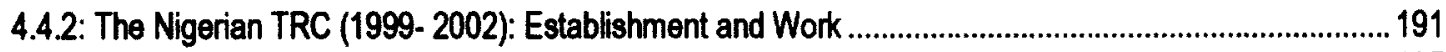

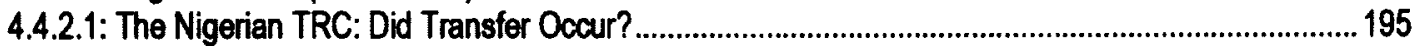

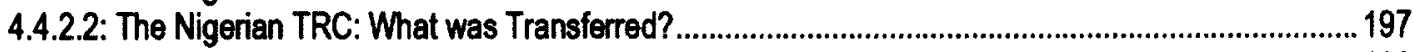

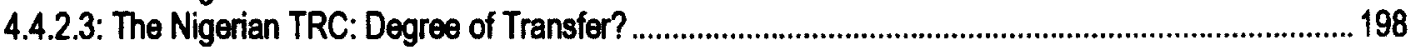

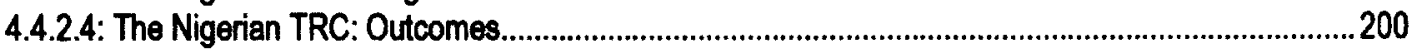

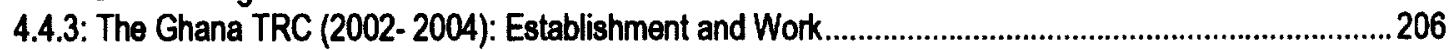

4.4.3.1: The Ghana TRC: Did Transfer Occur? .....................................................................................2210

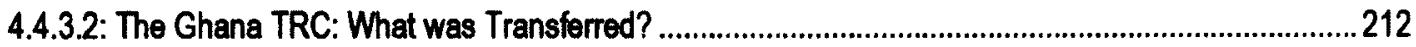

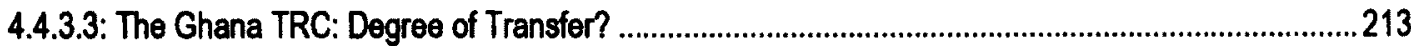

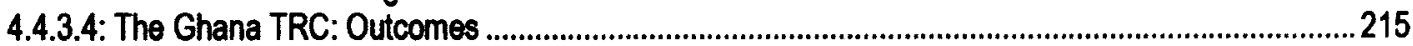

4.5. Analysing TRC Policy Transfer Success or Failure in South Africa, Nigeria and Ghana ..........................220

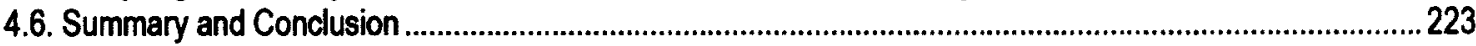

Chapter 5: Why the TRC-Approach Policy Transfer? ......................................................................... 226

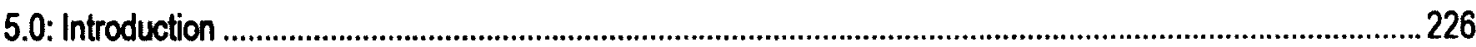

5.1: Political Transitions and the Transitional Justice Demands in South Africa, Nigeria, and Ghana ...........228

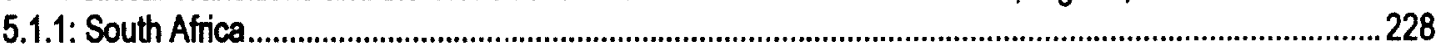

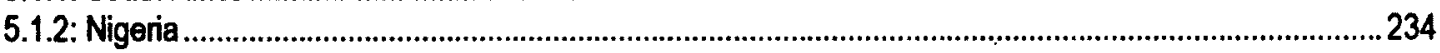

5.1.3: Ghana

5.2: Institutional Limitations and the Resulting TRC-Approach Policy Transfer in South Africa, Nigeria, and

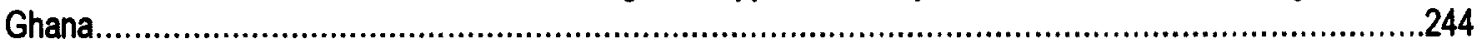

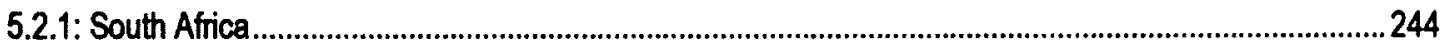

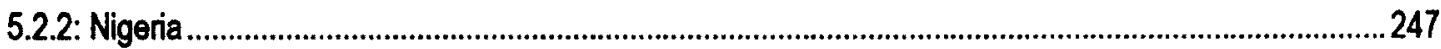

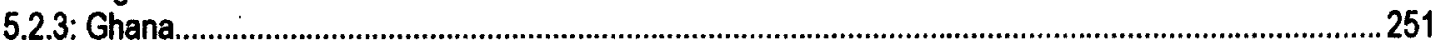

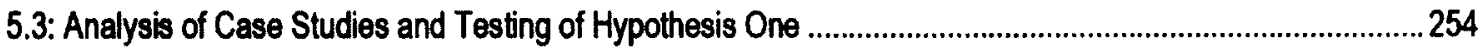

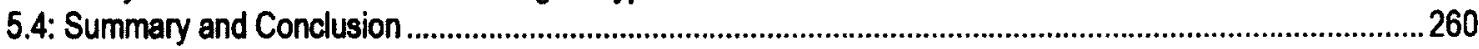

\section{Chapter 6: Actors and the TRC-Approach Policy Transfer and Formulation Processes}

6.0: Introduction

6.1: Actors, Roles and Stages of the TRC-Approach Policy Transfer Process .............................................2.265

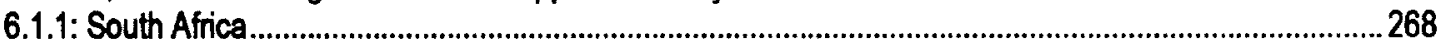

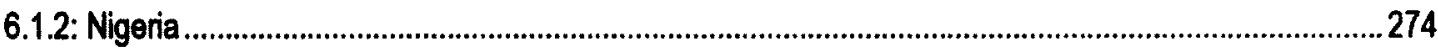

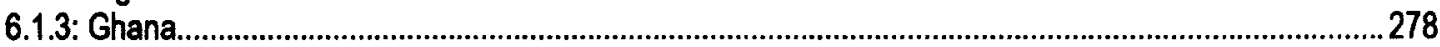

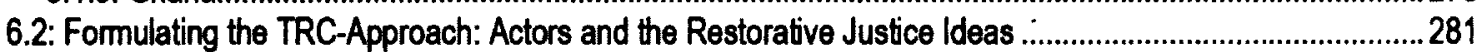

6.2.1: Actors and Foreground Assumptions in South Africa, Nigeria and Ghana .........................................28

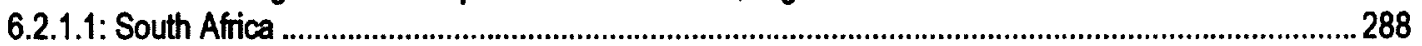

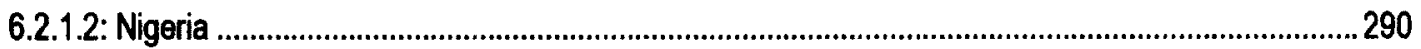

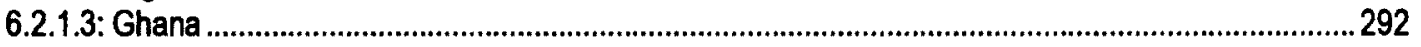


6.2.2: Actors and Background Assumptions in South Africa, Nigeria and Ghana ........................................296

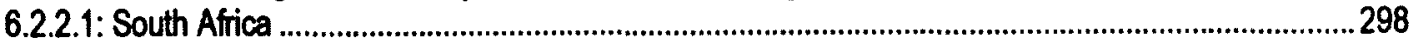

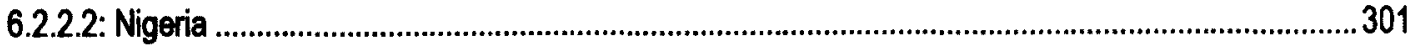

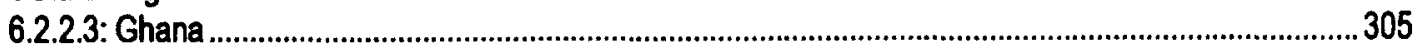

6.3: Analysis of Case Studies and Testing of Hypothesis Two ....................................................................310

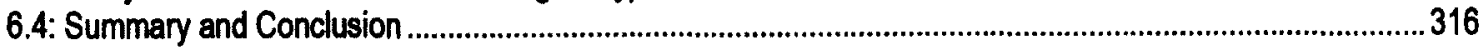

Chapter Seven: Domestic Structures and TRC-Approach Policy Transfer..............................320

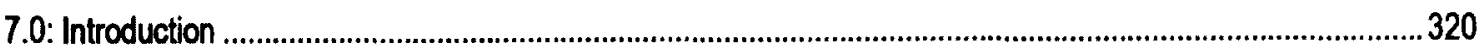

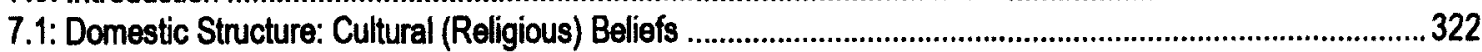

7.1.1: South Africa: Significance of the Judaeo-Christian Religious Beliefs ...................................................325

7.1.2: Nigeria: Promising Religious Beliefs Unutilized..................................................................................329

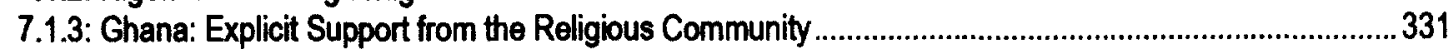

7.2: Domestic Structure: Political Platform for Citizen Engagement................................................................. 334

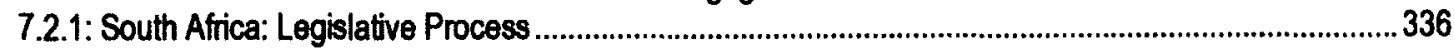

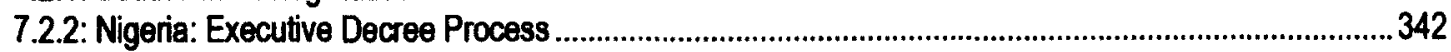

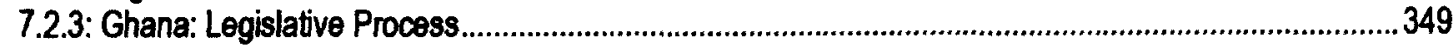

7.3: Analysis of Case Studies and Testing of Hypothesis Three .....................................................................355

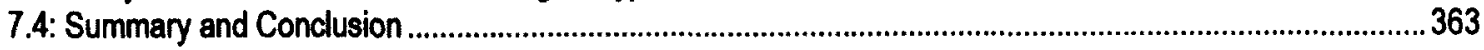

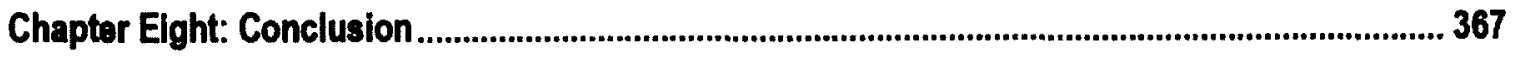

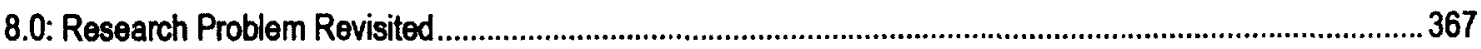

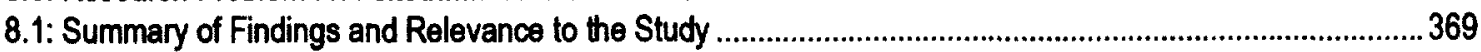

8.2: Policy Implications and Recommendations .............................................................................................377

8.3: Theoretical Implications of the Study and an Agenda for Future Research ................................................385

Appendices.......................................................................................................................................... 393

Appendlx A: Ethics Approval Information ........................................................................... 393

Appendlx B: Standard Questionnaire Instruments for Interviews........................................... 400

Appendix C: Interviows...................................................................................................................405

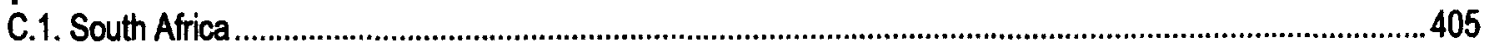

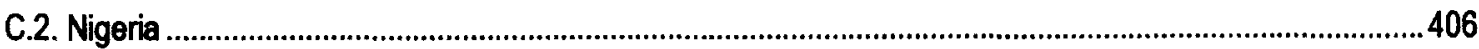

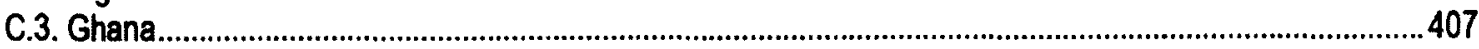

C.4. United States of America (Think Tanks/NGOs) ..................................................................................409

Appendix D: Participants at Focus Group Discussions ...............................................................410

Works Consulted/Bibliography..................................................................................................... 412 


\section{List of Figures and Tables}

Figure 1: The Policy Transfer Continuum (From Lesson-Drawing to Coercive Transfer) ..................................... 101

Table 1 A Policy Transfer Framework (adapted from Dolowitz, 2000a; Dolowitz and Marsh, 1998; 2000) .......... 110

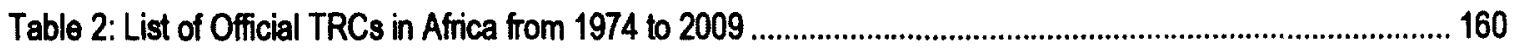

Table 3: Conceptual Definition of the Six-Dimensional Variables for Success of the TRC Policy

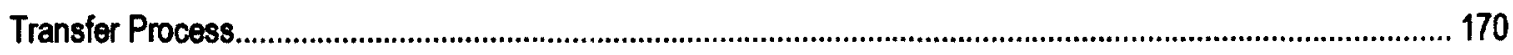

Table 4: Success and Failure in TRC Policy Transfer Outcomes in South Africa, Nigeria and Ghana................. 224

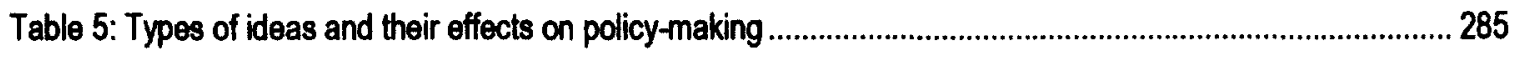

xii 


\section{Chapter One: Introduction}

\section{0: Establishing the Context}

This dissertation focuses on the policy formulation processes of recent official truth and reconciliation commissions (TRC) ${ }^{1}$ in their capacity as an approach to transitional justice in Africa. At the centre of this inquiry is, first, the issue of the replication of the TRC-approach across borders in Africa and, second, the policy formulation process of TRCs in the domestic politics of certain countries. Using South Africa, Nigeria and Ghana as case studies, the study seeks to expand on our understanding of the proliferation of the TRC and its accompanying domestic policy formulation processes in Africa. This study has two broad claims.

First, it posits that in each instance the development of a policy on the TRCapproach has involved an act of policy transfer that has been the mechanism for its reproduction across Africa. The study asserts that the institutional obstacles that become apparent during political transitions provoke the transfer of the TRC-approach for addressing transitional justice needs. Successor regimes are prevented by these obstacles from employing the usually preferred judicial or criminal justice approach to formulating a transitional justice policy. They respond to them by searching for alternative restorative justice ideas, which lay emphasis on the restoration of broken relationships between

\footnotetext{
${ }^{1}$ In this dissertation Truth and Reconciliation Commission (TRC) and Truth Commission are used interchangeably to mean the same quasi judicial investigative body established to investigate gross human rights violations of the past. I am fully aware of the differences between the two terms. Not all truth commissions are truth and reconciliation commissions--in the main, reconciliation is not always the goal for truth commissions. In this study, however, although the Nigerian and Ghanaian truth commissions were not specifically titled TRCs, unlike the South African version, they both had truth-seeking and reconciliation goals as part of their respective mandates. Thus, it is appropriate to refer to the generic acronym of TRC in this study.
} 
victims and offenders rather than vengeance. The successor regimes find these ideas in the TRC-approach. It was precisely this pattern of events that occasioned the TRCapproach in South Africa, Nigeria and Ghana.

Second, the study puts forward the idea that the domestic policy formulation processes of the TRC-approach result from the interplay of policy actors, both domestic and transnational, with the domestic structures. The policy formulation process of the TRC-approach in the domestic political environment is thus both constitutive and contextual. The restorative justice ideas are primarily sourced by domestic policy actors who attempt to situate them within the domestic social and political structures in an effort to indigenize them, legitimize them and seek public receptiveness to the approach. These ideas are generated and promoted, for the most part, by transnational transitional justice policy experts, who complement the efforts of the domestic policy actors with information on best practices of the to enrich the policy discourse.

In order to account for the degree of success or failure of a policy transfer of the TRC-approach, this study argues that the policy formulation process in domestic politics depends on how well domestic policy actors are able to indigenize and legitimize the restorative justice ideas in the domestic structures and, correspondingly, how welcoming these structures are to the ideas. Consequently, the policy formulation processes in the selected cases followed a pattern of social construction, and the nature of this construction affected the level of success or failure of the formulation process. 


\section{1: Establishing the Research Problem}

The TRC-approach features prominently in the transitional justice discourse. The field of transitional justice has become a global project (Nagy, 2008; Teitel, 2008), and its significance in post-conflict and post-authoritarian settings was acknowledged by the United Nations in 2004 (Secretary-General Report, 2004). In this globalized phase of the field the normative and explanatory logics behind an approach to transitional justice policy during transitions from conflict and authoritarian regimes to peace and democracy, respectively, have become issues of less contestation. In practice, however, there is little empirical evidence to verify the normative claims that transitional justice advocates espouse. Nevertheless, transitional justice processes continue to be advocated by their proponents and supported by the international community.

Interestingly, among African political elites the TRC-approach has become fashionable, and has dominated the transitional justice conversation. Yet far too little research addresses issues surrounding the politics of the TRC policy formulation processes in specific countries. Furthermore, the mode of the TRC-approach transmission from one society to another has been understudied. This current study attempts to fill this void by examining the mechanism of the approach's proliferation in Africa and the political dynamics around the policy formulation processes of the TRC-approach to transitional justice in the selected countries.

Undeniably, the formation of the South African TRC in 1995 revolutionized the conversation about TRCs around the world. It has since become the best known, and an international model for replication in many societies, both transitional and established, ${ }^{2}$

\footnotetext{
${ }^{2}$ While the phrase 'transitional justice' has assumed popularity and become globally accepted, its policy implications have been observed more in less developed countries in the global South (Latin America, 
seeking democratic accountability for and closure to past egregious and systematic human rights violations. The pre-eminence of the South African TRC experience as a source for recently established TRCs in Africa is clear. This appeal is informed by the assumption that the TRC-approach has the effect of contributing to peacebuilding, justice, human rights protection, truth-discovery, psycho-social healing of victims, reconciliation, rule of law and democracy. As Thoms, Ron and Paris (2008) observe, however, there is little factual evidence to substantiate these bold claims.

It is critical that researchers devote attention to investigating the impact of transitional justice approaches on societies. Nonetheless, this present study seeks to focus neither on the policy implementation of transitional justice approaches nor on the policy impacts of these approaches in societies. Its theme is rather the politics of policy formulation processes of transitional justice mechanisms, with the TRC-approach at the centre of investigation. Little effort has been made to explain the political processes surrounding policy formulation of transitional justice approaches, in particular TRCs. How can we account for the spread of the TRC-approach around the globe?

Furthermore, what informs how political decisions are made about the policy formulation of a TRC-approach? Specifically, why and how, for example, has the TRCapproach become the model in recent transitional societies in Africa? Research into the dynamics of political processes surrounding the formulation of a TRC-approach to a transitional justice policy, especially from a comparative perspective, is virtually non-

\footnotetext{
Africa and Asia) than in the established and developed societies in the global North. In developed societies, the Eastern and Central parts of Europe have been noted for experiencing some form of transitional justice processes. In recent years, transitional justice ramifications have been considered in North America. Canada's very first formal transitional justice policy has been developed since 2006 in the form of a TRCapproach to investigating the horrific abuses that took place in the Indian Residential Schools. It is also important to note that in the United States of America soon, after the election of Barack Obama, there were proposals for a TRC to investigate the era of former President George W. Bush's 'war on terror' interrogation techniques.
} 
existent. It remains critical and meaningful to ask questions about the impact of globalization, characterized by the cross-exchange and filtration of knowledge and ideas, and how it has translated into the formulation of transitional justice policy approaches in domestic societies. The literature on transitional justice and policy sciences has not examined these questions adequately, either empirically or theoretically.

Present understanding of the policy formulation processes of transitional justice approaches has produced three different explanations. The first invokes legal principles enshrined in national and international statutes (jurisprudence of human rights) as the basis for transitional justice policy. It emphasizes the moral and legal obligations of new regimes to account for past human rights violations under previous regimes by prosecuting and punishing the perpetrators. The second type of explanation examines the political balance of power in understanding the policy formulation process. The dynamics of the balance of power between the entering and exiting regimes during a democratic transition determine the choice of a transitional justice approach. The third, which is somewhat connected to the second, is associated with the role of political elites during democratic transitions. The bargaining strengths and consensus-building among political elites in designing and formulating political institutions, including transitional justice approaches, during transitions result in different outcomes of policy approaches.

These different types of explanations are informed by three different theoretical models -- the legalist/institutionalist, transitology, and the instrumentalist -- for understanding and studying transitional justice policy formulation processes. Although these models are insightful for and relevant to the current study, they are inadequate to address its fundamental research questions. They are not very helpful for explaining 
recent cases of the TRC policy formulation processes in Africa. These explanatory paradigms assume a 'top-down' transitional justice policy formulation process. They provide little space for discursive politics. ${ }^{3}$ The jurisprudence of human rights explanation, which is reflected in the criminal or judicial approach, yields limited insight into why TRCs, and not judicial approaches, were established in some of the transitional societies. Where moral and legal obligations demanded criminal justice, it is essentially able to account for the criminal justice approach being formulated in some countries; but it is unable to do the same for why a TRC was established in some other societies. ${ }^{4}$ For example, why was a TRC, and not a criminal justice, approach taken in South Africa, Nigeria and Ghana?

Similarly, the transitology and instrumentalist (political elite) paradigms lead to less coherent explanations. Why is it that in some transitional situations a criminal justice or TRC-approach was established, contrary to both the typology of the democratic transition in question and what sections of the political elites craved? The models supply variables less helpful in understanding the role of 'local' politics and citizens' discourse and inputs, as well as the relevance of social structures to the unfolding of the TRCapproach as a public policy. In addition, and significantly, these theoretical models are unable to account for the proliferation of TRCs beyond borders. Consequently, the current study departs from these existing paradigms, although elements inherent in them remain indispensable to the study.

\footnotetext{
${ }^{3}$ By discursive politics, I mean a political environment that fosters broad public/citizen debate towards finding policy solutions to a political/policy problem.

${ }^{4}$ Although it must be pointed out that the globalization and the continuous development of human rights laws and norms have witnessed the inclusion of attributes, such as the rights to truth and reparation, which are fundamentals to the work of TRCs.
} 
To explore its two broad claims this study applies the Dolowitz and Marsh (1996; 2000) policy transfer model to the policy development of the TRC-approach in South Africa, Nigeria and Ghana. It argues that the policy formulation processes of recent TRCs should, first and foremost, be understood as comprising a political process and neither a legal production, a transition to democracy discourse nor a consensus of elites. In other words, this study suggests that the discourse on transitional justice in recent years should be contextualized within public policy analysis. The political and social conditions that stimulate dialogue and actions among political elites and domestic social and political actors, including citizens' participation in the policy dialogue process, are critical to policy formulation processes. The domestic dialogue is informed by the impact of globalization, which has produced forms of communication and sharing of knowledge on issues of global importance.

Concisely, then, the study argues for focusing on the dialectical relationships among ideas, agency and structure in facilitating policy transfer and in the subsequent formulation processes of the TRC-approach to transitional justice. The TRC-approach policy formulation processes in South Africa, Nigeria and Ghana exemplified this course, and were therefore constructive in character. Subsequently this study suggests that a social constructivist framework does elucidate the policy transfer and the associated domestic formulation processes of recent TRC-approaches to transitional justice in Africa.

Understanding the complexities and intricacies surrounding the impact of globalization on domestic policy formulation processes in Africa enhances our analysis and understanding of whether African states do have indigenous public policy 
development. Moreover, it improves our understanding of why public policies in Africa do or do not successfully deliver, because knowing how the policy came to be formulated gives insight into its evaluation. Using the TRC-approach to transitional justice policy as the measure by which to analyse, explain and understand how African countries formulate policies towards democratic accountability, the study contributes to our knowledge of the politics of the state, public policy and democratic development.

\section{2: Research Questions and Preliminary Answers}

The larger question underlying the study's research questions is the why, who, and the source of the proliferation of TRCs around the globe and, in particular, in Africa. The difficulty of answering it is compounded by the weaknesses that become apparent in the existing paradigms when they are applied to explaining transitional justice policy formulation processes, the replication of these approaches beyond borders, and how they are being formulated in the domestic politics of recent transitional societies.

In 2003 it was reported that since 1974 over 25 TRCs had been established globally (Freeman and Hayner, 2003: 125). Prior to this, the TRC-approach to transitional justice was already being described as the centrepiece of transitional justice policy (De Brito, Gonzalez-Enriquez and Aguilar, 2001: 5). Kritz (2002a), for his part, observed that TRCs had become popular and instantaneous during political transitions. He noted specifically that "the policy decisions for truth commissions have become almost routine; it's become standard practice. A country has a transition and everybody immediately says 'we have to have a truth commission', without any clear understanding 
as to why, or what such endeavours are about" (Kritz, 2002a:7). As of 2009, the United States Institute of Peace (USIP) had recorded over 40 TRCs established globally. ${ }^{5}$

In the Global South, in particular, from post-apartheid South Africa to postconflict Timor-Leste, TRCs have become familiar tools for taking stock of crimes, especially human rights abuses, and for promoting accountability and redress in the wake of state violence in order to facilitate healing and reconciliation. Nearly half of the 40 TRCs were in Africa. Their appeal on that continent appears indefatigable. Recent examples include Togo in 2008, Kenya in 2009 and Mauritius in 2009. However, there is little empirical evidence to verify TRCs ability to deliver what they claim they will or, logically, the values on which those claims are based. Interestingly, most African countries appear to be drawing lessons about the TRC-approach from the South African experience. Although the South African TRC is perceived as a success story outside its boundaries, within South Africa there are, however, growing reservations and increasing pessimism about the ultimate impact of the TRC on the lives of the people. Nonetheless, on the African continent the popularity and appeal of this approach to transitional justice policy are undiminished. Accordingly, the research asks two broad questions:

- What explains the reproduction of the TRC-approach across borders in Africa?

- What factors and/or forces determine the policy establishment of the TRCapproach to shape its mandate and condition its success or failure?

\footnotetext{
${ }^{5}$ This information is sourced from the USIP webpage. Some countries had more than one TRC. The outcomes have varied, with some producing reports and others not. Sourced on November 302009 from: http://www.usip.org/resourcestools/latest?filterl=\%2A\%2AALL $\% 2 \mathrm{~A} \% 2 \mathrm{~A} \&$ filter0=\%2A $\% 2 \mathrm{AALL} \% 2 \mathrm{~A} \% 2 \mathrm{~A} \&$ filter2=2222\&filter $3=\% 2$ A\%2AALL\%2A\%2A\&filter4=Data for 
Given that transitional justice has become a globalized project that advocates state measures to address human rights transgressions, including bringing perpetrators of these abuses to account, it is critical to understand how these approaches to transitional justice goals are formulated within domestic politics. It is vital that the processes of formulating transitional justice policy in domestic politics avoid the 'one-size fits all' (SecretaryGeneral Report, 2004) method and the 'templatization' (Thoms, Ron and Paris, 2008) of transitional justice that the globalization of the field seems to bring with it. In other words, contextual relevance, which allows for local inputs in the design of approaches to transitional justice, is essential. Considering the transitional nature of most of the states in Africa and the increasing appeal to the TRC-approach as a transitional justice policy, it is not unrealistic to suggest that TRCs have not seen the end of their appearance in Africa.

Cases of TRC policy formulation processes ought to be empirically studied with a view to drawing lessons on how to make the formulation of this approach locally driven and relevant to the beneficiaries. As stated earlier, institutional obstacles to the application of the preferred criminal justice induced the policy transfer of the TRCapproach to transitional justice in the three selected cases. However, this does not explain why any of the other approaches to transitional justice such as vetting, reparation, institutional reform, or even a policy of amnesia, were not chosen to address transitional justice concerns. This study investigates questions such as why TRCs, rather than any other transitional justice approach, are adopted to address past human rights violations; what motivates leaders of successor regimes to opt for a TRC; what are the roles of external global and regional transitional justice think tanks and networks in the domestic policy formulation processes; what place is there for victims of human rights abuses and 
the citizenry to influence public debate over the policy formulation of the TRC-approach; and how is the policy discourse around the TRC shaped within the domestic political environment?

Answers to these questions, it is hoped, will yield lessons and show the best practices to policymakers with regard to developing an appropriate, context-relevant and all-inclusive policy approach to transitional justice in transitional African states and beyond. Furthermore, the findings from the study help to determine an alternative theoretical model and analytical approach for explaining and understanding recent cases of transitional justice policy formulation process.

The present research reveals certain barriers that prevented South Africa, Nigeria and Ghana from employing the criminal justice approach to transitional justice during their political transitions. These obstacles were in the form of legal statutes and institutional defects. The TRC-approach became the policy instrument adopted by the successor regimes in these countries for responding to the transitional justice needs and demands of victims of human rights abuses and the citizenry at large. The TRC policy formulation processes were informed by dialectical interactions among domestic official and unofficial policy actors using externally borrowed ideas linked to the TRC-approach. The policy process had a policy transfer dynamic, and its domestic policy manifestation was constructively engineered based on contextual relevance.

The major source of the restorative justice ideas that informed the TRC-approach in South Africa was the experiences in the Southern America region; Nigeria and Ghana, in contrast, borrowed from the South African model. The latter has since become the primary reference for the TRC-approach to transitional justice in transitional societies in 
Africa. The current study demonstrates that in societies such as South Africa and Ghana, where the policy formulation process was open and allowed for broad public participation in the policy discourse, the policy transfer of the TRC-approach was successfully formulated. In cases such as Nigeria, however, where the successor regime adopted a closed door policy formulation process, it was less successful. The success of the policy transfer of the TRC-approach in domestic politics depends on how domestic political forces respond to the notion of restorative justice, and how receptive are the domestic social structures to these ideas. This responsiveness and receptiveness may include the extent to which victims and the public participate in the policy formulation discourse and process, and cultural affinity for these ideas.

\section{3: Methodological Considerations}

This study has both policy-oriented and theory corroboration intents. It will yield various insights into best practices useful in developing policy recommendations for TRC policy formulation in successor societies, and the application of the Dolowitz and Marsh policy transfer model, integrated with social constructivism, will explain the spread of the TRC-approach. Regarding theory development, while not seeking to generate grand new theories of causal relationships, the study explores the possibilities of deploying and extending the social constructivist approach in analysing the policy transfer dynamics of the formulation processes of TRCs. The study looks at the TRC as a social and political phenomenon in its patterns of policy idea generation, their transportation, and their processing in domestic structures. 
It focuses on interactions among different types of actors, individuals and organizations, local and foreign, in developing ideas around the TRC-approach to solving transitional justice needs. It connects these generated TRC policy ideas with the domestic social systems and political arrangements that shape and produce the policy on the TRCapproach. This methodological approach makes the study discursive ${ }^{6}$ and interpretive (King, Keohane and Verba, 1994: 34-74). It seeks to understand and explain the processes that lead to the policy formulation of TRCs as the preferred approach to transitional justice.

The comparative approach is a classical method, typically employed with cases that are comparable and that share many features at the macro level, which helps in establishing a basis for comparison. It is the 'most similar systems' design (Przeworski and Teune, 1970), and allows for stronger claims for theory testing and confirmation than a single case study would provide. Within the cases or systems, though, there are significant variations and differences that make it possible to identify variables that explain the different outcomes. Przeworski and Teune, referring to this method, speak in terms of 'intersystemic similarities and intersystemic differences' (1970:33). The three selected cases, therefore, while they share many general characteristics that make them 'comparable cases', also have distinct histories, as well as unique structural and institutional systems, so that the different outcomes of their respective TRC policy formulation processes is not surprising. The similarities and dissimilarities among the cases are expanded upon in the section on selection of cases below.

\footnotetext{
${ }^{6} \mathrm{By}$ discursive, I mean deliberative or participatory. A discursive approach to social science investigations is built around discourse analysis and focuses on interactions, actions and processes of subjects/actors of study.
} 
The differences in TRC policy formulation outcomes present two sets of cases for the study: successful and less successful (failed) TRC policy transfer and formulation processes. This study develops a set of criteria for identifying a successful TRC policy transfer and formulation process. This is based on a six-phase multi-dimensional model, beginning with the establishment of the TRC institutions, and ending with the destiny of the final reports the institutions produced. This multi-dimensional modus operandi arranges the study's successful and less successful policy transfer and formulation outcomes along a continuum with four levels or degrees: success, partial success, partial failure, and failure. These degrees are determined by the extent to which the TRC institutions achieved the six phases of the TRC process: the establishment of the TRC institution; its operation within the given time period; co-operation from witnesses, in particular alleged perpetrators; production of the final report; government acceptance and public release of its final report (the general acceptability of the report); and implementation of some or all of the report's findings and recommendations.

Chapter 4 of the dissertation delineates in detail this continuum of what the study considers success, partial success, partial failure, and failure of the TRC-approach policy transfer and formulation process. Suffice to say that none of the three cases achieved complete success or failure in all phases. Nonetheless, the South Africa and Ghana cases are rated as having come closer to full success than the Nigeria case. There is a relationship between policy formulation and policy effect. In other words, the formulation of a TRC policy should have the ultimate effect of contributing to human rights culture of the society, victims' satisfaction regarding previous abuses, and pave the way for national reconciliation. Certainly, studying the policy formulation stage, and 
indeed its success, along the policy-making chain, is vital in understanding how a particular policy ultimately impact on society. This connection is expounded on in both Chapters 2 and 4.

The study uses the deductive research strategy (Blaikie, 2006:104-107), where the overriding objective is to match data with hypotheses. It begins with an abstract position with a set of expectations or provisional answers to the research questions. These expectations are identified in the three broad hypotheses outlined in chapter three. The hypothesis are guided by variables identified within the policy transfer model and as informed by the social constructivist analytical framework. Data gathered from field research are used to test the hypotheses. The study is qualitative analysis driven, and relies on a number of primary and secondary sources (See Blaikie, 2006:183-185).

Primary sources of data include interviews, focus group discussions and review of political party manifestos and government documents. The format and protocols for conducting the interviews were subjected to ethics review and received clearance prior to data collection (See Appendix A for sample of the approved letters of introduction and consent). ${ }^{7}$ One-on-one interviews, using a structured set of questions, were conducted with senior bureaucrats, policymakers, elected government officials, party officials, political leadership and persons who had been Members of Parliament at the time that the TRC policy was formulated. Interviews were also conducted with representatives of civil society organizations (CSO) and staff of national and international non-governmental organizations (NGOs) and think tanks. Included in the list of non-state transnational organizations that were interviewed are the International Center for Transitional Justice (ICTJ) and United States Institute for Peace (USIP), both based in the United States of

${ }^{7}$ These were approved by Carleton University Research Ethics Committee. 
America, and the Centre for the Study of Violence and Reconciliation (CSVR) and the Institute of Justice and Reconciliation (IJR), both based in South Africa.

Additional interviews took the form of written responses and telephone conversations with respondents. Participants for the focus group discussions were drawn from the public, and they included ordinary citizens who have suffered human rights abuses and have appeared before the TRCs. The focus group discussions were applied as part of the data validation process from individual interviews; the data were also used as quality control measures. All the interviews took place in the countries selected for the study or in the USA (See Appendix B for the standard questionnaire used for the interviews). The study also uses secondary sources of data, such as DVDs, transitional justice studies by other researchers, TRCs and policy analyses, and research reports. Even though it relies on qualitative data, the study employs existing quantitative data and analysis, where appropriate, to complement the qualitative data.

Like all social science research, this study has certain limitations. The focus on policy formulation at the expense of detailed discussion of the entire TRC policy process, including implementation and evaluation, denies this study of complete examination of the TRC-approach to transitional justice processes in these three countries. Nonetheless, the study builds on our understanding of the public policy formulation processes in Africa. The perspectives of local actors have been inadequately represented in the literature on policy formulation, particularly with respect to social and political change in Africa. However, because the three selected cases are in Africa, this may undermine the applicability in other contexts of the theoretical insights that emerge from the study. 
The study is also mindful of the limitations of the 'most similar system' method, which is weak in its ability to generalize about outcomes in systems with different characteristics. It holds strong for generalization among systems with similar features, mainly because the process of sampling is purposive and not random. While this is a limitation, it is insignificant for this study, because the study compares systems with similar characteristics. Further, and as previously stated, the aim of the study is not to develop broad generalizations or construct any grand new theory on transitional justice policy approach formulation. Rather, the aim is to extend and verify an alternative theoretical paradigm in order to broaden our understanding of the reproduction of TRCs as a policy response to transitional justice demands.

The comparative method employed in this study, although based on a small number of cases, will help explain why TRCs, and not any other approach to transitional justice, were established and have become fashionable. In addition, it will help explain why some cases experienced a successful TRC policy formulation process and others did not. To that extent alone it contributes to broadening the scholarship on the TRCapproach to transitional justice policy. The use of primary sources of data strengthens the study in its originality; and, by deploying a different explanatory and theoretical model in a comparative fashion, the study lends itself to new theoretical insights for the field of transitional justice. This study seeks not to generalize outcomes, but to test, corroborate and extend existing theoretical models. It is instructive to note, however, that comparative inquiries such as this one have the potential to yield some generalizations (George and McKeown, 1985; Riker, 1985). 
George and McKeown, for example, observe that small case studies with the controlled 'structured, focused comparison' method and 'process-tracing' procedures offer the promise of more powerful explanations for causal processes. Based as it is on dealing with selected, specific aspects of each case that are relevant to the research objectives, and using a standardized set of general questions for each case as part of data requirements, the 'structured, focused comparison' method can produce findings that cumulatively justify generalizations: especially when the data collection procedure is one promoted by the 'process-tracing' technique (George and McKeown, 1985: 34-43).

Riker argues that carefully defining events in an investigation makes generalizations more plausible. If the defining elements of events are ambiguous -- that is, if the beginning and end points (causes and outcomes) of the event are numerous -then any generalizations will also be confusing. It is therefore critical for the parameters of an event to be unambiguous if one wants to study its causes. The precise definition of events in case study research, notwithstanding the number of variables, is thus a crucial feature for generalization and theorizing (Riker, 1985: 59-64).

The current study falls within the methodological conditions proposed by these scholars. The selected cases compare the TRC policy formulation aspects of the three policy-making processes towards transitional justice. In this study, the defining element of the events around the TRC-approach is the policy formulation phase and the associated degrees of success. Furthermore, similarly structured general questionnaires are administered in all cases to track the processes of the TRC policy formulation. More specifically, the process-tracking involves investigating human and organizational 
engagement in the policy transfer and formulation discourse towards a TRC-approach to the transitional justice dilemma.

\subsection{1: Selection of Case Studies}

The 'most similar system' method, which identifies similarities as well as differences in comparable cases, justifies the selection of the research cases: South Africa, Nigeria and Ghana. All three have similar experiences of political history, social demographics, and political, as well as economic, systems. All three countries were once under British colonial rule. They all experienced several years of non-democratic rule, whether in the form of apartheid, military dictatorship, or civilian authoritarianism following their liberation from British colonial administration. They share socio-cultural characteristics with multiple ethnic and linguistics groups. They all have similar political systems, with executive presidential styles of government. In terms of their economic systems, they all adhere to neo-liberal economic policies that allow their political and economic spaces to accommodate foreign participation.

The main differences, on the other hand, are a matter of certain historical, structural and institutional distinctions that prevailed immediately before a transitional justice policy was considered, and in the style of policy process adopted by each country to formulate the TRC-approach. In 1994 South Africa emerged from more than 40 years of apartheid rule with a negotiated transition settlement. At that time transitional justice discourse became part of the politics. While apartheid rule was considered undemocratic because of its exclusion of the black majority, the successive white minority governments had over the years instituted certain democratic institutions and practices, such as 
parliament and judicial process, with limited space for civil society engagement. The struggle to end apartheid had also produced a political culture of civil society activism. That history of democratic practices and government-civil society engagement gave the new South African democratic transition an advantage that also enabled public discourse around transitional justice policy approach choices.

In Nigeria in 1999, following several years of military rule, a sudden political transition occurred that brought a new civilian, democratic regime to power. A transitional justice policy-approach was quickly instituted. With no recent history of democratic practices or institutions, such as a legislature and a strong judiciary, and with a weak history of citizen-government relations, public engagement with the transitional justice policy choices was woefully limited if not absent. In Ghana, transitional justice policy became a subject 10 years after the democratic transition in 1992. Like South Africa, Ghana experienced some form of democratic governance, with government-civil society engagement a growing feature when transitional justice policy became an issue. The history of democratic credentials and the timing of transitional justice policy thus account for the significant differences in the three cases.

The techniques of the policy process adopted to formulate the TRC-approach in the selected cases also had differences. In both South Africa and Ghana it took the form of public discourse, and was driven by a legislative process, albeit with certain procedural nuances. In Nigeria, however, the process was less public, and promulgated by an executive decree. These variations within the cases account, in spite of the broad similarities, for the different outcomes of the TRC policy formulation processes. Apart 
from the similarities and dissimilarities, other factors were considered in the selection of the cases.

The study considered transitional justice policy processes that were initiated by the countries themselves and not prompted by external pressures. The research distinguishes between two types of transitional justice project: ones that are wholly driven and formulated by the country itself (home-grown) and others created as a result of internationally supervised peace agreements or international initiatives (externally driven). The study looks at the first type. All three of the selected countries qualify. The focus on the home-grown cases leads to critical insights into the dynamics of domestic policy formulation processes in African states at a time most countries on the continent are embarking on democratization processes.

Moreover, the home-grown cases help us distinguish between the processes of transitional justice policy approach formulation that are initiated by domestic or local actors and those that are forced on them as a result of 'conditionalities'. Concentrating on home-grown cases makes it possible to respond to the criticism that the failure of economic and political policies in Africa is attributable to policy imposition by external powers. ${ }^{8}$ The home-grown focus facilitates examining the level of policy formulation capacities of African states and identifying African causes for the success or failure of these policies.

The study furthermore considers the legitimate procedures of public policy formation through the stages of policy-making: agenda-setting, policy formulation, decision-making, implementation, and evaluation. It thus identifies cases that were the

\footnotetext{
${ }^{8}$ The IMF and the World Bank, and international democracy promoters have been cited in these criticisms. Critics argue that these policies were forced on African states, and not driven by domestic actors and, therefore, lacked local legitimacy and contextual relevance.
} 
result of standard processes in formulating public policies, through either the parliamentary process or presidential decree. In all three cases these standard processes were present. The demands for national redress and accounting for human rights offences were firmly on the public agenda during the political transitions. These demands were acknowledged by the successor regimes, in some instances, long before they took political office. The design and development of policy options to address these social and political problems followed the procedures laid down for formulating public policies in these countries. Implementation by the agencies followed formulation, as mandated in the policy objectives.

The selected cases, therefore, uphold the basic tenets of policy science: understanding public demands and concerns and addressing them through public authorities' sanctioned policy choices. The processes meet the standard criteria for policy science research. How well were public authorities able to respond to these transitional justice demands and concerns from the public? The selected cases reflect these dilemmas.

Finally, each of the three cases is considered to have been a policy transfer phenomenon. The South African TRC was not the first to be established in the history of TRCs. South Africa borrowed the TRC policy ideas from outside its boundaries. The South African TRC, though, revolutionized and popularized the TRC concept. Moreover, as previously noted, it has since become the most popular and the best known international model for study and emulation. Both the Nigerian and Ghanaian TRCs were modelled, with modifications, on the South African experience. Therefore, while the source of transfer may differ between South Africa, on the one hand, and Nigeria and Ghana on the other, all three cases fit the concept of policy transfer. By focusing on 
Africa, this study contributes to affirming the applicability of policy transfer models beyond the developed societies.

The study concedes the limitations of the selected cases for examining the larger question of policy discourses in the ever growing field of transitional justice in Africa. The cases do not fully represent the multiplicity of transitional justice discourse currently underway on the continent. Likewise, they do not fully reveal the experience of policy formulation processes of all African states. Nevertheless, the set of cases being studied has the potential to generate useful insights into what informs the growing application of the TRC-approach to transitional justice policy in Africa. Because the selection represents three cases with similar attributes, but with different courses in and different outcomes of the TRC policy formulation process, the findings present lessons for policymakers considering the TRC or, indeed, any other approach to transitional justice policy. Notably, this study advances testable hypotheses that yield insights into social constructivist account of policy transfers. It does make an important contribution to the field of transitional justice by drawing into the discourse the perspectives of policy analysis. The findings from the study may also produce testable hypotheses in policy science.

\section{4: Outline of Chapters}

Following this introductory chapter is Chapter 2 which sets out the research agenda. It defines and traces the historical origins of the transitional justice concept, and identifies the main debates in the field. The goals and approaches to transitional justice policy are also examined. The chapter expands on the existing theoretical models for 
understanding transitional justice policy formulation processes. It emphasizes weaknesses in the existing paradigms for explaining and understanding the transitional justice policy formulation process that disqualify them for the current study. The chapter also devotes space to a general discussion of public policy formation, and focuses on the debate around public policy formulation processes in Africa. For the most part policy formulation processes in Africa, until the democratic wave, were characterized by government-led and controlled activity, with very limited citizen participation. The primary intention of this chapter is to offer an overview of the transitional justice phenomenon and a discussion of policy formulation process discourse, and thereby set the background for examining the theoretical model and analytical approach for the present research.

Chapter 3 builds the theoretical model and the analytical framework for the research. It suggests that a social constructivist account of policy transfer is the most helpful in explaining and understanding the policy development and formulation processes in the selected cases. The chapter examines the policy transfer model that was developed by Dolowitz and Marsh (1996; 2000), and then the social constructivism analytical approach, and how their inherent variables are deployed for the study. The chapter further presents the research propositions in the form of hypotheses.

In Chapter 4, the study's dependent variable - the TRC-approach policy formulation -- is examined. A brief overview of the TRC-approach -- its historical origins, its proliferation around the world, scholarly debates pertinent to the current study, and the conceptual definition and discussion of 'success' and 'failure' TRC policy transfer and formulation -- is presented. This is followed by profiles of each of the three 
TRCs in the selected cases and a discussion on how the TRC-approach became the policy choices of the respective successor regimes. The chapter examines three key questions -did transfer occur, what was transferred, and the degrees of transfer. The main thrust of this chapter is to situate the research's dependent variable in an appropriate context to begin the empirical analysis of the research questions in the following chapters.

This study does not follow case-by-case categorization approach to conduct the discussions of the research questions. Rather, it follows an analytical approach to examining the independent variables. The next three chapters $(5,6$, and 7$)$ broadly follow the three key concepts of social constructivism-- ideas, agency, and structure-- to examine all the three cases together in each chapter. Chapter 5 of the study thus addresses the questions why and when do actors engage in the TRC-approach policy transfer. Drawing on empirical data, the chapter demonstrates why and when the restorative justice ideas assumed prominence as alternative means to transitional justice processes in South Africa, Nigeria and Ghana.

The chapter begins by examining the political transitions in the selected cases and the ensuing transitional justice debate. It next discusses the institutional challenges that made it impossible for the application of the judicial process to transitional justice resulting in the policy transfer of the TRC-approach. The chapter argues that transitional justice concerns were part of the policy discourse during the political transitions of the three cases. The transfer of the TRC-approach to respond to citizens' demands was a voluntary act on the part of domestic policy actors, primarily in response to the institutional obstacles that were evident. The approach was also viewed as the appropriate transitional justice mechanism to reflect the contextual needs. The chapter thus 
demonstrates the instrumentality of ideas using the notion of restorative justice that inform the TRC-approach.

Chapter 6 focuses on the role of actors in the TRC-approach policy transfer. It places agency at the center of the discourse on the TRC policy formulation processes in South Africa, Nigeria and Ghana. The chapter first examines the functionality of agents in the TRC policy transfer process, and second the instrumentality of agents in the formulation process. The chapter addresses two broad questions -- who transfers the policy on the TRC-approach, and from where do these actors conduct the transfer? The drive in this chapter is to explore agency in the TRC policy formulation processes from three perspectives: agents as borrowers, agents as carriers, and agents as formulators. The chapter analyzes the roles played by domestic and international actors in the policy transfer process of the TRC-approach and the subsequent formulation in the selected cases. It suggests that domestic agents, in particular elected officials, initiated the policy agenda by sourcing policy ideas for the TRC-approach and also guided its domestic formulation processes; the international agents were the carriers and promoters of the restorative justice ideas that the TRC-approach carries, and the lessons learned around them.

In Chapter 7, the relationship between domestic structures and the policy transfer process is examined. The chapter devotes attention to analyzing how domestic structures were responsive and receptive to the restorative justice ideas that acted as impetus for the transfer of the TRC-approach. The two main questions that inform the chapter's analysis are what factors facilitate or restrict the TRC-approach policy transfer, and how is TRC approach policy transfer success or failure explained? Using the available data, the 
chapter suggests that domestic structure (culture and political) is vital in accounting for the degree of successful domestic policy formulation of the TRC-approach resulting from policy transfers.

Chapter 8 is the conclusion to the study. It revisits the study's two main research questions and draws insights from the preceding chapters to develop policy recommendations and theoretical insights. Drawing from the discussion in the previous chapters, the chapter asserts that the development of the TRC-approach as a policy solution to the transitional justice demands in South Africa, Nigeria and Ghana resulted from a policy transfer activity. The chapter suggests that the policy transfer process illustrated the interaction of policy actors--domestic and transnational--with domestic structures on the restorative justice ideas. The policy transfer was effectively made possible following institutional impediments of different kinds that manifested at the precise moment of the countries' respective political transitions. The chapter affirms that while South Africa transferred the TRC-approach from the South American region, both Nigeria and Ghana drew on the South African model. 


\section{Chapter Two: Setting the Research Agenda}

\subsection{Introduction}

This chapter sets out the research agenda for this study, which is about transitional justice processes as much as it is about public policy science. An overview of the transitional justice concept and the main contending issues in the field is followed by an outline of the goals of, and possible approaches to, a transitional justice policy. The chapter argues that the presently acknowledged explanatory paradigms - the legalist/institutionalist, transitology, and the instrumentalist (elite pact) -- do not provide adequate and useful model in accounting for the recent popularity of the TRC-approach to transitional justice policy, particularly in the African context. The chapter suggests that none of these paradigms explains how the domestic policy discourse that resulted in the formulation of the TRC-approach in South Africa, Nigeria and Ghana occurred. The theoretical models are not only unhelpful in understanding domestic politics around the TRC-approach formulation processes; they are also unable to explain why and how the ideas around the TRC-approach to transitional justice transcend borders.

After exploring the transitional justice field, the chapter examines the notion of public policy formation, and it establishes a context for policy formulation more broadly and, thereby, for the study's dependent variable, the TRC policy formulation process. The discussion in this chapter probes the debate around public policy formulation processes in Africa. It suggests that until very recently they have been state-centred, and have not taken a state-society approach. Policy formation processes, including the formulation stage, were characterized by executive dominance that prevented civil society from 
participating in the search for policy responses to societal problems. The examination of the discourse on policy formulation process in Africa is followed by the summary and conclusion to the chapter.

\section{1: Understanding Transitional Justice}

The notion of transitional justice captured global attention in the mid 1990s following the landmark publication in 1995 by Kritz of a three-volume compendium titled, Transitional Justice: How Emerging Democracies Reckon with Former Regimes. The view is commonly held that transitional justice is an idea conceived in the twentieth century, and the expression was popularized by Kritz in this compendium. Indeed, it is difficult to disagree with Arthur that "Kritz's book represented a key driver in the early proliferation of the term transitional justice" (2009: 331). But the concept itself is not necessarily that young. References to it and arguments for it date back more than 2000 years. Elster (2004), for example, in tracing trials, retributions, purges and reparations in ancient Athens in 411 and 403 B.C. and in France following the two Restorations of the Bourbon monarchy in the nineteenth century (1814 and 1815), demonstrates that transitional justice is not an exclusively modern exercise.

Even if we acknowledge its philosophical roots in ancient times, the fact is that by the early 2000 s, the expression "transitional justice" had become a standardized reference in the study of post-transition human rights accountability, justice and reconciliation processes. The concept is expressed in a series of actions or set of policies and their

\footnotetext{
${ }^{9}$ Although the term may not have been used in ancient times, the import of Elster's historical trace is to acknowledge that the whole notion of developing institutions or mechanisms to address historical injustices during political transitions is not only a recent phenomenon.
} 
resulting institutions, which may be enacted and created at a point of political transition from violence and repression to societal stability. The emergence of transitional justice was associated with the global third wave of democratization; ${ }^{10}$ its popularity resulted from experiences of the processes and mechanisms that newly democratic societies in Latin America, in post-communist countries in eastern Europe, and in South Africa after the demise of apartheid undertook to confront the history and legacies of political violence, crimes against humanity, and other gross human rights violations.

In application the concept is both backward-and forward-looking. On one hand, the mechanisms adopted seek to review and account for human rights abuses and injustices committed during the previous unjust and undemocratic regimes. On the other hand, the processes of transitional justice aim to build a future for just, democratic and human rights-friendly societies. The term "transitional justice" became popular in the $1990 \mathrm{~s}$, but had been in use for several years prior. ${ }^{11}$ Three phases of its origin have been posited. Each of the phases ${ }^{12}$ was characteristically associated with policy instrument or approach to transitional justice.

Phase one is typically traced to the post-Second World War Nuremberg and Tokyo trials conducted by the victorious Allied forces, based on the legal principles of

\footnotetext{
${ }^{10}$ The third wave of global democratization, according to Samuel Huntington (1991), started in the early 1970s with the democratic transitions of southern Europe (including Greece, Portugal, and Spain), followed by democratic transitions in Latin America and the post-communist states in eastern and central Europe in the 1980s. The wave caught up with societies in Africa and rest of the world in the late 1980s and early 1990s.

"Arthur (2009) suggests that the term appeared in studies on state, justice and terror in 1989 and 1992 by Milton Fisk and Juan E. Corradi, respectively. She further observes that a 1948 book on the US occupation of the New Mexico in 1846 (Black Robed Justice) by Arie W. Poldervaart had a chapter thus titled.

${ }^{12}$ De Brito, Gonzales-Enriquez and Aguilar (2001) refer to these phases as "waves".
} 
the Western world. ${ }^{13}$ In this phase, transitional justice was premised solely on legal principles based on the traditional conception of retributive justice, thereby criminalizing and judicializing the transitional justice processes. The initial stage of the literature on transitional justice was consequently dominated by human rights and criminal lawyers and legal jurisprudence (defining and clarifying laws abroad and legal processes dealing with human rights abuses, and holding perpetrators accountable). The dominance of legal principles as the basis for transitional justice would very much shape the discourse around the policy formulation processes of different transitional justice approaches as the field developed. This phase was routinely associated with the criminal or retributive approach to justice.

The second phase is tied to the political transformations in southern Europe (Greece, Portugal and Spain) in the 1970s, in South and Latin America from the late 1970s on, in Eastern Europe following the fall of the Berlin Wall in 1989, and in postapartheid South Africa in the 1990s. The criminal prosecutions pursued by a number of countries in transition from autocratic or military rule or both to democracy - notably the trials of military juntas in 1975 in Greece and in Argentina in 1985 -- were part of this wave. The trials over human rights abuses in this phase were domestic in nature.

Significantly, however, the discourse was transformed in this phase of transitional justice genealogy by the introduction of new forms of it and new meanings for it. The practice of transitional justice saw a gradual shift away from ideal processes based on rule of law and criminal trials toward more pragmatic post-transition values of nationbuilding and political legitimacy. It became apparent that discussion around transitional

\footnotetext{
${ }^{13}$ Teitel (2003a) goes a little further back to locate it in the aftermath of the First World War, and argues that there was an attempt then by the international community to define unjust war and the boundaries of permissible punishment.
} 
justice needed to take into account challenges that arise during trials (such as retroactivity of and tampering with the law, prosecutorial selectivity, and a compromised judiciary, among many others) and, also, the relevance of political and social circumstances within the domestic context peculiar to each country.

The necessity of political imperatives, in terms of consolidating the political transition (O'Donnell and Schmitter, 1986) and exploring new ways of achieving justice -what Teitel (2003a:76) calls multiple conceptions of justice -- were advanced. These conceptions included the formal acknowledgment of past human rights abuses without necessarily embarking on criminal trials. Transitional justice policy instruments that were visibly adopted by countries during this phase included the TRCs, which became popular, vetting and institutional reforms. To be sure, the policy of doing nothing (amnesia) was also associated with this phase. In this phase the concept of transitional justice drifted away from its historical meaning as a judicial exercise toward including values such as stabilizing transitions to democracy, peace promotion, healing, truth-telling, and reconciliation. Policy formulation debates on transitional justice thus became more comprehensive, and undertones of political and social conditions in these processes became significantly apparent. ${ }^{14}$

The third phase is the present globalized stage of transitional justice practice. In this global phase, transitional justice takes as its mandate addressing gross human rights violations, including the prosecution of perpetrators of war crimes, genocide, and crimes against humanity, as encapsulated in international human rights law and international humanitarian law. Teitel identifies this phase in the genealogy as "Steady-State

\footnotetext{
${ }^{14}$ Teitel (2003a) argues that in the second phase transitional justice's link to the notion of justice had became imperfect and partial, privileging truth, forgiveness and reconciliation over justice, and trading justice for peace. The field, she argues, moved critically toward a localized and alternative approach.
} 
Transitional Justice" (2003a: 89-93). ${ }^{15}$ Here the notion has withdrawn from the periphery (the local and alternative approach) to the centre (the principles of legality and the jurisprudence of human rights) -- where it was during the first wave. Whereas the jurisprudence of human rights and its consequence on transitional justice is essentially driven at the international level, it is not incorrect to suggest that this phase has also witnessed localized, bottom up approaches, including the use of indigenous mechanisms, for transitional justice process. The examples of 'Gacaca' in Rwanda, 'Mato Oput' in the Acholi community in northern Uganda, 'Magamba spirits' in Central Mozambique, and 'Kpaa Mende' in Sierra Leone (See Uvin, 2003; Longman, 2006; Huyse and Salter, 2008) are testimonies of such local level processes.

The concept presently bears witness to what Teitel argues is the "expansion and normalization of transitional justice", with legal foundations once again for post-conflict human rights accountability. The emergence of the permanent International Criminal Court (ICC), with its antecedents in the ad hoc International Criminal Tribunals for Rwanda (ICTR) and Yugoslavia (ICTY) that were created in the late twentieth century, is testimony to this normalization. Teitel has observed that "half a century after the Second World War, the ICC symbolises the entrenchment of the Nuremberg Model" (2003a: 90). In this current phase, trials or criminal prosecutions, TRCs, and other approaches to transitional justice such as institutional reforms, traditional justice mechanisms, and reparation programs are all present on the menu for choosing.

\footnotetext{
${ }^{15}$ This refers to the stabilization of the notion of transitional justice where the pursuit of transitional justice has become ever present and a global standard informed by the expansion of international and humanitarian laws. Its firm acknowledgment as a global phenomenon therefore makes it a permanent feature of international justice.
} 
The normalizing of transitional justice at the global level places emphasis on international laws, values and standards which require individual states to honour the international community's principles and demands when it comes to dealing with historical human rights abuses. Although in this globalized phase the primary responsibility for transitional justice belongs to individual states, the ICC's preoccupation, however, is to promote the individual criminal accountability for domestic abuses. The globalization of transitional justice is also evidenced in the historic United Nations (UN) Secretary-General Report of 2004, in which he called for strengthening UN support for tools and mechanisms for promoting transitional justice processes and rule of law in conflict and post-conflict societies (Secretary-General Report, 2004). To give meaning to this proclamation, the $\mathrm{UN}$ agencies devised several strategies to incorporate elements of transitional justice processes in their in-country support programs. ${ }^{16}$

The work of official international actors has been complemented by growing interest on the part of global non-state actors. Transitional justice research centres have proliferated, and international and regional transitional justice NGOs and networks, such as the Transitional Justice Institute (TJI), the ICTJ, the CSVR and the African Transitional Justice Research Network (ATJRN), to mention a few, have been established. The involvement of the UN and the wider participation of transnational NGOs and global civil society support Teitel's (2003a; 2008) assertion that the third phase in the historical development of transitional justice has shifted from the state to the

\footnotetext{
${ }^{16}$ The UN Department for Peacekeeping, for instance, expanded its Security Sector Reform unit to include aspects of transitional justice programs, such as demilitarization, demobilization and reintegration (DDR). The Office of the United Nations High Commissioner for Human Rights (OHCHR) has also produced tool kits and manuals on "Rule-of-Law Tools for Post-Conflict States: such as "Vetting", "Hybrid Courts" and "Truth Commissions" for its officers in order to enhance their field work. The UN bodies have also been assisting technically and financially in the creation of transitional justice institutions, such as ad hoc courts and truth and reconciliation commissions around the world.
} 
global level. Nagy (2008: 275-276) argues further that transitional justice has become part of the global landscape of human rights, emerging as a body of customary international law and normative standards. ${ }^{17}$

The increasingly multiple facets and varied expected end values, ranging from the legal to the theological, have caused transitional justice to be described, for the most part, as a "field" of inquiry. ${ }^{18}$ Its concepts, aims and claims for legitimacy, Arthur (2009) suggests, emerged from a set of interactions among human rights activists, lawyers and legal scholars, policymakers, journalists, donors and comparative politics experts interested in human rights and the dynamics of "transition to democracy" beginning in the late 1980s. The group of individuals concerned with these issues has grown to include theologians, historians, psychologists, sociologists and anthropologists, to mention a few. Notwithstanding, some have viewed transitional justice as not a field but, rather, a "label". Bell (2009), for example, refers to it as a cloak that covers diverse practices with quite different normative implications.

That field has even broadened to include issues and perspectives beyond traditional legal and judicial responses to human rights violations. Conceptualizing transitional justice from a legal perspective solely, as Teitel (2003b) does, has been criticized as too narrow (Alexander, 2003; Roht-Arriaza, 2006; Nagy, 2008). Such a restricted perspective limits the involvement of other, equally important, values, such as institutional reforms and economic justice, with which transitional justice ought to deal.

\footnotetext{
${ }^{17}$ Nagy notes further that transitional justice in this age has become part of an agenda setting by the international community prodding unwilling/uninterested governments to pursue transitional justice programs and projects that are "steeped in Western liberalism." The international community financially and institutionally supports these regimes in these endeavours.

${ }^{18}$ Arthur suggests that transitional justice as a field is an "international web of individuals and institutions whose internal coherence is held by common concepts, practical aims, and distinctive claims for legitimacy" (2009: 324).
} 
Further, argues Roht-Arriaza, it "overvalues the role of law and legislation, and may give short shrift to the roles of education and culture and of distributional justice" (2006: 1). It also undermines transitional justice itself by marginalizing the needs of women and the poor. Alexander (2003), for example, has suggested that transitional justice should have a positive relationship with poverty alleviation. A narrow definition of transitional justice tends to promote civil and political rights over economic, social and cultural rights. Transitional justice, it is argued, could provide remedies for victims of past violations of economic and social rights whose poverty situations have been thus aggravated (Alexander, 2003).

The understanding of transitional justice in its early, nurturing years appears to have been narrow, and focused on legal and political responses to human rights violations. Understanding of it has broadened to encompass legal, political, social and economic values of its effect. Some agree it encompasses economic, redistributive and social justice, and should also target other developmental goals (Mani, 2008; Nagy, 2008; Carranza, 2008). Recent experiences of transitional justice processes in Africa have extended investigation of them to cover economic crimes. ${ }^{19}$ The arguments for including issues of social and economic justice and development in the mandate of transitional justice are good ones, and deserve further inquiry. Caution is needed, however, to avoid turning the field into an ideological garbage receptacle, ${ }^{20}$ into which all societal needs are

\footnotetext{
${ }^{19}$ The Liberian transitional justice process is one case. The TRC established in 2006 was mandated to investigate economic crimes and corruption (Liberian TRC Final Report, 2009). The recently established Kenyan Truth, Justice and Reconciliation Commission (KTJRC) is mandated to investigate economic rights violations and other economic crimes (Kenyan TJRC Act, 2008).

${ }^{20} \mathrm{I}$ draw from the 'garbage can model' in public policy-making process to make this argument. The underlying assumption informing this model is that instead of a more programmatic and predictable means of decision-making process, policy-making in many situations, rather, follows an unexpected or an unforeseen convergence, opportunities, individuals and ideas. In short, decision-making processes are characterized by anarchy (See Cohen, March and Olsen, 1972; Kingdon, 1995).
} 
tossed. While the inclusiveness of the transitional justice mandate should be welcomed, realistic and achievable goals are necessary.

From its inception in the aftermath of the Second World War as an externally imposed process within a limited scope of jurisprudence of human rights foundations the field of transitional justice has expanded into a comprehensive examination of societies in transition. Individual states can now take the lead in, for example, in considering the relevance of political, historical and social factors when they design transitional justice policies. In this present age the field has rediscovered its legalistic principles, culminating in a globalized project that has included the establishment of the ICC. Yet it retains its comprehensive outlook, where states and societies in transition have the primary duty to initiate transitional justice processes. As Bickford (2004: 1045) observes, transitional justice is an inquiry into how societies should address legacies of human rights abuse, mass atrocities, and other forms of severe social trauma, including genocide or civil war, to the end of building a more democratic, just and peaceful future.

The continuing dual dimensions of the project -- looking back in order to reach forward -- are paralleled by what Kritz notes are its two basic components: firm dealing with perpetrators of atrocities, and adherence to the principles of democracy by the new government (Kritz, 1995: XXI). Justice, accountability, peacebuilding, healing, reconciliation and economic and social justice have been acknowledged as essential values in transitional justice programs, on both national and global platforms. An expanded definition and uncontrolled boundary can be problematic, however, when it comes time to evaluate outcomes. Advancing, implementing and assessing transitional justice process may become an ambiguous project as clarity of purpose and expected 
impact may be lost. Academically and in terms of policy, distinction of boundaries and clarity of principles may be imperative for understanding its current manifestations and foreseeing its future ones. As an interdisciplinary enterprise -- which it is presently setting its parameters by means of an academic discipline presents challenges. This is precisely because the pursuit of transitional justice advances multi-purpose objectives which permeate several scholarly boundaries.

Although transitional justice has gone from being a purely legalistic paradigm to an interdisciplinary concern, its justification is still informed by international human rights law, norms and standards. Being embedded in international law (ICTJ, 2008a) significantly influences transitional justice's normative policy conceptualization. The danger is that its processes in transitional societies may be over-determined by the dictates of that international law, which emphasizes civil and political rights over other values that may be dear to victims in particular societies. As Nagy observes, the overwhelming influence of the "international legalist paradigm" in transitional justice discourse has privileged the Westernized notion of civil and political rights, thereby undervaluing the effects of violent conflict on gender and socio-economic rights that may include HIV/AIDS, widowhood and poverty (2008: 278).

The over-emphasis on international law in designing domestic transitional justice processes has the potential to encourage one-size-fits-all mechanisms, especially when the process is externally sponsored. Elsewhere, it has been observed that northern-based donors and policymakers tend to promote a standardized set of choices of transitional justice policies, and that the international human rights groups and the UN agencies are encouraging the "templatization" of transitional justice without necessarily considering 
the unique contextual relevance of each case (Thoms, Ron, and Paris, 2008:17). ${ }^{21}$ Teitel recognizes this danger in her genealogical account when she notes that one of the dilemmas of globalized transitional justice in its contemporary phase is how to create space for local structures and needs to respond to outside obligations and forces (2003a). Practitioners nevertheless seem to agree that priority must be given to national efforts to implement transitional justice processes. As Bickford argues, researchers, scholars and practitioners are in consensus that the universal principle guiding transitional justice is that domestic strategies are required to confront historical abuses, depending on the specific characteristics and context of the country in question (2004: 1046).

A strategy for transitional justice targets accountability, an end to impunity, reconstruction of state-citizen relations, and the creation of democratic institutions for good governance, as well as enhanced standards of living. Stan confirms this belief when she points out that "transitional justice rebuilds trust among citizens and between citizens and the state, and in doing so allows the community and the state to come together and solve the problems of the nation" (2009:3). To what extent are these aspirations of a transitional justice project achievable? How do local structures and institutions respond to transitional justice discourse during the policy formulation processes? These are but a few of the issues that are constantly being analysed, discussed and debated by researchers. The current study is associated with the latter issue: that is the degree that local institutional configurations allow communities to be involved in the policy formulation discourse and processes.

\footnotetext{
${ }^{21}$ Nagy (2008), for instance, notes the propensity of the international community to enforce a similar strategy and the provision of technocratic and "decontextualized solutions" in different systems.
} 


\subsection{1: Debating Transitional Justice}

The transitional justice field witnessed several contentious debates among academics and practitioners in its formative years and, as it is still developing, new debatable issues continue to emerge. Some are long resolved; others rage on. In this study, three of the contentious debates relevant to the research questions are examined. The peace-versus-justice, the retributive-versus-restorative justice, and the conceptual boundary of transition (what, exactly, is the transition in transitional justice discourse?) debates are discussed in turn. These issues featured significantly at different stages of the policy discourse surrounding the formulation processes of the TRC-approach to transitional justice in South Africa, Nigeria and Ghana.

The peace-versus-justice debate, which occupied the centre stage of the field during the second phase of development, divided scholars and practitioners along the lines of political and legal imperatives. The questions were whether perpetrators of gross human rights violations should be prosecuted and punished in all instances, and what might best advance stability in the transitional society. These positions were said to represent the realist-versus-idealist dichotomy of justice in transition (Teitel, 2000). One argument was that political change and its consolidation were needed before mechanisms to examine the justice question ${ }^{22}$ for past wrongs could be established (Huntington, 1991). The essence of the political transition, especially transitions with democratization as the goal, was to make space for democratic structures to flourish. A similar argument regarded societies emerging from conflict to peace was expressed. Mixing the discourse with retributive justice at this stage of the transition could lead to destabilization of the

\footnotetext{
${ }^{22}$ Justice here was meant to be retributive. Transitional justice processes needed to employ a judicial or criminal justice process to exact appropriate punishment for perpetrators of human rights abuses.
} 
democratization process. ${ }^{23}$ Peace was thus the major theme of any transitional justice process in times of political transition. Once some semblance of peace and stability were guaranteed, the question of justice could be explored.

The opposite argument was that justice for human rights wrongs was considered vital during transitions if the culture of impunity was going to be consigned to history. Transitional justice was premised on a universal conception of justice, which required full retribution. Exacting punitive justice through the judicial process was deemed necessary for the political change that the transitions sought to advance (Orientlicher, 1995; Malamud-Goti, 1996; Teitel, 2000). Certain legal responses were required to precede political transitions because they created opportunities for democracy. Retributive justice contributed to establishing a commitment, on the part of new regimes, to a rule-of-law society and respect for human rights. Trials during political transitions for human rights abuses encouraged a sense of individual responsibility, which is fundamental to democratic citizenship; they could also facilitate peacebuilding because of their deterrence value (Malamud-Goti, 1996; Thoms, Ron, and Paris, 2008).

During the transitional justice policy formulation discourses in South Africa and Ghana, for example, this debate surfaced in the public space. While some groups and stakeholders -- in particular, victims of human rights abuses -- called for a judicial process, others advocated a non-retributive process, as the former had the potential to destabilize the social order. In South Africa it was feared that any attempt to institute criminal prosecution of leaders of the outgoing apartheid government could undermine

\footnotetext{
${ }^{23}$ The case of Argentina is often cited to support this view. In that country's post 1983 political transition, an attempt by the new Raul Alfonsin democratic regime to try leaders and junior officers of the former military junta as part of transitional justice processes was halted (with passage of amnesty laws) when the military establishment threatened to destabilize the democratic process with coup attempts.
} 
the transition to democracy. In Ghana, although there was an entrenched legal obstacle (indemnity laws) to any form of criminal prosecution of perpetrators of human rights abuses during previous military regimes, it was nevertheless felt that any attempt to amend and remove these indemnity laws from the statute books might be fiercely resisted by those who stood to lose: thereby, again, endangering the peace of the country.

The peace-versus-justice debate is no longer as significant in the transitional justice discourse. The consensus seems to be that there cannot be a lasting peace without some form of justice. Yet it is also acknowledged that there is no deadline for instituting a retributive justice process against perpetrators of human rights wrongs. ${ }^{24}$ The importance of sequencing in the transitional justice process has recently become prominent in the discourse (Murithi, 2010; Fletcher, Weinstein and Rowen, 2009; Quinn, 2009). Sequencing is necessary to maximize the benefits of peace, justice, social cohesion and democracy. These elements are viewed as not mutually exclusive, but rather as mutually reinforcing objectives (Secretary-General Report, 2004). Thus, while suspending retributive justice during a political transition in order to secure peace and stability is essential, the transitional justice processes themselves must result in an approach that will promote peace, and enable justice for later.

Concerns over the role of justice in transitional justice processes dovetailed into another controversial debate. The retributive-versus-restorative justice debate assumed prominence during the second wave of the transitional justice genealogy (Kritz, 1995;

\footnotetext{
${ }^{24}$ Recent instances relating to the pursuit of justice for historical human rights wrongs attest to this acknowledgment: the arrest and indictment in 1998 of Chile's late military dictator, General Augusto Pinochet, in the United Kingdom by a Spanish Court; the 2005 revocation of amnesty laws by the Argentina Supreme Court, paving the way for criminal prosecution of former military leaders; and the arrests and trials of former Liberian leader Charles Taylor (in 2006) and Radovan Karadic, former Bosnian Serb leader (in 2008 after 13 years hiding), in the Hague, Netherlands.
} 
Teitel, 2000; 2003a; Hayner, 2001; Gloppen, 2002; Chinapen and Vernon, 2006).

Sometimes referred to as "truth versus justice", the debate was about the kind of justice to pursue in times of political transition. Different forms of justice emerged in the transitional justice discourse.

Retributive justice was argued to advance democratic accountability. Failure to prosecute and punish human rights offenders at the time of transition was seen as detrimental to the rule of law and to reconciliation at both the interpersonal and societal levels. Supporters of retributive justice suggested that not exacting this form of justice undermines the accountability required to promote a rule of law culture in transitional societies. ${ }^{25}$ International human rights organizations, such as Amnesty International and Human Rights Watch, were also opposed to transitional justice processes that lacked retributive justice's attributes or worse, in their view, endorsed amnesties (Kritz, 1995: $217-218 ; 219-222)$.

Conversely, restorative justice was viewed as more consistent with political and social reconciliation processes than retributive justice. Restorative justice facilitates reconciliation by restoring broken relationships through acknowledgement of the offences and compensation to victims for the harm done (Molenaar, 2005:43). It is further argued that restorative justice process stresses on the humanity of both offenders and victims (Minow, 1998). It does not seek retribution as its focus is on promoting relations and communication between victims and perpetrators. Minow points out further

\footnotetext{
${ }^{25}$ For human rights activists, the contributions of retributive justice through judicial processes to accountability, reconciliation, and the respect for the rule of law are enormous. The establishments of ad hoc global tribunals, the ICTY and ICTR, as well as the Special Court for Sierra Leone, and the more permanent ICC to bring to justice perpetrators of human rights violations are cited as the right path towards addressing injustices and the culture of impunity and promoting accountability (Fatic, 2000; Longman, 2006).
} 
that "unlike retributive approaches, which may reinforce anger and a sense of victimhood, reparative [restorative] approaches instead aim to help victims move beyond anger and a sense of powerlessness" (1998:92).

Reparative and reconciliation processes were seen as less a matter of punishing perpetrators for wrongs or of uncovering the truth than of restoring the physical, psychological, social and economic well-being of the individuals damaged. Its themes of restoration, rehabilitation, restitution, reparation and compensation prompted supporters of this form of justice to observe that it advances the peace, accountability, stability and reconciliation essential to the success of the political transition.

Transitional justice processes in Africa appear to be informed by the restorative notion of justice. In all the cases selected for this study, the debate and argument in support for the TRC-approach was framed in this context. Government officials who advocated this approach argued that the restorative justice process was more beneficial to the victims than retributive justice, and it also contributed to national reconciliation. Retributive justice, they argued, would further divide the society, which could set off instability in the political system. The restorative justice option has attained fashionable status in Africa, especially since the South African TRC process. It is seen as promoting and achieving reconciliation in transitional societies (Villa-Vicencio, 2009). The argument is made that this option presents alternative non-judicial responses to the promotion of transitional justice, and that the restorative justice processes are akin to cultural and traditional approaches to achieving reconciliation in African societies. ${ }^{26}$

\footnotetext{
${ }^{26}$ Rwanda's Gacaca and the Acholis of northern Uganda's Mato Oput are two of the traditional processes often cited. In spite of potential merits associated with these traditional processes, there were difficulties in trying to associate African cultural and traditional practices with formal transitional justice processes. Some of these processes and procedures may disempower the individual victim who wants to go for the
} 
Similar to the peace-versus-justice debate, the retributive-versus-restorative justice debate appears reasonably settled in the present phase of transitional justice discourse. Both forms of justice are considered critical for any meaningful transitional justice process, and are viewed as critical to advancing reconciliation processes (Lederach, 1997; Kriesberg, 2004; An-na'im, 2005; Chinapen and Vernon, 2006). The importance of retributive justice in transitional justice processes is acknowledged. Pursuing it exclusively, however, may undermine the realization of other important aims. Chinepen and Vernon have observed that both retributive and restorative justice (the latter effected through truth commissions) aim for a moral equilibrium that needs to be restored when basic equality is violated, and that the nature of the transition provides sufficient explanation to the differences in their application (2006:117).

Both aspects of justice include advancement of accountability, respect for the rule of law, stability, reconciliation and an enhanced democracy. Bloomfield argues that if justice is defined from a multi-dimensional perspective to include not only crime and punishment but, also, the restoration of broken relationships, promotion of fairness and equality of all persons, then the trade-off between reconciliation (restorative) and justice (retributive) will be less of a problem (2006: 29). Retributive and restorative justice should be seen as complementary in a transitional justice process. Thus, what comes first during this process should not be viewed through an ethical lens, but understood as a political question.

retributive justice option, and in addition they fail to meet international standards of due process, gender rights and accepted forms of legitimate punishment (See Uvin, 2003; Longman, 2006). 
A third debate in the transitional justice discourse, within which the current study is also situated, concerns the conceptual boundary of transitional justice applications. ${ }^{27}$ Is transitional justice policy feasible only during the traditional democratic transition opening and breakthrough stages (Carothers, 2002), ${ }^{28}$ at the moment of regime change, in the midst of conflict, or is it applicable long after these stages? This recently arisen debate was provoked by the phenomenon of transitional justice policies being applied in societies that are not necessarily describable as transitional. ${ }^{29}$ Some have been democratic for a long time, and are also identifiable as developed societies. Notable instances are Ghana, which is one of the cases for this study, Morocco, Kenya, Northern Ireland and, arguably, Canada.

The debate may be new, but the early development of the content of the concept of transitional justice was obviously somewhat determined by how the term "transition" itself was understood. Confronting historical abuses in whatever form was instrumental to democratization and democratic good governance. The normative lens through which transitional justice was viewed was the reality of transition to democracy. It was from this view point that political change was interpreted and for which transitional justice became a critical element. Central to the discourse was the question of human rights accountability and promotion. As Arthur (2009) argues, prosecution, truth-telling, restitution and institutional reforms, apart from distributive justice, were recognized as legitimate transitional justice approaches during political change. Transitional justice was

\footnotetext{
${ }^{27}$ Arthur (2009) suggests this is one of the several challenges facing the field in this globalized phase.

${ }^{28}$ One of the central assumptions of the classical doctrines of transition to democracy was that democratization unfolds along three sequential stages: opening; breakthrough; and consolidation. The collapse of the old regime is followed by swift installation of a new democratic government through national elections, and democratic structures are established.

${ }^{29}$ Transitional societies in the sense that they may not be emerging from prolonged conflict or undemocratic regimes.
} 
initiated for the purpose of promoting democracy. Hence, it was correctly instituted at the time of the opening or breakthrough stages of the transition to democracy.

With time, however, this consensus on the assumption that all political transitions were from an undemocratic period to one of democracy was questioned. Uncertainties of democratic outcomes were expressed over this change in consensus over a movement towards democratization during political transitions (O'Donnell and Schmitter, 1986). ${ }^{30}$ Nevertheless, as the transitional justice field developed, its association with this paradigmatic notion of democratic political transition was widely acknowledged and promoted. The current debate is about whether transitional justice policy is applicable in societies atypical of the paradigmatic type of transitions. One argument is that transitional justice, or its reference in the context of transitions, is and should be limited to that brief period of political change-over, and should not commence beyond the opening or breakthrough phases. It may explain why the Ghana TRC did not attract wide international attention. ${ }^{31}$ Others, however, suggest that such a limitation is untenable with the goals of transitional justice.

At the core of this debate is whether transitional justice should focus on dealing with human rights abuses committed under previous authoritarian regimes and during violent conflicts, or whether it has an equally important function in established democracies that have experienced unattended, prolonged political and human rights violence. Making a case for transitional justice in non-paradigmatic settings, Ní Aoláin

\footnotetext{
${ }^{30}$ Some remained cautious in the face of this optimism. Moments of transition may have a variety of results, including movement toward values other than democracy: for example, from war and/or conflict to peace and/or stability; from military to civilian dictatorial rule; and from communism to a market economy. Nonetheless, it was argued that even if the immediate focus of the political transition is distributive justice, as has been argued elsewhere in the case of South Africa (Arthur, 2009), or, for instance, "transition to peace", the overriding objective is democratic good governance .

${ }_{11}$ Ghana's formal transitional justice process occurred several years following the opening and breakthrough phases of democratic transitions.
} 
and Campbell (2005) argue that there are such things as "conflicted democracies", ${ }^{32}$ and that they require transitional justice processes to shed the burden of the past. They often bear legacies that they cannot avoid addressing to create a more inclusive society and initiate institutional reforms. ${ }^{33}$ There is even the need for total social and political transformation of the society in order to prevent future conflict, as well as to deepen the liberal democracy.

In the conflicted democracy, the assumption is that there is a remnant of the abuses, tensions, conflicts and divisions of the past that threatens the peace, stability and democratic governance of the present. The need to confront these legacies is paramount for the future of democracy in such societies. The case of Ghana falls appropriately in this circumstance. Transitional justice goals, whether devised through the mechanism of trials, truth commissions or inquiries of various kinds, provide the forum and means to confront abuses of the past. This can take place whether in a paradigmatic transition or in a conflicted democracy. In other words, similar to the paradigmatic transitional context, transitional justice in a conflicted democracy requires building or rebuilding trust in the society and its institutions.

The expansion of transitional justice discourse beyond the traditional notion of transitions evidences the breadth of its terrain as exceeding transitions to democracy. Its premise is the need to assist societies that are attempting to find closure to and settlement of protracted social conflict, irrespective of the time these societies made their transition

\footnotetext{
${ }^{32}$ Conflicted democracies are defined from two perspectives: democratic states that meet the minimum requirements of the procedural form of democracy, but fall short if measured against the test of substantive democracy; and those with acute division in the body politic that threatens significant political violence. In both scenarios, especially the latter, long-standing and unaddressed violence may manifest in deep seated and sharp divisions (whether ethnic, racial or religious) in the society.

${ }^{33}$ The experience of Northern Ireland is cited as one case that does not nicely fit into the paradigmatic type of transition, yet it has undergone a series of processes classifiable as transitional justice.
} 
to democracy. As was recently stated by the ICTJ (2008a), transitional justice is not a special form of justice but, rather, justice adapted to societies transforming themselves after a period of pervasive human rights violations. These transformations may happen suddenly or over many decades after the formal transition. Succinctly stated, it thus defies the conventional notion of transition. The conceptual development of the field of transitional justice allows for greater focus on its end goals than on the timing of its application.

\subsection{2: Goals of Transitional Justice}

Consideration of various representations of what transitional justice seeks to achieve reveals several goals. In this study, these numerous identified goals have been grouped under five broad headings of equal merit. They are: accountability and rule of law; peace promotion and peacebuilding; truth seeking; psycho-social healing and reconciliation; and institutional reform.

The fundamental rationale for transitional justice is its accountability and rule of law objective. Transitional justice, it is claimed, creates avenues for accounting for human rights abuses. In so doing, it helps to establish a new order based on the rule of law that is necessary for transitional societies, especially those moving toward democracy. Mendez, for example, observes that "the pursuit of retrospective justice is an urgent task of democratization, as it highlights the fundamental character of the new order to be established" (1997: 1). Pursuing accountability and justice during political transitions is a legal and moral obligation for new regimes. 
The state is compelled by both national and international law, and by its duty to victims and society, to prosecute and punish perpetrators of human rights abuses (Orentlicher, 1995; Mendez, 1997). By the practice of transitional justice, violators of human rights are punished, thus contributing to reversing the culture of impunity that characterized the previous era. Proponents maintain that an end to a culture of impunity helps to further democratic governance and the well-being of a country so governed through the promotion of and respect for human rights (Malamud-Goti, 1990; 1996; Nino, 1991; 1996; Boraine, 2006).

The second significant goal is its contributions to peace promotion and peacebuilding. Transitional justice process is generally considered to help prevent reappearance of violent conflict and foster sustainable peace. To be sure, transitional justice process does not necessarily have a direct relationship with peacebuilding efforts. The pursuit of it, however, promotes conditions for a durable peaceful society (ICTJ, 2008a). Societies transiting from war or conflict are necessitated to institute a process to investigate the causes of the conflict in order to develop measures to forestall a repetition and foster peace. As observed by Zyl, "Transitional justice embodies an attempt to build a sustainable peace after conflict, mass violence or systematic human rights abuse" (2005: 205).

Transitional justice enacts peacebuilding through the process of establishing an historical record and counteracting denial; ensuring accountability and bringing closure to impunity; and fostering reconciliation and socio-political reconstruction. The UN acknowledges this critical role of transitional justice in maintaining long-term peacebuilding. It notes that consolidating peace in the wake of conflict requires the 
redress of grievances through legitimate structures for peaceful settlement of disputes and fair administration of justice on the basis of the rule of law (Secretary-General Report, 2004).

The third goal of transitional justice relates to its opening up of avenues to truth recovery. Transitional justice mechanisms are able to advance the discovery of truth about the past. In whatever form -- factual/forensic, personal/narrative, social/dialogical, or healing/restorative (Boraine, 2006: 27-29) -- the process contributes to historical documentation of the past that preserves lessons learned. The truth recovery role of transitional justice helps the state meet its obligation to let victims know the truth. Transitional justice with a focus on truth discovery strengthens states' ability to investigate any and all aspects of truths about still-secret past violations and to disclose these to the suffering victims and the society as a whole (Mendez, 1997).

A psycho-social benefit of a transitional justice process is identified as the fourth goal of its pursuit. Advocates of transitional justice suggest that the focus on truth recovery creates the space for psychological healing of victims of atrocities, and thereby facilitates reconciliation (ICTJ, 2008a). Promoting lasting peace in divided societies includes forging reconciliations among former enemies and, also, between perpetrators of violence and their victims. Achieving this reconciliation depends, to a large extent, on acknowledging victims, their knowledge of the truth, their belief that their grievances are being addressed, affirming their dignity, and their relief from psychological trauma as well as sincere efforts by perpetrators (individuals or the state, or both) to acknowledge responsibility for abuses. Besides developing mechanisms to unearth the truth, other forms of reconciliation, such as apology, forgiving but not forgetting, and reparations are 
considered critical for advancing psychological healing of victims and reconciliation at both micro (interpersonal) and macro (societal) levels (Mendez, 1997; Boraine, 2006).

Finally, besides serving individual needs, transitional justice has an equally important role of advancing institutional transformation and reform (Ní Aoláin and Campbell, 2005). Through investigations into and hearings about institutions of the state responsible for its breakdown and for the subsequent conflict and human rights abuses, if any, transitional justice processes have the ability to develop proposals and recommendations for the creation of new institutions to safeguard the rights of citizens, and also to build improved versions of old, repressive institutions in order to promote public trust in them. The cleansing of state and public institutions is also manifested in purging or vetting of leaders and other persons associated with them who committed atrocities against citizens. In so doing, the process contributes to building a credible and trusted image for these institutions (Mendez, 1997; Boraine, 2006).

These five broad goals are at the centre of transitional justice processes, but they are not the only ones to have been named. For instance, Bell (2009) identifies the following: restoring the rule of law and democratization; power sharing; reconciliation; promoting peace; and disarmament, demobilization and reintegration. While the goals associated with transitional justice are robustly asserted by advocates of the field, there are critics who challenge them. Some have suggested that implementing transitional justice does not necessarily lead to rule of law and democracy. In addition, its promotion may actually trigger renewed conflict by further dividing the society and rekindling the animosity between opposing groups, jeopardizing long-term peacebuilding, healing and reconciliation. The ability of transitional justice processes to discover the truth about the 
past -- wholly and genuinely -- has also been questioned and debated extensively (Ignatieff, 1996; Call, 2004; Mendeloff, 2004).

The sufficiency of the empirical evidence for the claims of transitional justice is not universally agreed on. Thoms, Ron and Paris (2008) are among the doubters. ${ }^{34}$ Whether transitional justice policies promote peace or something else in transitional societies, whether they promote respect for human rights and the rule of law, and even whether they facilitate reconciliation all requires empirical evidence -- which, however, is limited. Sustained, careful, and cross-national analysis of the transitional justice record is needed in order to make a strong case for transitional justice goals (Thoms, Ron and Paris, 2008; Bell, 2009). One can hardly disagree with the call for advocates of transitional justice to progress from desired goals to factual results of its implementation: what Thoms, Ron and Paris refer to as a move away from "faith-based" to "fact-based".

This current research does not focus on the impact of transitional justice mechanisms on societies. ${ }^{35}$ It is nonetheless grounded in empirical investigation of another aspect of the field: the political processes behind the policy formulation of transitional justice approaches in domestic politics. The study refers to the outcomes of selected cases of transitional justice implementation. As will be explained below, understanding how a particular public policy was formulated is critical for evaluating its impact. There is also a dearth of empirical evidence to help us understand how individual countries formulate a particular transitional justice mechanism to seek the objectives

\footnotetext{
${ }^{34}$ The authors suggest that there is still insufficient evidence to sustain claims that transitional justice mechanisms have had positive or negative effects on the promised goals. What is out there is questionable or contradictory.

${ }^{35}$ Evaluating the impact of transitional justice processes has assumed one of the central debating points in the field. A recent special issue of the International Journal of Transitional Justice (2010) was dedicated to evaluating the impact of transitional justice mechanisms.
} 
associated with it and, more important, how the globalization of transitional justice translates into local politics. The current research addresses these two questions empirically.

\subsection{3: Approaches to Transitional Justice}

Five approaches and associated institutions are commonly identified in the practice of transitional justice. They are criminal prosecution, truth commissions, vetting, reparations programs, and institutional reforms. Some have categorized the approaches differently. The ICTJ (2008a), which is involved in promoting transitional justice and advising countries around the world on its processes, identifies criminal prosecutions, truth commissions, reparations programs, security system reform, and memorialization efforts. In some instances, vetting and lustration are considered separate mechanisms. A policy of complete amnesia has also often been cited (Huntington, 1991; Thoms, Ron and Paris, 2008). Obviously, some of these approaches overlap. For instance, the truth commission approach may include in its operation memorialization, reconciliation, reparation and institutional reform (including security system reform). Similarly, criminal prosecution may include elements of reparation. The five most widely accepted approaches are elaborated on below.

Criminal Prosecution: Criminal prosecution was the first identified approach to transitional justice, and, apart from amnesia, was the only one associated with it as the field emerged. Also known as "trials" or "judicial proceedings", it is the most preferred process. It involves the prosecution and punishment (retributive justice) of individuals alleged to have committed gross human rights violations, and takes the form of judicial 
investigation of those responsible. The process may be instituted domestically or internationally. The domestic trials of military juntas in Greece in the 1970s, Argentina in the 1980s, and of the Mengistu Haile Mariam dictatorial regime in Ethiopia in the 1980s, are historical instances of the first wave of judicial proceedings as a form of transitional justice. In recent years, the internationally sanctioned ad hoc courts of the ICTY and ICTR may be cited. The judicial approach to transitional justice has taken different manifestations, including the hybrid system of the Special Court for Sierra Leone and the UN ad hoc Court for East Timor, both established in the 2000s, and which resulted in the creation of a permanent global judicial mechanism in the form of the ICC in 2002.

Although several criticisms have been levelled against the criminal prosecution approach -- particularly that the retributive form of justice it delivers is antithetical to peace promotion and peacebuilding ${ }^{36}-$ it nevertheless remains the most popular in the history of transitional justice, and is usually the first approach considered when societies are contemplating embarking on the transitional justice path. Advocates of criminal trials argue that they have several valid goals, including: deterrence, which promotes good political conduct; promoting the rule of law; encouraging opportunities to rebuild a shattered judiciary; and meeting victims' needs by offering them an experience of justice (Thoms, Ron and Paris, 2008:21-22).

Truth Commission: The second, and also very popular, approach to transitional justice is the truth commission. Sometimes referred to as the truth and reconciliation

\footnotetext{
${ }^{36}$ It has been argued that criminal prosecutions can trigger renewed conflict by strengthening societal divisions because perpetrators, who may be leaders of their communities, are identified, put on trial and punished. Criminal prosecutions may therefore revive entrenched antagonisms, obstructs reconciliation process, and aggravate hostile subcultures and network that may destabilize fragile peace settlements (Huyse, 2003a). Chandra Lekha Sriram (2007), for example, suggests that transitional justice process essentially supports the consolidation of peace in post-conflict societies, but she further argues that the opposite is also true: that transitional justice process may undermine stability in post-conflict settings.
} 
commission or truth-seeking approach, it is designed to produce a historical record of human rights transgressions. It seeks to uncover hidden truths, and may also result in reconciliation between and healing of victims and perpetrators. As a primarily factfinding enterprise, it may include other, related, approaches, such as reparations, both monetary and non-monetary, and memorials. A preventive contribution is the development of recommendations for broad institutional transformations and reforms. The origins of the truth commission are traceable to the Latin America region during the second phase of the transitional justice wave. By far the most admired and internationally best identified truth-seeking project is the South African TRC.

Similar to the judicial approach, this mechanism has been the subject of several criticisms, including those of being a second best option to trials because of its limited accountability; of its inability to promote complete truth recovery and reconciliation; and of not going far enough to exact punitive justice. Yet it continues to attract interest as a policy response to the challenge of human rights accountability. Thoms, Ron and Paris suggest that truth commissions after negotiated transitions have become popular, and also have become "a staple in the post-conflict peacebuilding efforts" (2008:15). This approach to transitional justice, which is the focus of this study, is explored comprehensively in chapter four of this dissertation.

Vetting: The third identified approach to transitional justice is what is commonly referred to as vetting. The United Nations Office of the High Commissioner for Human Rights (OHCHR) considers vetting part of personnel reform, which is part of institutional reform. It defines it as broadly assessing the integrity of personnel to determine their suitability for public employment in times of transition (OHCHR, 2006). To the UN body 
vetting is an effort to build fair and efficient institutions that will contribute to transitional justice. It does not follow a criminal justice procedure, but is considered administrative justice. The term is sometimes used interchangeably with "lustration", but they are distinct. Lustration takes the form of screening individuals, especially public officers, to determine if their past activities, memberships or affiliations make them ineligible for certain public offices.

Lustration was popular in post-Second World War Germany and in some of the post-communist European states, such as the former Czechoslovakia, Poland, Hungary, and Romania (David, 2003). In those settings, lustration emerged as comprising the application of governmental policies that limit the involvement of ex-communist officials, whether as informants or as members of a secret police force, in political and public service appointments of successor regimes. Vetting, on the other hand, assesses individuals on the basis of their record of commitment to international human rights standards. The UN does it to exclude individuals with questionable commitment in order to "re-establish civic trust and re-legitimize" these institutions (OHCHR, 2006: 4). Vetting and lustration have the same goal: keeping out of the new regime persons who may have committed or are predisposed to commit, directly or indirectly, human rights atrocities against fellow citizens.

Vetting in particular is meant to nurture citizens' trust in public institutions in the aftermath of the transition. As the OHCHR has noted, victims of abuses are unlikely to trust or rely on public institutions if individuals with serious integrity deficits remain at the helm. Supporters of vetting argue that these measures can promote reforms crucial for democratization and, also, prevent repetition. Although it has received limited academic 
attention, it was commonly instituted in post-communist Europe in countries such as Poland, Hungary and East Germany. Its manifestations have also been noted in postconflict and authoritarian societies, including Bosnia and Herzegovina, El Salvador and Greece (Mayer-Rieckh and De Greiff, 2007; Stan, 2009.) It is most applied in the security and judicial institutions.

Reparations: Reparations, including a compensatory policy program for victims of human rights abuses, constitute another approach to transitional justice. While this program may be featured in other approaches, such as truth commissions, it can also stand alone as a transitional justice mechanism. The ICTJ (2008a) defines this approach as consisting of the state-sponsored initiatives that help repair the material and moral damage of historical abuses. It comes in the form of distributing a combination of monetary and symbolic programs for victims of human rights violations, including restitution, rehabilitation, and apologies. The reparations may also include health (physical and mental) and education benefits (Bickford, 2004). In some instances memorials and development of public space for museums figure in symbolic reparations.

Institutional Reform: The fifth approach to transitional justice is comprehensive reform of abusive institutions. Not unlike reparations, institutional reform has found itself tied to other approaches, particularly the truth commission; and, as noted, vetting is also considered part of it. Nevertheless, as a stand-alone approach institutional reform is geared towards reforming institutions that have a long history of abusive behaviour in order to prevent repetition (Bickford, 2004). Institutions marked for reform may include the security services, educational institutions, human rights-unfriendly legal statutes, and other governance institutions. In some cases, institutional reform may entail the 
transformation of some institutions, the creation of new ones, and new legislation to govern their conduct. For example, reforms may address issues of gendered patterns of abuse. The primary objective is promoting social reconstruction that will facilitate a progressive state-society relationship in the new, transitional society.

These five broadly identified approaches to transitional justice can each be applied alone, or they can be used complementarily. In a recent study covering 192 countries in a period between 1979 and 2004, criminal prosecution and truth commissions were noted as the most common approaches to transitional justice processes: 49 of these countries had at least adopted trials, while 34 employed a truth commission. The study also revealed that the two are often combined (Sikkink and Walling, 2007). Indeed, the complementary approach is increasingly being employed in transitional societies. The transitional justice process in Sierra Leone that was established alongside a truth commission is a notable example. The UN recommends either a single method or a combination of approaches (Secretary-General Report, 2004). For its part the ICTJ advises a holistic approach to transitional justice, and notes that dealing with widespread human rights abuses presents large practical difficulties. They may include finding a balance in a delicate political climate, and impracticality and inadequacy of judicial measures.

To be effective transitional justice should take into account several complementary measures. The ICTJ says that practice and experience have shown that no single measure is as effective on its own as when combined with others (ICTJ, 2008a). The three cases.in this study employed the truth commission approach. Yet the mandates of the truth commissions that were established included recommendations for reparations 
and institutional reforms. It can be argued that the countries adopted a complementary approach to transitional justice, with trials and vetting approaches excluded, except in the case of South Africa, where the prospects for trials formed part of the transitional justice process only when individual amnesty was denied.

\subsection{4: Understanding of Transitional Justice Policy Formulation Theory}

The waves in which the transitional justice subject progressed included the emergence of models to explain how transitional justice policy approaches are formulated. Three models broadly prevail: the legalist/institutionalist; the transitology discourse; and the instrumentalist (elite pact). These three express causal variables in transitional justice policy formulation. They are usually invoked to justify the choice of an approach to transitional justice policy in transitional societies. The present study departs from these models by suggesting that none adequately accounts for the formulation of the TRC-approach in South Africa, Nigeria and Ghana and the associated reproduction across borders. The existing models are examined in the following pages.

Legalist/Institutionalist Model: ${ }^{37}$ Perhaps the dominant one, this model privileges the doctrines of human rights protection that are enshrined in laws and statutes, both national and international, and are associated with notions of justice and accountability for human rights transgressions. These beliefs controlled the direction of transitional justice in its formative phase following the Second World War and were associated with the criminal justice form of it. The model is based on the jurisprudence and ethics of

\footnotetext{
${ }^{37} \mathrm{By}$ institutionalist, I mean established legal codes, rules and laws that are promulgated by nations and international community which become governing regimes, referenced to and are sanctioned by authorities in these jurisdictions.
} 
human rights, and it appeals to the impulse toward an effective response to gross human rights abuses and to the need to respect the principles of universal human rights. The argument is that the legal principles contained in national constitutions and enforced by international norms and standards, such as the Universal Declaration of Human Rights (UDHR), provided grounds for acknowledging human rights violations, thereby supporting the execution of transitional justice policy programs (Nino, 1991; 1996; Zalaquett, 1995; Orentlicher, 1995; 2007; and Teitel, 1995; 2000; 2003b).

The ethical imperative to honour human rights and the demands of intemational law, even where the 'rights to truth and reparations' have become part of the globalized human rights laws and norms, predominantly dictates the adoption of a criminal or retributive form of justice, particularly for those with greatest responsibility. The formulation of the criminal justice approach to transitional justice policy during political transitions was, therefore, informed by this legalist/institutionalist model. The legal/institutional model continues to be a governing reference for any transitional justice policy approach. It is, however, more predisposed to the instrument of trials, as the ICC depicts, than other approaches to transitional justice process. Its application in domestic politics, however, suggests that a transitional justice process is a given that only requires a political transition to be activated. It connotes a top-down approach, and has little room for localized politics. It neglects the role of political elites and agency in the policy bargaining process that results in the adoption of a criminal justice approach or, indeed, any other approach.

One of the questions explored in this study is the extent of citizens' participation in the choice of the TRC-approach. As Orentlicher (2007) recently acknowledges, 
promoting victims' and citizens' participation in designing and implementing transitional justice programs is of central importance. In this respect, the legalist model is weak in explaining why and how these political elites come to the positions they bargain for; it is also unable to explain why certain societies do choose an approach other than criminal trials to transitional justice. ${ }^{38}$ Domestic statutes in countries may be invoked to undermine international legal principles that oblige successor regimes to prosecute and punish rights offenders.

Transitology Model: This model became popular during the third wave of democratization. It suggests that to understand why a particular approach to transitional justice was chosen over another, it is critical to know the nature of the political transition and the balance of power during the transition. The emergence of this approach, during the second phase of the genealogy, liberated transitional justice from the legalist/institutionalist paradigm. It also popularized other approaches, particularly the truth commission. Adherents to this paradigm, often referred to as the pragmatists or the politics school advocates, argue that different forms of transition to democracy produce different approaches to transitional justice policy ( $O^{\prime}$ Donnell and Schmitter, 1986; Huntington, 1991; Linz, 1995; Herz, 1995).

Fundamental to this approach was the preservation of the political transition that will sustain the democratization process. The key question for transitional justice is how to settle past accounts without derailing the democratic transition. This model offers three different forms of transition, as well as the corresponding transitional justice policy

\footnotetext{
${ }^{38}$ Perhaps this partly explains why in the history of transitional justice only three countries -- Greece in the 1970s, Argentina in the mid 1980s, and Ethiopia in the 1980s -- have opted for a criminal justice approach on their own. The rest have been imposed and adjudicated, more or less, by the international community.
} 
approach: transformation, replacement, and transplacement. ${ }^{39}$ Depending on the type of transition and the balance of power, transitional justice policy will involve different methods, including criminal trials with varying levels of punishment, and non-criminal approaches, such as truth-telling outside of the criminal judicial apparatus.

The transformation type is likely to result in complete amnesia or closing of the books, or both, as a transitional justice policy. The replacement form is expected to lead to criminal prosecution, while the transplacement type may produce other forms of transitional justice, including the truth commission. In some cases it may even involve a policy of silence (total impunity) on historical abuses (Linz, 1995; Herz, 1995). ${ }^{40}$ Skaar (1999) deploys this model to analyse how newly elected democratic regimes responded to previous violations of human rights. After analysing data from 30 countries she concludes that policy choice will favour trials when the outgoing regimes are weaker, and move away from trials when they are stronger. Skaar notes further that truth commissions are the most likely outcome when the strengths of the opposing demands are more or less equal.

Accordingly, this model allows that the choice of a policy approach to transitional justice is determined by the nature and type of the democratic transition and by the

\footnotetext{
${ }^{39}$ Other scholars have given different labels to these same types. For example, Huyse (1995) prefers to use words like (in order as above) reform, overthrow and compromise; Gill (2000) calls them transaction, replacement and extrication. The transformation type suggests that those in power in the authoritarian regime assume the lead and play a decisive role in ending autocratic rule and transforming it into a democratic system; the replacement model involves a democratization process that results from the opposition gaining strength and the government losing control over the management of the country until the government collapses; and the transplacement form is produced by the combined actions of government and opposition.

${ }^{40}$ Linz and Herz note that in order to co-opt some members of the erstwhile authoritarian regime, including bureaucrats and some leading political elites, for the sake of the survival and consolidation of the democratic transition, successor regimes may have to forgo transitional justice completely or adopt a less retributive approach.
} 
balance of power dynamics. To some extent the transitology model undoubtedly was a response to the weaknesses associated with the legalist/institutionalist paradigm. In particular, it addresses the role of localized politics. It makes room for contextual social and political relevance in the design and formulation of the transitional justice policy approach.

Nevertheless, the model suffers from defects similar to those of the legalist/institutionalist. It assumes that the type of transition will automatically determine the choice of transitional justice policy-approach. It fails to articulate the political elites' behind-the-scenes bargaining and negotiation processes. Specifically, it has little to no room for the generation of ideas around the truth commission, the participation of victims and ordinary citizens, and the role of external actors in the domestic politics around transitional justice. The latter is very important in view of the role of external factors and foreign democracy promoters in the democratization processes that opened up the space for transitional justice. Applied to current trends in transitional justice policy approaches, particularly the truth commission, in "conflicted democracies", this model is unhelpful in explaining why the truth commission is adopted, and not trials or any other approach.

Instrumentalist Model (Elite Pact): The instrumentalist model, in the form of elite pact theories, has also been connected with the transitional justice policy approach formulation process, and is also linked to a degree with the transitology discourse. It emphasizes the influence of the actions of political elites in shaping outcomes of democratic transitions (Di Palma, 1990; Higley, Pakulski, and Wesolowski, 1998; Gill, 2000), such as in designing policy processes to establish key political institutions, including transitional justice programs. Their role helps to address the gap left by the 
transitology approach's neglect of the political bargaining processes between the entering and exiting regimes that take place out of the public's view.

The instrumentalist school suggests that political elites are at the centre of the processes that result in a particular transitional justice policy-approach. In many instances, policy choice has tended to preclude prosecution and punishment in favour of other alternatives, such as a non-criminal approach and pardon ( $O^{\prime}$ Donnell and Schmitter, 1986). ${ }^{41}$ The establishment of the truth commission for South Africa has often been described as a result of elite consensus following the negotiated settlement nature of the transition from apartheid in 1994 (Wilson, 2001; Daye, 2004).

The elite pact model yields insights into the instrumentality of political elites in shaping the policy around transitional justice approaches. It is useful in understanding the nature of the policy process in societies, especially in the African political context where the rule of the elite few has been endemic of the greater part of its post-colonial history. In the context of transitional justice policy, however, it is unable to explain how pressures from below (citizens) affect the views of elites on transitional justice. Furthermore, it does not explain how legal obligations on both the national and global levels shape the direction of transitional justice discourse locally without the influence of political elites.

The three dominant models have helped to explain the policy formulation discourse around historical transitional justice policy approaches. They illuminated the variables determining selection of policy approach. They certainly continue to be relevant. The legalist/institutionalist approach, for example, continues to promote

\footnotetext{
${ }^{41}$ The significant role of the political elites in decisions about the adoption of transitional justice policy in the southern European and South American region is noted by O'Donnell and Schmitter. They argue that for the most part the political elites agreed on clemency and amnesty as alternative transitional justice policy approaches for the sake of a smooth transition to democracy.
} 
transitional justice as a globalized project. The present study shares the general principles associated with these models, and borrows from them, where appropriate, to analyse and discuss the cases for the study.

Nonetheless, none of them is effective alone, and all exhibit weaknesses when applied to the proposed investigations. The policy formulation processes of the truth commission-approach in recent transitional societies have defied all of these models. Successor governments, especially in transitional societies in Africa, have increasingly chosen, or shown a preference for, the truth commission-approach as an alternative to criminal justice. This trend indicates that regimes in Africa are avoiding the legal and moral duty to prosecute and punish (retributive) wrongdoings according to the demands of international law. ${ }^{42}$

The transitional situations in both Nigeria (1999) and Ghana (2001) exemplified the replacement type. One would, therefore, have expected a transitional justice policy with the criminal justice-approach. Yet a policy employing the TRC-approach was formulated. The existing models are unable to account for the adoption of truth commissions, rather than a judicial-approach, in those countries. Furthermore, the models are highly driven by institutional and actor-oriented dynamics at the expense of social structures. They don't allow for discursive approaches to human nature, perception and understanding of events. They are thus unable to explain adequately the policy formulation dynamics of specific individual cases regarding the truth commissionapproach to transitional justice policy. While the creation of the South African truth commission can be identified as an example of the transitology or elite pact model

\footnotetext{
${ }^{42}$ The cases of Morocco (2004), Liberia (2006), Kenya (2008), Togo (2008), and ongoing transitional justice discourses in Burundi and Uganda, to cite a few, attest to this changing trend.
} 
because of the negotiated settlement nature of its transition, these models shed little light on the local political dynamics in the shaping of the truth commission policy.

Finally, the approaches are unable to account for the replication of the truth commission-approach across borders. Undeniably the legalist model, in particular, may inform the normalization of transitional justice process and its associated implementation across borders. It does not, however, convincingly explain why countries choose to adopt forms of transitional justice approaches other than a criminal justice which is its mantra. In this era of globalized transitional justice, and with the proliferation of several transnational transitional justice networks, the influence of global dynamics on domestic politics around transitional justice is obvious. Yet none of these models helps to explain how, for example, the truth commission-approach to transitional justice is being reproduced around the world. The weaknesses of the existing approaches undermine their power to support our understanding of the formulation of the truth commission-approach to transitional justice policy in the study's chosen cases.

Certainly, these prevailing approaches provide less insight into the dynamics of the domestic political environments that occasioned the policy formulation of the TRC approach in South Africa, Nigeria and Ghana. They are unhelpful in understanding the machinations and influence of leading domestic political actors, the role of non-state actors, how well citizens participated in the policy discourse, and the power of policy communities in general--both domestic and international--during the TRC-approach policy formulation process. Considerably, applying any of them to study TRC policy formulation process does not create the scope to understand contemporary public policymaking in Africa, which this study seeks to illuminate. 
Consequently, this study departs from them, and deploys a policy transfer model to explain and to aid our understanding of why and how the truth commission-approach was formulated as a transitional justice policy in South Africa, Nigeria and Ghana. Employing a social constructivist approach, the model provides a better paradigm to explaining individual country cases as well as truth commissions' reproduction across borders. To be sure, the policy transfer model adopted for this study in no way suggests that the existing paradigms are now entirely without merit. Its application is rather to demonstrate a more useful way of understanding and interpreting a social and political phenomenon: in this case, the proliferation of the truth commission-approaches to transitional justice. The next chapter expands and builds on the model and the social constructivist analytical framework for the current study.

\section{2: Public Policy Science: The Formulation Process}

Harold Lasswell, a pioneer in the study of policy science, used the term policy to indicate the "most important choices made either in organized or in private life" (1951:5). In this understanding, policy is a phenomenon of organized society, such as the state, business and private spheres. Policy in organized society or the state became known as public policy, meaning the choices governments make as they manage society and citizens. Following Lasswell, several policy science scholars, including Dye (1972), Jenkins (1978), Anderson (1984), Pal (2006), and Goodin, Rein and Moran (2006), to cite

a few, have expanded on this understanding from different perspectives. Public policy is conceptualized as the conscious efforts of governments to design and implement a course of action that purports to serve the public's needs. It aims at improving the lives of 
citizens and, also, maximizing the public interest. At the core of this understanding is the notion that formulating public policy is the art of intelligently selecting options or processes that will be undertaken by elected or unelected public officials to solve a multitude of social, political and economic problems.

Public policy is crucial in a democracy because it allows elected governments to implement policy programs and visions that resonate with their electors and, generally, with the whole society. It enables citizens to hold elected governments accountable for their stewardship. Hence, public policy serves as a link between government and citizens' engagement. As Deleon (2006) observes, public policy science targets improvement of the practice of democracy. The study of public policy science is broadly divided into policy-making and policy implementation. The former is the art of finding or devising a conceptual tool to address an issue or problem. The policy implementation process, on the other hand, is the carrying out and delivery of public policies. Between the two processes are five cyclic stages: agenda setting; policy formulation; policy decisionmaking; implementation; and evaluation (Pal, 2006; Howlett, Ramesh and Perl, 2009). While a cycle of five or six stages ${ }^{43}$ constitutes a model for the study of public policy as a whole, scholars and students of the discipline agree that the public policy process is not as neatly or as firmly sequential as it may theoretically appear. In practice policy actors hardly go about the process in so orderly a manner.

As a methodological heuristic, however, the cycle model is helpful in understanding public policy processes. Dividing it into stages makes them susceptible to investigation individually or in relationship to one another (Howlett and Ramesh, 2003). Accordingly, this study follows the single stage investigative approach. It focuses on the

\footnotetext{
${ }^{43}$ Some scholars, including Deleon (1999), have included a sixth stage called 'termination' in this cycle.
} 
second stage in the cycle: the policy formulation process, which comes after agenda setting. ${ }^{44}$ Besides the methodological legitimacy in focusing on a single stage of the policy process, studying the policy formulation process of a particular policy provides the background and historical knowledge for understanding how a particular public policy formation.

Investigating policy formulation process helps researchers and policy analysts put in context how implementation occurred. The lack of attention to implementation strategies during policy formulation process can affect the implementation stage: for example, the shortage of required resources for undertaking the objectives of the policy or an underestimation of the intricacy of the policy (Corkery, Land and Bossuyt, 1995). Indeed, as will be examined in the subsequent chapters, this was precisely what transpired in the Nigerian case. Studying the policy formulation stage of the policy cycle is also useful in informing the evaluation stage. It helps in conducting impact studies on a terminated policy. The method for formulating a particular policy, in terms of the degree of public receptiveness and participation, will typically inform, notwithstanding implementation dynamics, the extent to which outcomes are broadly appreciated by beneficiaries.

Policy formulation involves measuring potential solutions to policy problems. The potential solutions may appear at the stage of agenda setting, either at the same time an issue arises or after it moves from recognition onto the official agenda of a government. For instance, an issue or public problem may be recognized in the manifestos of political

\footnotetext{
${ }^{44}$ Agenda-setting is the stage where issues, concerns and demands from the public appear on the list of groups or governments (before they are elected), on the campaign list of candidates or in the manifestos of political parties for redress or resolution.
} 
parties, but it will not necessarily be accompanied by a solution. Once elected, this issue may (or may not) move from the manifesto onto the agenda for a policy response. In South Africa, for instance, the subject of transitional justice was one of the issues discussed during the negotiations that produced the 1994 landmark transition from apartheid to a democracy. Following the 1994 transitional elections, which brought the African National Congress (ANC) into political office, a search for policy solution to address transitional justice concerns surfaced publicly. Similarly, in Ghana the policy on truth commission was included in the manifesto of the New Patriotic Party (NPP) during the 2000 election campaign. The truth commission became an official government policy agenda item when the NPP won the elections.

Once the solution is on the agenda, the process of defining, refining, considering, and accepting or rejecting options -- the essence of policy formulation -- occurs. Howlett, Ramesh and Perl note that policy formulation is "the process of generating options on what to do about a public problem" (2009:110). The search for solutions includes identification and analysis of responses capable of addressing the issue, and narrowing them down to the one that is most practical. The process has six broad characteristics.

First, it needs not be limited to one group of actors, and those it does involve may produce complementary or opposing solutions. Second, the process may take place without any clear definition of the problem at hand, and without formulators ever having any preliminary contact with potential beneficiaries of the policy response. Third, there may be no relationship between policy formulation and particular implementing institutions. Fourth, policy formulation and reformulation may happen over a long period of time, without concrete support for any one proposal. Fifth, it presents several 
opportunities for those who lose in the process to appeal for reconsideration. Finally, the policy formulation process is not a win-win situation: some lose. These characteristics suggest that the process is multifaceted and diffuse, and varies from situation to situation.

Beyond the six broad features, the policy formulation process is further divided into sub-phases, identified as appraisal, dialogue, formulation, and consolidation (Howlett, Ramesh and Perl, 2009: 110-112). These phases help in understanding the mechanics or the art of the policy formulation process. They involve: the generation of data and evidence to contextualize the policy problem (appraisal); opening up communication and discussion between policy actors, experts and stakeholder representation on the problem at stake (dialogue); development of draft policy response options (formulation); and a choice of policy response after feedback, comments and suggestions about the draft response options have been received (consolidation).

The consolidation stage is not the end, however. Those dissatisfied with the draft proposal can continue to demonstrate their opposition outside of the consensus draft as far as the third stage of the policy cycle -- policy decision-making -- where final decisions are made. Arguing, bargaining and getting agreement are thus constant features of the policy formulation process. Susskind (2006) observes that it is characterized by actors and stakeholders interminably seeking to influence one another's thinking and behaviour through argument and dialogue.

Technical viability, political acceptability and administrative feasibility are all factors in addressing a policy problem. There are challenges in applying these criteria, however. One is the question of what informs the policy options chosen by the participants in the dialogue. The nature of the challenge is the degree to which the 
solutions proposed depart from the prevailing policy. Two primary dimensions are involved in addressing it: policy goals, and the means of achieving them. Policy formulation processes may be informed by the introduction of new ideas and new ways of policy deliberation. In the context of the current research, the notion of restorative justice as new form of addressing transitional justice demands led to the formulation of the TRC-approach in the selected cases. The introduction of new ideas may lead to changes in policy goals: in this case, a preference for restorative over retributive justice.

The change in policy goals as a result of the introduction of new policy ideas may or may not result in changes in program specifications and instruments. The nature of this innovation may unearth technical and political impossibilities yielding yet another set of economic, social, political and technical limitations on government or policy actors' actions. For example, there may be funding constraints. Policymakers may find they cannot do everything their constituents want. Ideas for pursuing important social goals may also be in short supply. Sometimes the nature of the problem makes it difficult to find a suitable policy option. There may simply be no known effective solution, or the only available one leads to another policy challenge. Policymakers may also come up against organizational, tactical, or institutional obstacles (such as constitutional provisions). These limitations are identified as substantive and procedural constraints that regularly face politicians or policymakers in their consideration of policy options (Howlett, Ramesh and Perl, 2009). As will be examined in the subsequent chapters, the policymakers in South Africa, Nigeria and Ghana faced certain institutional obstacles that prevented them employing what may have been the preferred policy option. 
Policy formulation processes exhibit contending and conflicting perspectives on the part of the players. Unlike the agenda-setting stage, where the space of engagement is open to all - including citizens and domestic and international organized actors, all of whom are referred to as the policy universe - the set of actors in the policy formulation stage is limited to certain key, specialized or qualified, players. The privileging of these specialized people (for example, scientists and government experts) may exclude others. The players and actors involved in this formulation process, who are classified as a policy subsystem, represent a subset of the policy universe. Relevant actors in the subsystem discuss, influence and negotiate to advance their respective interests. The policy subsystem helps to represent the relationships of actors, institutions, and ideas in the policy formulation process of policy-making (Howlett, Ramesh and Perl, 2009). Some of these actors may be deeply connected with the policy process, others only marginally.

Three main models of policy subsystems -- referred to as sub-governments, iron triangles, and issue networks; policy networks and policy communities; and advocacy coalitions -- have been identified and extensively examined (Sabatier, 1988; Sabatier and Jenkins-Smith, 1999; Pal, 2006; Sabatier and Weible, 2007; Howlett, Ramesh and Perl, 2009). The development of these models - particularly the policy networks and policy communities and the advocacy coalition models -- affirms public policy as the function of the whole political structure through the demands of the public in respect of policy choices. They communicate the fact that the policy formulation process allows for varied interest groups' participation, outside of government, in the search for policy responses to an issue problem. 
The role of interest groups from the non-state arena has expanded and become critical in recent years. At the formulation stage the state or government is no longer dominant in the policy process. As Pal notes, the present policy process suggests an arena where the "state is [a] central but not dominant player in policy process, where citizens and interest groups demand more access to policy development and implementation, and consequently where there is a broader tableau of players and actors" (2006: 238).

Over the past decade the context of public policy-making has changed. The globalization caused by the proliferation of international non-state actors is challenging basic assumptions about sovereignty and the role of nation-states in the policy process. The increasing economic and political interdependence of states has impacted the substance and procedures of national and domestic policy formulation processes. Domestic policy agenda setting has been influenced by global norms, standards and actors. For instance, the central role of the Bretton Wood institutions, the International Monetary Fund (IMF) and the World Bank, in economic policy formulation processes in domestic politics has been clearly evident (Thomas, 2004; Pal, 2006).

The dominance of these institutions in the economic policy-making in subSaharan Africa from the 1980 s until the mid 1990s is also obvious. A former cabinet member of the erstwhile military government in Ghana (1981-1992) is reported to have observed that World Bank officials attended cabinet meetings in Accra during the formulation of the structural adjustment programs (Akokpari, 2004: 199). Conteh and Ohemeng (2009) also claim that the policies surrounding the privatization of state-owned enterprises in Ghana were highly influenced by the Bretton Wood Institutions. 
Similarly, when it comes to transitional justice, which has now become a globalized project, policy formulation processes in domestic politics are highly affected by international human rights and humanitarian laws and by the global political environment and its players (Secretary-General Report, 2004). The flourishing and transmission of ideas about social, political and economic policy beyond borders has been a function of the global transnational organizations and networks.

Debates over the impact of globalization on domestic policy-making have led to two fundamental arguments (Majone, 2006: 241-242). On one hand, the question asked is whether globalization impedes national agenda setting and its policy formulation

processes because it limits the channels of democratic expression of preferences by citizens. On the other hand, does the deepening of globalization improve the quality of domestic decision-making processes because it allows national leaders to be open to ideas from outside the national boundaries, from their foreign counterparts, international institutions, and international NGOs, and also for them to engage with international best practices, as well as build international cooperation?

In the subsequent chapters, the nature of the international systems and of the actors and their roles in the domestic policy formulation processes of the truth commission approach to transitional justice in the three selected cases are examined.

\subsubsection{Public Policy Formulation Process in Africa}

Until the political and economic liberalization that began in the latter part of the twentieth century, public policy-making in Africa assumed a state-centred rather than a state-society policy approach. The post-colonial African states of authoritarian, dictatorial 
and military regimes had made political systems less open to conventional policy formulation processes, as already examined. These closed political systems inhibited citizens' participation in policy formulation process, thereby making the discourse more government-led.

The discourse on the public policy process in Africa also tended to focus on policy implementation rather than on formulation. The assumption was made that African states were recipients of policies; and analysts were, therefore, primarily concerned with policy implementation. Part of the challenge may have resulted from a lack of empirically obtained in-depth knowledge of policy processes in African states. ${ }^{45}$ The limited studies that took place, focusing on economic policies of privatization and structural adjustment programs, concluded that African states lacked the capacity and expertise to formulate policies (Nhema, 2004; Carroll, Carroll and Ohemeng, 2003; 2007; Conteh and Ohemeng, 2009).

An examination of the history of policy formulation processes in developing countries reveals two distinct approaches: the society-centred and the state-centred (Grindle, 1980; Grindle and Thomas, 1989; 1991; Turner and Hulme, 1997). The former is based on power relations among classes, social and interest groups. Public policy results from constant interactions and bargaining among coalition formations in pursuit of their members' interests. The state-centred approach focuses on decision-making processes within the organizational context of the state, thereby giving primacy and considerable capacity in policy choice and its formulation to the actors in the machinery of the state. It demonstrates the state's relative autonomy against the expressed interests

\footnotetext{
${ }^{45}$ It has also been suggested that for a long time African scholars did not take any serious interest in public policy (Nherma, 2004).
} 
of the dominant class. Societal preferences and constraints are thus less important, leaving the policy formulating job largely in the hands of state actors and organizational politics. Three different levels can be identified within this approach: the rational actor, bureaucratic politics and state interest. ${ }^{46}$

Post-independence Africa favoured the state-centred approach to political and economic policy developments. The state and its actors pursued interests that it identified as similar to societal interests. The collective interest was premised on their shared location in the state. Policy formulation processes left little room for stakehoiders, outside of the state, to participate in the discourse. In situations where there was any consciousness of state-society relations in the policy formulation process, it was from a corporatist perspective (Carroll and Carroll, 1999; Carroll, Carroll and Ohemeng, 2007).

Further to that, policy formulation processes in sub-Saharan Africa revolved around the person of the ruler or the few political elites, coupled with restrictions in official channels on participation by ordinary citizens and individuals. The centrality of the state and its apparatus (bureaucrats) in policy formulation in Africa has been documented extensively elsewhere (Bates and Loftchie, 1980; Bates, 1981; 1988; Saasa, 1985; Grindle and Thomas, 1989). In all these accounts, governments' interventionist policy formulation approaches resulted in bad policies that negatively affected political, social and economic developments.

\footnotetext{
${ }^{46}$ The rational actor approach shares with the public choice approach elements of the society-centred model, which seeks information, assesses it and chooses from the altemative courses of action to maximize outcomes. Unlike public choice, though, it places decision-makers at the centre of the process. The bureaucratic politics approach views the state as the arena in which public officials engage in political manoeuvres to secure the desired policy decisions. This may involve coalition formation between state public officials and other interest groups to bargain and/or compromise to further the interests of these officials and their organizational objectives. The third approach has the state appearing to have some autonomy in defining and shaping the nature of public policy. The latter is epitomized by the "Bringing the State Back In" school (Evans, Rueshemeyer and Skocpol, 1985), which advanced the role, autonomy and centrality of the state in public policy formulation.
} 
The above picture of state dominance in policy formulation processes has not been that different from the three cases selected for this study. In Nigeria since independence, political, social and economic policy formulation processes have been engineered by the political leadership, for the most part the military rulers, in partnership with senior bureaucrats and other strategically identified societal elites (Koehn, 1983; Adamolekun, 1986; Tamuno, 1989; Aborisade and Mundt, 2002). Koehn, for instance, observes that Nigerian bureaucrats -- senior public administrators -- have dominated the policy-making process.

In Ghana, with a political history similar to Nigeria's, for a long time initiating and designing public policy were the privilege of a nucleus of government bureaucrats and political elites (Ayee, 2000; Akokpari, 2004; Ohemeng, 2005; Handley, 2007; Amoako-Tuffour, 2008). The military and civilian dictatorships that ruled were hostile to civil society participation in governance, including the development of public policy. As Ohemeng (2005) points out, until the period beginning in 1992, Ghana's policy-making environment could be described as a "closed circuit network" involving politicians and civil servants.

In South Africa for several decades apartheid rule, which ended in 1993, resulted in a policy formulation process confined within white minority rule. The shift in governance from white minority rule to black majority government has included attempts to promote an enhanced participatory and inclusive policy formulation discourse (Klotz, 2000). The democratic transition brought a wider range of voices, both within the parliamentary process and from the civil society, to inform policy debates and formulation processes. Yet despite some semblances of public participation and avenues 
for public input into policy formulation discourse, the policy process has remained the dictate of the central government, driven by the Presidency and the ANC and its alliance (Hughes, 2004; Friedman, 2004; Booysen, 2006). Booysen, for example, observes that "the most powerful policy-generating cluster in South Africa centres on top government, in particular the Cabinet, the presidency and the structures of the governing party, the ANC" (2006:178).

The state-centred approach to the policy formulation process in Africa in the years following independence demonstrates two underlying factors. First, many African political leaders assumed this paternalistic posture in the area of service delivery. They felt that they knew what their citizens needed, and that controlling and managing the policy process would prevent delays and promote equal opportunities for all. The control of the political leadership in the policy formulation process was rationalized in the plan for developing and promoting coherent programs that advance the national interest. The activities of civil society were viewed as competitive and counter developmental. The guidance articulated by the political leadership, which informed policies to be developed by policy actors (many of them within the state establishments), emphasized the ideological and politically accepted context in which policy programs had to be developed.

Second, the constitutional and legal models according to which most of these countries were governed made the executive branch the sole source of policy formulation. For example, the 1992 Constitution of Ghana, following previous ones, makes the President and the Cabinet the formulator of public policy (Government of Ghana, 1992). Similar constitutional provisions, with historical antecedents, are provided 
for in the laws of South Africa (Government of South Africa, 1996; Cloete, 1998), Nigeria (Government of Nigerian, 1999), and many other African countries. While it is not uncommon to find in the constitutions of many societies, developed and less developed, policy formulation powers located in the executive, in practice the situation has differed from society to society. In Africa the political leadership has, for the most part, interpreted these constitutional powers in both letter and spirit, and thereby made policy formulation processes the exclusive domain of the executive.

The turn of global events-- political and economic liberalization-- from the 1980 s onwards redefined the role of political leadership in Africa in policy formulation processes. The changes in political governance and economic management resulted in broader public consultations. As several African states embraced democracy, with its good governance attributes, the involvement of non-state actors and the masses in policy formulation discourse expanded. The proliferation of CSOs, think-tanks, special interest groups and other non-state actors led to the widening of the policy formulation discourse beyond official state or government agencies.

Coalition formation and lobbying for policy change have been evident in Tanzania since 1994, with particular focus on influencing policy formulation discourse on government initiatives on land and environment and on activities of NGOs (ElliotTeague, 2008). In Botswana, the 1990s witnessed a push by donor organizations and local civil society groups, in the form of civic networks, towards popular participation in public policy formulation discourse (Carroll, Carroll and Ohemeng, 2007). In Ghana, public consultations for government policy initiatives have become routine, as demonstrated by the development of the policy model for the Poverty Reduction Strategy 
(PRS) papers (Ohemeng 2005; Amoako-Tuffour, 2008). The end of apartheid rule in South Africa saw the expansion of civil society engagements with the state, exemplified by several policy initiatives, such as local government reforms, and others relating to education, housing, land, and health/HIV (Booysen, 2006; Lehman, 2008).

In spite of this changing trend in state-society relations, public participation in policy formulation discourse has been described as limited and still government driven. The impact of citizens, interest groups and coalitions, and of civic participation and consultations in these processes has been mixed, inadequate and partial (Nhema, 2004; Booysen, 2006; Elliott-Teague, 2008; Amoako-Tuffour, 2008). Nhema is emphatic when he states that "public policy processes in Africa are very conservative and restricted, with very little public involvement and insignificant input from target population and the wider community" (2004: 18). In South Africa, for example, policy formulation still emphasizes centralized political direction (Friedman, 2004).

Besides, the influence of the international arena and its policy actors, specifically the Bretton Wood Institutions, continues to be prominent in domestic political, economic, and social policy formulation processes. Tungaraza (2004) is very insightful in this regard when he notes that domestic policy formulation in Africa, including social policies, have been triggered by international conferences (norms and standards), which then subtly pressure African countries to formulate policies on particular problems.

From the foregoing discussion two main issues emerge regarding policy formulation processes in Africa. The first issue is the limited nature of citizens' input in the policy formulation process. The level of popular participation and public consultations in public policy formulation, on the whole, remains low. The second issue 
relates to the disproportionately large number of external policy actors in local policy formulation processes. The impact of globalization has intensified the reach of international actors, including policy epistemic communities, ${ }^{47}$ in domestic policy politics.

Consequently, the current study is interested in investigating how these two main issues affect the policy formulation processes of the truth commission-approach to transitional justice in South Africa, Nigeria and Ghana. To what extent were citizens' inputs factored and considered in the policy formulation process, and what influence and role did international exposure and external policy actors have in these domestic processes? These questions are addressed in the following chapters.

\section{3: Summary and Conclusion}

This chapter has presented the background to the study and, in particular, to the two research questions. It examined the field of transitional justice and its evolution. In doing so, it also addressed the limits of existing theoretical paradigms for understanding the TRC policy formulation processes. The chapter revealed that these approaches were unhelpful in explaining the domestic policy formulation processes of the truth commission-approach to transitional justice in South Africa, Nigeria, and Ghana because, among many other reasons, they are unable to provide sufficient explanatory account for the reproduction of the TRC-approach to transitional justice across borders.

\footnotetext{
${ }^{47}$ These are internationally connected experts who attempt to influence global and domestic policy-making processes with ideas and expertise generated from science and expressed through professional organizations or respected individuals.
} 
Departing from these approaches, the chapter noted that a social constructivist account of a policy transfer model is better suited to explain the politics around the policy formulation processes of the truth commission-approach in the selected cases. Consequently, a key issue emerging from this chapter is social constructivism. The next chapter explores this approach and how it is conceptualized in accounting for domestic policy formulation processes of the TRC-approach in South Africa, Nigeria, and Ghana. The policy transfer model adapted for this study is also examined in the next chapter to put in context the policy transfer dimension of this process.

This chapter further discussed the stage of policy formulation in the cycle of public policy science. While consensus exists that the public policy process follows a cyclical pattern of comprehension, it is appropriate and useful to investigate a stand-alone stage, such as the formulation process. Such an approach helps us better understand the policy process, particularly in ways that subsequent outcomes of the policy implementation and impact on beneficiaries are contextualized and evaluated. The chapter examined the history of policy formulation processes in Africa, and noted that for the most part the process has been the exclusive domain of the executive. Civil society has participated relatively little in the policy discourse until the late twentieth century. Its participation, even now, in the policy processes appears to be limited.

The effect of globalization has been to extend the reach of non-state global policy actors. How significant have been the contributions of domestic civil society to the policy formulation processes of the truth commission approach in the selected cases, and what particular role did global non-state actors play in them? These additional fundamental issues arose from this chapter, and are addressed in subsequent chapters. 


\section{Chapter Three: Theoretical Model for TRC Policy Formulation}

\section{0: Introduction}

The chapter builds the theoretical paradigm for analysing the TRC policy formulation processes. It asserts that the policy formulation of the TRC-approach in Africa results from a policy transfer activity best understood through the lens of social constructivism. In each case, political leaders find the restorative justice ideas that underpin the TRC-approach sufficiently appealing such that they borrow the mechanism and use it to address transitional justice needs. The elected political actors are helped in this endeavour by domestic CSOs that support these restorative justice ideas, contribute to the policy discourse and rally public support for the TRC-approach. The work of the domestic policy actors is complemented by that of transnational transitional justice epistemic communities, who supply content knowledge of the restorative justice ideas, as well as best practices of the TRC-approach to deepen the domestic policy debate in the formulation processes. The restorative justice ideas are consequently promoted through political processes and indigenization using the enabling domestic structures. These processes, viewed from a social constructivist perspective, result in the policy transfer of the TRC-approach to transitional justice in Africa.

In the previous chapter it was suggested that the three currently popular theoretical models -- the legalist/institutionalist, transitology, and the instrumentalist (elite pact) -- notwithstanding their relevance in the transitional justice discourse, do not adequately provide convincing and informed explanations of recent domestic policy formulation processes of the TRC-approach to transitional justice or of the associated 
reproduction of the approach in Africa. Consequently, this study departs from those conventional models, and employs a policy transfer model informed by social constructivism to analyse the policy formulation processes of the TRC-approach to a transitional justice policy. This alternative approach presents a more plausible theoretical paradigm for explaining and understanding the proliferation of the TRC-approach across borders, particularly in Africa.

This chapter examines the Dolowitz and Marsh $(1996,2000)$ policy transfer model in section 3.1.1. Of all the currently favoured policy transfer models, this particular one is by far the most comprehensive in its propositions. It brings together the different labels for what are essentially the same phenomena: the borrowing of innovative policy ideas by policymakers, and their transmission across geo-political boundaries. The study's application of the Dolowitz and Marsh policy transfer model constitutes an opportunity to test that model's viability in Africa. It has mostly been applied in studying policy transfers in the Organization for Economic Cooperation and Development (OECD) countries. Certainly, by integrating it within the broad social constructivism framework, its potentials are enhanced. Preceding the examination of the Dolowitz and Marsh model is a general discussion of the concept of policy transfer in section 3.1. The fundamentals of a policy transfer are the production of ideas, their transportation, and their successful implanting in the domestic structures of political systems.

Policy transfers are human endeavour processes. The social constructivism framework, which privileges ideas, agency and structure in explaining human actions, is presented next. The chapter examines social constructivism in section 3.2 , and elaborates on its three main features: the power of ideas, the instrumentality of agency, and the 
receptiveness of structure. Collectively, these features account for the production and reproduction of social and political events that arise from the interplay of agency and structure and employ new ideas and forms of knowledge. The discussion of social constructivism is followed by a summary of the theoretical model being proposed in this study. Section 3.3 integrates the two levels of approaches--the Dolowitz and Marsh policy transfer model and the social constructivism framework--that constitute the theoretical model for the TRC policy formulation. Finally, the hypotheses that motivate the study are outlined in section 3.4 , and this is followed by a summary and conclusion in section 3.5 .

By discussing the Dolowitz and Marsh policy transfer model and social constructivism, and outlining the research hypotheses, this chapter seeks to offer an alternative theoretical platform for investigating the TRC-approach to transitional justice policy formulation processes, which is the study's dependent variable.

\section{1: The Concept of Policy Transfer}

Policy transfer is understood in this study as a phenomenon generally involving the transmission of policy rationales, policy content or policy implementation instruments from one or more political and/or administrative units to another or others. It denotes a situation where a public policy successfully implemented in one political environment or jurisdiction is borrowed by another to address another, similar and urgent, policy problem. The three elements that inform policy transfers are: the importance of ideas and knowledge, specifically new ones; the role of actors, both individual and organizational; and the significance of domestic structures. Policy transfer, for the most part, assumes a 
rational process by policymakers of searching for best practices; that process is then followed by replication and adaptation.

The concept itself has been described variously, and the term has sometimes been used interchangeably with band-wagoning, policy convergence, lesson-drawing, social learning, policy learning, emulation, innovation and diffusion. ${ }^{48}$ Evans (2006), for example, suggests that the different labels for similar policy processes present the policy transfer domain with two main schools. ${ }^{49}$ Policy transfer endeavours come in two forms: policy transfer in relation to policy formulation, which this study is about; and policy transfer regarding policy implementation (Tavits, 2003).

The advent of the policy transfer discourse is traceable to the United States of America at the time that efforts were made to explain the adoption and increased diffusion of policy throughout the federal system (Stone, 2004). Contemporarily, however, policy transfer has in part been triggered by the globalization that has transformed how knowledge and ideas are generated and transmitted across geopolitical boundaries. Globalization also facilitates operation of the two factors that fundamentally determine the policy transfer discourse: the instrumentalities of agency (both national and transnational), and the receptiveness of the domestic structure (Evans and Davis, 1999). The transnational agency, identifiable as manifestations of "elite networking of transnational policy communities or global public policy networks" (Stone, 2001: 8), have, through their relationships with national public policy communities, including

\footnotetext{
${ }^{48}$ See the following works: Ikenberry, 1990; Rose, 1991; 1993; 2005; Bennett, 1991; Dolowitz and Marsh, 1996; 2000; Berry and Berry, 1999; 2007; Stone, 2001; Lodge, 2003; Ladi, 2005a; Evans, 2004a; 2004b; 2006; Goldfinch, 2006.

${ }^{49}$ On one hand are those who refer not to policy transfer, but, rather, to different forms of policy transmission from one political unit to another. On the other are those who prefer to use the expression 'policy transfer' directly.
} 
advocacy coalitions, and through employing new ideas and knowledge, engineered policy transfers in domestic politics.

Although globalization has generated the impetus for policy transfer in recent years, the policy transfer literature has not adequately addressed the links between globalization and policy transfers (Ladi, 2005a). Even beyond the globalization factor, the increasing complexity and urgency of global exigencies intensify pressure on governments all over the world to look for quick fixes and prefabricated policy solutions to domestic policy problems, resulting in correspondingly superficial policy transfer activity. As Common (1998) observes, policy transfer analysis offers an explanation of the spread of New Public Management (NPM) ${ }^{50}$ ideas across the globe. The transmission and application of knowledge, or of policy ideas, takes place not only within the boundaries of the nation-state; once ideas have been dispersed, they proliferate, international lessons are drawn, and policies are promoted beyond the traditional territorial and legal jurisdictional boundaries.

The keys to understanding policy transfers are innovation, learning and diffusion. Policies are transferred following innovations that prompt new policy ideas and policy instruments. They generate social learning that results in diffusion of the ideas and instruments, either within or across states. Consequently, at the centre of policy transfer is the application in one jurisdiction of knowledge of a set of policy instruments from another (Lodge, 2003:160). The glue that connects these processes of innovation and

\footnotetext{
${ }^{30} \mathrm{NPM}$ is an approach to doing government business/public administration that was in vogue in the latter stages of the twentieth century and stressed the importance of governments being businesslike in their public service delivery.
} 
diffusion is thus social learning; ${ }^{51}$ its students carry new ideas and promote their domestication in political systems. Beyond the generation of new ideas and the role of agents, the structural conditions, including rules, resources, systems, institutions and culture, among many others, in the policy-receiving environment are equally significant in understanding the phenomenon of policy transfer. Domestic structural feasibility is critical in determining the successful formulation of externally borrowed policy ideas.

It is essential that the social and political consequences of globalization are contextualized within the domestic structures in which they occur. Evans and Davis (1999) suggest that it is vital to assess whether structural conditions external to the process of policy transfer have any direct impact on the context, strategies, actions and intentions of the agents facilitating the transfer. It is equally critical to find out whether the strategies, actions and intentions of agents have constraining or enabling powers, or both, over the structure to facilitate policy transfer. Thus, both structures and agents have corresponding effect on one another. Accordingly, understanding the agent-structure relationship is critical to understanding policy transfer. The relationship reflects the dynamics of actors in producing social phenomenon, and the corresponding structural effect on them in constructing these social practices and events. Structures shape the actions of agents and, reciprocally, the actions of agents reproduce structures. Stated differently, the social environment in which agents live in and operate does shape the motives, interests and ideas of these agents, manifesting in the production and reproduction of social practices and structures.

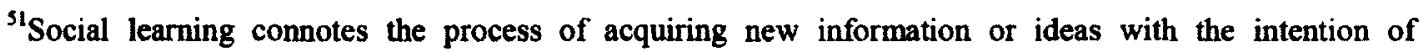
translating the information into a practical policy response.
} 
In other words, there is an agency dimension as well as structural element that inform the behaviour and actions of individuals and groups in their daily life and their reproduction. Therefore, the agent-structure relationship resulting in an action, such as policy transfers, mirrors the duality of agency and structure as described above. Ladi (2005a), for example, argues not only that understanding the agent-structure relationship helps to identify the power distribution that informs social, political and economic change, but that, because the relationship changes over time, it also constitutes the external environment for actions of agents.

This study follows Evans' (2004b; 2006) concept of policy transfer analysis as a theory of policy development that seeks to make meaning of a set of processes whereby knowledge about institutions, policies or delivery systems of one sector or level of governance is used in the development of institutions, policies or delivery systems in another. It shares Jones and Newburn's (2007) position that this phenomenon represents another way of understanding the movement of political ideas and policies around the world. Globalization has an inevitable place in these processes: increasingly globalized political and economic systems, the improvement in communication technology and the function of supra-national institutions have all progressively opened the domestic public policy process to the influence of forces, both individual and institutional, operating outside the territorial boundaries of the nation-states. In simple terms, policy transfers are associated with the generation of new ideas, and with actors importing and exporting these ideas and planting these ideas in domestic political structures to respond to policy problems. 
Several reasons have been proffered for policy transfers. Underlying them is the notion that no organization or political system possesses a sufficient repository of expertise to deal with all of the problems that confront humankind. Continuous sourcing of new ideas and policy solutions from outside one's organization or political jurisdiction is a normal activity especially in this age of the global village. Conditions that influence policy transfer range from voluntary reasons to external coercion. To begin with, voluntary reasons may be informed by adopting best practices, drawing lessons (both negative and positive), and emulating successful cases of policies. They are premised on rationality and an action-oriented approach to responding to policy problems.

Policy transfers may also occur through a coercive approach. For example, a country may adopt a particular policy as a result of conditions tied to donor aid or international agencies, ${ }^{52}$ political pressure from domestic social forces, competition among states or the dictates of international norms. Evans (2006) argues further that another form of coercive policy transfer occurs in a situation whereby one government mandates or forces another government to undertake certain political, economic and social policies against that government's will, or against that of the people of the recipient nation, and without any exchange.

There are quite a number of schematic models for studying policy transfer (Evans and Davis, 1999; Dolowitz and Marsh, 1996; 2000; Berry and Berry, 2007). This study employs the model developed by Dolowitz and Marsh to investigate the policy transfers of the TRC-approach to transitional justice in South Africa, Nigeria and Ghana. As noted earlier, the model, which is elaborated upon below, is the most inclusive scheme

\footnotetext{
${ }^{52}$ Evans (2006) calls this type a negotiated coercive transfer, as there is an element of exchange between the enforcer and receiver, even if the latter is unable to opt out of the exchange
} 
developed in the policy transfer literature, and is also widely used in investigations. The literature on policy transfers that use any of the prevailing schemes is extensive, especially where it has occurred among OECD members. ${ }^{53}$ Policy transfer research has focused on the developed countries, ignoring, for the most part, the developing ones. ${ }^{54}$ For developing countries and, in particular, transitional societies or countries emerging from conflict, policy transfer remains, principally, a rational process--an intelligent and calculated endeavour. As Evans (2004a) suggests, these states need to begin to draw lessons from the examples of successful developed or post conflict societies in order to be able to promote effective national reconstruction and development.

In the developing world, and especially in Africa, there are indications that the learning or borrowing between countries of policy knowledge and ideas on political, economic and social issues is common. The difficulty is that researchers investigating policy-making processes in the developing world have most of the times not situated their analysis in the policy transfer discourse. For example, in his recent study on the citizen charter system in Ghana, Ohemeng (2010), while acknowledging that the idea of a citizen charter in Ghana to enhance public service delivery was an externally influenced policy, failed to demonstrate the policy transfer nature of its domestic formulation process.

\footnotetext{
${ }^{53}$ For example, Dolowitz, Greenwold and Marsh (1999) examine the exchange, at different times, of electoral politics strategies and social and welfare policy ideas between the Labour Party of the UK and the Democratic Party in the US (with the US becoming the most sourced from), resulting in changes in the domestic politics of each; Radaelli (2000) borrows from Dolowitz and Marsh's (1996) policy transfer model and the concept of isomorphism to discuss public diffusion of programs -- single currency, tax policy, and media ownership -- in Europe; Jones and Newburn (2002) reference Bennet (1991) policy convergence and explore the emulation of the US criminal justice and penal policy in the development of domestic policies of the same in Britain; and Stritch (2005) explains the origins of workers' compensation laws in Quebec (Canada) through a policy learning by both state and societal actors from different jurisdictions: in particular, the British and French legal systems.

${ }_{34}$ Evans (2004b) points out that there have been inadequate representations in the literature of policy transfers between countries in the developing world, between countries in the developed and developing countries, and from the developing to the developed countries.
} 
Investigations of policy transfers have focused on economic policy formulation processes, with the role of international financial institutions (IFIs) dominating in the spread of micro-economic and other poverty alleviation policy programs. A typical instance is a study of privatization policies in Botswana and Ghana (Conteh and Ohemeng, 2009). In this study, the authors deploy Ikenberry's (1990) three forms of policy transfer -- external inducements, social learning, and emulation or policy bandwagoning -- to argue that the policy formulation processes regarding privatization policies in Ghana and Botswana characterized a policy transfer phenomenon. They conclude that while the case of Ghana emphasized the external inducement or coercive nature of policy transfers, in Botswana it was more one of voluntary policy transfer. 55

Beyond economic policies, other areas of public policies in Africa or in countries developing politically and socially have largely been neglected. It is this particular gap in the policy transfer literature that the current research seeks to fill. In one of the rare cases of policy transfer analysis in the developing world, Larmour (2002) employs the Dolowitz and Marsh policy transfer model to analyse the policy adoption surrounding customary land registration in Melanesia: in particular, in Papua New Guinea, the Solomon Islands and Vanuata. ${ }^{56}$ Similarly, by applying the Dolowitz and Marsh model to

\footnotetext{
${ }^{35}$ Conteh and Ohemeng suggest that in Ghana the policy on privatization was influenced by external actors, the IMF and the donor community. In Botswana the process was initiated by local political actors, policy and private sector elites; the policy on privatization was neither part of any structural adjustment programs (SAPs) nor was it suggested to the government by any foreign government or international organization. Instead, it resulted from a search for public sector efficiency and effectiveness -- a policy agenda that was pushed by some of the country's powerful elites, including private sector interests, public servants, and some proponents in academia. Whereas in both countries the policies on privatization were borrowed from outside, the processes determining the type of actors and their role as carriers of the policy ideas were different.

${ }^{56}$ Lamour argues that the circumstances of the formulation of policies of land titling in these countries were that they were borrowed from countries in the eastern part of Africa, with varied outcomes that depended on the recipient institutional and structural conditions.
} 
the study of the policy transfer formulation processes of the TRC-approach in South Africa, Nigeria and Ghana, this study attempts to contribute to the filling of that gap by remedying the lack of study of the area of policy transfers in Africa, especially in the spheres of politics and accountability institutions.

Significantly, by combining the model with insights from social constructivism, this study departs from earlier works using the model alone, such as those cited above, and in so doing enhances the viability of the Dolowitz and Marsh model. Certainly, focusing on Africa helps to prove the usefulness of policy transfer models outside of the OECD countries, thereby contributing to the policy transfer scholarship.

Alongside this gap is the lack of multi-level and comprehensive empirical studies of policy transfers. Much of the research into policy transfer have been of the mechanics of internal decision-making processes and the role of domestic actors in these processes, with less attention to the role of transnational actors. Stone (2004) suggests that research on the role of international actors in these phenomena remains limited generally. There appears to be a focus on official actors in the transfer discourse to the neglect of non-state actors, both domestic and international. The international group of actors have increasingly become influential in domestic politics, sometimes at the expense of the state actors, as a result of the force of globalization.

Moreover, state-to-state policy exchange has been overemphasized, which has affected the understanding of the role of transfer agents that are not based in either of the direct importing and exporting (so to speak) states. Stone (2004) observes that the policy transfer literature assumes a state-to-state bilateral horizontal relationship, whereas in fact policy transfers can take place as a result of multiple lessons drawn. For example, and as 
will be demonstrated in subsequent chapters, the policy formulation process of the TRCapproach in South Africa was informed by the learning of multiple lessons.

Concerns have also been raised over the difficulty of establishing whether policy transfer has, indeed, occurred. Some observers are suspicious of the argument that cases of policy transfer have increased since the Second World War due to the growth in several forms of communication (Dolowitz and Marsh, 1996; James and Lodge, 2003; Evans, 2004b; Stone 2004; Jones and Newburn, 2007). The concerns are informed by the challenge of distinguishing the specifics of policy transfer processes from the broader policy development process. As Evans notes, "proving that policy transfer has taken place is a particularly thorny problem in policy transfer analysis" (2004b: 19). The real domain of policy transfer investigations is unclear. Addressing this challenge of defining the domain requires clear indicators in order to substantiate trends in global policy transfers. As Dolowitz, Greenwold and Marsh (1999: 719) and James and Lodge (2003: 183) suggest, concrete evidence is needed to establish that policymakers searched for a policy to respond to a domestic policy problem, that these policymakers attempted, either by visiting or sourcing, to learn these available policy options, and that key elements in these policy options were incorporated into the domestic policy.

All these limitations in the policy transfer literature inform the current research. The Dolowitz and Marsh policy transfer model is particularly helpful in accounting for internal and external factors affecting policy transfers. Its multi-level approaches (process-centred, ideational) to investigating cases of policy transfer are vital for the study's research questions. For example, the study directs attention to the role of transnational actors in the development and spread of ideas on the TRC-approach to 
transitional justice and in the policy formulation processes. The reason for doing so is to remedy the neglect of the role of transnational actors as currently identified in the literature. Focusing on transnational non-state actors, in particular, the study contributes to strengthening the connections between globalization and policy transfers.

The comparative methodological approach adopted for this study makes it possible to interrogate critically the usefulness of the model from the multi-level perspective of policy transfers. One of the indicators in the Dolowitz and Marsh model gives clues that are useful in confirming whether policy transfers occurred. Extending the model to this study helps to distinguish the specifics of policy transfers from conventional policy designs. By incorporating the model within the social constructivism framework in studying the three cases, the study further contributes to establishing clarity in the policy transfer domain, and indeed, boosts the usefulness of policy transfer models in studying contemporary policy-making processes.

\subsection{1: Dolowitz and Marsh Policy Transfer Model}

Dolowitz and Marsh $(1996 ; 1998 ; 2000)$ build their policy transfer model around a set of eight indicators. These indicators are framed as questions with corresponding hypothetical answers. The indicators, when grouped, articulate how the functioning of ideas, the instrumentality of agency, and the feasibility of domestic structures account for policy transfers. Contextualized in this study, the policy transfers of the TRC-approach in the selected cases resulted from appeals by elected political actors and domestic civil society groups (human rights activists, research and policy think-tanks) to the restorative justice ideas that motivate the TRC-approach. These ideas were generated and promoted 
by transnational transitional justice epistemic communities led by practitioners associated with previous TRCs.

The political actors domesticated these restorative justice ideas in the domestic structures by appealing to cultural beliefs and by way of the prevailing governance structures in the form of political institutions that allowed for citizens' participation and inputs in the formulation process. These political and social processes account for the production and reproduction of the TRC-approach in countries and across borders in Africa. The eight questions constituting the Dolowitz and Marsh policy transfer model are framed as follows:

1. Who transfers policy?

2. Why engage in policy transfer?

3. What is transferred?

4. Are there different degrees of transfer?

5. From where are lessons drawn?

6. What factors facilitate or restrict policy transfer?

7. How can researchers demonstrate the occurrence of policy transfer?

8. How is policy transfer success or failure accounted for?

The first question, of who is it that transfers policy, speaks to the actors involved in the transfer process. Dolowitz and Marsh identify a wide range of them, both individuals and organizations. They include elected officials, political parties, bureaucrats and civil servants, pressure groups, policy entrepreneurs and experts, transnational corporations, think tanks, supra-national institutions and governments, and NGO and consultants. Elaborating on the categories of actors, the authors observe that apart from 
understanding why policy transfer takes place, it is also critical to recognize the key people or groups involved. Dolowitz and Marsh (1988) point out that in any specific case of policy transfer, several groups of actors are likely to be involved at various stages. They may be in different countries but not citizens of those countries, and may be different from the actors engaged in the direct process of policy, and connected through series of policy networks, epistemic communities and NGOs. Succinctly put, actors in the policy transfer processes can be official or unofficial, or both, and individuals or groups, or both, as well as domestic or international, or both.

The second question, of the reason for engaging in policy transfer, and for doing so at certain times, addresses the underlying issues that motivate actors to borrow from elsewhere. The authors suggest two main reasons: voluntary and coercive (coercive is further divided into direct and indirect). Voluntary transfer assumes intentional and deliberate sourcing of policy ideas; direct coercive policy transfer largely depends on externalities attributable to interdependence, and that may or may not involve any exchange $;{ }^{57}$ indirect coercive policy transfer results from competition among states (leading to regional diffusion) and/or pressure on domestic states to meet national and international standards and obligations. Responding to criticism (Ladi, 2005a) that the model fails to clarify distinctly these two levels of transfer and does not analytically demonstrate what leads to actions like voluntary or coercive policy transfer, Dolowitz and Marsh suggest that it is rather simplistic to characterize the policy transfer process as either voluntary or coercive. Such a distinction gives the impression that the process of transfer is two-dimensional.

${ }^{57}$ The transfer is forced on the receiving state by the inherent cost that may accrue to it if it refuses. 
Dolowitz and Marsh propose, instead, that transfer is more accurately understood as "lying along a continuum that runs from lessons drawing to the direct imposition of a program, policy or institutional arrangements of one political system by another" (Dolowitz and Marsh, 2000: 13). The Dolowitz and Marsh continuum approach is represented in the Figure 1 below. The authors assert that many cases of policy transfer will occupy the middle of the continuum, with direct coercive transfers being uncommon. Employing a continuum approach to understanding the reasons behind policy transfer is heuristically useful. It helps researchers think analytically about the processes involved, to identify categories they can use to frame empirical questions, and to establish and acknowledge the fact that several cases of policy transfer entail both voluntary and coercive elements (Dolowitz and Marsh, 2000).

The above view is, however, contested by Evans (2004b), who argues that the continuum approach is the weakest aspect of the model. He notes that the location of rational/voluntary and non-rational/coercive policy transfer activity at opposite ends of the scale suggests that all coercive transfers are non-rational -- implying that not all coercive transfers are considered irrational, and that by implications all voluntary transfers are rational. Certainly, such a conclusion would be incorrect. Not all voluntary policy transfers can be considered rational, in the same way that not all coercive transfers are considered unreasonable. Indeed, Evans suggests that some of the products of imperialism, such as administrative systems, irrigation and sanitation systems and road networks, emerged from coercive processes of transfer, and have endured, and remain rational legacies (Evans, 2004b: 21). 
Figure 1: The Policy Transfer Continuum (From Lesson-Drawing to Coercive Transfer)

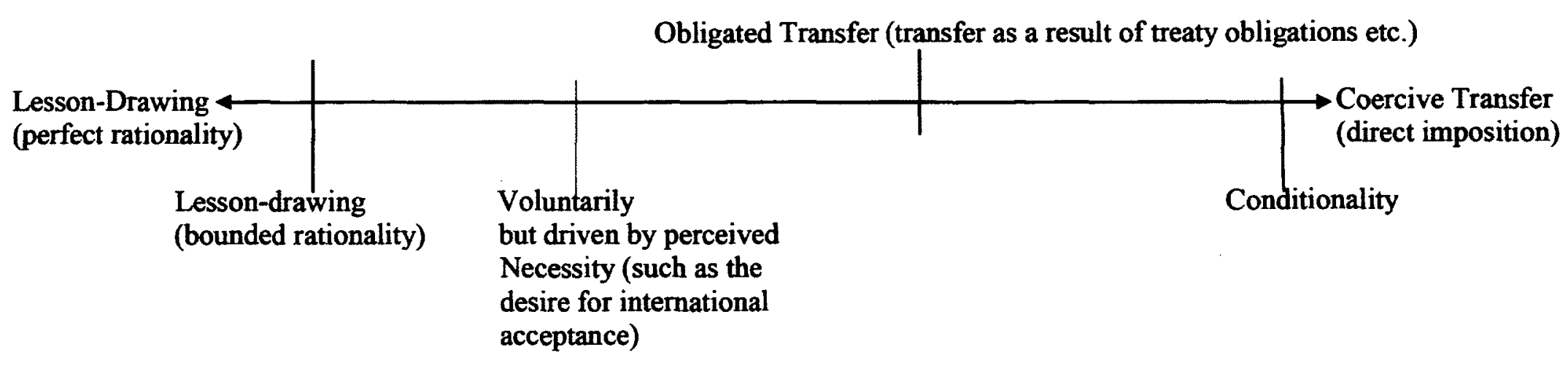

(Source: Adapted from Dolowitz and Marsh, 2000: p.13). 
In spite of this criticism, this study deploys the continuum approach in analysing the case studies. As will be examined in Chapter 5, although the policy transfer of the TRC-approach was voluntarily conducted in all the three cases, however, some form of coercion by way of domestic pressure for some form of transitional justice during the respective political transitions, induced the transfers. Undoubtedly, consistent with the view expressed by Dolowitz and Marsh above, the three cases represented a combination of voluntary and indirect coercion of policy transfer. Adopting the continuum approach allows a careful interrogation of the processes involved in the policy transfer. It prevents one from drawing a simplistic conclusion regarding the rationale behind policy transfers.

The third question in the model relates to the content of policy transfer. Asking, "What is transferred?", the indicator seeks to find out what aspect of the policy is learned or borrowed, or both. Dolowitz and Marsh suggest that nine objects of transfer are considered in this process. These objects include policy goals, policy content, policy instruments or administrative techniques, policy programs, institutions, ideology, ideas, attitudes and concepts, and negative as well as positive lessons. The authors argue that any of these objects can be transferred, depending on who is doing the transferring, what the issue or situation is, and what are the objectives for the transfer. Dolowitz and Marsh observe that in most instances policy borrowers are more interested in the instrument/mechanism than the effect the instrument might produce in the borrowing country. Thus, the policy instruments, administrative methods and institutions, and sometimes personnel, used to implement the policy are sometimes transferred. Political elites or policymakers also sometimes borrow ideas, attitudes and concepts. In other words, any of these objects can be transferred singly, wholly or in combination. In the 
current study, policy goals, ideas and concepts, instruments and lessons were part of the transfer processes in various ways. This will be examined in subsequent chapters.

The fourth question, which concerns the different degrees of transfer, brings forth four alternative methods, and draws from Rose's (1991; 1993) five typologies of lessondrawing research. Dolowitz and Marsh identify copying as one level of transfer, which involves direct and complete adoption of a program without any change. The easiest way of detecting copying is by examining the wording of the legislation that resulted in the formulation of the policy. Another level is emulation, which involves the transfer of ideas behind the policy or program. Dolowitz and Marsh suggest that emulation occurs when a society or country rejects copying in every detail, but acknowledges that a particular program in another jurisdiction provides an appropriate reference or standard for designing a legislative policy in the home country. The third degree of transfer is what the authors refer to as 'mixtures'. This level combines Rose's hybridization and synthesis. Mixtures connote assembling and putting together policy programs found in more than two countries as one desired policy.

The fourth degree, labelled 'inspiration', occurs when a policy in a different jurisdiction inspires a domestic policy change in another. It assumes that an emulator will be inspired or stimulated by new ideas and fresh thinking about what is possible at home after studying familiar problems in a different setting. The outcome of the transfer does not, however, depend on the original case. Dolowitz and Marsh caution that irrespective of these gradations, policy transfer will vary from case to case. This will depend on who is involved in the process and where within the policy-making process that transfer occurs. They state further that while politicians are usually in favour of 'quick fix' 
solutions, and are therefore amenable to copying or emulation, bureaucrats may be more interested in drawing from multiple sources to develop a unique policy.

Dolowitz and Marsh identify three platforms in response to the fifth question, which relates to sources of transfer. The first is identified as the local (in-country), where drawing lessons from the country's own past regarding similar policy problems or from other political and administrative systems or units (if the country is federally governed or meaningfully decentralized) is undertaken. Besides being a logical place for agents of policy transfer to start from, the authors argue that the local level helps to direct actors' attention to what has worked well in the past and, also, to avoid repetition. It also saves time and resources. The second level is outsourcing beyond a country's borders. Policy transfer agents can draw lessons from other political systems. This results in state-to-state or multiple lesson-drawing, or both. The third level of policy transfer source is regional and/or other supra-national and international institutions whose primary concern is to export policies or to advocate specific standardized norms in states and member organizations. At this third level, policy transfer comes from the multi-lateral or international binding institutions, singly or together.

The sixth question, of what facilitates and restricts policy transfers, concerns the structural constraints and feasibilities to policy transfers. The authors suggest that the more complex the policy, the lower its degree of transferability. Dolowitz and Marsh, drawing on Rose $(1991$; 1993), note the following: single goal programs are easier to transfer than multiple ones. The simpler the problem, the more direct the relationship between the problem and the solution, and the fewer the perceived side effects of a policy, the more likely the transfer; the more information agents receive about the 
program in the source country, the easier the transfer; and, the more easily outcomes can be predicted, the simpler a program is to transfer. Dolowitz and Marsh, however, concede that these complex conditions require further scrutiny. The authors further observe that not only may structural and institutional constraints affect the transfer process, they may actually facilitate policy transfers. Examples of these structural and institutional constraints are ideology, culture, technology, economic resources, bureaucracy, language, and history of policies.

The seventh question addresses ways of establishing that policy transfers have occurred. As noted, the policy transfer literature suffers from an unclear distinction between policy transfers and conventional policy-making processes. Dolowitz and Marsh attempt to provide researchers with ways of definitively identifying manifestations of the former. They suggest that there are several ways, including examining government statements, whether verbal or in written records, media reports, studies commissioned by the government, physical meetings, official references to studies published by independent organizations, and personal interviews. By examining and scrutinizing these sources of information, one is able to determine whether a case of policy transfer was involved in a particular policy formulation process. The authors point out, however, that the primary technique for identifying policy transfers is to study government statements and records.

The last, but not the least important, question in the model addresses determining policy transfer success or failure. Stated differently, the indicator seeks to investigate how the process of policy transfer results in policy successes or failure in domestic politics. Dolowitz and Marsh identify three explanations as to whether policy transfers may be 
successful or not. The first, labelled uninformed transfer, occurs when the borrower has insufficient information about the policy or institution and how it operated in the source country. The second is incomplete transfer, where the essential building blocks that ensured the success of the policy or the institution in the originating country have not been transferred. And the third is inappropriate transfer, which results from contextual (economic, social, political and ideological) differences between the source and receiving countries.

In advancing these proposed answers to the question, the authors argue that most studies of policy transfers have tended to concentrate on the success stories. Not all policy transfers, however, have been successful or, indeed, were intended to be. Examining why some transfers are successful and others are not, and what factors may account for these variations, is critical. The authors define policy transfer success as achieving the aims set by a government at the time it engaged in the transfer or as perception of success by the actors involved in the policy field (Dolowitz and Marsh, 2000: 17). In formulating these hypotheses, the authors concede that that there are obvious problems with defining success and failure in the discourse of policy transfer and, indeed, in the broader policy formation discourse. It is no surprise that this conceptualization has been described as insufficient for analysing cases of policy transfer success or failure. Jones and Newburn, for example, suggest that not only does it presume subjective issues; it is also not normal to find situations where policymakers set out clear objectives and the process follows an exceedingly rational and predictable path (2007: 29). ${ }^{58}$

\footnotetext{
${ }^{58}$ James and Lodge (2003) criticize Dolowitz and Marsh's (2000) use of these propositions to analyse the case of the British Child Support Agency, suggesting that their accounts of failure do not develop
} 
Nevertheless, the Dolowitz and Marsh model is the first that attempts to include ways of definitively identifying a successful policy transfer. The authors acknowledge the need for further research in this area. The platform they build provides guideposts in analysing policy transfer success and failure: something this current study seeks to do as it relates to policy formulation processes. The conceptual definition developed in Chapter 4 for analysing policy transfer success of the TRC-approach extends beyond the subjective aspect of their definition. It considers manifestations and perspectives external to the views of the official policymakers. This will include the operational phase and outcomes of the formulated policy, as well as the degree of citizen-participant cooperation during policy implementation.

Concisely, the foregoing discussion outlines the eight formulated indicators constituting the Dolowitz and Marsh policy transfer model. The model is presented in a schematic Table 1 below for easy reference. The authors suggest that the eight questions in the model could be used to organize future research in policy transfer cases. The indicators collectively illuminate the significance of ideas and knowledge, the role of agents, and the substance of domestic structures in the policy transfer process.

In particular, questions two (why engage in policy transfer?--part of which speaks to justification of policy transfers), three (what is transferred?) and four, (are there different degrees of transfer?) shed light on the ideas behind what is transferred; questions one (who transfers policy?) and five (from where are lessons drawn?) bring out the role of the actors behind what is transferred; while questions six (what factors

explanations resulting from the features of the process of policy transfer, but instead advance reasons that go beyond the processes involved in the policy transfer. 
facilitate or restrict policy transfer?) and eight (how is policy transfer success or failure accounted for?) address the issue of the importance of domestic structures in accounting for policy transfers. Question seven (how can researchers demonstrate the occurrence of policy transfer?) helps researchers seek evidence to support the manifestations of policy transfers. It yields clues for the verification of the occurrence of policy transfers, thereby distinguishing it from the normal policy-making processes.

The Dolowitz and Marsh policy transfer model is comprehensive, and the indicators are sufficiently broad to contribute to the understanding of policy transfers. The authors have been credited for their elaborate conceptual model for investigating policy transfer cases (Evans, 2004b; Ladi, 2005a; Jones and Newburn, 2007). The exhaustive nature of the model makes its adoption for this study appropriate. In its entirety, the Dolowitz and Marsh model presents this study with a causal explanation of the policy transfer of the TRC-approach as a transitional justice policy in the selected cases. The model presently constituted suggests that policy transfers can be either an independent or a dependent variable. As the former, the eight questions could be used to explain why a given dependent variable was adopted; as a dependent variable, it reflects a given policy formulation outcome.

This broad latitude allows researchers the option of deploying it as an independent or dependent variable. While Dolowitz and Marsh acknowledge the usefulness of their model in both aspects of investigation, however, they appear to treat it more as a dependent variable. This current study largely accords with this position. It suggests that the policy formulation processes of the TRC-approach in the selected cases are explained by employing the Dolowitz and Marsh policy transfer model. The questions posed in the 
model seek to address either the characteristics of or the reasons for policy transfer. Whereas two of the questions -- what was transferred, and what degree of transfer took place -- address the characteristics of the policy transfer, the other three questions - who transfers policy, why is policy transferred, and what factors constrain or facilitate policy transfer -- allow further inquiry into the causes of policy transfers.

Categorized differently, and as deployed in the current study, questions 3 (what is transferred), 4 (the degree of transfer), and 7 (definitively identifying instances of transfer) create the context for specifying the dependent variable. The rest of the questions--1, 2, 5, 6 and 8--collectively provide the independent variables that help explain the dependent variable. Seeking answers to the issues of who conducts transfers and from where lessons are drawn illuminate the role of agents in the transfer process -elected political office holders, NGOs, and transnational transitional justice experts, among others. Further, questions as to why actors engage in policy transfers help us understand the rationale by which the policy actors draw the lessons they draw, and the significance of ideas in lesson-drawing--which, in this context, means the notion of restorative justice. 
Table 1 A Policy Transfer Framework (adapted from Dolowitz, 2000a; Dolowitz and Marsh, 1998; 2000)

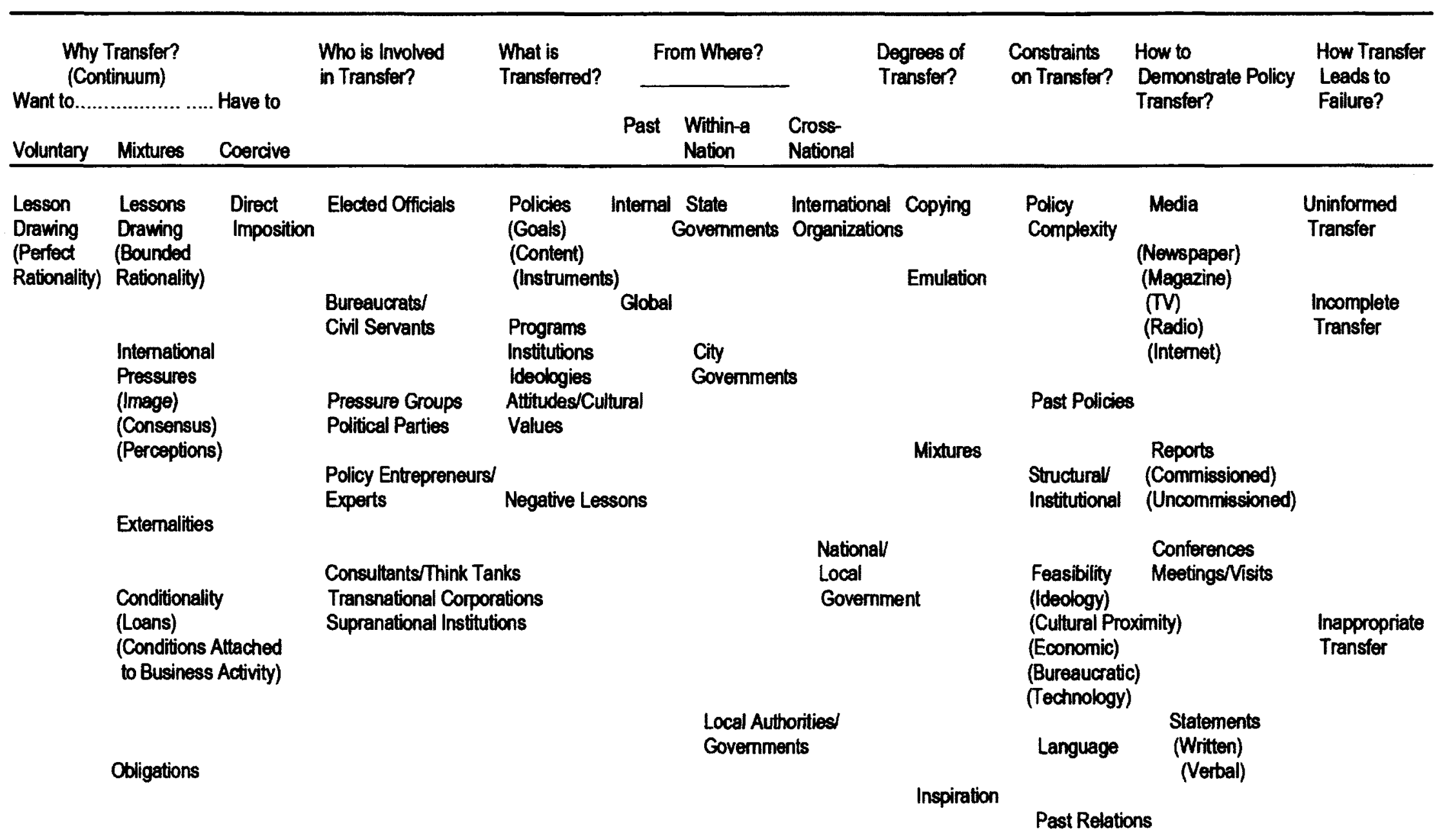


The questions of which factors facilitate and which constrain policy transfers, and of how to account for policy success or failure, emphasize the significance of domestic structures in policy transfer processes. Indeed, the questions of success and failure, while framed to seek answers about outcomes, allow for a deeper scrutiny of the constraining and enabling structural conditions for successful policy transfer. It allows for investigating the reasons behind successful or failure policy transfer outcomes. The three explanatory variables inherent in the model -- uninformed transfer, incomplete transfer, and inappropriate transfer-- seek to provide independent indicators to analyse policy transfer outcomes. These variables are applied in Chapter 7 to account for why the TRCapproach policy transfer was highly more successful in some cases than others.

From the above, it is obvious that the concepts of ideas, agency and structure are implicated in the eight questions that constitute the Dolowitz and Marsh policy transfer model. The model thus operates within, although not explicitly noted by Dolowitz and Marsh in their narration of their model, a broader theoretical and analytical framework: social constructivism. Consequently, the study extends the social constructivism framework to analyse the TRC policy formulation processes collectively as a case of policy transfer. The framework privileges ideas, agency and structure in accounting for human actions, such as policy transfers. It helps to elucidate the significance of ideas and the role of agency in the processes of agenda-setting and as carriers of policy transfers. Put differently, the framework helps to examine the constitutive nature of agents and structure in employing new ideas (restorative justice) to formulate policy (TRCapproach) in the domestic political environment. 


\section{2: The Social Constructivist Framework}

The social constructivism framework is premised on the view that many socialpolitical events are constructed by human activity, specifically social interactions that flow from shared understanding of their values and significance. Consequently, the framework contests the notion that events in the realm of social life happen naturally, or that they occur solely through calculation of material interests. Grounded in the significance of ideas, functionality of agents, and structures, social constructivism offers a context in which to study social relations. It is particularly interested in how the objects and practices of social life are constructed.

At the centre of the framework are people, rules, speeches, practices, institutions, and deeds or acts that constitute social arrangements and, in complex, connected ways, result in the production and reproduction of norms, social rules, and social and political events (Onuf, 1998; Kratochwil, 2001; Finnemore and Sikkink, 2001). In simple terms, social constructivists emphasize the importance of ideas, interest, norms, knowledge, culture, and argument in politics. They strongly uphold collectively held or 'intersubjective' ideas and understandings of social life. While deeply concerned with the role of ideas in constructing social life, social constructivism also seeks to demonstrate the socially constructed nature of agents that flows from the dialectical relationship between agents and structures.

Social constructivism can be traced to its origins in Anthony Giddens' work on the constitution of society (1984). The framework, however, re-emerged strongly as a critical response to the inability of the dominant rationalist and realist theories to explain global 
changes that occurred beginning in the late $1980 \mathrm{~s}^{59}$ The weaknesses of those theories in explaining such phenomena as the demise of communism, the collapse of the Soviet empire and the subsequent end of the Cold War, created the space for what Richard Price and Christian Reus-Smit (1998) call the new generation of critical theorists to argue for social constructivism. The framework presents a reflective process in studying global socio-political events. ${ }^{60}$ As a reflective discourse, it is embedded in the interpretive approach to social inquiry advanced by critical theorists. ${ }^{61}$

Consequently, social constructivists affirm the critical importance of an interpretive approach to political discourse, one where agency matters. Premised on a dynamic and changing world, ${ }^{62}$ social constructivism emphasizes intersubjective understandings, in the sense of determining the ways actors understand what kinds of actions are important and suitable. Thus, as Kratochwil observes, the ontological assumption underlying social constructivism is a human world that is not simply given or

\footnotetext{
${ }^{59}$ Kratochwil (2001) traces the classical understanding of social constructivism to the 'linguistic turn' beginning in the second half of the twentieth century. He argues that the constructivist advancement was premised on the recognition of language as a rule of governed activity.

${ }^{60}$ Arguably, Robert Keohane was the first to use the term 'reflective' in his 1988 presidential address to the International Studies Association (ISA). Keohane proposed 'reflective' to describe "human reflection" as a response to the ontological and epistemological challenges that faced the International Relations discipline during the 1980s (Kubalkova, Onuf and Kowert, 1998)

${ }^{61}$ Critical theory in social science scholarship refers to a school of thought that challenges established or traditional knowledge. The established knowledge is argued to be loaded with bias and to not account for the role of human agency. Traced to the German Frankfurt School, critical theory's primary objective is human emancipation and bringing human action to the fore in understanding social inquiry. Proponents of this approach are opposed to positivist explanations of social and political events that limit the role of human actions. Forms of critical theory include the interpretive approach, feminism, and discourse analysis. It suggests a reflective knowledge through practical understanding of the meaning of the human element, linguistics and symbolic expression. The focus of critical theory is an enhanced understanding of modern social events, including how these events are transformed and connected, and what societal conditions affect these transformations. Advocates (critical theorists) thus claim that social inquiry ought to put agency and structure at the centre of such endeavours. This task of understanding social outcomes is pursued through a multi-disciplinary approach that draws on perspectives from other fields of study.

${ }^{62}$ Fierke (2001) argues further that the point of departure for social constructivism, as against other approaches, is that it views the world as changeable, and that the past, present, and the future are constructed through human practices and interactions with others.
} 
natural but, rather, constructed through the actions of actors (2001: 16-17). To a large degree, the centrality of actions of actors in social constructivism opened the way for the return of agency into social structure accounts -- norms, ideas, and culture. The framework does not take agents for granted in social explanations, but, rather, subjects them to analysis in accounting for social and political phenomena. In other words, a substantial interaction exists between agents (in whatever form) and society. The agentstructure relationship is thus fundamental to the social constructivism framework.

The agent-structure relationship suggests that just as the social environment defines actors, actors also create, reproduce and change the social environment through regular practices. As was stated above, the societal milieu in which agents operate has a corresponding effect on their actions and behaviours. There is a complementarity effect on agents and structures which results in the production of ideas, norms and systems. Clearly stated by Giddens (1981), structure is both the medium and the outcome (production of social systems) of actions and practices by agents. In other words, agents operate in a structural environment, shaped and motivated by the social practices and systems contained in it, which then reproduces itself as a result of the actions of agents.

Accordingly, underlying the mechanics of social constructivism are the elements of agency and structure in producing and explaining social events and outcomes, among other things, by the same logic as structuration analysis (Giddens, 1984; 1993). ${ }^{63}$ Onuf (1998:59) puts this logic as follows: "[C]onstructivism holds that people make society, and society makes people. This is a continuous, two-way process". Social constructivism

\footnotetext{
${ }^{63}$ Gidden's structuration theory speaks to the duality of structure in producing social action. It points to the relationship between agents and structure in accounting for the constitution of social events and life. At the core of this theory are the understanding of how the actions of agents a reflection of the structural characteristics of society and how these structural features inform the reproduction of social action in everyday life. In short, the theory demonstrates the dualism of structure and agency.
} 
thus integrates agency and structure in the production and reproduction of social action. This integration is informed by the existence, generation and circulation of ideas, norms, and interests, among other social practices and systems, and it is also dialectical, involving a two-directional conversation. Agents and structures are thus mutually constituted on the basis of prevailing social practices and ideas.

In other words, the construction of social structure is influenced by agents, using intervening variables such as social practices and ideas contained in the structure, which are in turn influenced by these social structures (Finnemore, 1996; Price and Reus-Smit, 1998; Risse, 2002a). Indeed, the watchword for constructivists is that "ideas matter" and these are collective ideas and norms (Dessler, 1999; Houghton, 2007). The importance of ideas is critical in the social constructivism framework because they construct identities and interests. Thus, while this study understands ideas, agency and structure to be the three main pillars of social constructivism, it recognizes that ideas dovetail into interests and identities which inform agency, and the socially created meanings of events.

The strengths of social constructivism are in its methods of investigation. Methodologically, it employs tools that include discourse analysis, process tracing, genealogy (historical), structured focus comparison, interviews, participant observation, and content analysis to accomplish the search for intersubjective interpretations of a social or political phenomenon. These tools, although not exclusively restricted to social constructivism, allow for interpretive and discursive processes in explaining social and political events.

Consequently, social constructivists believe that there is no neutral position from which objective data can be gathered. As Price and Reus-Smit suggest, the framework 
rejects the hegemonic, exclusive, scientific method of generating knowledge (1998: 261). Social constructivists also place emphasis on what they call the power of discourse to understand processes of social change. Equally fundamental to social constructivism is its ability to give a holistic or widely shared interpretation (as a result of intersubjectivity) which is not reduced to individual/rationalist account of events. The framework employs a broad perspective that goes beyond the individual viewpoint to include collectively held beliefs, and it also seeks to include both domestic and international observable facts.

In spite of the foregoing points, critics argue that the framework's inability to establish causal relations and develop testable predictions (generalizations) about political and social outcomes undermines its strengths. It is suggested that even where social constructivists claim to identify causal relations, confirm hypotheses or demonstrate variations (inconsistencies) across issues and over time, they do so inappropriately or poorly (Fierke, 2001:125; Finnemore and Sikkink, 2001:393; Carpenter, 2007: 100-101). Consequently, the causality and generalization limitations have remained one of the main criticisms.

Further, the framework is faulted for its multiple generations of knowledge about global events, which is attributed to its position that there cannot be any ultimate knowledge that corresponds to Truth about an issue (Price and Reus-Smit, 1998). In other words, from the standpoint of social constructivism, there is no big- $T$, truth, but there are always several narratives (small-T truths). If this is what social constructivism projects, then what becomes of the 'small-T' truths that social constructivists tout as the best account of a researchable event, critics argue (See Price and Reus-Smit, 1998; Finnemore and Sikkink, 2001). Moreover, critics observe that social constructivists' argument that 
they offer an alternative interpretation or explanation (which presumably implies a more viable, and singular, causal explanation than the first one) contradicts the framework's core principle of the impracticality of producing a single source of generating knowledge.

While the criticisms just identified may have some legitimacy, they do not fundamentally weaken the potency of the framework, nor do they undermine its applicability to the current study. Regarding its supposed inability to account for causality and to generalize, a criticism emanating from positivists' focus on variability and comparison, social constructivism is founded on the principle that it is difficult to transfer into the human world the natural sciences' logical method of explanation. Price and Reus-Smit (1998), for example, observe that the language of variability undermines both the significance of historical and contextual specificity and the mutually constitutive nature of political phenomena.

Social constructivism is concerned with the constitutive role of agency and social structures, not just causal explanations. A simple example of social constructivism logic of explanation will be as follows, using the example of a researcher who seeks to examine the frequent occurrence of human rights violations in developing countries. A social constructivist perspective will be less interested in seeking information that view the events as predictable or expected based on prevailing circumstances, such as the lack of democratic form of government, and therefore less focused on deductive analysis that results in a law-like generalization. Rather, a social constructivist will focus not on expectations but on an understanding of the events by way of appropriate concepts such as historical contingency, contextual and cultural relevance, and by placing agency at the center of these events. A social constructivist perspective of this event will thus be 
interpretative and not predictive. As Dessler, for instance, points out, interpretivists define explanation "in terms of intelligibility rather than expectability" (1999:128).

To be sure, although social constructivists' primary interests may be interpretation and explanation, they sometimes are interested in, and do make, generalizations that are clearly different from those preferred by positivists. Social constructivists are uninterested in grand theories that claim the superiority of one account over the other and by way of rational choice analysis and sometimes statistical models, of interpretations. They are, however, interested in the constitutive view of global political events. As Price and Reus-Smit point out, constructivists' generalizations are not law-like rules that transcend time and space; rather, they underscore the historical contingency, cultural peculiarities and contextual relevance of a given situation (1998: 273-275). This process is consistent with critical theory's rejection of positivists' law-like generalizations about international politics.

Regarding the concern over big- $T$ and small-T truths, social constructivists affirm that claims about small-T truths are subject to change according to the dynamics of the global system. This view is consistent with the model's flexibility and with the interpretive philosophy of critical theory, which rejects what it calls totalizing discourses. Rejection of totalizing discourses based on big- $\mathrm{T}$ truth claims does not mean that small-t truth claims cannot be made. Social constructivists have always acknowledged that their claims about global events are contingent and partial interpretations of a complex world, while appealing to the weight of evidence to sustain them (Price and Reus-Smit, 1998: 271-272). With respect to alternative interpretations, although social constructivists have sometimes suggested that the claims they make result in a more plausible interpretation 
of social and political events, those claims are made without the intention of substituting one totalizing discourse for another.

As Price and Reus-Smit (1998) assert, all global narratives are partial and, just as with other approaches, the best that can be claimed by social constructivism is the ability to elucidate an aspect of an event or phenomenon that necessitates further and adequate enquiry. They further suggest that, in practice, empirical works that use social constructivism tend to relate their studies to already understood explanations, whether to displace them or complement them or, even, to generate a completely different set of questions. $^{64}$

The current research, which is situated both in comparative politics and policy science, follows the core principles that inform social constructivism. It is undertaken to solve the puzzle of the proliferation of the TRC-approach to transitional justice and its formulation processes in domestic politics in Africa. The framework is used to explain the policy transfer dynamics of the TRC-approach across borders in Africa. As pointed out, restorative justice ideas that inform the TRC-approach are promoted by domestic and transnational actors, and are domesticated in the structures of the political environments of the selected cases, resulting in the policy formulation of the approach to respond to transitional justice needs. Employing the social constructivist framework helps to explain the processes involved in the policy transfer of the TRC-approach in the three countries. Accordingly, the study is interpretive and discursive, but not predictive. It seeks to offer

\footnotetext{
${ }^{64}$ The social constructivism framework has been applied in multiple areas of investigation (See Hacking, 1999). In international relations and comparative politics, areas in which it has motivated research include: 'Global Norms versus Local Effects', 'Ideas and Power', 'Identity and State Action', 'Norm Entrepreneurs', International Organizations and Law', 'Epistemic Communities', 'Speech, Argument, and Persuasion', and 'Structural Configuration', 'Ideas and Political Change', 'Political Culture', 'Social Movement Discourse', and 'Identity and Ethnicity' (Finnemore and Sikkink, 2001; Green 2002).
} 
alternative interpretations of the phenomena of TRC-approach reproduction across borders in Africa. While interested in generalization, the study does not seek to produce a grand theory on TRC-approach proliferation.

As observed in Chapter 1, this study utilizes mainly qualitative data (interviews), but also quantitative data when necessary to conduct the analysis and interpretation. As a comparative study, it employs structured focus comparison, process tracing, and documentary content analysis as tools of investigation. The holistic methodological approach to social constructivism, in which both domestic and international phenomena are considered in the interpretation of events and their outcomes, is adopted. To be sure, this study is interested in how the ideas informing the TRC-approach proliferated during the political transitions in the selected cases, how actors employed these ideas to respond to transitional justice needs, and how domestic structures facilitated or constrained the policy formulation processes. In what follows, the three core features of social constructivism -- ideas, agency, and structure -- are expanded upon.

Separating the concepts of ideas, agency, and structure in this study does not in any way take from the mutually constitutive relationship between these three pillars. Certainly, the social constructivism framework deployed in this study reflects the intermutual composition of these concepts and the interactions that flow from them and their resulting social phenomena. These three core features of the framework, which also correspond with the three broad tenets constituting policy transfers (and significantly in the Dolowitz and Marsh model as examined above) in the forms of the substance of ideas and knowledge, the role of actors, and the impact of domestic structures, are unpacked, elaborated on, and their use in this study clarified. 


\subsection{1: Ideas (Knowledge and Learning)}

The concept of ideas is used in this study to mean a source from which actors extract information to manage social life. Unquestionably, issues of interests underlying ideas are also brought to the fore when actors search for policy ideas. From that context, broadly shared societal values are developed, as policy programs and structures, to shape perceptions of how things ought to be done. In this study, ideas about restorative justice that inform the TRC-approach helped individual actors and groups in the selected cases to construct a transitional justice policy.

Broadly understood as the individually or collectively held beliefs that, when activated, have the potential to identify desired outcomes for a social, economic or political problem (Goldstone and Keohane, 1993; Campbell, 1998; Howlett, Ramesh and Perl, 2009), ideas also facilitate those outcomes. As Goldstone and Keohane observe, ideas constitute a road map; they help in coordinating policy solutions by acting as glue keeping the whole together, or by serving as a focal point that produces a unique equilibrium, and they also facilitate the entrenchment of durable institutions to produce policy outcomes (1993:13-24). Ideas come in variety of ways: they can be statements of value or worth; they can specify causal relationships; they can be solutions to public problems; they can be symbols and images; and they can be world systems and ideologies (John, 1998:144).

In policy studies, the concept of ideas is used both instrumentally and functionally (Blyth, 1997). Instrumentally, ideas are used in determining the content of public policy. Campbell (1998) identifies four types of ideas usage in shaping content in policy formulation processes. Each of these types -- ideas as programs, as paradigms, as frames, 
and as public sentiments -- Campbell argues, contributes to the supply of new policy approaches to solving policy problems. Functionally, the concept is applied to describe the mode of transmission of policy across countries. Ideas are presented as social learning, which refers to the spread of new information that allows government to make policy choices. Social learning informs policy design and policy transfer discourse (Ikenberry, 1990; Doern and Phidd, 1992; Hall, 1993). The learning process occurs when individuals assimilate new information (ideas) based on experience, and sometimes interests, of the past and utilize it to their own situation. The assimilation of new ideas takes place through interactions at various levels, both international and national, and also at the group or individual levels where new information is shared.

Ideas are among the forces that shape global politics. Researchers may generate ideas that may be useful in policy debate and formulation, and networks and institutions are the instruments by which researchers generate ideas that can affect policy decisions and outcomes (Pedersen, 2005). There are concerns, however, regarding what kind of ideas matter, and whether they have an independent role in policy process. Ideational scholars agree that there are many ideas circulating at any point in time, but the key dispute is about which set of ideas is the best for addressing a particular policy problem (John, 1998). What is obvious is that ideas flourish well when there is an institutional gap or obstacle to existing policy responses to a policy problem. However, critics suggest that advocates of ideas have failed to provide convincing empirical evidence to support the argument that they affect policy outcomes (Campbell, 1998). ${ }^{65}$ The current study attempts to correct this deficiency in ideational scholarship by demonstrating how the

\footnotetext{
${ }^{65}$ Campbell points out that the ways ideas are used to affect policy outcomes have been poorly conceptualized.
} 
restorative justice ideas were exploited by the domestic policy actors with specific sets of interests to inform the policy formulation outcomes of the TRC-approach in South Africa, Nigeria and Ghana.

Both notions of ideas -- as policy content (instrumental) and as social learning (functional) -- are thus applicable to the study. As policy content, Campbell's four-typesof-ideas treatment, noted above, is extended to this study. As a policy or social learning, the study follows both Ikenberry's (1990) and Hall's (1993) concept, which suggests that learning made available by the spread of new information (ideas) produces policy choices that result in policy change or outcomes. The study therefore proceeds on the assumptions, first, that the policy content of the TRC-approach, informed by ideas (and interests) around the restorative option for transitional justice, was made prominent by certain institutional and structural obstacles that prevented the adoption of originally preferred judicial processes in the selected cases. Second, the proliferation of TRCs across borders is the result of social learning around the TRC-approach that is made available from the experiences of other jurisdictions.

Certainly, ideas matter in policy discourse. Yet, it is also acknowledged that ideas do not possess functional autonomy. As Risse-Kappen observes, ideas do not float freely (1995a: 187). They do not necessarily become the underlying causes of public policies. For ideas to inform policy formulation processes they must be processed by actors who are within the existing political and social structures. Hogan and Doyle emphasize the role of actors in processing ideas when they argue that "significant policy change is dependent upon agents of change reaching a broad consensus upon, and subsequently consolidating around, one particular set of new ideas" (2007:891). Obviously, such 
consensus building is usually informed by particular reasons or interests. Who are these agents in the TRC policy formulation processes? The next section examines the notions of an agent and agency.

\subsection{2: Agents and Agency (Carriers of Ideas/Knowledge)}

This study borrows from Giddens' $(1984 ; 1993)$ conceptualizations of agents and agency as constituting those knowledgeable actors who intervene in the ongoing process of events in the world, including domestic affairs of states. Agents and agency are interconnected. On one hand, agents are conscious of their actions, possess some degree of control and monitor their actions in society; on the other hand, agency suggests the flow of actions that an individual consciously conducts. In short, agency refers to the capability of agents or actors. The idea of agency corresponds to the means by which voices and perspectives of stakeholders in any political, economic and social endeavour may be factored into interpreting and understanding the phenomenon and its outcomes.

Agency in this study means actors who have the capacity and influence to act in global and domestic political systems and structures with respect to transitional justice policy processes. The groups of actors considered include elected officials, NGOs, human rights organizations, research and policy think-tanks, and transnational transitional justice epistemic communities. These actors, by various means, played different roles in sourcing and providing ideas around the restorative justice process to transitional justice that inform the TRC-approach, leading to the policy formulation processes in the domestic political environments of the selected cases. Whereas these actors exhibit capabilities in the policy discourse phase of the TRC formulation processes, their 
capacities, interests and influence differ, depending on their level and location. As Apter (2006) suggests, agency creates discourse communities that facilitate narratives, enabling ordinary people to talk, discuss and think collectively about how to solve their dilemmas.

The nature of agency has been characterized from different levels (Josselin and Wallace, 2001; Halliday, 2001; Risse, 2002b; Ladi, 2005a; 2005b). Agency is divided into domestic and international, state (official) and non-state (unofficial), and individual, groups and organizations. Within these categories are several agents, including pressure groups, advocacy coalitions or networks, think-tanks, experts, research institutes and special knowledge groups (epistemic communities), and eminent and global citizens, among many others.

Domestic agency has generally been considered to include elected politicians, the public, bureaucracy, political parties, interest and pressure groups, think-tanks and research organizations, the mass media, and academic policy experts and consultants (Howlett, Ramesh, and Perl, 2009: 61-75). Actors in the international realm include intergovernmental agencies, such as the $\mathrm{UN}$ and its affiliate bodies, IFIs, transnational corporations (TNCs), multi-national corporations (MNCs), INGOs, and transnational social networks and movements (Tarrow, 2001: 10-14; Stone, 2001; 2004). Individual actors have usually been identified as former heads of states, religious leaders, Nobel laureates, and other notable or famous personalities, including successful and famous musicians and athletes.

The diverse categories of agency have objectives, interests or identity promotion pertaining to policy formulation discourse, and play different roles in this process. In some instances, interests may converge; in other cases, interests and objectives may be 
diametrically opposed. Some may play the role of borrowers, some of carriers of policy ideas and innovation; yet others play a simple role in the formulation and decisionmaking processes. It is certain, however, that agents attempt to influence policy in a definite direction, with rational objectives as the goal. While some may have a selfinterested agenda, including projecting one's own identity, others seek to advocate a course of action deemed morally and legally appropriate for the well-being of society. ${ }^{66}$

There are, however, others, mainly domestic pressure groups, think-tanks, and NGOs, whose main interest is disseminating or advocating, or both, the enforcement of new international norms, rules, programs and models of political systems and structures. Others, like the epistemic communities, both national and international, may be interested in sharing values, ideas or solutions and best practices to solve political, economic, and social problems.

There is no doubt that agency matters in constructing and shaping policy formulation discourse. Although its role in influencing policy discourse and its formulation processes has been widely acknowledged in the scholarship, whether comparative politics or policy analysis (Sikkink, 1993; Keck and Sikkink, 1998; Keeley and Scoones, 2000; Klotz, 2002; Freeman, 2006), theorizing about agency has, however, continued to be an issue under scrutiny. In particular, research questions around the significance of different categories of agency, different levels of its impact on domestic policy formulation politics, and how local and foreign actors relate to one another in advancing a common goal continue to be explored in the literature. Furthermore, limited

\footnotetext{
${ }^{66}$ For example, individuals or groups of politicians who assume positions of power may advance and influence the adoption of a particular public policy in order to transform self-interested claims and actions into higher principles. These politicians or public officials not only strengthen their own positions but, also, become revered community leaders.
} 
attention has been directed to understanding domestic actors, particularly those located in the developing countries, in policy formulation discourse. These are among the research questions that are examined in this study.

Besides these issues, research questions such as what informs the position that agents take and for which they argue, and how these positions are articulated by agents in domestic politics, continue to engage researchers. The current study addresses these research gaps using investigations conducted in the selected cases. It involves actors in domestic and international environments, as well as in the state and non-state realms. They are called upon to explain how agents contribute to the policy formulation processes of the TRC-approach in the selected cases, as well as the approach's replication across borders. The study identifies these actors as borrowers, carriers, and formulators of the TRC-approach. It recognizes who the specific actors are and their sources of the TRC-approach. Why and how domestic agency sourced the restorative justice ideas that inform the TRC-approach are also examined. The investigation also seeks to delineate the specific functions of domestic and international actors, as well as their relationships in the search for and articulation of ideas relating to the TRC-approach. It focuses on transitional justice epistemic communities.

The study proceeds with the propositions that the sourcing of the policy knowledge about the TRC-approach was primarily the responsibility of domestic actors, and transnational actors played a role in this transfer process to the extent of providing content knowledge and best practices of the TRC-approach, which they did in order to legitimize its adoption. Elected officials in the selected countries led the articulation of the policy on the TRC-approach and its formulation in the domestic structures. They were 
complemented by the domestic non-state actors, who partnered with transnational transitional justice epistemic communities in providing content during the policy discourse.

Agents exist neither in a vacuum nor independently from their social and political environments and their collectively shared systems of meanings. Klotz (2002) observes that agency alone cannot account for the transformations that are being witnessed in both local and global politics. There are structural capabilities that determine the parameters within which agents act (Keeley and Scoones, 2000). The agent-structure relationship, as elaborated on above, is vital in understanding the construction and shaping of policy formulation process. Consequently, agency and structure are not opposed to one another; they reinforce each other. Agents are constituted, in part, by the elements (ideas, interests) of the social environment. It is by reference to these parameters that one seeks to demonstrate the socially constituted nature of agents. The next section examines the structural capabilities that constrain and/or enable agency to act in diverse ways in policy processes.

\subsection{3: Structure (Cultural and Political)}

Structure is understood in this study as synonymous with rules, resources and intersubjective negotiated meanings, understandings, systems and institutions that produce actions and outcomes. The study draws on Giddens' (1984) social structure, which he defines as organized sets of rules and resources that agents draw upon to produce and reproduce societies in their various activities. Structure thus embodies critical collective meanings (norms, culture) and understanding arising out of rules, 
resources, and institutions that govern society, and the interactions that go on in order to produce certain outcomes. It does not have physical existence on its own, and depends on the habitual actions of agents to reproduce itself. Agents and structure are therefore mutually constituted. They depend on one another to produce and reproduce social life.

Some observers argue that social structure elicits a certain ambiguity, because it is difficult to tell whether structures exist in reality, or only in abstract form (Onuf, 1998; Wight, 2006). Nonetheless, various elements of structure, including viewing it as patterns of aggregate behaviour that are stable over time, as law-like regularities that govern the behaviour of social facts, as rules and resources, and as intersubjective negotiated meanings, have been identified (Wight, 2006: 127- 173). The current study designates two elements of structure -- culture and political set-up -- to help account for the policy transfer and the subsequent formulation of the TRC-approach as a transitional justice policy in the selected cases.

Culture is considered in this study to include norms, beliefs, values and attitudes that people employ collectively to manage their everyday social and political life. Culture in this context is dynamic and it evolves. The study investigates the extent to which policy actors in the selected cases drew upon culture at that precise moment to enrich the policy formulation discourse and attract public support for the TRC-approach. Culture has been defined broadly to consist of shared social norms, morals, ethics, and practices that a group of people uses in their daily lives (Geertz 1973; Kottak, 1974; 1996; Ross, 1997; Pietkiewicz, 2008). Geertz defines it as "an historically transmitted pattern of meaning embodied in symbols, a system of inherited conceptions expressed in symbolic forms by means of which men [sic] (society) communicate, perpetuate, and develop their 
knowledge about the attitudes towards life" (1973: 89). These expressions create the basis for facilitating or constraining the adoption of a particular public policy. They endow people with social and political identity, argues Ross (1997), which shapes their worldview regarding how certain decisions ought to be made.

This study is particularly interested in certain values, in particular religious beliefs, that people in a community share, and that are invoked at certain critical junctures $^{67}$ to address societal concerns. Cultural analysis offers a contextual, intersubjective account of social and political events that rely on how actors understand social and political action. Definitely, these cultural beliefs do sometimes have bearings on ideas and interests that people possess. The study investigates the extent to which agency were shaped by culture -- in this instance, religious beliefs -- resulting in the policy formulation outcome of the TRC-approach. The extent to which ideas of and interests in restorative justice, as exploited by agents, corroborated with this identified culture is also examined.

The use of culture in this study is not to project its singular function as either the underlying explanation, or the direction, of the TRC policy formulation process. The study is not oblivious to the continuing debate over the efficacy of culturalist views as an explanatory or predictive model, especially when it comes to issues of governance, democracy and policy (Ross, 1997; Przeworski and Cheibub, 1998). The porous, lively, varied and changing nature of culture makes it usually difficult to deploy it as a

\footnotetext{
${ }^{67}$ Critical junctions are trigger events that result in processes of institutional or policy change, or both. This change is produced from among alternatives, and the duration of critical junctions can be momentary, leading to a short-term change or long, resulting in re-orientation. See Hogan and Doyle (2007) for a discussion of this approach and its application in comparative studies research.
} 
dependable explanatory variable that remains neutral and same across space and time. In other words, by its nature it is unable to lend itself for developing universal assumptions.

Instead, in this study, culture is used to demonstrate how, in situations described as critical junctures, culture frames can be appealed to by political elites and policymakers at that defined moment to facilitate or constrain a public discourse. In this instance, how well did domestic policy actors exploit religious beliefs to attract public support for the TRC-approach, and were the holders of these beliefs sufficiently responsive to result in the formulation of the TRC-approach to transitional justice?

The political component of structure represents the rules, systems, platforms and institutions of political engagement by agents in a political system. The study draws upon Risse-Kappen's concept of domestic structures (1995a; 1995b). Risse-Kappen refers to them as "the political institutions of the state,... societal structures, and... the policy networks linking the two" (1995b: 20). Thus, domestic structures include the organizational machinery of political and societal institutions, their routines, and the decision-making rules and procedures built into law and custom, as well as the values and norms rooted in the political culture. The issue of the degree to which this machinery is accessible to domestic and external agents in policy transfer and formulation processes is fundamental to this study.

In his discussion on domestic structures, Risse-Kappen identifies three components of this machinery: state structure, societal structure, and state-society structure (1995b: 20-28). The last two are of particular interest to the current study. Societal structure machinery is determined by the level of non-state actors' interventions in political discourse, examining the extent of civil society formation and input for 
political causes. It represents citizens' political attitudes, ideological positions and social beliefs that are brought to bear on the processes that result in policy change.

The state-society structure links those entities in policy formulation discourse in which non-state actors, such as policy networks, play an intermediary role by mobilizing societal demands and channelling them into the political process. Risse-Kappen raises key issues about the nature of the political culture of these networks, including whether they espouse a culture of consensus or of distributive or dissenting political policy processes. He applies his models in relation to non-state actors and international institutions, arguing that transnational actors' access is more open in decentralized political systems and in pluralistic societies than it is in closed and centralized ones (1995b). Risse-Kappen's concept of domestic structures is limited to accounting for transnational actors; also, as Tarrow (2001) notes, it does not account for why some actors are able to succeed while others fail in the same context. Furthermore, it appears that Risse-Kappen is focused more on the political aspect of domestic structure than on the social dimension of domestic culture.

As stated, the study's use of structure is in both the cultural and the political contexts. Referring to the cultural element of domestic structure is meant to fill the social element gap in Risse-Kappen's domestic structure. In addition to analysing the extent to which transnational actors have access to domestic political systems, the study extends Risse-Kappen's societal and state-society structures to the analysis of the degree to which domestic agents participate in the policy formulation processes of the TRC-approach in the selected cases. It is interested in the set of political platforms that facilitate how members of the community participate in the political decision making processes that 
affect their lives. Of particular significance is the history and level of openness of the policy formulation structural arrangements and citizens' participation in the policy discourse. The study asks: do different political platforms and styles of policy formulation allow for wide public consultations, or do they stifle public input during the policy formulation processes of the TRC-approach in the selected cases?

Consequently, the current study examines the levels of receptiveness and responsiveness of both cultural and political elements of domestic structure to the ideas that inform the TRC-approach during the policy formulation processes. It proceeds on the assumption that widely embraced societal values, in this context religious beliefs, are influential in shaping the policy formulation discourse on the TRC-approach, and that there are certain pathways by which these beliefs and the restorative justice ideas, including truth and reconciliation, that inform the TRC-approach meet. Accordingly, citizens of these countries are predisposed to accept the TRC-approach if the policy actors consciously invoke these congruencies at the critical junctures during the policy discourse.

Further, a political stage for policy formulation process that is open and transparent, with avenues for the public to make inputs into the policy discourse and formulation process, allows for public ownership, and enhances not only the content of the policy on the TRC-approach, but also the capacity for the success of the work of the TRC institution. The domestic structure of societies is therefore significant in policy transfer processes. 


\section{3: The Theoretical Model: Social Constructivist Account of Policy Transfers}

To emphasise, this study suggests that the three existing theoretical models--the legalist, transitilogy, and instrumentalist--are unable to sufficiently explain recent policy formulation processes of the TRC-approach, and, in particular, the reproduction of this approach across borders in Africa. To be sure, this study does not imply that the models have outlived their usefulness and, therefore, it does not seek to reduce or replace them in the transitional justice scholarship. However, as argued in Chapter 2, when applied to interrogate the reproduction of the TRC-approach in the selected cases, they do not provide persuasive and informed explanation regarding the policy formulation processes. Consequently, the current study builds an alternative theoretical paradigm, in the form of a social constructivist explanation of policy transfers, to offer a more conceivable explanation and understanding of the proliferation of the TRC-approach to transitional justice in Africa. What, then, is the theoretical model for the TRC policy formulation being proposed in this study? And what purpose does this model serve?

The alternative theoretical and analytical paradigm being developed to investigate the study's selected cases and described above is at two levels. The first level of this paradigm is the Dolowitz and Marsh policy transfer model which provides the lens through which to explain and understand the manifestations of the TRC-approach as a policy response to transitional justice demands in South Africa, Nigeria and Ghana. At the center of this model, which has 8 questions, are the usefulness of ideas, the role of agents, and enabling structural factors to facilitate the policy transfer processes. The study asks, how are these three significant features embedded in the model constituted and constructed to advance policy transfers? The second level of the proposed theoretical 
and analytical model is the social constructivism framework. The study suggests that the Dolowitz and Marsh policy transfer model fits well in this framework. The social constructivism framework, which privileges ideas, agency and structure in a mutually constitutive fashion, elucidates the Dolowitz and Marsh policy transfer model. The framework brings to the model the centrality of human actions in facilitating the policy transfers and subsequent domestic formulation processes of the TRC-approach in the selected cases.

The social constructivism framework strengthens the Dolowitz and Marsh policy transfer model by illuminating the interaction between actors in the domestic and international realms of agency that result in the policy transfer of the TRC-approach in domestic political environment. The agent-structure relationship, which is fundamental to social constructivism, provides insights into the discourse on how agents transfer restorative justice policy ideas and how agents, functionally and instrumentally (their deeds/acts, speeches, practices), process these ideas to shape the policy on the TRCapproach in domestic politics. In sum, social constructivism, which is a broader framework, provides a shelter in which the 8 questions constituting the Dolowitz and Marsh policy transfer model manifest to account for the policy transfer and the subsequent domestic policy formulation processes of the TRC-approach to transitional justice in the selected cases.

The integration of these two levels of model and framework makes the proposed theoretical paradigm capable of being used to explain and understand the global proliferation of the TRC-approach as a transitional justice policy. The dynamic relationship between agents from the domestic and international arenas in the global 
production of the TRC-approach is made apparent; the interactions between domestic agents and structure on the notion of restorative justice is also clearly explicated to account for the policy formulation of the TRC-approach as a social and political phenomenon in the domestic political systems of the selected cases. Certainly, if nothing else, the integration of the two levels makes the proposed theoretical model seek alternative means of explaining and understanding the political and policy formulation processes involved in the proliferation of the TRC-approach across borders in Africa, which has human endeavours at the center of it.

\section{4: Hypotheses for the Study}

The study proceeds with three broad hypotheses that take the TRC policy formulation process as its dependent variable. Drawing from the Dolowitz and Marsh policy transfer model as integrated into the social constructivism framework, the processes that resulted in the TRC policy formulation outcomes are the study's independent variables. Specific ideas (restorative justice) and particular agency (elected officials, NGOs, transitional justice experts) and structure (culture and political institutions) explain the policy transfer and formulation processes of the TRC-approach to transitional justice in the cases selected for study.

The hypotheses expanded upon below guide the investigations, and help in addressing the research questions. They yield indications regarding conditions that allow the restorative justice ideas underpinning the TRC-approach to flourish. They produce an understanding of the nature of agency, whether domestic or external, and its role in the policy transfer and formulation processes of the TRC-approach. The hypotheses also help 
us to understand the domestic structural enabling and constraining factors that account for policy transfers of the TRC-approach. They expand on the dialectical relationships between agent and structure in accounting for the policy formulation processes of the TRC-approach using restorative justice ideas.

To begin with, it is hypothesized that restorative justice ideas that inform the TRC-approach prospered in South Africa, Nigeria and Ghana as an altemative means of addressing transitional justice needs following the emergence of obstacles that prevented the employment of retributive notions of transitional justice. There were urgent demands for justice from victims of human rights abuses in these countries. To respond to these demands, the successor political elites voluntarily drew on restorative justice ideas to address societal concems, and also to bolster their image nationally and internationally. Consequently, ideas of restorative justice thrive when considerable institutional obstacles occasion non-applicability of the prevailing judicial policy responses to transitional justice. The effect of such a circumstance is policy transfers of the TRC-approach. The first hypothesis of this study follows.

Hypothesis 1: Ideas (restorative justice) that informed the TRC-approach to transitional justice in South Africa, Nigeria and Ghana were conditioned by institutional barriers that limited the application of existing judicial approaches to transitional justice. Specifically, the entrenchment of institutional obstacles, such as any of the following, will facilitate the policy transfer of the TRC-approach to transitional justice:

Hla: If there is a history of policies, including legal statutes, that outlaw or limit formal judicial inquiries into previous human rights offences, the more likely are restorative justice ideas (TRC-Approach); and 
HIb: If the strength and capacity of the institution that undertakes judicial inquiries is evidently weak and compromised, then the more relevant is the restorative justice process; hence the policy transfer and subsequent application of the TRC-approach.

Second, it is hypothesized that domestic and international agents are instrumental in the policy transfer processes of the TRC-approach to transitional justice. The restorative justice ideas informing the TRC-approach are sourced willingly by elected officials, domestic NGOs, and research and policy institutions. These domestic policy actors are also the principal agents initiating the discourse on the restorative justice process and engineering its policy formulation in the domestic politics. In South Africa, Nigeria and Ghana, the newly elected political leaders, the human rights NGOs and other non-state actors were primarily responsible for sourcing the TRC-approach from outside their countries, initiated its policy public debate, and propelled its policy formulation. They employed these ideas to shape the content of transitional justice policy. The international agents -- independent transitional justice policy and research organizations and individual experts -- acted as carriers of the ideas and best practices that inform the TRC-approach. In other words, they served as its repository of knowledge and learning and, therefore, played the catalyst role in facilitating policy transfers. The second hypothesis for the study is stated as follows:

Hypothesis 2: Both domestic (elected officials and domestic CSOs) and international (transitional justice expert groups) agents were active in the policy transfer processes that resulted in the formulation of the TRC-approach to transitional justice in 
the domestic politics of South Africa, Nigeria and Ghana. Domestic actors were the borrowers and formulators, while the transnational actors served as carriers. The specific roles played by the two categories of agency are different, and depend on the following: H2a: If the policy transfer of the TRC-approach is sourced voluntarily by domestic actors, and in particular by elected political officials, the probability is high that they will be the leading policy actors to guide its policy discourse, formulation process and content development in the domestic political environment; and

$\mathrm{H} 2 \mathrm{~b}$ : If the policy transfer of the TRC-approach is voluntarily initiated by domestic policy actors, the transnational transitional justice policy epistemic communities only play a limited role as providers of content-- that is the restorative justice-- on the approach and its legitimization.

Third, it is hypothesized that domestic structures are critical for policy transfer situations. The more receptive and responsive domestic structures are to transferred policies, the higher their rate of successful formulation in domestic politics. Both culture and political platforms for the policy process are taken in this study to constitute domestic structures; when the restorative justice ideas that inform the TRC-approach coincided with certain beliefs and values of the citizens in the selected countries, the formulation of the TRC-approach was highly successful; and when the political stage (historically, based on the democratic credentials of the borrowing country, or currently) in the selected cases allowed for transparency in the policy formulation process, and characterized an inclusive 
process, the TRC-approach policy formulation was successful. Therefore, the third hypothesis for the study is:

Hypothesis 3: There is a relationship between domestic structures (culture and political) and a policy transfer process of the TRC-approach to transitional justice, such that:

H3a: If there is an approximation in cultural beliefs of the restorative justice ideas, the TRC-approach policy transfer and formulation process is likely to succeed; and

$\mathrm{H} 3 \mathrm{~b}$ : If the domestic political arrangements allow for and support victims of human rights abuses, and the more complete citizens' participation in the policy discourse during the formulation process, the more successful will be the TRC policy transfer process.

The hypotheses just listed reveal three key propositions for the study. First, in the three cases being studied, the restorative justice ideas that inform the TRC-approach to transitional justice assumed prominence as a result of the weighty nature of the institutional constraints that prevented the use of judicial processes. The TRC-approach was viewed by its leading proponents, in all the cases, not as a second best but as a promising alternative approach to the purpose demanded by victims of human rights abuses and the entire citizenry. Consequently, the policy transfer of the TRC-approach in domestic politics of societies in Africa is helped by marked blockades to judicial process and, also, a genuine appeal to the notion of restorative justice. 
Second, domestic agents, led by elected political officials, are the primary borrowers of the TRC-approach, as well as responsible for its formulation in the political system. They make clear from the start their intention to go for the TRC-approach once they are convinced that the judicial process is untenable and the restorative justice process is, preferably, necessary for the country. This manifested in all the three cases under investigation. Actors from the international realm are the content providers in the policy transfer processes of the TRC-approach. They are less involved in the public discourse and the formulation process, and only provide technical assistance to the domestic actors -- state and non-state -- to ensure that best practices inform the policy debate and formulation. Accordingly, in the sphere of TRC-approach policy transfers, at least in the African context, domestic agents are restricted to borrowing and formulating, while international actors play the role of carriers and promoters.

Third, that domestic structure (culture and political) is significant in policy transfers of the TRC-approach is contended in this study. In cases such as South Africa and Ghana, where the domestic structures were favourable, the transfer and formulation processes of the TRC-approach proved successful. In the Nigerian case, where domestic structures were not favourable, either through lack of effort on the part of policy actors in appealing to cultural beliefs or through the absence of transparent and legislative processes leading to the formulation, the policy transfer of the TRC-approach was not successful. Therefore, the policy transfers of the TRC-approach in domestic politics are more likely to succeed when domestic structures respond positively to those restorative justice ideas: when cultural beliefs of the citizenry correlate well with these ideas, and when there are avenues for the public to be involved in the policy formulation process. 


\section{5: Summary and Conclusion}

This chapter has put forward the theoretical model and analytical framework for this study. It examined the Dolowitz and Marsh policy transfer model adopted in the context of the policy transfer discourse. The chapter also delineated the social constructivist framework, and applied it to explain the policy transfer dynamics and the formulation processes of the TRC-approach in the three selected cases. The main thesis in this chapter is that the social constructivist account of policy transfer of the TRC approach produces a more credible and convincing approach to explaining and understanding processes resulting in the policy formulation of the TRC-approach.

Having established the theoretical paradigm and analytical context, the subsequent chapters examine the various stages and processes that led to the formulation of the TRC-approach in the selected cases. The discussion and analysis in the following chapters are guided by the hypotheses set out in this chapter. Before then, and to start with, the next chapter analyses the dependent variable of the study -- the policy transfer of the TRC-approach. The specific analytical questions to be addressed in the chapter include those pertaining to: establishing that the TRC-approaches that were formulated in the selected cases were, in fact, cases of policy transfer; the aspect(s) of the TRCapproach that was transferred to the selected cases; and the degree of transfer that took place. 


\section{Chapter 4: The Policy Transfer of the Truth and Reconciliation Commission (TRC)-Approach}

\section{0: Introduction}

The TRC-approach to transitional justice has proliferated globally during the past two decades. Since its popular inception in South America in the 1980s, and the growing attractiveness of its South African version since the mid-1990s, the TRC has become an exciting way of undertaking a historical memory project and post-transition accountability for human rights transgressions. This study holds that the recent proliferation of the TRC-approach across borders in Africa is an act of policy transfer. Using the South African, Nigerian and Ghanaian TRC cases, this chapter demonstrates the policy transfers of the TRC-approach: South Africa transferred the approach from lessons drawn from around the world; both Nigeria and Ghana borrowed from South Africa.

The chapter, first, establishes the manifestations of the TRC policy transfer in each of the cases. The content of the TRC model that was transferred in each case is analysed. The scope of the policy transfer that occurred in each of the three cases is also examined. Consequently, drawing from the Dolowitz and Marsh (1996, 2000) policy transfer model used in this study, the three main questions that inform this chapter are: Did TRC policy transfers occur? What aspect or aspects of the TRC-approach were transferred? And, what was the degree of transfer that occurred?

The chapter asserts that government statements and documents, official reports, media reports, and conference and meeting reports found in these three countries made references to learning and borrowing from the TRC-approach to transitional justice. 
Further, public pronouncements by key political and policy leaders in these countries, as well as by TRC practitioners, attest to the TRC-approach being a foreign concept when it came to solving a transitional justice dilemma. Thus, the TRC-approach to transitional justice in South Africa, Nigeria and Ghana was externally sourced.

This chapter further suggests that while in all three cases the policymakers transferred the policy goals and the corresponding policy instrument for implementing the policy goals, South Africa, in addition, transferred the positive and negative lessons associated with previous TRCs. The TRC goals of promoting restorative justice and advancing reconciliation were the main contents of the transfer. The administrative mechanism for implementing the objectives of the TRC, being a quasi judicial commission of inquiry and a victim-centred process, was another aspect of the TRC model that was transferred in each of the three cases. There were, however, significant differences in the administrative modi operandi in the three countries.

The degree of transfer of the TRC-approach, however, differed across the three cases. In all three cases direct copying was avoided. In South Africa the degree of transfer represented the "mixtures" type, because the transfer was informed by assembling policy programs of past models of TRCs from more than two countries to develop a unique legislative framework. In Nigeria the transfer was informed by the "inspiration" type, where policymakers were motivated by events in South Africa that resulted in similar policy goals and instruments to address similar domestic policy concerns. In Ghana the degree of the TRC-approach transfer was of the "emulation" type, where the ideas behind the South African TRC-approach informed the development of 
domestic legislative policy without necessarily copying the source's wording of the legislation.

This chapter discusses these three questions for each of the three cases. Following this introduction is an account of TRC origins and its distinctive features. An overview of the notion of the restorative justice that underpins the TRC-approach, which is also pertinent to this study, is examined next. This is followed by identifying the goals associated with the TRC-approach. The global proliferation of the TRC-approach and its manifestations in Africa are also examined. The conceptual definition of success or failure of the TRC policy transfer process follows. As stated in the first chapter, the implementation and impact of the TRCs are not the focus here but, rather, the politics of the policy formulation process. Accordingly, success or failure of TRC policy transfer is conceived of in this study as a six-phase multi-dimensional variable, with degrees of success or failure.

These phases are identified as TRC establishment, TRC operation, TRC cooperation from witnesses, production of the TRC final report, government acceptance and public release of the TRC report, and implementation of all or some of the TRC recommendations in the TRC final report. This conceptualization is inherent in the Dolowitz and Marsh policy transfer model. It takes into account both subjective and objective views of the TRC outcomes. By adopting this scheme, the study extends Dolowitz and Marsh's subjective definition of policy transfer success, and adopts clear indicators that transcend the aims set by policy actors.

The next section of the chapter examines the case studies of South Africa, Nigeria and Ghana. The discussion of each case study covers the establishment and working of 
the TRC, manifestations of TRC policy transfer, content of TRC policy transfer, degree of transfer, and outcomes of the TRC work. The discussion on the outcomes of the three TRCs in this chapter is limited to the degree of success or failure of the policy transfer process as conceptualized in this study. After the case studies comes a comparative discussion of the success or failure of the TRC policy transfer outcomes of the three cases. The analysis is conducted by deploying the six-phase multi-dimensional variables conceptualized for identifying policy transfer success. This is followed by a summary and a conclusion.

\section{1: The TRC-Approach: Concept, Features and Origins}

A truth and reconciliation commission is fundamentally a mechanism for historical memory or remembrance of human rights wrongs, with the intention of achieving restorative justice and preventing the recurrence of such abuses (Hayner, 1994; 1995; 2001; Rotberg, 2000; Secretary-General Report, 2004; Freeman, 2006). Hayner, one of the most quoted observers, defines TRCs as "bodies set up to investigate a past history of violations of human rights in a particular country -- which can include violations by the military or the other government forces or by armed opposition forces" (1995: 225). Truth and reconciliation commissions are types of commissions of inquiry. Commissions of inquiry are tools of fact-finding missions inquiring into any subject deemed important enough for national investigation and redress.

Truth and reconciliation commissions are, however, conceptually distinct from formal commissions of inquiry. While the latter takes the form of either a judicial or a non-judicial inquiry into any single, particular subject or event, whether political, 
economic, social, or some combination of those, TRCs are quasi-judicial institutions that focus solely on human rights violations within a specified period of time. ${ }^{68}$ Truth and reconciliation commissions investigate gross human rights abuses that relate to civil and political rights and, in recent years, to social and economic rights that have been enshrined for protection in national and international human rights and humanitarian laws.

Both the UN and the ICTJ, a notable global epistemic institution concerned with transitional justice processes, have designated TRCs as official, temporary, non-judicial, independent fact-finding bodies typically set up to investigate a pattern of abuses of human rights or humanitarian law committed over a number of years (Secretary-General Report, 2004; ICTJ 2008a). The distinctive features of TRCs comprise the following. First, TRCs are normally set up in the aftermath of political transitions. Consequently, TRCs focus on past events and past regimes. Second, TRCs are temporary bodies with a defined period of time to function. Third, TRCs typically investigate national events. Their focus is on long, gross and systematic human rights abuses. Fourth, TRC processes are victim-centred. Finally, TRCs are vested with some authority and power that facilitates wide scrutiny and greater protection to investigate sensitive information, and that enables their reports to have greater impact on societies.

The features just mentioned make it apparent that TRCs have both a backwardand a forward-looking mandate. As a backward-looking exercise, TRCs embark on an

\footnotetext{
${ }^{68}$ Freeman (2006:18) defines a TRC as "an ad hoc, autonomous, victims-centred commission of inquiry set up in and authorized by a state for the primary purpose of investigating and reporting on the principal causes and consequences of broad and relatively recent patterns of severe violence or repression that occurred in the state during determinate periods of abusive rule or conflict, and making recommendations for their redress and future prevention."
} 
investigative process in which abuses of the past are examined to unearth the truth about them, in which victims and culpable offenders of these abuses are identified, and in which an authoritative national narrative about these events is produced. They aim to present a broad picture of certain human rights violations of international humanitarian law that occurred over a period of time. As Freeman (2006) acknowledges, TRCs are concerned with underlying causes and resulting consequences, and with the presentation of larger and comprehensive truths about the past. As forward-looking exercises, TRCs seek closure on the dark past through restitution and/or restoration programs for victims; fostering accountability, justice and reconciliation; and offering recommendations towards institutional reform to build a future human rights-friendly and democratic society. Rotberg (2000) sums up this dual mandate of TRCs as both preventive and restorative.

The history of TRCs is traced to Uganda in Africa as the first country to have created a body conceptually defined as a TRC. The literature, however, generally converges on the South American region as the place where many of the early TRCs were established (Kritz, 1995; Hayner, 2001; Sikkink and Walling, 2006; Freeman, 2006). Truth and Reconciliation Commissions emerged as part of the second phase of the transitional justice genealogy, and surfaced to symbolize forms of justice other than criminal or retributive justice. As a result of practical exigencies of political transitions in South America (i.e. immovable blanket amnesties) during the early 1980 s, other forms of non-retributive transitional justice became known. Truth and reconciliation commissions became the face of an approach devised to achieve a public accounting of how and why human rights crimes were committed. 
By their nature, TRCs are not designed for prosecution and punishment because they are not established on the same principles of retributive justice as the formal courts. They come, rather, to represent the notion of restorative justice for victims of human rights abuses. The TRC process emphasizes truth seeking, facilitates acknowledgement, apology and forgiveness, and promotes reparative measures, reform and reconciliation. Consequently, TRCs are one of the many, and arguably the most popular, of the processes that are established on the restorative justice ideas. ${ }^{69}$

\subsection{1: The Notion of Restorative Justice and the TRC-approach}

The debate about restorative and retributive justice in transitional justice processes was explored in Chapter 2. Nonetheless, the controversy over restorative justice in the literature on TRCs is expanded on below because of its fundamental significance for this study. The TRC-approach to transitional justice is restorative by process. The concept and its features as described above, particularly the victim-centered element, seek to promote restorative justice. In this current study, the inspired idea that underlies the policy transfer of the TRC-approach is the notion of restorative justice. In South Africa, Nigeria and Ghana, the argument for the TRC-approach was informed by the need for restorative, rather than retributive, justice.

Restorative justice is essentially about relationship-building following a violation. It seeks to correct such a breach and in so doing restore broken relationships. Llewellyn (2004), for instance, suggests that restorative justice is relational in nature. Its processes

\footnotetext{
${ }^{69}$ The following are identified as other processes that are inherently restorative: sentencing circles, victimoffender mediation, family group conferencing, non-custodial sentencing, and some customary law mechanisms.
} 
take into account victims, survivors, perpetrators, and the community in the pursuit of some levels of justice to repair the damage, promote trust-building, and reconciliation (Villa-Vicencio, 2004). Consequently, TRCs are argued to have therapeutic effects for victims of abuses because of their victim-centeredness (Llewellyn and Howse, 1999; Huyse, 2003; Llewellyn, 2006; United Nations, 2006). The storytelling process and the acknowledgment of abuses by offenders arguably can facilitate the psychological healing of victims, and thus restore them to society.

Further, proponents argue that the reparation programs that follow TRCs' work contribute toward restorative justice. Reparation policy is informed by the belief that all parties to a conflict have the opportunity to participate in resolving the dispute, and that the needs of victims, offenders and the community are taken into account, with the ultimate aim of restoring broken relations. Restorative justice recognizes the harm done, and seeks to address it and restore the relationship. The process toward the restoration and/or renewal of relationship has to be inclusive. Truth and reconciliation commissions are considered appropriate models for restorative justice because they are able to bring all parties and stakeholders into a forum to establish an understanding of human rights abuses, and they seek to determine the responsibility and obtain the accountability of those who committed these abuses, and develop appropriate plans for the restoration of future relationships (Llewellyn, 2006; Rushton, 2006).

However, some critics argue that the restorative justice produced by TRCs is of little to no consequence to victims (Call, 2004; Nesiah, 2006; Brahm, 2007). There is little tested evidence to back claims of the restorative healing power of TRCs. As Brahm observes, "no truth commission has provided the degree of support that exists in many 
clinical settings that might be more likely to facilitate healing" (2009:126). The restoration of relationships in the form of reconciliation has also become an albatross in the work of TRCs as its realization appears to be far remote in many societies after the work of TRCs. The meaning of reconciliation also has some ambiguity associated with it as it means different things to different people.

In addition to their weak healing power, critics suggest that TRCs have become an excuse for avoiding criminal justice for offenders of gross human rights abuses. Call (2004) argues that TRCs are a second best alternative to judicial punishment. Not only are TRCs labelled as a soft option, but they are described as coming at the expense of the prosecution of human rights abuses (Nesiah, 2006: 378). For victims of human rights abuses and for human rights activists, the lack of retributive justice may appear to be a mockery of justice. It may undermine future adherence to the rule of law, as the forgoing of punishment of human rights abusers could reinforce the perception that some persons are above the law (Brahm, 2007: 23; Huyse, 2003: 97-98).

In spite of these limitations of the restorative justice and their effect on TRCs, the approach has flourished worldwide as a legitimate, rather than "second best" approach, and continues to draw interest in Africa. The underlying restorative justice goals associated with it, in part, account for this interest.

\subsection{2: The TRC Goals}

Truth and reconciliation commissions have come to be associated with five broadly held goals: discovering, clarifying, and acknowledging past abuses; responding to specific needs of victims; contributing to justice and accountability; outlining 
institutional responsibility and recommending reforms; and promoting reconciliation to reduce tension and conflict over the past (Hayner, 2001: 24- 31).

To begin with, it is claimed that TRCs have the potential to establish general truths about the past by instigating public debate, and thereby incorporating the past into a society's history. The essence of this truth-seeking process is to establish an accurate and complete record for documentation and for public historical records. The public platforms and private statement-taking that TRCs offer victims, witnesses and perpetrators to tell their stories of human rights abuses are the main avenues for truthseeking. The platforms help to clarify contested and disputed truths about the past, and are also an opportunity for offenders to acknowledge these abuses. It is significant that in some cases the TRC work does not bring forth new truths about the past, but is a forum for the formal acknowledgment of already known truths. As Hayner (2001) suggests, such processes prevent denial of past abuse. Such a process facilitates the restoration of broken relationships because the forum it generates is able to bring former enemies together in ways that seek to address differences and acknowledge the harm done.

Second, TRCs have the goal of responding to the needs and interests of victims. As a non-retributive justice mechanism, TRCs are designed to focus on the victims of human rights abuses. Their ways of operating, including the collection of statements and testimonies from victims, offering platforms for hearings (either publicly or privately), and developing recommendations towards symbolic and non-symbolic reparations, have directed attention to victims rather than to alleged perpetrators. The overriding attention given to victims is to facilitate their healing from trauma and other psycho-social 
suffering caused by the abuses meted out to them with an objective of restoring their human dignity.

The public testimony aspect of TRCs' work recognizes the experiences of victims, especially the marginalized, in an attempt to restore their dignity in society. Hayner argues that restoring the dignity of victims may occur in two ways: the opportunity for victims to be heard can help them feel acknowledged and supported, and this appreciation can facilitate inner healing; second, the public hearings can help identify needs for short-and long-term psychological services and support for victims through targeted recommendations in their final reports (Hayner, 2001: 152-153).

Third, it has been claimed that TRCs contribute to justice and accountability. They focus less on retributive and more on restorative justice. It is argued that TRCs, through the truth-seeking and truth-telling processes, provide an avenue for some form of accountability. Their processes emphasize accountability for past wrongs and, in so doing, contribute to laying a firm foundation for respect for human and individual rights and for the rule of law. For example, Mendeloff (2004) suggests that in democratizing societies the work of TRCs may contribute to creating the needed platform for inculcating the rule of law [by way of accountability] in a society, and also for demystifying the culture of impunity that characterized the past era.

Although TRCs are more interested in restorative justice, they can also contribute to retributive justice. They do investigate the involvement of the abusers in human rights crimes. As Freeman and Hayner observe, the work of TRCs may complement criminal prosecution processes through gathering information in their findings, organizing and preserving evidence relating to certain crimes by identifiable individuals that can be used 
by prosecutorial authorities for future criminal trials (2003: 125-126). For instance, Kritz (2002b) asserts that the work of TRCs in Argentina, Chile and Guatemala has subsequently proven significant for attempts at prosecution in these countries.

Fourth, a noteworthy aspect of TRCs is their forward-looking mandate. The contributions TRCs make to institutional, constitutional, legal and policy reforms, proponents claim, allow transitional societies to achieve the long-term social, economic and political objectives that are essential for preventing civic and/or democratic collapse in the future. Reforming abusive institutions is imperative because it eliminates the conditions that permitted the previous state of widespread atrocities and repression. In nascent democratic societies, especially those emerging from conflict or authoritarian regimes, these recommendations by TRCs are widely acclaimed as effective in strengthening democratic institutions and good governance practices and values. The investigative role of TRCs is thought to give them a unique opportunity to make relevant recommendations toward institutional reforms, including the creation of new institutions to protect human rights, dismantling or restructuring institutions prone to abuse, removal of abusers from public positions, reforming and professionalizing the security services, and promoting programs for human rights training for public officials.

Finally, TRCs have the goal to promote national reconciliation. Brahm (2009) calls this goal the "holy grail" of most TRCs. The processes that are involved with the work of TRCs, including truth-seeking and truth-telling, and healing through story-telling and reparative mechanisms, create the platform for victims and perpetrators, or groups on different sides of social divides, to forge reconciliation. Hayner (2001) observes that by focusing on and responding to victims' needs through the offer of restorative justice, the 
processes of reconciliation and inclusiveness are promoted in deeply divided societies through the work of TRCs. The reconciliation agenda of TRCs is also premised on the ability of its truth-seeking process to bring popular consensus over disputed and pivotal historical events. Freeman and Hayner, for example, suggest that TRCs can advance tolerance and understanding by facilitating conflicting parties' listening to each other's grievances and accounts of suffering, which can help build empathy in order to prevent vengeance (2003: 126).

It is thus evident that TRCs are designed to achieve wide-ranging goals. Nevertheless, these goals associated with TRCs are in themselves not certain. The goals and claims associated with the TRC-approach have stimulated debate among scholars, researchers and practitioners. The subjects of the debates range from the ability of TRCs to discover the truth about the past and advance healing to their ability to uphold accountability and justice and to promote reconciliation. How TRCs seek the truth, how much truth is inquired into, what kind of truth is produced by them, whether truth acknowledgment is enough for closure and healing, and how reconciliation is achieved have continuously been debated (Ignatieff, 1996; Mamdani, 2000; Hayner, 2001; Call, 2004; Boraine, 2006; Rushton, 2006; Brahm, 2007; Sachs, 2009). These are important debates in the literature on TRCs. However, they are not the focus of this current study.

Suffice to observe, however, that the degree to which TRCs are able to advance the goals they claim to possess is sharply contested. As Hayner clearly notes, "the complexity and sensitivity of the task have meant that many commissions have trouble reaching these goals" (2001:31). In other words, the capacity of TRCs to deliver on these goals has become a source of concern. Besides, there is not enough empirical knowledge 
to support the claims with which TRCs are associated (Thoms, Ron and Paris, 2008; Brahm, 2009). Yet they have proliferated globally. The varied expectations and lofty goals associated with TRCs have become the compelling force for countries to adopt them for the transitional justice process. As Brahm (2009) observes, the assumption is created that the work of TRCs helps to advance human rights promotion, promote peace and stability, facilitate healing and reconciliation, and contribute to strengthening democracy; but there is no significant evidence to support these claims.

\section{2: The Global Proliferation of the TRC-Approach}

Truth and reconciliation commission approaches to transitional justice started spreading in transitional societies in South America in the 1980s. It began with Bolivia in 1982, and that was followed by Argentina in 1983 and Chile in 1990. As was stated in the first chapter, between 1974 and 2003 TRCs established worldwide totalled 25 (Freeman and Hayner, 2003: 125). As of 2010, 40 official TRCs were created worldwide since 1974 (Amnesty International, 2010). ${ }^{70}$ The Argentina experience was the first major TRC with sufficiently enduring impact to set off a TRC "justice cascade" at the regional and global levels (Sikkink and Walling, 2006). The earlier TRCs, in Uganda (1974) did not make its final report public and Bolivia (1982) did not produce final report of its findings. It was the Argentinean TRC that provided useful lessons for subsequent ones -- four of which were established in the region during the decade (Sikkink and Walling, 2006: 308).

\footnotetext{
${ }^{70}$ The United States Institute of Peace TRC database confirms this global proliferation of TRCs. Some countries have had more than one TRC. The outcomes have varied, with some producing reports and others not. See http://www.usip.org/resourcestools/latest?filterl =\%2A\%2AALL\%2A $\% 2$ A\&filter0=\%2A $\% 2$ AALL $\% 2 A \% 2 A \& f i l t e r 2=2222 \&$ filter $3=\% 2$ A\%2AALL\%2A\%2A\&filter4=Data for. Sourced on November 302009
} 
Truth and reconciliation commissions created since 2005 have included the Republic of Korea (2005), Liberia (2005), Canada (2007), Ecuador (2007), Solomon Islands (2008), Kenya (2008), Togo (2009), and Mauritius (2009). The global explosion has included both official and unofficial TRCs. ${ }^{71}$

Famous in the developing world, TRCs have been created in the developed societies as well, the best known being the Canadian TRC on the Indian Residential Schools and the unofficial TRC in 2004 in Greensboro, North Carolina in the United States of America. ${ }^{72}$ It is, however, in the developing world that TRCs have spread. In a dataset of TRCs established between 1974 and 2004, Sikkink and Walling observe that South America and Africa together accounted for 74 per cent, with the remaining 26 per cent representing the rest of the world (2006: 309). According to Sikkink and Walling (2006), Africa followed South America closely in the number of TRCs established during this period, with South America accounting for 38 per cent and Africa 36 per cent. The study also reveals that the rate of TRC creations in Africa, as in South America, suggests an upward trend. Indeed, since the establishment of the South African TRC in 1995, TRC formation in Africa has multiplied, spreading across all parts of the continent.

\footnotetext{
${ }^{71}$ The unofficial TRCs are not government-initiated inquiries, and are usually undertaken by civil society organizations, particularly human rights movements, to discharge similar functions. Prominent among these unofficial TRCs have been the 1994 Cambodia Genocide Program, initiated by the Cambodia Documentation Center, an NGO, to study and safeguard information about the human rights violations in Cambodia between 1975 and 1979; the 1995 Guatemala Recuperation of Historical Memory started and coordinated by the Catholic Church to unofficially compile testimonies of victims of the Guatemala civil war between 1960 and 1999; and the 2005 Iraq History project, initiated by the Human Rights Law Institute of DePaul University College of Law in the USA to collect testimony about repression committed by the erstwhile Ba'ath party of Saddam Hussein during the period 1968 to 2003. Bickford (2007) discusses in detail the work of some of these unofficial TRCs.

${ }_{72}$ The TRC in the USA addressed divisions and hostility lingering since the 1979 shooting deaths of civilian demonstrators by the Ku Klux Klan and the American Nazi Party.
} 


\subsection{1: Africa and the TRC Projects}

Roughly 17 Commissions of Inquiries styled as TRCs of different kinds were formed in Africa between 1974 and 2009 (See Table 2 below). It is instructive that some countries, like Uganda, have had two different TRCs. ${ }^{73}$ of these $17 \mathrm{TRCs}, 12$ were established after the 1995 South African Truth and Reconciliation Commission (SATRC). There is no doubt that the externally perceived success of the South African TRC has contributed to the reproduction of this approach to transitional justice in Africa and elsewhere. As was recently stated elsewhere, "while truth commissions have a long history in Africa, the idea has gained popularity following the perceived success of the South African model" (Center for Conflict Resolution, 2007: 15).

The list of TRCs in Africa includes those that were formed as part of internationally supervised peace agreements and others that were consciously formed by domestic political actors. The TRCs in Africa also represent both high profile TRCs, such as the South African, Sierra Leonean, and Liberian versions, and low profile TRCs, including those formed in Ghana, Nigeria, and Chad. Some TRCs have produced and publicized their reports, and others have not.

It would not be incorrect to suggest that the TRC-approach to transitional justice has caught on with African countries. As Bosire (2006) argues, transitional justice measures in Africa, including TRCs, continue to be laden with high expectations. The upward trend of this phenomenon on the continent seems likely to continue in the near future, with recent announcements of TRCs in Cote d'Ivoire and Burundi, to cite a few. Several arguments have been proffered in support of Africa's interest in the TRCapproach. It has been suggested that TRCs create the space for a national conversation

\footnotetext{
${ }^{73}$ It must be noted, however, that the two truth commissions focused on different abuses.
} 
that involves all parties to conflicts, from grassroots to leadership (Center for Conflict Resolution, 2007). In addition, the TRC process fosters wider public participation than criminal trials.

It is further argued that the principles underlying the continent's political organization, the African Union (AU), also encourage this restorative justice form of transitional justice. Villa-Vicencio (2009) suggests that the AU seeks a restorative approach to justice that supports inclusivity and reform, rather than radical change. He argues further that the AU modus operandi, which is captured in the Constitutive Act, reflects the approach of communal and participatory African mechanisms for justice and reconciliation. $^{74}$

\footnotetext{
${ }^{74}$ While this assertion may be generally true, there are other $\mathrm{AU}$ mechanisms such as the African Court for Justice and Human Rights that are not necessarily communal and participatory.
} 
Table 2: List of Official TRCs in Africa from 1974 to 2009

\begin{tabular}{|c|c|c|c|c|c|}
\hline Country & Name of TRC & $\begin{array}{l}\text { Year of } \\
\text { Establishment }\end{array}$ & $\begin{array}{l}\text { Period of } \\
\text { Investigations }\end{array}$ & $\begin{array}{l}\text { Completion } \\
\text { Year }\end{array}$ & $\begin{array}{l}\text { Submission of Report \& } \\
\text { Publicity }\end{array}$ \\
\hline 1. Algeria & $\begin{array}{l}\text { Ad hoc Inquiry Commission in Charge } \\
\text { of the Question of Disappearances }\end{array}$ & 2003 & $1992-1999$ & 2005 & $\begin{array}{l}\text { Report submitted but kept } \\
\text { confidential in Parliament }\end{array}$ \\
\hline 2. Chad & $\begin{array}{l}\text { Commission of Inquiry on the Crimes } \\
\text { and Misappropriations Committed by } \\
\text { Ex-President Habre and his } \\
\text { Accomplices }\end{array}$ & 1990 & 1982-1992 & 1992 & Yes \\
\hline 3. Cote d'Ivoire & $\begin{array}{l}\text { Mediation Committee for National } \\
\text { Reconciliation }\end{array}$ & 2000 & 2000 & 2001 & No \\
\hline $\begin{array}{l}\text { 4. Democratic } \\
\text { Republic of Congo }\end{array}$ & Truth and Reconciliation Commission & 2003 & $1960-2003$ & 2007 & Yes \\
\hline 5. Ghana & National Reconciliation Commission & 2002 & $1957-1993$ & 2004 & Yes \\
\hline 6. Kenya & $\begin{array}{l}\text { Truth, Justice, and Reconciliation } \\
\text { Commission }\end{array}$ & 2008 & $1963-2008$ & $\begin{array}{l}2011 \\
\text { (expected) }\end{array}$ & TRC still in operation \\
\hline 7. Liberia & Truth and Reconciliation Commission & 2005 & $1979-2003$ & 2009 & Yes \\
\hline 8. Mauritius & Truth and Justice Commission & 2009 & $\begin{array}{l}\text { From colonial } \\
\text { period to } \\
\text { present }\end{array}$ & $\begin{array}{l}2011 \\
\text { (expected) }\end{array}$ & Ongoing \\
\hline 9. Morocco & $\begin{array}{l}\text { The Equity and Reconciliation } \\
\text { Commission }\end{array}$ & 2004 & $1956-1999$ & 2005 & Yes \\
\hline 10. Nigeria & $\begin{array}{l}\text { Human Rights Violations Investigations } \\
\text { Commission }\end{array}$ & 1999 & $1966-1999$ & 2002 & $\begin{array}{l}\text { Report produced but never } \\
\text { officially made public (civil } \\
\text { society released report to } \\
\text { public) }\end{array}$ \\
\hline 11. Rwanda & $\begin{array}{l}\text { National Unity and Reconciliation } \\
\text { Commission }\end{array}$ & 1999 & $1990-1994$ & $\begin{array}{l}\text { Since } 2002 \\
\text { has become a } \\
\text { permanent } \\
\text { body aimed at } \\
\text { facilitating }\end{array}$ & $\begin{array}{l}\text { No final report yet but has } \\
\text { issued, publicly, various } \\
\text { interim reports titled annual } \\
\text { reports e.g. Reports on } \\
\text { Unity and Reconciliation }\end{array}$ \\
\hline
\end{tabular}




\begin{tabular}{|c|l|l|l|l|l|}
\hline Country & Name of TRC & $\begin{array}{l}\text { Year of } \\
\text { Establishment }\end{array}$ & $\begin{array}{l}\text { Period of } \\
\text { Investigations }\end{array}$ & $\begin{array}{l}\text { Completion } \\
\text { Year }\end{array}$ & $\begin{array}{l}\text { Submission of Report \& } \\
\text { Publicity }\end{array}$ \\
\hline & & & & reconciliation & $\begin{array}{l}\text { Forums, and on Student } \\
\text { Clubs for Unity and } \\
\text { Reconciliation }\end{array}$ \\
\hline 12. Sierra Leone & Truth and Reconciliation Commission & 2000 & $1991-1999$ & 2004 & Yes \\
\hline 13. South Africa & Truth and Reconciliation Commission & 1995 & $1960-1994$ & $1998 / 2003$ & Yes \\
\hline 14. Togo & $\begin{array}{l}\text { Truth, Justice, and Reconciliation } \\
\text { Commission }\end{array}$ & 2009 & $1959-2005$ & Ongoing & Ongoing \\
\hline 15. Uganda 1 & $\begin{array}{l}\text { Commission of Inquiry into the } \\
\text { Disappearance of People in Uganda }\end{array}$ & 1974 & $1971-1974$ & 1975 & $\begin{array}{l}\text { No (but confidential report } \\
\text { given to president) }\end{array}$ \\
\hline 16. Uganda 2 & $\begin{array}{l}\text { Commission of Inquiry into Violations } \\
\text { of Human Rights }\end{array}$ & 1986 & $1962-1986$ & 1994 & $\begin{array}{l}\text { Yes, but not widely } \\
\text { disseminated }\end{array}$ \\
\hline 17. Zimbabwe & Commissions of Inquiry & 1985 & 1983 & 1985 & $\begin{array}{l}\text { Report produced but not } \\
\text { made public/kept } \\
\text { confidential }\end{array}$ \\
\hline
\end{tabular}

Compiled with background information from the following sources: Hayner (2001); Fombad (2002); Villa-Vicencio and Doxtader (2004); Freeman (2006); Sikkink and Walling (2006); Brahm (2009); Amnesty International (2010); USIP Truth Commission Digital Collection (2010). 
Similarly, the principles of one of the AU's special projects, the New Partnership for African Development (NEPAD), emphasise conciliation methods in promoting postconflict reconciliation, rehabilitation and reconstruction as cardinal beliefs in the advancement of peace, security, democracy and political governance in Africa (NEPAD, 2001:16). It may therefore come as no surprise that the AU decided to sever all relationships with the ICC following the indictment of the President of Sudan, Omar Hassan Ahmed El Bashir, by the ICC Pre-Trial Chamber (African Union, 2009). In rejecting the ICC demands, the AU affirmed that the Constitutive Act provides the model and the method for combating impunity and promoting democracy, as well as rule of law and good governance on the continent. ${ }^{75}$

Although the subject of AU's resistance to the ICC is not the focus of this study, it is important to state, however, that the issues around AU's apprehension with the ICC have more to do with territorial independence and peaceful resolution of conflicts than the restorative and retributive justice debate. It appears that the $\mathrm{AU}$ views the restorative justice model as more appropriate to conflict management and its associated peaceful resolution than the criminal justice process. One African observer, for example, suggests that African societies are better off adopting this restorative justice process, relying on truth and amnesty, than they would be pursuing retribution. He argues further that the restorative justice process is more consistent with African tradition than the Western style of criminal proceedings (Kende, 2007: 140). This view, however, appears to be

\footnotetext{
${ }^{75}$ In the Sudan case the $\mathrm{AU}$ expressed concerns over the effects of the indictment on the peace process. To be sure, the AU Constitutive Act emphasizes conciliation and reconciliation methods to post-conflict accountability rather than the retributive process. It is noteworthy that the AU has for the most part shunned the retributive notion of justice in its leadership.
} 
inconsistent with the reality, as many victims of human rights abuses have indicated support for criminal justice processes (Pham et al., 2005; Vinck et al., 2008). ${ }^{76}$

The interest in the TRC-approach in Africa is also informed by the view that the SATRC may have contributed to a smooth and peaceful post 1994 political transition. Many African countries contemplating TRCs see the SATRC as a "magic bullet" that transformed South Africa into the present rainbow nation. Therefore, if it worked for South Africa, with its complex apartheid politics, it would work anywhere. Indeed, the ability of South Africans to forge unity and to manage their democracy following the demise of apartheid rule has been traced, in part, to the work of the TRC. It is suggested that the highly publicized notion of a rainbow nation is largely deemed to have emerged from the work of the SATRC (Center for Conflict Resolution, 2007).

It appears that African countries, following the South African experience, are informed largely by this perceived success story in terms of the Commission's role in the political transition. As Kukah (2004), a member of the Nigerian TRC, observed, many observers outside South Africa believed that the Commission had brought peace, harmony and justice. This perception has been aided by the projection of this nonretributive approach by some members and leaders who were associated with the SATRC. ${ }^{77}$ The sharing of the SATRC story not only in Africa but globally by these high profile individuals has contributed to implanting the TRC experience in the minds of many African societies and elsewhere.

\footnotetext{
${ }^{76}$ Empirical evidence suggests that these African traditional justice and reconciliation initiatives do not attract broad support from victims of human rights abuses.

${ }^{77}$ I am referring to such individuals as Archbishop Emeritus Desmond Mpilo Tutu, the former chair of the TRC, and his deputy, Alex Boraine, who is the founder of the ICTJ. Yasmin Sooka, a member of the SATRC, served on the Sierra Leonean TRC.
} 
Unfortunately, while TRCs have stirred up interest, outcomes from their work in Africa have been a mix of affirmation and disillusionment. Fombad (2002) suggests that the experience of TRCs in Africa has been positive for peacebuilding. He argues that they are a flexible instrument for managing Africa's numerous open and latent conflicts through the emphasis on restorative justice (Fombad, 2002). Nonetheless, the deficiencies associated with TRCs in Africa have also been acknowledged. The absence of an inclusive and consultative approach to the policy formulation process and the difficulties TRCs have initiating prosecution of alleged perpetrators of human rights abuses following their work are some of the defects that have been identified (Fombad, 2002; Bosire 2006). Bosire (2006), for example, suggests that the expectations that have welcomed TRC institutions in Africa have not been met comprehensively. She describes TRC experiences in Africa as "overpromised, [and] underdelivered", highlighting the mitigating realities of institutional deficiencies, poor leadership, poverty, and the chasm between the government and the people (2006).

Interestingly, although all the TRCs created in Africa have faced the abovementioned challenges equally, they have not all dealt with them with equal degrees of success. The performance of TRCs globally has stimulated scholarly interest in evaluating their outcomes. Some studies have focused on the dearth of empirical knowledge about the outcomes and impact of TRCs and, broadly, transitional justice approaches as a whole (Pham and Vinck, 2007; Thoms, Ron and Paris, 2008). Others have touched on tools, measurements and parameters for assessing the outcomes of TRCs based on their values, claims, and impact on societies (Hayner, 2001; Hamber, 2002; Zyl, 2002; Borer, 2004; OHCHR, 2006; Brahm, 2007; 2009). 
Significantly, the proliferation of TRCs in the recent past has aroused interest in their impact on societies and on the lives of individuals who are the beneficiaries of the policy on transitional justice. Further, there is interest in the political processes that result in the policy formulation processes of transitional justice approaches; this study is situated in that interest. It focuses on how the policy on the TRC-approach to transitional justice is formulated and the convergence, if any, among local, national and international actors in the policy process. Accordingly, the study's conceptual definitions of success and failure of the TRC policy transfer process are informed by operations, products and outcomes of the TRCs.

\section{3: Conceptualizing and Defining TRC Policy Transfer Success or Failure}

The conceptual definition that this study develops to analyse TRC policy transfer success or failure extends beyond that provided by Dolowitz and Marsh, particularly its subjective element, in their policy transfer model. It also takes from Hayner's (2001) categorization of means of evaluating the success of TRCs. The definition put forward is captured in a six-phase multi-dimensional variable as follows: the establishment of the TRC, the TRC operation, co-operation and support from witnesses for the TRC, production of the TRC final report, government acceptance of and public dissemination of the TRC report, and the implementation of all or some of the TRC recommendations in the final report. The path adopted is grounded in policy sciences and it is an attempt to contribute to the search for appropriate and comprehensive fashion of defining and determining policy success or failure, which remains one of the contentious issues in policy sciences. 
Significantly, when one examines the literature on TRCs, there are not enough empirically-based studies on the policy analysis dimension of the approach to transitional justice. Indeed, the limited existing empirical studies on TRCs have concentrated on implementation and impact to the neglect of the policy formulation intricacies. Researchers and practitioners have been interested in the degree to which TRCs accomplish their mandates in the areas of peacebuilding, healing, reconciliation, democratization, and development, among many other themes (Hamber, 2002; Zyl, 2002; Boafo-Arthur, 2006; Brahm, 2007; 2009). Brahm, for example, observes that in the 1990s, TRCs' success was largely defined as "the degree to which a commission fulfilled the duties assigned to it" (2007: 17). Further, the political will to promote an agenda for national reconciliation and the mere acceptance of guilt by some perpetrators were seen as commendable signs of success for TRCs (Boafo-Arthur, 2006).

Since this study is focusing on policy formulation outcomes and not the entire stages of the policy formation process of the TRC-approach, it takes a different path from some of the propositions developed in some of these existing studies. Nonetheless, it is important to point out that because it is sometimes difficult to separate one stage of the policy formation chain from one another, although methodologically legitimate to focus on one stage, the conceptual definition provided to analyse policy transfer success or failure of the TRC-approach will have elements of its variables associated with other stages of the policy formation chain. In other words, the conceptual definition for the policy transfer success or failure of the TRC-approach, while focusing on the formulation stage of the policy formation process, will by the nature of policy formation have 
implications for the other parts of the policy process, particularly the implementation phase, that are not the main focus of this investigation.

Consequently, the six-phase multi-dimensional variable -- the establishment of the TRC, the TRC operation, co-operation and support from witnesses for the TRC, production of the TRC final report, government acceptance of and public dissemination of the TRC report, and the implementation of all or some of the TRC recommendations in the final report -- covers aspects of the agenda-setting, decision-making, operational or implementation, and termination phases of the TRC policy formation process and outcomes. The policy formulation processes of TRCs, particularly if they result from policy transfers, have significant impact on these TRC outcomes. Hence, the study's conceptualization of policy transfer success or failure considers what became of the TRCs from inception to termination.

In policy sciences, defining policy success or failure has always been difficult (Howlett and Ramesh, 2003; Pal, 2006). For example, a whole policy may sometimes be judged a success or failure, while in some instances the policy programs or aspects of them are described as a success or failure. In some situations policies get formulated, but remain as statutes without any action towards establishing corresponding institutions to implement the objectives in the formulated policy. In other instances, the implementation of a formulated policy is curtailed for several reasons, including change of regime or financial constraints. Judging success or failure in such conditions becomes challenging. Moreover, assessment of policy success has been subjective. It usually depends on the beliefs or intentions of government actors, which in some instances may be unclear or relative in the sense that there is no agreed-upon instrument for measuring them. The 
subjectivity element, either on the part of policy actors or beneficiaries of the policy, influencing policy design and its outcomes has compounded the difficulty of defining the success or failure of public policies.

To respond to the deficit in the prevailing policy science discourse regarding definition of policy success or failure, and as it particularly concerns the TRC-approach, the study borrows from Hayner's (2001: 252) three different categories -- process, product and impact - for evaluating the success of TRCs. ${ }^{78}$ In her contribution to the discourse on how to evaluate TRC outcomes, Hayner suggests that the process category should consider the degree to which the TRC engages the public in understanding the truth, the extent to which the TRC is able to gain full participation from all actors, including former perpetrators, and the extent that its work is supportive of victims; the product part should examine the quality and nature of reports produced by TRCs, the degree of truth that was disclosed, and the nature of recommendations made toward reparation and reforms; while the impact category, which focuses on post TRC, should consider the long-term effect of the work of the TRC, such as reconciliation, healing, reform, acknowledgment and apology from perpetrators, distribution of final and the implementation of fundamental recommendations in the report.

Hayner's three-dimensional classification is broad and useful. It helps to divide the entire gamut of the TRC-approach into phases in its life. However, her classification does not clearly lend itself to the policy formation cycle. It does not allow one, for example, to apply it to assess the policy formulation stage of the policy formation process. Her classification is more associated with the implementation and evaluation

\footnotetext{
${ }^{78}$ It must be noted that Hayner did not elaborate on this categories except to briefly state each category of what the focus should be.
} 
stages. In addition, some of her elements for assessment, such as reconciliation, do not manifest soon after the TRC completes its work -- reconciliation is not a one-off event but a long process. Drawing from Hayner's proposals, this study conceptualizes and defines a TRC policy transfer success, as it relates to the policy formulation stage of the policy formation cycle, along the six phases in the form of a scale. As stated above, this definition will have elements of it connected to the other stages of the policy formation cycle, some of which are captured in Hayner's categories.

Accordingly, the conceptualization of the success or failure of the TRC policy transfer process is not restricted to the adoption of the policy of the TRC, its work and completion as viewed by government policy actors; it is also a matter of the extent to which TRCs: received cooperation from key persons, including victims, witnesses, and alleged perpetrators; produced a final report that was made public and widely disseminated; received broad acceptance of the report's findings and recommendations from victims and the society in question; and witnessed the recommendations made in the report being partly or wholly implemented. The ability of TRCs to be able to do all these is a matter of its policy formulation processes and how their mandates were structured. The six-phase conceptualization thus presents the success or failure of the TRC-approach policy transfer as occupying a continuum, with degrees of success (and, reflexively, of failure), and not as a dichotomy of the two extremes. The six phases is captured in Table 3 below for easy comprehension. 
Table 3: Conceptual Definition of the Six-Dimensional Variables for Success of the TRC Policy Transfer Process

\begin{tabular}{|l|l|c|}
\hline Phases & Variables & $\begin{array}{l}\text { Degree of Success of } \\
\text { Failure as they } \\
\text { relate to the 6 } \\
\text { phases }\end{array}$ \\
\hline Phase 1 & TRC Establishment & Success \\
\hline Phase 2 & TRC Operations & \\
\hline Phase 3 & TRC Receives Cooperation from Witnesses and Key Persons & \multirow{2}{*}{ Partial Success } \\
\hline Phase 4 & TRC Production of Final Report & \\
\hline Phase 5 & TRC Report Accepted by Government and Publicly Disseminated & Partial Failure \\
\hline Phase 6 & TRC Recommendations Wholly or Partially Implemented & \\
& & \\
\hline
\end{tabular}

${ }^{79}$ This column captures the degree of success or failure as they apply to the six phases individually. They do not reflect correspondingly as they appear in the table. 
In this model, the capacity of a formulated truth commission project to achieve all the six phases constitutes TRC policy transfer success, while a total failure means not achieving any of them. Between the two extremes are degrees identified as success, partial success, partial failure ${ }^{80}$ and failure as they pertain to each of the six phases. The conceptual definition proposed in this study for assessing TRC policy transfer outcomes is less concerned with the detailed operational mechanics developed by the TRC institutions to achieve their stated policy goals. It is also less focused on the impact of the TRC work. ${ }^{81}$ Further, the definition makes it possible to investigate the processes involved in the TRC-approach policy transfer rather than the implementation of the transferred policy. By adopting this approach, the subjectivity element associated with Dolowitz and Marsh's (2000) original definition of policy transfer success, which revolves around the perceptions by key official actors of the achievement of set aims by a government that is engaged in the transfer, will be eliminated.

The conceptualization of TRC policy transfer success as presented in the preceding discussion is by no means comprehensive, and does not address fully the difficulty of establishing clear standards for measuring policy success or failure. The current study also recognizes the concern over the advisability of delinking the policy formulation stage from policy implementation in defining and assessing the success or failure of a public policy. While this concern may be informed by what the current literature on policy science dictates, conceptually, analytically and heuristically, the

\footnotetext{
${ }^{80} \mathrm{By}$ partial success and partial failure are meant the levels of completeness in the set target or act and vice versa.

${ }^{81}$ The import of this conceptualization is in the manifestations of these phases, and not necessarily the contents, impact or desirability. Thus, for instance, the presence of key persons before the Commission does not take into account how truthful or helpful their testimonies were, but the ability of the TRCs to invite persons considered relevant to their work; similarly, the implementation of recommendations is viewed from the point of view of the actions of the government, and not the adequacy (for example, quantum of monetary compensation) and popular reception to their implementation.
} 
aspiration to study policy science in its stages or sub-processes is a perfectly legitimate one (Howlett and Ramesh, 2003).

Moreover, analysing the policy stages on their own merit, rather than leaving the entire examination of the policy process to the evaluation stage, ${ }^{82}$ which most of the time focuses on the implementation stage, is helpful in understanding the intrigues that are often associated with policy process. As Howlett and Ramesh note, investigating subprocesses of the policy cycles facilitates the understanding of the public policy process (2003: 245). The object of focusing on the TRC policy formulation stage of the policy cycle in this research is to elaborate on our understanding of background conditions and dynamics that inform the policy formulation of the TRC-approach to transitional justice. These background conditions may have an adverse or a favourable impact on implementation of the policy mandates, and, indeed, on the goals of TRCs.

The conceptualization of policy transfer success or failure developed in this research, particularly in the absence of any meaningful definition of or criteria for determining a policy transfer success, is a modest attempt to stimulate and contribute to the discourse on the TRC policy transfer and formulation processes. Having such a definition is imperative in order to establish clear criteria and indicators with which to analyse an instance of TRC policy transfer in domestic politics. With the conceptual tools for assessing the TRC policy transfer outcomes thus formulated, the next section presents the policy transfer of the TRCs in the three selected cases.

\footnotetext{
${ }^{82}$ The evaluation phase of policy process refers to the stage where a determination is made about how a particular policy unfolded during implementation. It usually involves measuring the means extended to achieve set objectives in a formulated and implemented policy (Howlett and Ramesh, 2003; Pal, 2006).
} 


\section{4: Policy Transfer of TRCs in South Africa, Nigeria, and Ghana}

The policy transfer of the TRC-approach in South Africa, Nigeria and Ghana is examined in this section. The three informing questions are: Did the TRC policy transfer occur? What was transferred? And what degree of transfer occurred? Each of the case studies begins with a profile of the TRC, with emphasis on the establishment and work, followed by the three questions around the policy transfer process. It ends with the TRC outcomes.

\subsection{1: The South African TRC (1995-2003): Establishment and Work}

The SATRC was established in 1995 by an Act of Parliament to investigate gross human rights violations during the era of racist apartheid rule. Specifically, the Act (No 34) was passed by the South African Parliament on May 17, 1995 and assented to become law by the President, Nelson Mandela, on July 19, 1995. The objectives of the SATRC were to promote national unity and reconciliation in a spirit of understanding that transcends the conflicts and divisions of the past (Hamber, 2002; Doxtader and Salazar, 2007). Unlike the TRCs before it, the South African process took the form of parliamentary creation. The SATRC legislative framework, the Promotion of National Unity and Reconciliation Act (No 34), tasked the SATRC with seeking and establishing a full and reliable record of human rights violations between 1960 and 1994, when apartheid rule was official and resistance to it was entrenched in South Africa. According to Hayner, the Act gave the SATRC a complex and sophisticated mandate and "carefully. balanced powers and investigatory reach" (2001: 41$)$. 
The SATRC Act (No 34), specifically, required the following main tasks to be accomplished:

- establish a complete picture of the causes, nature and extent of the gross violations of human rights committed from March 1, 1960 to May 10, 1994;

- conduct investigations and hearings into these violations;

- facilitate the granting of amnesty to persons who make a full disclosure of all relevant facts relating to acts associated with a political objective;

- establish and make known the fate or whereabouts of victims;

- restore the human and civil dignity of such victims by granting them an opportunity to relate their own accounts of violence;

- recommend reparation measures in respect of these violations; and

- compile a report providing as comprehensive as possible an account of the activities and findings of the Commission, recommending measures to prevent the recurrence of these abuses in the future. ${ }^{83}$

The mandate of the SATRC was the most complex of any TRC to date, as the tasks delineated above required it to compile a detailed record of the nature, extent, and causes of gross human rights abuses that took place during the period of apartheid rule, and to listen to and document the victims subjected to these abuses. In sum, the SATRC was mandated to achieve the five main broad goals of TRCs already outlined in this chapter: seek complete and accurate truths about the past; respond to victims' needs by restoring their dignity in society; promote accountability and restorative justice; recommend

${ }^{83}$ See the SATRC Act (No 34): The Promotion of National Unity and Reconciliation Act, 1995. 
institutional reforms; and contribute to reconciliation. The setting up of the SATRC was meant to contribute to the promotion of national reconciliation and to reshape South Africa's identity following the 1994 political transition (Center for Conflict Resolution, 2007).

In order to facilitate its work and, in particular, to accomplish the task of truthseeking, the Act granted the SATRC the power to grant amnesty to persons or alleged perpetrators (who were otherwise threatened with prosecution) who elected to disclose fully the truths about their involvement in historical human rights abuses. This power of amnesty distinguished the SATRC from any of the previously established TRCs. Indeed, it was one of the unique features of the SATRC that has made it an exemplar TRC around the world. Hayner describes this specific mandate as the "greatest innovation of the commission, and the most controversial of its powers" (2001: 43). Three sub-committees constituted the SATRC. It had the Human Rights Violations Committee (HRVC), which took charge of receiving statements from victims and witnesses, documenting the nature and extent of human rights abuses, and spearheading the public hearings. The Amnesty Committee, which was responsible for reviewing applications for amnesties, organizing hearings for these applicants and granting amnesties to individual applicants, was the second. The third committee was for Reparations and Rehabilitation (RRC), and it was tasked to design a package of recommendations towards reparation.

These committees were interconnected, and were the main institutions that carried out the SATRC mandate. The committees were assisted by four large offices around the country located in the cities of Cape Town, Johannesburg, East London and Durban (Hayner, 2001). In addition to these structures were the investigative unit and the research 
department, which worked in collaboration to conduct investigations and other enquiries into the complaints and statements submitted by victims and witnesses. Other operational structures included the media, legal, and counselling support units. The SATRC was made up of 17 commissioners and a staff of, at various times, 300 to 600 , including foreign interns, investigators and researchers (SATRC Report Volume One, 1998; Hayner, 2001; Fombad, 2002; Center for Conflict Resolution, 2007). It is on record that the SATRC had a running budget of about $\$ 18$ million per year for more than two years, with a total budget of more than $\$ 35$ million (Hayner, 2001). This budgetary allocation per year, coupled with the staff strength, made the SATRC the largest TRC to that time. ${ }^{84}$ Hayner, for example, states that the SATRC "dwarfed previous truth commissions in its size and reach" (2001: 41).

Following some initial delays after it was formally set up, the SATRC commenced work with investigations and hearings on April 15, 1996. The SATRC received statements from 21,519 victims and witnesses (SATRC Report Volume Six, 1998), between 1,800 and 2,000 (less than $10 \%$ ) of whom were heard in public throughout the country (Boraine, 2000; Wilson, 2000; Hayner, 2001; Fombad, 2002; Posel and Simpson, 2002; Center for Conflict Resolution, 2007). The country-wide public hearings took place in about 80 local communities (Backer, 2007). The Commission recorded around 38,000 types of gross human rights violations. Most $(90 \%)$ of the people who came before it represented the South African black population (SATRC Report Volume One, 1998). In addition to the individual hearings, there were stakeholder hearings, including ones for

\footnotetext{
${ }^{84}$ One account puts the annual budget at $\$ 9$ million (Fombad, 2002). Attempts to verify the exact budgetary allocation to the SATRC have had little success. In terms of budgetary size, however, the recently established Canadian TRC, with an estimated budget of $\$ 60$ million, may set the new record. See ICTJ (2008b).
} 
political parties, the legal community, businesses, the labour and health sectors, and faith communities. These institutional hearings were also new in the work of TRCs.

The HRVC and the RRC operated for close to three years, and concluded in 1998. On October 29, 1998 the SATRC submitted a five-volume interim report to the then President, Nelson Mandela, under whose watch the Commission was formed. The report contained much of the work of the HRVC and the RRC. The Amnesty Committee, however, continued until the early years of the 2000 s. It received over 7,000 applications. Following the conclusion of the work of the Committee, two additional volumes of reports, including aspects of reparations, were presented to the African National Congress (ANC) ruling government on March 21, 2003. Subsequently then President Thabo Mbeki issued a proclamation dissolving the Amnesty Committee, thus officially bringing to conclusion the work of the SATRC.

\subsubsection{1: The South African TRC: Did Transfer Occur?}

The generally received wisdom is that the SATRC was the first of its kind in the annals of TRCs. To be sure the SATRC was a novelty in its mandate, structure and operations; yet it was not new as a policy response to transitional justice problems. The TRC model was drawn from the previous experiences of TRCs from around the world. It was a case of policy borrowing from elsewhere. Kader Asmal, an academic who doubled as a leading member of the ANC, and who is generally acknowledged by many (Boraine, 2000a) as the architect of the SATRC, confirms that the South African TRC learned considerably from previous TRCs. He notes, for example, that "at that time what we had 
was Chile,...so we are going to find out from Chile" (Personal Interview, March 10, 2009).

Examining official documents and personal recollections of actors who were involved in the policy formulation of the TRC confirms that the emergence of the TRC was a product of policy transfer with lessons drawn from previous TRCs in South America and Africa. In the explanatory memorandum accompanying the Promotion of National Unity and Reconciliation Bill before Parliament in 1994, the government referred to the idea that a TRC is consistent with international experience and, hence, requires that gross violations of human rights be officially investigated and the truth about them be made known to the public. ${ }^{85}$ During the second reading of the Bill in Parliament, members made references to experiences of TRCs in other parts of the world, including South America (Republic of South Africa, 1995: 1354-1362). Further, lessons from commissions of inquiries set up by the ANC to investigate human rights abuses in its camps outside of South Africa informed the ruling party's support for the SATRC (Minister of Justice, 1995).

Beyond government and official documents, independent accounts by leading ANC officials, civil society actors and academic researchers confirm that the SATRC built on previous TRCs. For instance, Howard Varney, a human rights lawyer and a former staffer at the TRC, had this to say "yea, in fact the South Africans looked at what happened in South America" when asked how the TRC policy formulation came about (Personal Interview, October 10, 2008). Furthermore, the head of Governance and Policy think-tank in South Africa (the South Africa Institute of International Affairs), Tim

\footnotetext{
${ }^{85}$ This is clearly stated in the memorandum presented to the South African Parliament in May 1994. See http://www.justice.gov.za/trc/legal/bill.htm. Sourced on June 10, 2011.
} 
Hughes, while underscoring South African ownership of the policy formulation process, acknowledged that the SATRC, as a public policy instrument, was an act of borrowing. He concedes as follows: "remember that we took our TRC from Chile..." (Personal Interview, September 26, 2008).

In addition to the above, documentary evidence supporting the view that the SATRC was an act of policy transfer can be found in the works of: Sachs (2009), another leading member of the ANC; Boraine (2000a; 2000b), a leading civil society activist who assisted in the policy formulation process, and who ended up becoming the deputy chair of the TRC; Hayner (2000), a keen observer of TRCs; Zalaquett (2006), a member of the Chilean TRC; and academics such as du Toit (1997), Shea (2000), Christie (2000), and Graybill (2002).

The written and verbal records from these sources corroborate and establish that the SATRC typified a policy transfer formulation process. They do not, however, undermine the reality that the discourse on the policy formulation process was informed by contextual need and relevance. As one civil society activist remarked, "the TRC was developed out of the history of Latin America, but I think the nature in which the amnesty hearings were defined, that was a home grown. I think the idea of a Truth Commission was taken, but it was not taken and just implemented..." (Personal Interview with Carnita Ernest, October, 5, 2008). In a nut-shell, while the SATRC policy formulation process was associated with some uniqueness, compared to previous TRCs, and therefore making it an exemplar, this does not negate the fact that its policy formulation process resulted from an act of policy transfer. 


\subsubsection{2: The South African TRC: What was Transferred?}

In the Dolowitz and Marsh policy transfer model, nine objects are considered in the context of policy transfers. These objects range from policy goals to lessons from implementation. The TRC policy goals, administrative instruments for implementing the objects of the TRC and lessons learned formed the contents of the SATRC policy transfer. The restorative justice and reconciliation goals of TRCs were the overriding objectives that informed the SATRC. The purpose was not, as with the Argentinean experience, criminal prosecution of perpetrators (du Toit, 1997; Hayner 2011). In the Bill on the TRC presented to the South African Parliament, it was clearly stated: "We are seeking to create a process which will make it possible for us -- all South Africans -- to come to terms with our painful past with dignity and in a spirit of forgiveness, but with considerable acknowledgment and the need to provide reparation or compensation for the victims" (Minister of Justice, 1994:189).

As with all previous TRCs, the focus on investigating the truth about past gross human rights violations, putting victims of these violations at the centre of the process, providing compensation to the victims, and forging national reconciliation were the main goals that the Act (No. 34) mandated the TRC to pursue. As Piers Pigou observes with respect to the TRC goals, "the Latin American experiences were certainly drawn upon very heavily, both in terms of just truth recovery processes and the generic principle of truth recovery being an important part or option to pursue accountability objectives" (Personal Interview, September 16, 2008).

To pursue these goals, the administrative instrument of a quasi judicial commission of inquiry was also transferred. The South African TRC adopted the same 
approach, of a commission of inquiry with limited judicial powers, as with previous TRCs. The mechanics of this instrument, however, were a significant departure. To start with, the power of the SATRC to grant amnesty to perpetrators was conditional upon full disclosure of the truth. The same amnesty provision was associated with the Chilean TRC -- a prime source for the SATRC -- but it was a blanket one. This principle was an attempt at a creative response to the need to avoid indiscriminate blanket amnesty - a phenomenon that was associated with previous TRCs and had caused apprehension among human rights activists and other critics of TRCs because of the total impunity with which such an arrangement is usually associated.

In addition to the amnesty powers, the commission was granted wide powers of subpoena and of search and seizure in order to arrive at the complete truth. The three separate working committees -- the HRVC, the RRC and the Amnesty Committee -- with their own commissioners were novelties in the TRC context. The SATRC also departed from the closed door investigation process that had characterized previous widely known TRCs. ${ }^{86}$ Its public hearings, some televised nationwide, were unprecedented; ${ }^{87}$ they were meant to make the process victim-centred. Not only were the public hearings designed for victims, witnesses and perpetrators -- the institutional hearings also sought to widen the reach of investigations so as to understand institutional culpability of human rights crimes committed. Therefore, although the content of the policy transfer regarding

\footnotetext{
${ }^{86}$ The investigations processes of these previous truth commissions, to a large degree, were closed-door. Some, however, did have hearings in public.

${ }^{87}$ However, it is on record that the first known TRC, established in Uganda in 1974 and the subsequent 1986 truth commission, and some others in South America conducted most of its investigations through public hearings. See USIP TRC Digital Collection on http:/www.usip.org/resources/truth-commissionuganda-74 Sourced on March 17, 2010
} 
administrative technique was similar to that in previous TRCs, the manner in which the mechanism was structured and operated was a complete departure.

Consequently, another transferred content was the positive and negative lessons that were associated with previous TRCs. Asmal, for example, observes that the negative lessons, such as closed door operations and blanket amnesties, that were associated with previous TRCs -- in particular, the Chilean -- were avoided (Personal Interview, March 10, 2009). Pigou also emphasises the lessons drawn from past TRCs when he suggests that "the Argentine and Chilean experiences of in camera hearings was going to be unacceptable" for South Africa (Personal Interview, September 16, 2008). These lessons enhanced the effectiveness of the processes of the administrative body by which they sought to achieve the TRC goals. The new ideas that the South African TRC developed were generated from within by following lessons learned from the previous TRCs.

These innovations associated with the SATRC, as stated above, would propel it to international prominence. While its originalities were unprecedented in the history of TRCs, the innovations nevertheless did not take away the premise that the use of the commission of inquiry style as the TRC administrative technique was the same as previous TRCs. Certainly, these originalities associated with the SATRC do not suggest that it was the South Africans who were the first to employ the TRC-approach and its associated commission of inquiry method as a transitional justice policy option. They simply improved upon it. 


\subsubsection{3: The South African TRC: Degree of Transfer?}

Based on the above, the degree of TRC policy transfer that took place in South Africa is therefore best described as a "mixture". Dolowitz and Marsh explain mixtures as drawing from multiple lessons to design a required domestic policy. As discussed, the South African TRC policy transfer was informed by several experiences in South America and Africa. Thus, for example, while the Argentinean TRC had criminal prosecution as part of its goal, this was not a goal of the SATRC. The South African TRC extended the victim-centred process that was associated with the Chilean TRC. Moreover, the administrative instrument, structured as a quasi-judicial commission of inquiry, that was associated with the Ugandan, Argentinean and Chilean TRCs was also transferred. However, as demonstrated above, certain new features were introduced to the instrument.

The TRC policy goals and administrative method that emerged were gleaned from multiple experiences, and were situated in the particular domestic political and social contexts. The degree of TRC policy transfer in that case followed the assembling of manifold TRC experiences from around the world and the creation of a desired TRC policy for South Africans. Boraine (2000a), for example, observes that one would, upon reading the SATRC Act (No. 34), detect the influence of the contributions of previous experiences in South America. These lessons were adapted to suit South Africans' own particular needs and context. This process elevated the status of the TRC to "homegrown", and it is what Sachs acknowledges as emerging from the "very intense and specific South African needs" (2009: 66). 


\subsubsection{4: The South African TRC: Outcomes}

The entire operation of the South African TRC took eight years, from 1995 until the submission of final reports in 2003, upon receipt of which the ANC government officially dissolved it. The production of the seven-volume report of its work, which contained findings and recommendations, marked a significant milestone in the life of the TRC. The reports presented to the ANC were wholly accepted and made public by the government. This did not occur, however, without reservations and legal controversies. Prior to the submission of the first sets of reports in 1998, attempts in the courts were made by the last President of the apartheid regimes, Mr F.W. de Klerk, and the ANC (acting as a liberation movement and a political party) to contest some aspects of the Commission's findings on gross human rights violations that were critical of them. These attempts were, however, dismissed.

The SATRC reports, which were tabled in the South African Parliament by the ANC government, were extensively and publicly debated by members. The five-volume interim report was officially debated from February 25, 1999, when it was first presented, while the additional two-volume report was debated beginning April 15, 2003 (Boraine, 2000a; Salazar, 2004). The parliamentary debates on the reports were characterized by emotions, support and endorsement as well as critique, including some reservations from then-Vice-President Mbeki and some members of the ANC on aspects of the findings that were damning of the ANC in its activities as a liberation movement.

Despite the differences within and reservations on the part of the ANC leadership, the ANC collectively accepted the reports of the SATRC (Mbeki, 2003). While there were some reservations expressed by and uncomplimentary remarks from the general 
public on the products of the TRC, the public appears generally to have been satisfied with the final reports. For example, on the basis of an empirical survey (against varied degrees among race and other methodological caveats) Gibson (2004) suggests that the story produced in the SATRC report was generally accepted by many South Africans as accurately reflecting the collective memory and the truth about the apartheid past.

Although Gibson's study has received some criticisms for its methodology and contrasting findings (Backer, 2006; Chapman, 2009), the public, particularly victims, however, seems largely to endorse the reports produced by the Commission. To buttress this position, a survey of victims interviewed following the presentation of the first set of reports in 1998 showed they believed that the SATRC did "a pretty good or excellent job of providing a true and unbiased account of South Africa's history" (Backer, 2007: 179). ${ }^{88}$ Considering the volume of statements and testimonies that came before the SATRC -- over 21,000 victims' submissions and more than 7,000 amnesty applications from perpetrators -- the Commission received high levels of cooperation and support from South Africans.

The Commission managed to engage leading and key personalities from all sides of the conflict who were deemed relevant to pursuing its mandate. Persons such as thenVice President Mbeki, President Mandela's ex-wife, Winnie Mandela, and other members of the ANC leadership, as well as top commanders of the ANC armed wing, Umkhonto we Siziwe, honoured the invitations of the TRC. Similarly, Chief Mangosuthu Buthelezi and other leading people of the Inkatha Freedom Party (IFP), former President De Klerk,

\footnotetext{
${ }^{88}$ The study conducted between 2000 and 2001 by Backer involved a focus group discussion and randomly sampled survey that took place in Johannesburg and Cape Town. Using a database of the Khulumani Group, victims in this study were defined as those who qualified to submit statements to the SATRC, and included those who actually submitted and testified at the public hearings, those who submitted but did not testify, and those who did not submit statements to the Commission.
} 
former Foreign Minister Pik Botha, and other leaders of the then-apartheid ruling National Party (NP), operatives of the South African Defence Force (SADF) and intelligence officials of State Secret Council (SSC), including the notorious Eugene de Kock, did appear before the Commission. ${ }^{89}$ Perhaps the only exception on the list of high profile personalities was the former Defence Minister and former President of apartheid South Africa, P.W. Botha. Mr. Botha refused to appear before the TRC even after two subpoenas. The South African Court found him guilty of contravening sections of the SATRC Act (No 34) of 1995.

Not all aspects of the findings and recommendations in the TRC report have been implemented yet. The extent to which those aspects of the findings and recommendations have been implemented and, how well they have been, is a subject beyond the scope of this study. Suffice it to say that the post-SATRC period has witnessed some implementation of some aspects of the recommendations, such as institutional and human rights reforms, educational reforms, affirmative action for the black population and reparations that were directly stated in the report. The reparations component of the recommendations has witnessed some active implementation notwithstanding some levels of disappointments.

An aspect of reparations that has received greater attention is that of symbolic reparations, including memorials and remembrance, such as the annual national reconciliation day. The ANC government implemented the payment of interim monetary

\footnotetext{
${ }^{89}$ For persons associated with the intelligence and security community, it may be that the incentive of amnesty and the fear of future prosecution triggered their voluntary appearances before the TRC. Some key high-profile people, particularly from the National Party, who appeared did so only upon being subpoenaed. It is also instructive that some of the submissions before the TRC were negligible contributions to truth-seeking. In particular, the testimonies by former President de Klerk were viewed by many as inadequate (Boraine, 2000a).
} 
reparation to address urgent financial needs of some victims identified by the TRC. These payments, made through the Presidential Fund, sought to address medical, emotional and educational needs of victims. Payments to about 2,500 recipients, ranging from $R 2,000$ to $\mathrm{R} 6,000,{ }^{90}$ were made by the end of 1999 , and by the end of November 2001 about 17,000 victims had received interim reparations (Hayner, 2001; Fombad, 2002; Makhalemele, 2004; Burton, 2004). The ANC subsequently went ahead and paid one-off lump sum final monetary reparation of $R 30,000$ to each of the more than 16,000 listed victims. As of 2008 the South African Minister of Justice and Constitutional Development reported that about 15,866 of the listed victims had been paid by the government (Surty, 2008).

While this one-time payment of reparation was inconsistent with what the SATRC final report recommended, and was sharply condemned by a disappointed section of the populace, including victims' groups, civil society groups, and some members of the SATRC (Burton, 2004; Makhalemele, 2004; Nagy, 2006; Orr, 2006), it nevertheless fulfilled the promise of the government to follow up with the findings and recommendations in the report. The manner in which the ANC handled the monetary reparation process dismayed many victims and human rights groups. Some argue a lack of political will on the part of the ANC government to undertake a thorough and complete implementation of the SATRC recommendations (Walaza, 2000; Fombad, 2002; Trevor Ngwane Written Response, October 24, 2008). Nonetheless, the fact remains that the ANC government did not entirely renege on its promise to act on the SATRC report. It may have been slow in its action-oriented programs for implementation; but it cannot be

\footnotetext{
${ }^{90}$ The Rand is the name of the South African Currency. These amounts represented roughly the equivalent of between US\$330 and $\$ 1000$ at the exchange rate of the time (Hayner, 2001).
} 
said that there was no implementation of some aspects of the findings and recommendations. $^{91}$

The extent to which the SATRC was able to fulfil its task of seeking and recording the complete and accurate truth about the past, advancing justice and accountability, and promoting healing and reconciliation has been extensively discussed (Cherry, 2000; Mamdani, 2000; Fombad, 2002; Posel, 2002; Boraine, 2006; Backer, 2007; Kende, 2007; Sachs, 2009). On the one hand, the direct beneficiaries of the policy on the TRC, the victims of gross human rights abuses, are generally not satisfied with, indeed are perturbed by, the outcomes of the SATRC, especially when it comes to the recommendations. Increasingly, South Africans are questioning the extent to which the SATRC achieved the "rainbow nation" (Center for Conflict Resolution, 2007). Ngwane, for instance, suggests that the TRC failed in many respect, including its justice accountability deliveries for victims. He remarks that "I don't see stability in South Africa. I see semblance of stability that is brittle and often exposed as such....Xenophobia is not a sign of a society that is reconciliated [sic] to itself..."(Written Response, October 24, 2008). ${ }^{92}$

On the other hand, the SATRC is credited in part with the smooth political transition to the post-apartheid regime (Boraine, 2000a; Villa-Vicencio, 2009; Sachs, 2009). The SATRC is generally acknowledged to have served as one of the most important pillars on which peace in a deeply divided South African society could be built (Fombad, 2002). Close to two decades following the creation of the SATRC, South

\footnotetext{
${ }^{91}$ At present, the South African Department of Justice and Constitutional Development has been entrusted with the responsibility to follow up on the outstanding findings and recommendations of the TRC.

${ }^{92}$ Trevor Ngwane is a former member of the ANC and a grassroots human rights activist based in Johannesburg, South Africa.
} 
Africa has managed to forge unity and to sustain its democracy without any major destabilization. It could be argued that the SATRC fostered stability during the transition and aftermath.

Notwithstanding the mixed domestic responses to the SATRC, the model continues to receive attention globally. Unfortunately, it seems that many countries that seek to develop TRCs based on the South African model are less informed about the challenges that the SATRC faced in its lifetime and beyond. Part of its continuing eminence as a replicable platform is its popularity. In part, the novel features that were introduced to the administrative technique and that surpassed previous TRCs made it fashionable and exemplary compared to the previous TRCs from which the South Africans borrowed. The amnesty for truth process, public and daily televised hearings, the extensive public debate on the formulation process, both inside and outside Parliament, and the huge scale of its operations are some of the features that transformed it into the one of most well-liked international models for TRCs ever established.

Certainly, the SATRC is described as one of the five most strongest or substantial TRCs (Hayner, 2011). Fombad observes that it is one of the best models ever operated, and as what "can only be described as probably the greatest transition of the twentieth century" (2002: 195). The two cases - Nigeria and Ghana -- that are examined next were formulated based on the South Africa model. These TRCs followed the SATRC experience of victims' participation through public and televised hearings, emphasized restorative justice, and sought broad national reconciliation. 


\subsection{2: The Nigerian TRC (1999- 2002): Establishment and Work}

The Nigerian version of the TRC was titled the Human Rights Violations Investigation Commission (HRVIC). It was also popularly known as the Oputa Commission. ${ }^{93}$ Unlike South Africa, the HRVIC was established by executive decree. Relying on the powers of the executive under an existing 1966 Tribunals of Enquiry Act (as amended in 1999), the HRVIC was created by the presidential order of Statutory Instrument (No 8) on June 7, 1999. ${ }^{94}$ President Olusegun Obasanjo inaugurated it on June 14, 1999. The Commission was tasked to investigate human rights abuses in the time between January 15, 1966 and May 28, $1999 .^{95}$ The HRVIC was mandated to establish the causes, nature, and extent of human rights violations, including assassinations and attempted killings during this period in Nigerian political history. The Commission would investigate and identify perpetrators, determine the role of the state in the violations, and recommend means to pursue justice and prevent future abuses. The main objectives were to seek the truth about the past, to whatever extent possible, to heal wounds, and to promote national reconciliation.

Specifically, the Statutory Instrument listed the following tasks for the Commission:

- to ascertain or establish, to whatever extent the evidence and circumstances may permit, the causes, nature, and extent of human rights violations or abuses and, in particular, all known suspected cases of mysterious deaths and assassinations or attempted assassinations committed between January 15, 1966 and May 28, 1999;

\footnotetext{
${ }^{93}$ The name Oputa was from that of the Chair of the Commission, a former Supreme Court Justice, Chukwudifu Oputa.

${ }^{94}$ The Statutory Instrument (No 8) was subsequently amended on October 4, 1999.

${ }^{95}$ The 1966 start date marked the first military coup in Nigeria and the 1999 cut of date reflects when Nigeria made the political transition to the present democratic dispensation.
} 
- to identify the person or persons, authorities, institutions or organizations that may be held accountable for such mysterious deaths, assassinations or attempted assassinations or other violations of human rights, and to determine motives of these violations, victims and circumstances, and the effect on such victims or the society generally;

- to determine whether such abuses were the product of deliberate state policy, or the policy of any of its organs, institutions or individuals, or their office, or whether they were the acts of any political organization, liberation movement or other group or individual;

- to recommend measures that may be taken, whether judicial, administrative, legislative or institutional, to redress past injustices and to prevent future violations or abuses of human rights;

- make any other recommendations that are, in the opinion of the Commission, in the public interest and are necessitated by the evidence; and

- receive any legitimate financial or other assistance, from whatever source, that may aid and facilitate the realization of its objectives (Obasanjo, 1999; Fombad, 2002; Obiagwu and Odinkalu, 2003; Nwogu, 2007).

While in the main the Commission interpreted its mandate as being to promote national reconciliation based on the knowledge of the truth about the past, and to reconcile the injured with their oppressors, the terms of reference as listed above were so broad that it could undertake investigations into anything it considered a human rights abuse. Some argue that the Commission was expected to investigate aspects of corruption 
on the part of previous military leaders as included among human rights abuses (Hayner, 2001; Fombad, 2002). The Tribunal of Enquiry Act empowered the Commission to issue summonses similar to the SATRC to undertake its work. The consequences for noncompliance were weaker, however. It also had the powers to conduct search and seizure, as well as to issue arrest warrants.

Unlike the South African version, the Commission did not have the power to offer official amnesty. Operationally, though, the Commission borrowed similar processes from the SATRC that were intended to seek truth and forgiveness, as well as to promote national reconciliation (HRVIC Volume One Report, 2002). The HRVIC interpreted or understood its mandate to include fostering truth revelation, even if it meant developing mechanisms to facilitate amnesties to alleged perpetrators.

The Tribunal of Enquiry Act under which the HRVIC was formed provided the legal basis for immunity for any testimony or evidence given by witnesses. Section 8 of the Act granted the inadmissibility of any civil or criminal proceedings against any person for evidence provided, except such evidence as is false. This provided the Commission the flexibility to adopt an amnesty for truth process similar to the one used by the SATRC. The HRVIC was made up of seven members and a secretary. It was assisted by a secretariat. To facilitate its operations, it had representation in six areas of the country reflecting Nigerian traditional geo-political zones. These zones were: North East, North West, North Central, South East, South West, and South South. The Commission planned to have each zone headed by a Commissioner, but this did not happen. Hence, the work of its zonal offices was farmed out to private research institutions. Furthermore, the Commission, unlike the SATRC, had difficulties setting up 
distinct sub-committees and properly structured legal, research, investigations, media liaison, logistics and human resource departments.

The Commission could not hire its own staff. It staff were seconded from government departments. They totalled 15, and included two lawyers (ICTJ Internal Document, 2001). Nwogu (2007) notes, for instance, that the government seconded only two lawyers to the Commission when the Commission had requested 24. Apart from administrative challenges, the HRVIC was also poorly funded. The government failed to allocate funds to the Commission as it had promised to. ${ }^{96}$ Indeed, lack of sufficient funding caused the Commission to suspend hearings at one point (ICTJ Internal Document, 2001; Yusuf, 2007). It took the United States-based private organization, the Ford Foundation, to bankroll the Commission (reportedly over $\$ 400,000$ ) to enable it to complete its work (ICTJ Internal Document, 2001; Freeman, 2006; Yusuf, 2007; Nwogu, 2007; Personal Interview with Father Matthew Kukah, January 28, 2009). Overall, the lack of well staffed and well remunerated human resources, a weak functional secretariat and an absence of adequate offices undermined the Commission's work (Freeman, 2006; Yusuf, 2007; Nwogu, 2007). The HRVIC report testifies to the fact that these administrative challenges slowed it down (HRVIC Volume One Report, 2002).

Nonetheless, one year $^{97}$ after its inauguration the Commission started work by soliciting from the general public complaints, statements and exhibitions that might aid its investigating work. The phase of collecting statements was followed by public hearings. The public hearings were held in five cities, covering the six geopolitical

\footnotetext{
${ }^{96}$ It has been difficult to establish the levels of funding from government.

${ }^{97}$ Between October 1999 and October 2000 the Commission organized itself, determined its operating procedures and prepared to receive complaints and conduct public hearings (ICTJ Internal Document, 2001).
} 
regions or zones of Nigeria: Abuja, Lagos, Port Harcourt, Enugu and Kano. ${ }^{98}$ The hearings caught on with most Nigerians to the extent that they were described as a "national TV soap opera" (West Africa, 2001; Personal Interview with Priscilla Ankut, January 21,2009 ). After nearly three years of operation, the Commission reported that it had received close to 10,000 testimonies from the public. It conducted public hearings for 340 of these testimonies (HRVIC Volume Four Report, 2002), which was less than five per cent of all the statements received. In addition, it received over 1,700 exhibits related to some of these testimonies.

Similar to the SATRC, the HRVIC conducted special hearings for relevant stakeholders, including civil society organizations, human rights organizations, the National Human Rights Commission, the armed forces, the police, the prisons, and the State Security Service (HRVIC Volume Four Report, 2002). Furthermore, the Commission tasked independent research institutions to conduct background research on specific issues and themes. It concluded its work by presenting a seven-volume report, in addition to a separate summary and recommendation chapter, to President Obasanjo at a public ceremony on May 28,2002 . This ceremony marked the official completion of the Commission.

\subsubsection{1: The Nigerian TRC: Did Transfer Occur?}

There are enough reports by news media, as well as research documents and pronouncements from public officials and human rights activists, to establish that the policy formulation process of the HRVIC resulted from a policy transfer. In other words,

\footnotetext{
${ }^{98}$ Abuja served two geopolitical zones where three separate hearings took place.
} 
the creation of the Commission was not the result of a conventional domestic policymaking process, but rather of lessons drawn from the South African experience. The West Africa magazine of 2001 captured it succinctly: "[T] for Nigeria what the Truth and Reconciliation Commission did for South Africa" (West Africa, 2001: 6). Several written accounts point to the fact that the philosophical foundation for the HRVIC is traceable to the South African TRC (Kukah, 2004; Yusuf, 2007; Center for Conflict Resolution, 2007; Nwogu, 2007) ${ }^{99}$ Anyanwu (2001), who was a member of the Nigerian House of Representatives at the time the Commission was established, observes that the conception of the Nigerian TRC was informed by the South African model.

Further, conversations with persons who were close to the HRVIC suggest that a policy transfer occurred in Nigeria regarding the choice of a TRC as a policy response to transitional justice concerns. Among others, Father Matthew Kukah, a member of the HRVIC, Professor Akinseye George, an academic who doubles as a human rights lawyer and who consulted for the Ministry of Justice in the formulation of the HRVIC, and Dr. Olatunji Abayomi, a human rights lawyer and someone who was initially named a member of the Commission, confirm that Nigeria transferred the South African TRCapproach in order to solve its own transitional justice problems. While Father Kukah, for example, observes that the "idea of what happened in South Africa may have been sufficiently attractive to Nigeria" (Personal Interview, January 28, 2009), Dr. Olatunji says Nigeria "followed the South African example" (Personal Interview, February 2, 2009).

${ }^{99}$ Most people interviewed (Focus Group Discussion \# 2, February 12, 2009) in Nigeria in 2009 believed that the HRVIC was a borrowed version of the South African TRC. 


\subsubsection{2: The Nigerian TRC: What was Transferred?}

The content of the TRC policy that was transferred to inform the HRVIC consisted of the goals and the instrument required for achieving them. The notions of restorative justice and reconciliation informed the work of the HRVIC. Inaugurating the Commission, President Obasanjo (1999) stated that the punishment of alleged perpetrators who acknowledge culpability did not form part of its mandate. Restoring the dignity of victims in society through knowledge of the truth and psycho-social healing, as well as promoting national reconciliation, which are goals associated with TRCs and which the South African TRC also sought, were fundamentals of the HRVIC. President Obasanjo noted in his address to inaugurate the HRVIC that the Commission was to work towards healing the wounds of the past, and towards putting the past behind "so as to continue to stretch our hands of fellowship and friendship to all Nigerians for complete reconciliation based on truth and knowledge of truth in our land" (1999: 50).

Consequently, regarding the policy goals that were transferred, the HRVIC did not depart from the SATRC. It did, however, depart from the SATRC in some of the operational methods of the administrative structure set up to achieve the goals. To be sure, the quasi judicial commission of inquiry technique used by SATRC was transferred. The Commission adopted for its work the conceptual definition of the term "gross violations" as it was given in Act (No. 34) that set up the SATRC (Yusuf, 2007). Further, the HRVIC transferred the South African innovation of nationwide and televised public hearings. Similar to the SATRC, the Commission decentralized its operations by setting up offices in selected parts of the country. Despite these similarities with the SATRC, 
there were considerable design weaknesses -- legal, conceptual and operational -- that departed from the South African model.

The lack of specific legal provision in the form of amnesty that could serve as an incentive for perpetrators to cooperate with the Commission was one area of departure. Even though the Commission attempted to interpret its mandate in such a way as to enable it to do so, this was, however, not enough to assure the public. Fombad (2002) observes that the Commission could not guarantee that confessions made by perpetrators or witnesses could not be used against them in the future. Further, the HRVIC did not create structured sub-committees, such as the South African HRVC, the RRC and other operational units, as already noted, to assist in its work. While the HRVIC transferred the administrative body, it did not fully transfer all the methods and support mechanisms that were associated with the SATRC and made it attractive and inspiring.

\subsubsection{3: The Nigerian TRC: Degree of Transfer?}

The source of transfer for the HRVIC was the South African model; hence, it was a single source, and not a case of mixtures. The degree of transfer in Nigeria, however, was neither copying nor emulation, because there is no evidence of direct transfer of the South African legislation that was behind its TRC in Nigeria. Similarly, although the idea of restorative justice informed the HRVIC, resulting in a similar administrative body to advance this goal, the legal, conceptual and operational details that were needed to strengthen the technique were absent. For example, and as was noted above, the precise legal powers to enable the Commission offer amnesty, as was the case for the SATRC, was not given. 
Accordingly, the degree of transfer that took place in Nigeria could be considered the "inspiration" type. According to Dolowitz and Marsh, inspiration occurs when a policy in one political environment motivates a domestic policy change in a different setting, although the outcome of the policy transfer does not depend on the original case or policy. The TRC policy transfer that occurred in Nigeria exemplified this typology. The Nigerian HRVIC was set up at a time that the South African TRC was, perhaps, enjoying its greatest level of appeal globally. The SATRC had just completed its hearings and submitted its interim reports.

The ramifications of the dramatic South African political transition, five years following the April 1994 transitional elections, were still unfolding. South Africa was still at the centre of global attention, and the TRC-approach to transitional justice was viewed, as observed earlier, as being one of the principal factors that had held this divided country together. The manifestations of the South African TRC and its apparent success greatly inspired its choice by the Nigerians as the approach to take in responding to that country's domestic transitional justice needs (Kukah, 2004; Center for the Conflict Resolution, 2007; Nwogu, 2007). As Professor Akinseye George remarked in a conversation: "Absolutely, there is no doubt the whole idea of the Oputa Panel and the truth and reconciliation committee in Nigeria was informed by the success of the exercise in South Africa.... Thus the experience of South Africa was useful to us" (Personal Interview, February 2, 2009).

When he set up the HRVIC, President Obasanjo sought to emulate the South African approach of President Mandela, addressing human rights injustices through a non-retributive justice process (Focus Group Discussion \# 2, February 12, 2009). For 
some Nigerians, Obasanjo's setting up of the HRVIC was a publicity stunt aimed at making him appear the "Mandela of Nigeria". ${ }^{100}$ The Peoples' Democratic Party (PDP) government was inspired by restorative justice ideas as popularized in South Africa, and felt that such a process was achievable in Nigeria. While the policy transfer of the TRCapproach in Nigeria was inspired by what had happened in South Africa under President Mandela, the policy transfer process failed to draw lessons on the context and the policy processes for the establishment of the SATRC. As noted, there was a marked departure from the policy process that led to the emergence of the Statutory Instrument (No. 8), and there were also significant differences between the administrative techniques of both mechanisms.

\subsubsection{4: The Nigerian TRC: Outcomes}

In 2002 the HRVIC handed over its final report to the government of the Peoples Democratic Party (PDP), headed by President Obasanjo. The public presentation of the seven volume report also signalled the last time the report would be officially seen publicly. It was, however, leaked to the public in 2005 by a Coalition of Civil Society, some of whose members consulted for the Commission during its operation and report writing. The release followed the failure of the Obasanjo government to issue a white paper on the report and make it available to the public, even after persistent calls by civil

\footnotetext{
${ }^{100}$ It is noteworthy that President Obasanjo, before he became President in 1999, was serving a jail sentence for alleged subversion against General Sani Abacha, one of Nigeria's powerful military dictators. Nwogu (2007) suggests that some Nigerians see in Obasanjo's actions an attempt to copy Nelson Mandela's example in South Africa of a leader pursuing reconciliation after emerging from a prison sentence imposed by an unpopular and oppressive regime.
} 
society and human rights groups to do so. ${ }^{101}$ The government claimed that a Supreme Court ruling prevented it from making the report public. ${ }^{102}$ This position by the government attracted condemnation from the civil society community, which felt that the government's argument was untenable. There is, however, no consensus on the effect of the Supreme Court judgment (Yusuf, 2007; Hayner 2011). Some suggest that the government would be contravening the Court's ruling if it made the report public. Others argue that the Court's ruling was only in respect of the findings as they affect the plaintiffs.

Sections of the Nigerian public believe that the government deliberately hid behind the Court's ruling to suppress the truth (Yusuf, 2007; Focus Group Discussion \# 2, February 12,2009 ). This latter view seems closer to the reality. The worst of it is that, as was not the case in the South African experience, the HRVIC final report never made it to the National Assembly (Parliament) of Nigeria. The National Assembly never had the opportunity to debate the findings and recommendations in the Commission's report. The executive order that established the Commission did not oblige the presidency to forward the report of the Commission to the National Assembly. The trouble with no official release, no debate and no publicized report containing the findings and recommendations is that everything the HRVIC did was for naught.

\footnotetext{
${ }^{101}$ It is on record, however, that the Obasanjo government released portions of the report to participants at the 2005 All Nigerians National Constitutional Conference to find ways of reforming the Nigerian state (Personal Interview with Olawale Fapohunda, January 31, 2009).

${ }^{102}$ The ruling related to the successful injunction obtained by three former generals preventing the Commission issuing its power of summons under the Tribunal Enquiry Act. They claimed that the President lacked the powers under the existing laws to establish a body like the HRVIC for the whole country. The details of the Court ruling and interpretations, as well as counter interpretations, have been well documented by Yusuf (2007). See also Constitutional Law Classics Volume One (undated) by Alero Akeredolu (ed.).
} 
Public endorsement for the Commission was positive at the inception phase, but tilted towards the negative after the submission of its report. At the initial stage of its work, national interest soared, and citizens were optimistic about outcomes. Through the extensive media coverage of the public hearings, Nigerians became interested in and supportive of the work of the Commission during the periods of collection of statements and the public hearings (West Africa, 2001; Yusuf, 2007; Nwogu, 2007; Focus Group Discussion \# 2, February 12, 2009). Adeshida (2000), for example, reports that the Commission received applause from a cross section of the public at the end of the first rounds of public hearings in Abuja City.

The levels of cooperation from citizens, and in particular from victims, were evidenced in the number of submissions made to the Commission. Nonetheless, the refusal of three former military generals to appear before the HRVIC dimmed civil society's interest in and respect for it. These former military heads of state, General Muhammadu Buhari (1983 to 1985), General Ibrahim Babangida (1985 to 1993), and General Abdulsalami Abubakar (1998 to 1999), whose reigns included some heinous human rights abuses, including murders of prominent citizens, went to the Supreme Court to secure injunctions against subpoenas by the Commission.

While President Obasanjo himself appeared on two occasions before the Commission to testify, first as a victim of human rights abuses under General Sani Abacha's rule, and second as a defendant against allegations of abuses during his reign as a military leader between 1975 and 1979 , the inability of the Commission to pursue the three generals to help it discover the truth about certain unacknowledged crimes of the 
past devastated its public image (ICTJ Internal Document, 2001; Yusuf, 2007; Focus Group Discussion \# 2, February 12, 2009).

The HRVIC, as was the case with SATRC on P.W Botha, did go ahead to make findings in its report about these generals. Nonetheless, the generals' refusal to appear and the Court's subsequent apparent stopping of the report undermined the modest success that the Commission had achieved through its public hearings earlier. To be sure, the public hearings had revealed some significant truths that had been unknown, for which Nigerians commended the HRVIC (Nwogu, 2007; Focus Group Discussion \# 2, February 12, 2009). As a result, while the refusal of the three former heads of state to go before the HRVIC was condemned by civil society, the refusal of the PDP government to publicly acknowledge the report and officially release it to the public was the climax of civil society's disapproval of the final outcome of the HRVIC.

There is no disputing the fact that officially publicized TRC reports may engender controversies, as the South African experience suggests. Nevertheless, public acknowledgment and its release contribute to the restorative justice goal of TRCs. At the least, public acknowledgment recognizes the harm done to victims and this can have therapeutic effect on them and their restoration. If the TRC report is acknowledged and publicized, irrespective of reservations the creator or other persons might have, it helps to advance the process of closure to contribute to the process of restoring the dignity of victims.

As the South African experience demonstrates, the ANC leadership, and President Nelson Mandela in particular, accepted the report despite its concerns about portions of it. It may be argued that in Nigeria, through the public hearings, the Commission 
contributed to the creation of a collective memory for that country. Yet the failure to acknowledge the HRVIC report as the collective memory and the subsequent failure of the PDP government to officially release it gravely damaged the transitional justice process. As Nwogu (2007) observes, without a published report, all that has been achieved in Nigeria is the wider dissemination of long-held, and now, unfortunately, reinforced beliefs that some known alleged perpetrators were perhaps innocent. Even worse, none of the findings or recommendations in the HRVIC report have been implemented, which is hardly surprising in view of the failure to officially acknowledge it. $^{103}$

Nigerians generally thought the HRVIC to be a good thing, and they considered it unprecedented (West Africa, 2001; Focus Group Discussion \# 2, February 12, 2009). There is a general perception that because of the wide media publicity that surrounded the public hearings and representations by some high-profile individuals from the military establishment and the civic community, the Commission helped to shed some light on previously concealed truths about Nigerian society (ICTJ Internal Document, 2001; Center for Conflict Resolution, 2007; Focus Group Discussion \# 2, February 12, 2009).

Concerning the Commission's work towards addressing victims' needs and healing, and advancing restorative justice as well as national reconciliation, however, both the Commission and the PDP government -- more so with the latter -- were faulted for under-performing (Onyegbula, 2004; Bosire, 2006; Yusuf, 2007; Focus Group

\footnotetext{
${ }^{103}$ Upon receiving the final report, President Obasanjo stated his government's commitment to studying the recommendations for implementation. Unfortunately, to date the report remains unacknowledged, and has not been made public, and, as already stated, not a single finding or recommendation has been implemented. It is instructive to note, however, that the HRVIC took a cue from the South African TRC by recommending comprehensive reparations that included monetary compensation and restitution of some identified victims, and non-monetary, or symbolic, forms (HRVIC Volume Six Report, 2002). While it recommended the creation of victims' fund to cater to their needs, unlike the SATRC, however, the Commission did not specify how much should be paid as compensation.
} 
Discussion \# 2, February 12, 2009). For victims of human rights abuses in particular, who thronged the Commission daily, the lack of monetary compensation, as was expected, diminished any desire for a TRC. As Onyegbula (2004) observes, the absence of monetary compensation was disappointing to victims who had high expectations for the Commission.

The refusal of the Nigerian government to own the final report and make it public made many Nigerians doubt the sincerity of its political commitment to a genuine transitional justice process (Focus Group Discussion \# 2, February 12, 2009). A member of the HRVIC observed recently that the President's failure to disclose publicly the final report undermined the Commission's work, and negatively affected public appreciation of its product (Kukah, 2010). This act by the government, coupled with failure to implement a single recommendation contained in it, significantly undermined the process of building a unified and reconciled nation state. ${ }^{104}$ As one informant eloquently remarked, "the panel [Commission] was beautiful, the recommendations went very well, but it is a failure in the sense that nothing from the recommendations of the panel has been implemented to date by this government" (Personal Interview with Clement Nwankwo, January 27, 2009).

For some Nigerians, the report not being made public confirms the view that the Commission was a "hollow mimicry of the South African TRC" (Nwogu, 2007: 43). The continuous manifestations of inter-ethnic and inter-religious conflicts, waves of violence in the Niger Delta and the distrust in the political system are partly results of the failure to use the HRVIC as a transition from the haunted past to a new phase of democratic good

\footnotetext{
${ }^{104}$ This position is confirmed by views from some informants interviewed in Abuja and Lagos in 2009. It also reflects the consensus of the focus group discussion held in Lagos 2009 (Focus Group Discussion \# 2, February 12, 2009).
} 
governance. More than a decade after this attempt, the hopes for a new dawn in the wake of the 1999 transition, argues Yusuf (2007), have gone largely unfulfilled.

\subsection{3: The Ghana TRC (2002- 2004): Establishment and Work}

The TRC in Ghana was named the National Reconciliation Commission (NRC). The NRC was established through an Act (Act 611) of Parliament. The process of creation followed the same path as the South African TRC, but was unlike the Nigerian approach in that it followed a parliamentary policy-making process. Enacted by Ghana's Parliament on December 21, 2001, it was given Presidential assent on January 9, 2002. Ghana's TRC and, for that matter, its transitional justice process, took place almost a decade following the formal democratic political transition that occurred in late 1992 and early 1993. The timing of Ghana's TRC was thus inconsistent with that of its transitional justice process precedents, ${ }^{105}$ and unlike the South African and Nigerian TRCs. The timing of Ghana's process defied the paradigm of political transition in transitional justice processes as discussed in Chapter 2. Ghana's post-authoritarian human rights accountability process could best be described as "transitional justice without the formal notion of a transition'.

\footnotetext{
${ }^{105}$ The main reason for this inconsistency was that in the 1992 transitional elections the last of the military leaders, Jerry Rawlings, succeeded himself. He transformed his PNDC military junta into a political party, the NDC, and contested the elections, acting as the umpire and a player at the same time. He subsequently ruled as a civilian president until December 2000 , when he was barred from contesting again after serving two consecutive terms as required by the 1992 Constitution. His party was also defeated during the elections. The 1992 transition exemplifies the transformation type of Huntington's (1991) transition typologies and, therefore, tended to forgo any form of transitional justice. Although during the 1990s Rawlings had the opportunity to initiate a formal non-retributive transitional justice process, nonetheless, as noted by Attafuah (2004), he appeared uninterested in creating a special statutory agency to pursue the goal of national reconciliation.
} 
As examined in Chapter 2, to an extent Ghana's case fits into the discourse on transitional justice in a 'conflicted democracy' (Ní Aoláin and Campbell, 2005). ${ }^{106}$ The conception of the TRC indicates the expansion of the parameters of transitional justice, and the value of transitional justice even in democratic dispensations. The NRC was mandated to investigate gross human rights abuses committed during all previous unconstitutional as well as civilian regimes since 1957, when Ghana attained independence from the British. Its primary objective was to seek and promote national reconciliation amongst the people of Ghana. The NRC Act (611) mandated it to investigate the records of four different military regimes that spanned 22 years between 1957 and 1993. In addition, the NRC could investigate allegations of human rights abuses under civilian regimes during this period.

Act 611 specifically mandated the NRC to undertake the following tasks:

- to establish an accurate, complete and historical record of violations and abuses of human rights inflicted on persons by public institutions and holders of public office or persons purporting to have acted on behalf of the State during the period of unconstitutional governments, namely from: February 24, 1966 to August 21, 1969; January 13, 1972 to September 23, 1979; and December 31, 1981 to January 6, 1993;

- to receive applications of human rights abuses of any other period between March 6, 1957 and January 6, 1993, notwithstanding the above specific periods;

- to investigate violations and abuses of human rights relating to killings, abductions, disappearances, detentions, torture, ill-treatment and seizure of properties suffered by any person within the specified periods;

\footnotetext{
${ }^{106}$ The transitional justice process in Ghana focused on addressing hang-over of human rights abuse that had resulted in tensions, conflicts and divisions in the body politic, and the reform of democratic governance institutions.
} 
- investigate the context in which the causes and circumstances under which the violations and abuses occurred and identify the individuals, public institutions, bodies, organizations, public office holders or persons purporting to have acted on behalf of any public institution responsible for or involved in the violations;

- identify and specify the victims of the violations and abuses, and make recommendations for redress;

- investigate and determine whether or not the violations and abuses were deliberately planned and executed by the state or any person representing the state;

- conduct investigations relevant to its work, and seek the assistance of the Police and any public or private institution, body or person for the purposes of an investigation;

- investigate any other matters it considers require investigation in order to promote and achieve national reconciliation; and

- educate the public and give sufficient publicity to the achievement of the object of the Commission (Act 611, 2002; Attafuah, 2004; NRC Executive Summary Report, 2004; Boafo-Arthur, 2006).

To assist the NRC in undertaking the abovementioned tasks, the Act (611) granted it unlimited access to information, records, institutions, and persons that relate to its investigative objectives. Further, and similar to the South African model, the NRC had the powers of entry, search, and seizure of any documentary evidence relevant to investigations. It also had the powers to compel or subpoena a witness to appear before the Commission or produce any evidence that might help in its work. Finally, among its powers fashioned along the South African model was the one to grant amnesty to 
witnesses for the purposes of full disclosure of knowledge of an instance of abuse. This power of amnesty was offered to persons who voluntarily (and requesting amnesty) or by subpoena appeared before the Commission to give evidence, and who by doing so may have incriminated themselves. These persons were exempted from any future civil or criminal proceedings as a result of testimonies given at the NRC.

There were nine members in the NRC, and they sat to listen to submissions from victims and witnesses. The Secretariat, the headquarters for the NRC, was headed by an Executive Secretary. The Secretariat had five divisions: finance and administration; public affairs and community liaison; investigations and research; counselling and support services; and legal. In addition to its headquarters in Accra, the Commission also set up regional offices in five regional capitals, representing five operational zones covering the entire country. The Zonal Offices were: Bolgatanga, which served the Upper East and Upper West regions; Ho, serving the Volta and Greater Accra regions; Kumasi, which served the Ashanti and Eastern regions; Sekondi-Takoradi, serving the Western and Central regions, and Tamale, serving the Brong-Ahafo and Northern regions. ${ }^{107}$ Unlike the Nigerian HRVIC, but similar to the SATRC, the Zonal Offices were headed and staffed by the NRC's own hired personnel.

Overall, the NRC had total staff strength of between 100 and 200. The projected budget for the NRC at its inception was US\$5 million, to cover the entire duration of its existence. That amount was reduced to $\$ 3$ million, of which the Ghana government provided \$2 million (West Africa, 2003; Ameh, 2006a; Hayner 2011). ${ }^{108}$ The Commission was inaugurated by the President, John Agyekum Kufuor, on May 6, 2002,

\footnotetext{
${ }^{107}$ Politically and administratively, Ghana is divided into 10 regions.

${ }^{108}$ The rest of NRC funding came from foreign sources, including the United States government and the Open Society for West Africa (OSIWA).
} 
and it started receiving statements of human rights violations from the public on September 3, 2002. Its first public hearings were held on January 14,2003 . The public could submit statements in any of its offices across the country. Following the blueprint set up by the SATRC, nationwide and televised public hearings took place in all 10 regional capitals in Ghana.

The NRC completed its public hearings in June 2004. It received a total of 4,240 statements, and conducted public hearings for 1,866 victims or witnesses, or more than 40 percent of the total submissions. This made Ghana's TRC the one with the most publicly heard testimonies (although not in absolute numbers), more than those of the SATRC and the HRVIC. In addition to the public hearings, it conducted in camera hearings, as permitted by Act 611. Similar to the SATRC, the NRC conducted institutional or thematic hearings. The institutions covered in these hearings were the Security Services, the Legal Profession (including the Judiciary), the Media, the Labour, Student and Youth Movements, Professional Bodies and Civil Society Organizations, and Religious Bodies and Chieftaincy (NRC Executive Summary Report, 2004). In October 2004 the NRC concluded its mandate by presenting its final report to the President and the sponsoring government.

\subsubsection{1: The Ghana TRC: Did Transfer Occur?}

In a 1995 publication by Mike Oquaye, an academic and a leading member of the NPP, then in opposition, called on Ghanaian opposition parties to adopt a policy of reconciliation towards human rights violations by previous military regimes. He cited the Chilean TRC as a model worth emulating (Oquaye, 1995: 572-573). The notion of a TRC 
as an approach to transitional justice for consideration surfaced in the political debate from the mid to late 1990s. It was around the same time that the South African TRC had just started its work and had been attracting global attention.

Toward the end of the decade the perceived success of the SATRC appears to have been firmly planted in the minds of Ghanaian political and policy elites. Most observers and accounts of Ghana's TRC share the view that the South African process was the source that informed the birth of the NRC (Freeman, 2006; CDD-Ghana, 2006; Gyimah-Boadi, 2006; 2007; Focus Group Discussion \# 1, January 15, 2009). In an interview granted by the newly elected President, John Agyekum Kufuor, in February, 2001 , barely a month after taking office, he noted that the NRC to be established was "in the spirit of the South African experience" (New African, 2001: 17).

Further, the report by the Committee on Constitutional, Legal and Parliamentary Affairs (CLPA) of Ghana's Parliament reveals that the legislations that created TRCs for South Africa, Guatemala, El Salvador, Sierra Leone and East Timor were sources of reference in its deliberations on the NRC Bill (Parliament of Ghana, 2001). While the official policy actors may have examined the policies on TRC-approaches from many sources, it was obvious that the South African model, as stated by the President, held much sway in informing the Ghanaian policy process. Leading members of the ruling NPP government confirm this view. Personal conversations with Oquaye and with Papa Owusu-Ankomah ${ }^{109}$ revealed that the Ghana TRC policy formulation was an act of policy transfer.

\footnotetext{
${ }^{109}$ Oquaye, who is currently the Second Deputy Speaker of Ghana's Parliament, was a member of the NPP manifesto committee for the 2000 general elections; Owusu-Ankomah was the Majority Leader in Parliament at the time the policy on the TRC approach was being formulated, and he later on, when the NRC was in operation, became the Minister of Justice and Attorney General.
} 
When asked whether the NPP was influenced by the South African model in proposing a TRC for Ghana, Oquaye said, "Oh yes, definitely, yes we were. I felt it was a good example, it brought out the truth without being vindictive..." (Personal Interview with Oquaye, May 8, 2009). Other sources confirming that a policy transfer of the TRCapproach occurred in Ghana can be found in conference publications. One account, for example, states that "based on the South model, the NRC was mandated..." (Center for Conflict Resolution, 2007:22). Features and news stories that were published in Ghanaian newspapers prior to Parliament enacting the NRC Bill, such as the Daily Dispatch Newspaper (May, 2001; July, 2001), made references to South Africa as the source of policy transfer.

\subsubsection{2: The Ghana TRC: What was Transferred?}

The TRC policy goals of restorative justice and reconciliation outcomes, as well as the mechanism for achieving these goals, were transferred to Ghana. Drawing from the South Africa model, Ghana's TRC sought not criminal justice, but the restoration of citizens who had suffered gross human rights abuses. As the then President stated, the NRC process would not threaten prosecution but, rather, seek to reconcile aggrieved persons (New African, 2001:17). Similar to what the SATRC sought to achieve, the NRC's main preoccupation was to address the needs of victims of human rights abuses by uncovering the truth about these abuses, and restoring the victims in society by way of reparations, and in doing so to forge national reconciliation between the victims and perpetrators of these abuses. This primary objective of the policy on the NRC was consistently stressed in all pronouncements by government officials at public forums and 
in the contents of official documents, such as the NPP Manifesto for the 2000 elections and the memorandum accompanying the National Reconciliation Commission Bill to Parliament.

It is inconceivable that the transfer of TRC policy goals would occur without the mechanism to achieve them. A similar administrative mechanism employed in South Africa was transferred to Ghana. Ghana's TRC adopted the quasi judicial commission of inquiry with the required investigating powers to enable the Commission to pursue its mandates. In particular, drawing on the South African model, the NRC was granted the power to offer amnesty for truth. As stated, the NRC could grant immunity to individuals for any incriminating evidence that would assist the Commission in uncovering the truth. Further, the Ghana TRC policy transferred SATRC methods, such as decentralized structures, and individual and institutional public hearings. While the Ghana TRC policy extended SATRC operational structures, such as legal, investigation, research and counselling units, the policy did not require the setting up of distinct committees, such as the SATRC's HRVC, RRC and Amnesty Committee. Perhaps this distinction was the major departure from the SATRC for the Ghana TRC policy transfer regarding support structures for the TRC administrative mechanism.

\subsubsection{3: The Ghana TRC: Degree of Transfer?}

Ghana's TRC policy transfer characterized the "emulation" type of the Dolowitz and Marsh policy transfer model. According to Dolowitz and Marsh, emulation occurs when a country avoids direct copying, but recognizes that a particular policy in a different political system is a useful standard for domestic policy response to a similar policy 
challenge. It essentially involves the transfer of ideas behind a particular policy. As already noted, the TRC-approach to transitional justice in Ghana had long been considered worthy of emulation. Before the NPP won the 2000 general elections, and still when it was in government, prominent individuals associated with the party saw the TRC-approach as an appropriate option for Ghana. This preference on the part of the policy elites coincided with that of sections of the Ghanaian civil society community, including the clergy, which had since 1993 persistently called for a process of national reconciliation (Attafuah, 2004; Mensah-Bonsu, 2005; Boafo-Arthur, 2006).

Ghana's TRC policy transfer came after the extension of the restorative justice ideas behind the TRC-approach as it has been established elsewhere, but in particular in South Africa, and after designing a domestic legislative policy for its creation. Even though Ghana created its TRC out of its own enacted legislative policy instrument, the outcomes of this instrument very much depended on the South African original case. In other words, it emulated the fundamentals that were associated with the South African model. For instance, similar to the South African process, Ghana used the parliamentary process, and not an executive order. In addition to the policy goals and administrative technique transferred, Ghana also adopted some of the TRC mandates, such as the amnesty provision, without necessarily copying (verbatim) the South African style.

Moreover, it instituted similar operational structures, such as legal, investigation and research, without extending in totality every structure that was developed by the SATRC. In sum, the degree of transfer in Ghana exemplifies emulation. The character of the transfer was not the copying type; neither did it exemplify the mixtures, nor the 
inspiration typology. The TRC-approach transferred in Ghana was essentially a duplicate of the South African version, without necessarily copying verbatim.

\subsubsection{4: The Ghana TRC: Outcomes}

The NRC presented a five-volume report to the NPP government on October 12, 2004. Upon receiving the report, President Kufuor pledged his government's commitment to study it and respond appropriately. In April 2005 the NPP government issued a white paper on the report, accepting it and its entire findings and recommendations, and promised to implement them. ${ }^{110}$ By this act, Ghana's TRC followed the South African experience, but departed from the Nigerian case. The government acknowledged the NRC report as reflecting the collective memory of the nation. This position was, however, unlike that of the South African government. In the latter case, although it accepted the SATRC report, it did so by expressing reservations on portions of it. In Ghana, this was not the case--the report was wholly accepted without any reservations.

The Ghana process also departed from the South African process regarding the role of parliament. The NPP government, unlike the approach adopted by the South African ANC but similar to the Nigerian PDP's, did not submit the report to the legislature for debate. ${ }^{111}$ The failure of the NPP government to hand over the report to Parliament to a degree prevented the public's ownership of the exercise. Nevertheless, public reaction to the work of the NRC and its report has generally been to endorse it.

\footnotetext{
${ }^{110}$ Copies of the report were made available to public libraries. Civil Society Organizations produced popular versions for wider distribution to the public.

${ }^{11}$ The Ghana TRC, unlike the SATRC and the Nigerian TRC, did not face any legal battles.
} 
Aside from the public hearings, which stimulated considerable excitement among the citizenry, the work and the report of the NRC enjoyed national support from ordinary citizens and victims of human rights abuses (Boafo-Arthur, 2006; CDD-Ghana, 2006; Focus Group Discussion \# 1, January 15, 2009). Boafo-Arthur (2006) observes, in a study of the Ghanaian populace in 2005 , that the majority of Ghanaians ( $86 \%$ ) were of the view that the NRC achieved its goals as expressed in Act 611.

Views from victims of human rights abuses who appeared before the NRC also showed a favourable response to the work and the report of the NRC. In an opinion survey of selected victims conducted in 2006 by an independent research organization, it was revealed that close to 80 percent of the respondents agreed or strongly agreed that the NRC provided accurate historical records for the country (CDD-Ghana, 2006). In conversation some victims confirmed that they were generally content. As one observed, "It [the NRC] has been the best approach that anybody can think of in addressing the human rights abuses of the past" (Personal Interview with Tina Aforo-Yeboah, May 19, 2009). Such a view generally reflects what a cross-section of Ghanaians think about the NRC. ${ }^{112}$

In its lifetime, the NRC received considerable cooperation from the public, including victims, witnesses and alleged perpetrators. In some cases, participants at the NRC voluntarily came before it. In other instances the NRC relied on its extensive powers to invite them. Some Ghanaians who had been in exile, voluntarily or otherwise, under the previous military regimes came before the Commission to give testimony. The NRC was also able to bring before it the former two-time military head of state, who was also the immediate past civilian head of state, former President Jerry Rawlings. His

\footnotetext{
${ }^{112}$ Personal interviews at a focus group discussion held in Accra on January 15, 2009.
} 
presence at the Commission surprised many Ghanaians, as it contradicted speculation that he might copy former South African apartheid President, P.W. Botha, and his colleagues in Nigeria. Not only did Jerry Rawlings go before the NRC, all of his military associates, including his former national security adviser, Captain (retired) Kojo Tsikata, and other senior members of his regimes went before the NRC to answer allegations of human rights abuses. The level of cooperation received from key prominent persons surpassed that of South African and the Nigerian TRCs.

To fulfil its promise of implementing the recommendations in the report, the NPP government initiated actions towards reparations. The government earmarked 13.5 billion Cedis, which translated to about US\$1.5 million, in its 2006 supplementary budget as compensation to victims recommended by the NRC. The NRC report proposed a one-off payment in the range of 1 million Cedis and 30 million Cedis $^{113}$ to each of the recommended victims, based on the severity of abuse and loss. Between October 2006 and December 2008 the government, through the Attomey General's office, disbursed payments to a total of 1,554 persons out of the 2,117 listed in the report. ${ }^{114}$ The government also began with other recommendations on restitutions -- including a process of de-confiscation of assets, as recommended by the NRC (Ameh, 2006b; Daily Graphic, 2008; Personal Interview with Justice Crabbe, July 24, 2008).

The NPP government did not, however, attend to some other areas of the recommendations, such as the non-monetary reparations, including individual apologies

\footnotetext{
${ }^{113}$ Ghana re-denominated its currency in 2007 , and also changed the name of the currency code from the original "Cedi" to "Ghana Cedi". In the year 2004, when the NRC proposals were made, the old Cedi was used for computation, and it was exchanged at 9000 Cedis for US\$1. At the time of conducting this research, in 2008, the exchange rate for the new Ghanaian Cedi, based on the re-denomination, was 1 Ghana Cedi to US\$1.The proposed NRC payment thus translated roughly to between $\$ 100$ and $\$ 3000$.

${ }^{114}$ Interview with Justice VCRAC Crabbe on July 24 2008, who was the Chair of the three-member team formed at the office of the Attorney General and the Ministry of Justice to manage the disbursement.
} 
to victims, memorials, and institutional reforms. Many of the victims who received monetary compensation expressed reservations about the piecemeal approach adopted by the government, the delay in the process of implementation and, also, the amount paid (ICTJ, 2008c; Focus Group Discussion \# 1, January 15, 2009). ${ }^{115}$ Despite these concerns, the fact remains that the government did implement some aspects of the NRC recommendations.

Ghana's TRC contributions towards the telling of complete and accurate truths about the past, addressing the needs and concerns of victims of human rights abuses, and promoting national reconciliation have been subjects of review and debate by observers in the past and currently (Ayee, 2006; Ameh, 2006a; 2006b; Boafo-Arthur, 2006; Bosire, 2006; Gyimah-Boadi, 2006; Valji, 2006; Asare 2008). These accounts have included both affirmations of its work and condemnations of all or some aspects of it. While the subject of impact is beyond the scope of this study, suffice it to say that on the subject of truth seeking, most victims commend the NRC for the efficiency with which it revealed the truth about the past in spite of the difficult political terrain in which it operated (CDDGhana, 2006). ${ }^{116}$ Ameh (2006a), for example, notes that the standard of proof adopted, the elaborate information management process, and the internal control mechanisms put in place by the NRC enabled it to ascertain the truth with respect to the cases it investigated.

Notwithstanding, there are some victims who are still seeking the truth because the NRC was unable to fully address their petitions (Boafo-Arthur, 2006). Further,

\footnotetext{
${ }^{115}$ In an unpublished survey of 63 victims drawn from the list in the NRC report, roughly two-thirds (77\%) of the respondents were unhappy with the reparation process. The survey was conducted by a local consultant for the ICTJ in August 2007.

${ }^{116} \mathrm{~A}$ victims' survey conducted by the CDD-Ghana revealed that close to 60 per cent of the victims felt that the NRC obtained truthful confessions from abusers.
} 
partisan citizens view the NRC report as only one version of Ghana's dark past and, that not as a reflection of Ghana's collective memory of the period between 1957 and 1993. The NDC, as a political party, rejected the NRC findings as being one-sided and promised to set up its own version of the TRC to unearth the accurate truth and to promote what it called genuine national reconciliation whenever they assumed political office (The Chronicle Newspaper, 2004). ${ }^{117}$ As Boafo-Arthur (2006) argues, however, such statements were mere red herrings, and beg the question of why the NDC did not initiate such a process when it was in political office between 1993 and 2000 . Indeed, the NDC has been back in political office since 2009 , but there is no policy agenda for another TRC.

Regarding addressing victims' needs and victims' healing, the NRC made considerable efforts to respond to and address those needs both on and off its platform. Many victims felt they had gained some relief from the burdens of their experience through the NRC (CDD-Ghana, 2006; Brahm, 2009). Nevertheless, not all were satisfied with the way the NRC work turned out. In particular the NRC has been criticized for recommending a meagre amount for reparation. There is a real possibility, however, that if the NPP government had comprehensively implemented the entire reparation recommendation, including both the monetary and non-monetary, victims' doubts would have been assuaged. Many of the victims who appeared before the NRC seem to have been satisfied with its achievement of its reconciliation mandate (CDD-Ghana, 2006; Brahm, 2009); on the other hand, ordinary Ghanaians are of the view that the NRC

\footnotetext{
${ }^{117} \mathrm{~A}$ leading member of the NDC, Mr. Kwamena Ahwoi, is reported to have suggested that the NRC did not investigate other human rights abuses under the regime of the Progress Party and that makes the NRC report not implementable. He noted that the NDC will set up another TRC to do the proper thing by investigating human rights abuses over the years.
} 
achieved no meaningful reconciliation because of the undue politicization of the process from the start (Ayee, 2006; Boafo-Arthur, 2006).

With all the constraints that faced the NRC, the partisan ramifications that engulfed its creation and operations may remain its lasting regrettable legacy. The political milieu in which it was born (See Ayee, 2006; Boafo-Arthur, 2006; Valji, 2006) continued to impair its work and, subsequently, its report. The creation of the TRC was viewed by members of the NDC as a political witch hunt and, most significant, as a political tool of the NPP with which to damage the reputation of the party's founder, Jerry Rawlings. ${ }^{118}$ Throughout the existence of the NRC, the NDC criticized its work and, in the end, as stated before, rejected the report produced by it as incomplete. ${ }^{119}$ Certainly there is no doubt that the work and outcomes of the NRC were viewed positively by many of the victims who appeared before it and by other well meaning Ghanaians. It is also true that the undue politicization of the NRC process undermined its quest for political reconciliation.

\subsection{Analysing TRC Policy Transfer Success or Failure in South Africa, Nigeria and Ghana}

The examinations of the TRCs in South Africa, Nigeria and Ghana suggest that in each case it was formally established as a legitimate governmental public policy response to transitional justice concerns. The TRCs also operated throughout their mandated

\footnotetext{
${ }^{118}$ These views from the NDC were not without validity, as statements by and postures on the part of some members of the NPP suggested certain political mischief behind the setting up of the NRC. See also comments made by former vice-president who was then the NDC candidate for the 2004 general elections on http://www.modernghana.com/news/119516/1/mpp-wants-to-destroy-ndc-mills-alleges.html. Sourced on September 12, 2011.

${ }^{119}$ The NDC supporters strongly view the exercise as a failure, because it was designed to target Jerry Rawlings and his associates.
} 
period, and were formally terminated after completing their work and producing the required final reports. Consequently, the TRCs followed the valid public policy processes of formulation, implementation, production of report and termination. Based on the study's six-phase multi-dimensional conceptualization of TRC policy transfer success or failure, the TRCs in South Africa, Nigeria and Ghana were successful in the three phases of establishment, operation and production of the final report. There were, however, significant differences in the outcomes in the remaining three phases, regarding the degree of cooperation from witnesses and key persons the TRCs received, the extent to which the reports produced by the TRCs were accepted by the government and publicly released, and the extent to which the appointing government implemented all or aspects of the recommendations made by the TRCs in their reports.

The discussion of the outcomes of the TRCs in the selected cases makes it clear that the level of cooperation the TRCs received varied. While they received maximum cooperation from victims, as was expected, the level of cooperation expected from key prominent individuals, among them alleged perpetrators, differed across the cases. In South Africa the TRC did receive eventual cooperation from almost all of the key people required by it except for one, P.W. Botha, even when the TRC used all of its powers to compel him to appear. In Nigeria, while the TRC received some cooperation from some alleged perpetrators, its inability to bring three former heads of state before it damaged its reputation. The presence of these three former generals would have been vital to the TRC's work, since the years of their cumulative reigns witnessed the most gruesome human rights abuses in the recent political history of Nigeria. In Ghana the TRC managed to bring all necessary witnesses, including a former military head of state and his 
associates, before it. Based on these outcomes, the study designates both the South African and the Ghanaian TRCs as, respectively, a partial success and a success as far as the phase of cooperation from witnesses is concerned. The Nigerian TRC is considered a partial failure.

Similarly, regarding the phase of the acceptance or otherwise of the TRC report and its public release, both the South African and the Ghanaian TRCs are considered success cases, while the Nigerian TRC is assigned a failing grade. In South Africa and Ghana the TRCs' reports were publicly accepted by the sponsoring governments, subsequently released to the public, and widely disseminated. The reports by the TRCs also received broad acceptance from the public, despite some reservations by certain sections. In the case of the Nigerian TRC, the report was neither officially acknowledged by the sponsoring government, nor made public by way of release and dissemination. There is also little evidence to support the broad acceptance by the Nigerian public of the content of the concealed report. Finally, in both South Africa and Ghana, there was partial implementation of the findings and recommendations, in particular on reparations. In Nigeria there has been no implementation of the findings and recommendations. Accordingly, the South African and Ghanaian TRCs are measured to be partial successes, with Nigeria a failure.

It is clear that the TRC policy transfer outcomes in the three cases varied across the phases and across the countries. South Africa recorded four successes and two partial successes; Nigeria recorded three successes, one partial failure and two failures; and Ghana recorded five successes and one partial success (See Table 4). In terms of ratings, Ghana's policy transfer outcomes were highly successful, followed by South Africa. The 
Nigeria TRC policy transfer outcomes were less successful. This confirms that it is no accident that Ghana's TRC has been described as one of the 15 illustrative TRCs globally, the South African TRC as one of the five strongest TRCs ever established, and the Nigerian TRC as one of the 20 weakest TRCs ever created (Hayner, 2011).

Accounting for the different outcomes and the degree of success of the TRC policy transfer in the three cases can only be done by referring to the domestic policy formulation processes of the transferred policy. The extent to which the restorative justice ideas embedded in the TRC-approach were successfully planted in the domestic political and social structures has significant repercussions for the degree of success of the TRCs in the formulation process. These issues as they relate to the current study are examined in subsequent chapters. 
Table 4: Success and Failure in TRC Policy Transfer Outcomes in South Africa, Nigeria and Ghana.

\begin{tabular}{|l|l|l|l|l|l|l|}
\hline Phases & Phase 1 & Phase 2 & Phase 3 & Phase 4 & Phase 5 & \\
\hline Variables & TRC Establishment & TRC Operations & $\begin{array}{l}\text { TRC Receives } \\
\text { Cooperation From } \\
\text { Witnesses and } \\
\text { Key Personalities }\end{array}$ \\
$\begin{array}{l}\text { TRC } \\
\text { Final Report }\end{array}$ & $\begin{array}{l}\text { TRC Report Accepted by } \\
\text { Government and Publicly } \\
\text { Disseminated } \\
\text { Wholly or Partially } \\
\text { Implemented } \\
\text { Trouth Africa } \\
\text { TRC Success }\end{array}$ & Success & Partial Success & Success & Success & Partial Success \\
\hline Nigeria TRC & Success & Success & Partial Failure & Success & Failure & Failure \\
\hline Ghana TRC & Success & Success & Success & Success & Success & Partial Success \\
\hline
\end{tabular}




\subsection{Summary and Conclusion}

The subject of this chapter is the examination of the study's dependent variable: the policy transfer of the TRC-approach. Three broad questions informed the discussion of the dependent variable: Did TRC policy transfer occur? If it did occur, what was transferred? And, what was the degree of transfer that took place? Examining the South African, Nigerian and Ghanaian TRCs, the chapter established that in all three cases, TRC policy transfer did occur. By scrutinizing government statements, official records, pronouncements by official policy actors, media reports and other written conference reports, as well as personal communications -- all of which are sources identified in the Dolowitz and Marsh policy transfer model -- it was confirmed that the formulation of the TRCs in the selected cases resulted from policy transfers.

The chapter also revealed that both TRC policy goals and the policy instrument or administrative mechanism were the primary aspects of the TRC-approach that were transferred in all of the three cases. South Africa, in addition, transferred the positive and negative lessons associated with previous TRCs to inform its own TRC policy formulation process. In all cases the TRC policy goals transferred were similar, and conformed to the standard TRC goals. The transfer of the TRC policy goals, its administrative method and lessons confirm Dolowitz and Marsh's observation that in policy transfer endeavours, policymakers may borrow any of the nine objects singly or in combination. The latter, combination, was what happened in South Africa, Nigeria and Ghana.

All three cases transferred the standard quasi judicial commission of inquiry method. There were, however, significantly differing nuances in the operative structures 
of the administrative method, including, for example, differences in the powers entrusted to the commissions. Dolowitz and Marsh further suggest in their model that policy borrowers are usually more interested in the structure or administrative method than in the effect of the policy. The record of the Nigerian TRC appears to confirm this observation.

The degree of transfer also differed across the cases. In South Africa, the degree of transfer was of the mixtures or combination type; in Nigeria, it was the inspiration type; and in Ghana, it was the emulation type. Dolowitz and Marsh suggest in their model that the emulation type of transfer is usually preferred by politicians for rapid and convenient solutions to policy problems. As will be discussed in the next chapter, Ghana's TRC policy on addressing transitional justice needs may have been just such a "quick fix" solution.

Having examined the policy transfer dynamics of the TRC-approach in the selected cases, the chapter analysed the success or failure of the TRC policy transfer outcomes using the study's definition of success. The analysis suggests that the TRC policy transfer outcomes in South Africa and Ghana recorded a combination of successes and partial success across the six phases, while that of Nigeria recorded a combination of success, partial failure and failures. Explaining what may account for these variations of outcomes across the three cases requires investigation of the relationship between domestic structures and policy transfer process. That exercise is undertaken in Chapter 7.

After demonstrating the policy transfer of the TRC-approach in the selected cases, and analysing the success of TRC policy transfer outcomes, the next chapter analyses the question of why did the societies and their policymakers engage in TRC policy transfers. 
Among the issues that inform the next chapter is why the adoption of a TRC-approach, and not any other, to transitional justice in the three countries. 


\section{Chapter 5: Why the TRC-Approach Policy Transfer?}

\section{5,0: Introduction}

In the previous chapter it was established that South Africa, Nigeria and Ghana engaged in a policy transfer of the TRC-approach as a transitional justice policy. In each case policy transfer of the TRC-approach resulted from a voluntary act on the part of the new political leadership, which responded to demands from its citizens -- in particular, victims of gross human rights abuses -- to address injustices associated with the previous regime or regimes. Further, the successor regimes saw the demands from citizens as an opportunity to distance their governments from previous abusive regimes, and to promote a human rights friendly image in the international community. Why did the new regimes in South Africa, Nigeria and Ghana pursue the TRC-approach policy transfer, and not any other transitional justice options? What triggered this voluntary action?

This chapter asserts that the voluntary transfer of the TRC-approach was a reaction to certain institutional obstacles that prevented the application of the familiar and prevailing criminal justice policy response to transitional justice during the countries' political transitions. These obstacles made the restorative justice process, with which the TRC-approach is associated, more attractive and structurally appealing than the retributive justice option. The circumstances that led to the policy transfer of the TRCapproach in South Africa, Nigeria and Ghana are examined in this chapter.

The chapter begins with a discussion of the nature of the political transition and of the transitional justice discourse that ensued in each country. The chapter demonstrates that transitional justice concerns were part of the policy discourse during the political 
transition in each of the three countries. The desire for a judicial policy approach to transitional justice in each country was also apparent. However, varied domestic institutional challenges ${ }^{120}$ that manifested during the political transitions did not promote a judicial policy approach. Rather, the TRC-approach was formulated by the posttransition regimes in order to respond to the demands for transitional justice.

The study next analyzes the institutional limitations that prevented the application of the existing judicial policy approach, and thereby influenced the successor regimes to undertake policy transfer of the TRC-approach. The fundamental question that informs the analysis is: were these institutional obstacles daunting enough to prevent the use of the judicial policy approach and to inspire a TRC-approach policy transfer? This discussion is followed by an analysis of the case studies that contributes to verifying the study's first hypothesis. Next come the summary and the conclusion.

It will be demonstrated in this chapter that the policy actors' appeal to the notion of restorative justice (as informed by interest) and the manifestations of identities all combined to facilitate the policy transfer of the TRC-approach to transitional justice process. In spite of the fact that varied institutional impediments during the respective political transitions of the three cases prevented the application of a judicial policy approach. In other words, insights from social constructivism framework, in particular agents-structure relationship, are drawn to illuminate how the interactions occurred resulting in the policy transfer of the TRC-approach.

\footnotetext{
${ }^{120}$ By Institutions, this study extends perspectives offered by North (1990), Thelen and Steinmo (1992), Hall and Taylor (1996), and Thelen (1999), among others, to generally connote state-sanctioned rules such as regulations, constitutions, and laws, and formal organizational structures such as the Legislature, the Judiciary, the Bureaucracy, and the Executive that exist in the state as instruments for public service delivery.
} 


\section{1: Political Transitions and the Transitional Justice Demands in South Africa, Nigeria, and Ghana}

The political transitions that occasioned transitional justice demands are examined in this section. It begins by looking at the 1994 South African political transition from apartheid rule to a democracy, then the 1999 Nigerian transition from military rule to democratic governance, and then the Ghanaian 2001 political transition from one democratically elected government to another. The three political transitions followed different trajectories. In all cases, however, the demands for transitional justice by citizens and in particular by victims of human rights abuses emerged during the transitional phase, and assumed prominence following the conclusion of the formal transition process. The discussion of each case pointedly acknowledges that the citizenry continued to be haunted by the memory of the human rights abuses it endured, and shows how in all cases the new political leadership promised to be different from that of the previous, abusive, regimes, and consequently created the opportunity to revisit the past and address the legacy of gross human rights violations.

\subsection{1: South Africa}

April 1994 marked the end of one important period in the history of South Africa, and the beginning of a new one. The shackles of apartheid were formally broken following a multiparty election that saw adult South Africans of all races going to the polls. The transitional elections marked the demise of over 40 years of apartheid rule. Between 1948 and 1994 South Africa was an apartheid society, where a minority white race ruled over the majority black race. Through a policy of "separate development" (See Dugard, 1972; Mulder, 1972), the successive white minority apartheid regimes instituted 
and maintained racially discriminatory policies that trampled on the fundamental human rights of the majority of South Africans.

The apartheid policies discriminated against white and black in all aspects of their social, political and economic lives. Policies on education, health, livelihood, sexual preference and relationship, marriage, political governance and aspirations for self determination, among others, were affected by apartheid rule. Resistance to these racially discriminatory and unfriendly human rights policies was dealt with forcefully by the South African apartheid governments. In the late 1960s resistance assumed the form of armed struggle between the opposition black groups and the state security forces, accompanied by unprecedented levels of violence and abuse.

The scale of the repression, massacres, and torture, including the long, sometimes lifelong, jail sentences inflicted on protestors, and other heinous human rights violations during this period is well known and recorded elsewhere (Davis, 1987; Worden, 1994; O' Meara, 1996; Asmal, Asmal, and Roberts, 1997; Ellis, 1998). Some of the notable violations that occurred between 1960 and 1980 include the March 1960 Sharpeville massacre of unarmed protesting Africans, in which hundreds lost their lives through indiscriminate shooting by the South African Police; the June 1976 Soweto uprising, which estimates put between 200 and 700 deaths of black students peacefully protesting against the forced study of Afrikaans (the official Apartheid language); the clandestine state security operations that targeted and assassinated prominent leaders of the black resistance groups, including the arrest, torture and death of Steve Biko of Black Consciousness (BC); and the banning of the leading black resistance groups, including the ANC and the PAC. 
The oppressions continued with unabated intensity during the dying days of Apartheid rule. Over 14,000 South Africans, for example, are reported to have lost their lives through politically-related violence between 1990 and 1994 alone (Ellis, 1998; Stanley, 2001). In the late 1980s, it became increasingly obvious that apartheid rule could not be sustained indefinitely. A combination of factors resulted in the 1994 political transition: crisis in economic management, the escalation of the resistance movement, changing dynamics of global politics -- the end of the Cold War and the collapse of the Soviet Union -- and the intensification of international sanctions against South Africa (Morris, 1991; Murray, 1994; Worden, 1994; O’ Meara, 1996; Marais, 1998; Zunes 1999; Butler, 2004).

Most significant, the worsening economic situation that had begun in the 1970 s sent the apartheid regime hurtling toward the dramatic political transition. In the 1980 s the economic stress was such that cracks began to appear in the support base of the apartheid ruling NP government. By the beginning of the 1990s, these dynamics forced the NP into negotiations with the ANC, during which each party recognized its own weakness and the strength of the other. ${ }^{121}$ Both parties leveraged on aspects of the negotiations to suit their respective interests due to the rough political equilibrium that existed between them.

The 1994 elections followed nearly four years of tense and difficult negotiations that began with the launch of the Convention for a Democratic South Africa (CODESA)

\footnotetext{
${ }^{121}$ The NP, while it had initiated the political transformation under President F.W. de Klerk, recognized the strength of the ANC-led opposition in terms of numbers and, also, the political legitimacy that a new multiracial South Africa would bring. The ANC-led opposition was also conscious of the military and economic might of the NP, as well as its own deficiencies in governing. For instance, it is described elsewhere that the ANC entered the negotiations without any clear program to dismantle the foundations of apartheid (Marais, 1998).
} 
in December 1991. The unsurprising outcome of the transition was a compromise informed by the interests and influence of the political actors. The negotiations, in fact, became a direct confrontation between the NP and the ANC-led opposition. One of the significant issues that the parties had to address right from the start was the subject of transitional justice. As Berat, for example, observes, "[T]he question of treatment of those both within the government and within the opposition who had committed human rights abuses became a contentious issue" (1995:268). The National Party sought unconditional blanket amnesty for all persons associated with its rule since 1960; this was the party's condition for a successful and peaceful transition (Christie, 2000; Simpson, 2002).

In view of its awareness that it would no longer have any role in governing after the multi-party elections in South Africa, the National Party's demands for unconditional amnesty for the actions of its operatives during apartheid rule seemed only rational. The ANC, recognizing the possibility of the breakdown of the negotiations and the threat of potential destabilization in the aftermath of the transition, had no choice but to accept. It compromised its position by agreeing not to pursue judicial vendettas against NP operatives. As Marais states, fear of disloyalty in the security forces compelled the ANC to agree to this amnesty (1998:92). The provision was understood at the time to be one agreement fundamentally necessary for what it was hoped would be, and was, an uneventful political transition. Graybill quotes Kader Asmal, an influential member of the ANC, to the effect that the nature of the South African political settlement was that it was concerned with how best to consolidate the transition peacefully but without forgetting justice (2002:1). 
The 1993 Interim Constitution that emerged from CODESA and, subsequently, the post-apartheid "Government of National Unity"122 were the products of this political transition. Accordingly, the South African political transition has often been described as a negotiated settlement and an "elite-pact" political transition (Berat, 1995; Marais, 1998; Harbeson, 1999; Christie, 2000; Bond, 2000; Saul, 2004). Both descriptions have merit, for it was a transition that produced no absolute winner, and that was decided by the top political leadership of both parties; hence the compromise nature of the outcomes. ${ }^{123}$ The South African political transition to democracy is, however, best explained as an example of the "transplacement" type of democratic transition (Lemarchand, 1994). It was characterized by the combined efforts of all parties, and in particular of the government of the NP and the ANC-led opposition, in the negotiations. ${ }^{124}$

In a transplacement democratic transition (Huntington, 1991; 1995), outcomes are expected to defy conventional assumptions. One such contradiction in the South African transition was the agreement not to pursue criminal justice against operatives of the NP for human rights violations. Such an agreement defied international law and conventions, as well as accountability principles that are realized in the pursuit of criminal justice against violators of national and international human rights laws. Nevertheless, that

\footnotetext{
${ }^{122}$ This was a formula for sharing power between the ANC and the NP, where the entering and exiting parties were represented in the first post-apartheid government for South Africa. Christie (2000) suggests that it was a dignified exit from the political stage for the NP.

${ }^{123}$ Aside from the amnesty compromise, negotiation outcomes reflected a multi-party democracy, resulting in black majority rule and upholding the economic and capital interests of the white minority. The 1993 Interim Constitution produced liberal democratic principles as the new foundation for South Africa. For the NP and its supporters, this agreement protected property rights and limited the state's ability to commandeer privately owned property.

${ }_{24}$ On the NP side, the reformists, led by President de Klerk, were able to overshadow the "standpatters", and moved the party into negotiations with the ANC. Equally, on the opposition side, the ANC understood the need to negotiate, and represented a moderate view unlike that of the Pan Africanists Congress (PAC), which had an entrenched radical stance on South Africa being solely for South African blacks. While the ANC's moderate views prevailed, they were not strong enough to completely overthrow the government of the day.
} 
defiance was informed by political pragmatism, and by imperatives targeting stability following the transition. As Huntington (1995: 81) admonishes, regarding transitional justice during democratic transitions: "[]f transformation or transplacement occurred, do not attempt to prosecute authoritarian officials for human rights violations. The Political costs of such an effort will outweigh any moral gains".

Certainly, this caution fits the South African political transition well. Any attempt to avoid accommodating the interests and concerns of the NP may have caused trouble for South Africa's political future, especially with the threat of civil war lurking during the negotiations (See Murray, 1994; Marais, 1998; Arnold, 2000; Christie, 2000). Notwithstanding, before the transition was formally concluded, sections of the South African populace opposed the amnesty agreement. Groups within the ANC and sections of the victims' community criticized it (Graybill, 2002). Some of the radical black antiapartheid groups, such as the PAC and the Azania Peoples Organization (AZAPO), strongly condemned it. The latter group subsequently challenged the constitutionality of the provision when it was activated by contesting the powers of the TRC to offer such amnesties. Although AZAPO lost the court case, the contestation of the TRC power to grant amnesty to perpetrators was an indication that sections of South Africans preferred a criminal justice process to transitional justice; and soon after the 1994 transitional elections, demands for transitional justice re-emerged in the public space.

These demands were, indeed, especially urgent in the public sphere (Berat, 1995; Dugard, 1997; Simpson, 2002). The amnesty provisions agreed on and made part of the 1993 Interim Constitution prevented any such judicial policy measures, however. The provisions enraged victims of apartheid crimes and human rights organizations who had 
opposed them for their unfairness. They argued that the amnesty deal only served the interest of the perpetrators of apartheid crimes, and derided the agreement's disregard for victims (Simpson, 2002). Attempting to respond, the newly democratically elected ANC government initiated a transitional justice process that brought victims into the equation by drawing on the restorative justice ideas that the TRC-approach advances.

\subsection{2: Nigeria}

The sudden and mysterious death in mid 1998 of General Sani Abacha, one of the many generals who had in succession ruled Nigeria since 1983, instigated a process of political transition from military to civilian democratic governance. His successor, another general, Abdusalami Abubakar, initiated the transition in the latter months of 1998, with elections held in February 1999. The political transition was completed in May 1999 when former military head of state President General (rtd) Olusegun Obasanjo $^{125}$ and his PDP took over as the democratically elected government. It was the third attempt at democratic governance in Nigeria since attaining independence from Great Britain in 1960. It marked the end of over 30 years of a series of military administrations in the post-independence country. Previous attempts at restoring democratic rule since the first military intervention in 1966 were curtailed by the military (lhonvbere, 1996; Mustapha, 1999; Obiagwu and Odinkalu, 2003; Okafor, 2006; Idowu, 2008). The 1999 political transition is often described as the result of luck because of the unexpected death of General Abacha. Nwogu (2007) describes it as a mixture of providence and sensibleness on the part of General Abubakar.

\footnotetext{
${ }^{125}$ General Obasanjo was a military ruler in the $1970 \mathrm{~s}$.
} 
While there had been considerable civil society pressure on General Abacha to transfer power to civilian rule, there was no indication it would happen (Obiagwu and Odinkalu, 2003; Omotola, 2007). Persistent and widespread domestic and international pressures on the military to exit politics followed the death of General Abacha, and were reinforced by the image of the military, discredited by its poor human rights record. The disdain for the military establishment was reflected in an Afrobarometer opinion study conducted in early 2000 (Lewis and Bratton, 2000). Over 3,000 adult Nigerian respondents, the majority of them (78\%), ranked the military the least preferred political alternative. The Afrobarometer is a standardized research instrument that measures the social, political and economic atmospheres in sub-Saharan Africa. An independent and non-partisan research project, it currently covers over 20 countries. One key objective is to compare trends in public attitudes on these issues over time. It has conducted four rounds of research, beginning in $1999 .{ }^{126}$

In this study, the former military regimes earned a mean score of 2.5 , far lower than the former colonial regime and the traditional system, which scored 4.1 and 4.0, respectively. The extent to which the military had lost favour among Nigerians was confirmed by the 90 percent of respondents who said that it should never govern again. The military establishment was forced to retreat from politics. ${ }^{127}$ As Mustapha (1999:281) observes, General Abubakar realized the depths to which the military, and the country, had sunk.

The 30 years of military rule in Nigeria saw several forms of gross human rights abuses, including severe repression of individual human rights, state sponsored ${ }^{126}$ For further information on Afrobarometer and the dataset on Nigeria, See:
http://www.afrobarometer.org/
${ }_{127}$ Only 37 percent of Nigerians demonstrated any trust for the military in this survey. 235 
assassination of prominent Nigerians, including politicians and journalists, and restrictions on civil liberties (Joseph, Taylor and Agbaje, 1996; Obiagwu and Odinkalu, 2003; Agbaje, 2004; Onyegbula, 2004; Yusuf, 2007; Kazah-Toure; 2007). The most notorious of these military regimes, perhaps, was the one under General Abacha from 1993 to 1998. It was a time of widespread repression of human rights advocates, prodemocracy activists, journalists and critics of his rule. Extra judicial killings, torture, imprisonments without due process and harassment of citizens were typical. It was during his rule that rights activist Ken Saro-Wiwa and eight other compatriots from the oil rich Niger Delta were executed for asserting their civil and political rights (Ihonvbere, $1996)^{128}$

Nigeria also endured three years of civil war, popularly known as the Biafra War, between 1967 and 1970, which claimed an estimated one million lives (Fombad, 2002). On top of this contagion of military rule and civil war have been the perennial religious and ethnic conflicts that have divided the nation since 1960. When President Obasanjo came to power there was little dispute that Nigeria was a divided country, partly the result of a history of gross human rights abuses and, partly, the result of growing ethnic nationalisms.

The 1999 political transition exemplified the replacement mode of Huntington's

$$
\text { types of democratic transition. }{ }^{129} \text { The unexpected death of General Abacha }
$$

\footnotetext{
${ }^{128}$ This incident is popularly known in Nigerian and international circles as the murder of the Ogoni nine. Led by Ken Saro-Wiwa, these were human rights and environmental activists protesting against Nigeria's and foreign oil companies' disregard for the safety of the Ogoni people, an ethnic group in eastern Nigeria, and of their land. The activists were arrested by the Nigerian authority and put on trial --a trial that was generally described as a flawed process.

${ }^{29}$ In this type the authoritarian or military regime falls, and is replaced by a new set of civilians and a democratic regime. The collapse is precipitated by weaknesses within the dictatorial or authoritarian regime that lead to its loss of political strength, with the opposition to the regime growing stronger until the former collapses or is overthrown.
} 
weakened the Nigerian military. The accumulation of several years of misrule, corruption, and egregious human rights abuses damaged its credibility, preventing the perpetuation of its rule. The credibility of General Abubakar was also undermined through his association with General Abacha. The opposition in Nigeria, then organized into vociferous civil society groups (Agbaje, 2004; Omotola, 2007), grew stronger with support from the international community, and was able to help steer the transition process.

Between June 1998 and February 1999 the influence of the opposition was greater than that of the military. Therefore, while the military initiated the transition process, it was too weak to influence it sufficiently in its favour. The exit of the military and the entrance of civilian democratic government resulted, not from negotiations or an elite pact agreement, as the case of South Africa suggests, but from a complete replacement of the military. Its reduced political power and its discredited image precluded it from posing any significant threat to the transition. The peace versus justice quandary was consequently of little pertinence during the Nigerian political transition.

While the Nigerian civil society groups had been protesting against the culture of impunity long before General Abacha rose to power in 1993, calls for justice and accountability by Nigerian human rights and democracy forces had been rife throughout his rule (Ikelegbe, 2001; Edigheji and Momoh, 2005; Omotola, 2007). This demand intensified following his death, and continued when the transition was completed (Ojo, 2006; Omotola, 2007). Expectations of justice for human rights violations and corruption from civil society groups and individual victims of abuses grew under the newly civilianelected President Obasanjo government (Onyebula, 2004; Yusuf, 2007). 
This above view is also affirmed by representatives of the civil society community: Godwin Aidenagbon recalls that civil society expected some form of transitional justice process to emerge from the Obasanjo government because of the victimization of members of the civil society community during the era of military regimes and, subsequently, the role some of them played during the political transition; Sam Amadi also observes that Nigerians saw an opportunity to demand for investigations into grievous human rights abuses, extra-judicial killings and disappearances that have occurred prior to the political transition (Personal Interviews, January 27 and 29, 2009 respectively). The PDP government responded, and also promised to take steps to safeguard the human rights of all Nigerians (Obiagwu and Odinaklu, 2003; Ojo, 2006).

Many Nigerians expected and supported judicial inquiry into the rule of military regimes: in particular, those beginning in $1983 .{ }^{130}$ Nigerian civil society expected President Obasanjo's PDP government to initiate a process of transitional justice that included criminal justice and accountability for the human rights transgressions of previous military regimes. As Innocent Chukwuma remarks, "for us in the civil society, we felt that impunity had been allowed to bring riot in this country for a long time but we should go all out, get those guys, try them in a formal court, put them behind bars to serve as a deterrent" (Personal Interview, February 5, 2009). Another observer, Priscilla Ankut had this to say "the greater expectations came to civil society because the expectation was for justice [retributive] to be done and I don't even think the civil society was calling for reconciliation, civil society was demanding justice, it was demanding redresses for rights

\footnotetext{
${ }^{130}$ This position represented the view of a majority of respondents interviewed in Nigeria in 2009 . The 1983 date was significant because it was the year that the military overthrew the civilian administration, curtailing the second attempt at democratization, resulting in a series of military adventures that lasted until May 1999.
} 
that had been violated in the past and that didn't happen" (Personal Interview, January 21, 2009).

Certainly, the replacement type of political transition that occurred encouraged the criminal justice approach to the transitional justice process. As Huntington advises, "If replacement occurred and you feel it is morally and politically desirable, prosecute the leaders of the authoritarian regime promptly" (1995:81). Contrary to popular expectations of a judicial trial however, President Obasanjo's government promoted and established a TRC, the Human Rights Violations Investigation Commission (HRVIC), inspired by the South African TRC, to review cases of human rights abuses under all military regimes, beginning with the 1966 military intervention. In reality, the Nigerian account suggests that, unlike South Africa and Ghana, the institutional barriers that stood in the way of a criminal justice process to transitional justice were not that acute. Therefore, the expectations of the Nigerian civil society for a criminal justice process were not completely out of place.

Nonetheless, it is significant to point out, as it will be examined in detail below, that the primary institution to undertake judicial trials--the Judiciary--had been bastardized over the years during the successive military regimes to the extent that it had been rendered too weak and distrusted to pursue any meaningful transitional justice process. As will be demonstrated below, this manifestation may have informed President Obasanjo and the PDP government to draw from the South African experience with the TRC-approach. 


\subsection{3: Ghana}

The political transition in Ghana that bore a quest for transitional justice occurred in January 2001. It was a transition within a democracy, and not a transition from military or authoritarian rule or civil war to a democracy. While the focus of this study is associated with the 2001 political transition, it is necessary, however, to briefly sketch Ghana's 1992 democratic transition. Describing this particular transition provides an understanding of the contradiction surrounding the timing of Ghana's transitional justice processes as was examined in Chapter 4. Significantly, it helps to appreciate the institutional constraint that led to the choice of a non-retributive justice policy approach.

As observed in Chapter 4, Ghana made such a momentous democratic transition in November and December 1992 with a civilian administration assuming political office in early 1993. The transformation from authoritarian military rule to a democracy was dictated by the Provisional National Defence Council (PNDC), which ruled a military junta headed by Flight Lieutenant Jerry John Rawlings. The PNDC transformed itself into a political party, the NDC, and contested and won the 1992 transitional elections (both the presidency and legislature). ${ }^{131}$ Thus the PNDC, in a controlled, carefully managed and guided way (Shillington, 1992; Gyimah-Boadi, 1993; Ninsin, 1998; Quainoo, 2000), transferred political power to itself (the NDC) on January 7, 1993, and ruled as a civilian government for two consecutive four-year terms until January 2001, when the main opposition group, the New Patriotic Party (NPP), won political power through an election victory in December 2000.

\footnotetext{
${ }^{131}$ Flight Lieutenant Rawlings, who resigned as a military officer a few months before the elections, remained head of state to run for office on the NDC ticket.
} 
Ghana's 1992 political transition epitomized Huntington's

"transformation" typology of democratic transition. As with this type of transition, the engineering and manipulation of the process enabled the PNDC to safeguard its interests and those of previous military regimes by preventing any future judicial inquiry into human rights violations of the preceding era. The Rawlings-led PNDC inserted an indemnity provision that entrenched a self amnesty to cover members of its leadership and associates in the 1992 Constitution that facilitated the transitional elections. BoafoArthur (2005) argues that the indemnity provisions were "secretly" inserted into the Constitution by the leaders of the PNDC military regime. ${ }^{132}$ Accordingly, a transitional justice process to address human rights abuses during the 11 years of the PNDC rule did not surface during the 1992 transitional phase itself or its aftermath. The self-indemnified clauses -- a product of the 1992-3 transition - closed all avenues for any judicial inquiry into the rule of any and all previous military regimes.

As with Nigeria, Ghana's political history since independence in 1957 had been chequered. Until the 1993 democratic political transition, Ghana was ruled by four different military juntas, spanning a total of 22 years. These periods were characterized by widespread gross human rights violations and a culture of impunity. The regimes of Jerry Rawlings -- the Armed Forces Revolutionary Council (AFRC) from June 4, to September 23, 1979 and the PNDC from December 31, 1981 to January 6, 1993 -- are described as the worst years of egregious abuses of human rights in Ghana's history (Oquaye, 1980; 1995; 2004; Haynes, 1991; CDD-Ghana, 200la; Busia, 2003; Attafuah, 2004; Boafo-Arthur, 2005; 2006; Ameh, 2006a; 2006b; Gyimah-Boadi, 2006). Ameh, for

\footnotetext{
${ }^{132}$ The national consultative assembly that drafted the 1992 Constitution did not include any amnesty clauses. The provisions were also extended to cover all previous military regimes since 1957.
} 
example, describes Rawlings' two regimes as "socialist-inspired military regimes" that witnessed the most callous and vicious acts against Ghanaians (2006b: 96). Both of his military juntas saw flagrant arrests of men and women, stripped naked and publicly flogged, either for hoarding essential commodities or selling them above prices stipulated by the government.

Furthermore, it is also on record that over 300 people were proclaimed missing or extra-judicially killed: among them three high court judges and a retired military officer abducted and murdered, allegedly, by a government death squad in a famous and politically very tainted episode (Gyimah-Boadi, 2006). Boafo-Arthur describes this period of PNDC rule as "a decentralized structure of tyranny and violence" (2005: 105). It is no surprise that when exiting office in 1993 the PNDC ensured that there would be no formal inquiry into the regimes - not only the two of Jerry Rawlings, but all previous military rules -- by guaranteeing for itself a blanket amnesty.

The 2001 political transition was, however, a replacement of the NDC regime ("the offshoot" of the PNDC). The NPP won the presidency, and gained a slight majority in Parliament in the elections organized in December 2000. The 2001 transition marked the liberation of Ghana from the long period of military and military-infused civilian administrations of Jerry Rawlings. ${ }^{133}$ The public euphoria that greeted the formal handing-over of power on January 7, 2001 was a testimony to the authenticity of the

\footnotetext{
${ }^{133} \mathrm{Jerry}$ Rawlings became the longest serving head of state in Ghanaian political history, with a total of 19 years (1981-2000), not including his three-month short stay in 1979. His two civilian administrations were generally no different from his military regime. Although Jerry Rawlings presided over a democratic system of governance, he was unable to extricate himself from his military background. He was very much attached to the military establishment, and many of his antics were anti-democratic and militaristic. He was notorious for savaging the Constitution and intimidating the autonomous governance institutions, as well as stifling free speech, throughout his civilian regimes. All of his regimes were hostile to constitutionalism (Agyeman-Duah, 2002; 2008). Adedeji (2001) argues further that the political atmosphere in the aftermath of the 1992 democratic transition did not present a congenial or suitable political environment for wider public participation.
} 
transition and an expression of the sense of independence from Rawlings' authoritarian rule. $^{134}$ The quest for transitional justice was a central part of the 2000 electioneering campaign. Jerry Rawlings, after serving his two-term limit, was, as required by the Constitution, going to be replaced either by a candidate from his party or from the opposition. The latter scenario appeared likely. The political debate focused on how to address the unattended human rights violations during the PNDC rule.

It became obvious that the policy of amnesia, which itself is consistent with the transformation type of democratic transition that occurred in 1992, that had characterized the eight years of NDC rule was not sustainable in the long term. All the political parties, including the NDC, made public statements about addressing the history of human rights violations (Focus Group Discussion \# 1, January 15, 2009). Having replaced the NDC, the NPP departed from the conventional norm of undertaking criminal prosecutions of those who have perpetrated severe human rights violations against citizens. Indeed, the majority (63\%) of Ghanaians polled in 2001 before the development of a bill for the transitional justice process supported a criminal justice approach to transitional justice. ${ }^{135}$ Instead, the NPP government enacted a law to create a TRC: the National Reconciliation Commission, modelled on the South African TRC, to address the wanton disregard for historic human rights violations. The NPP chose a restorative justice process instead of the expected retributive one.

\footnotetext{
${ }^{134}$ The 2001 transition should be considered the real democratic transition in Ghana. The 1992 election was flawed from several perspectives (Oquaye, 1995; Boahen, 1995; Quainoo, 2000). A Ghanaian academic is reported to have remarked that many Ghanaians saw the day as instituting independence all over again. See the news story on Ghanaweb.com retrieved on July 8, 2010 from: http://www.ghanaweb.com/GhanaHomePage/NewsArchive/artikel.php?ID=12975

${ }^{135}$ This survey, conducted in May 2001 by CDD-Ghana (2001), sampled the views of 1,000 throughout the country, and was based on the probability sampling technique, which involved a multi-stage stratified and nationally representative cluster sample. Using systematic sampling, the survey targeted individuals aged 25 years and above.
} 


\section{2: Institutional Limitations and the Resulting TRC-approach Policy Transfer in South Africa, Nigeria, and Ghana}

The political transitions of the three cases examined above demonstrate diverse paths, and yet they all ultimately employed the TRC-approach as their transitional justice policy. The present study suggests that certain institutional obstacles stood in the way of the then-prevailing judicial policy that could have advanced retributive transitional justice in South Africa, Nigeria and Ghana. These obstacles encouraged the policy transfer of the TRC-approach to transitional justice policy in the three cases. What were the nature and circumstances of these barriers? This section examines these obstacles, and suggests that they were varied and more consolidated in South Africa and Ghana than in Nigeria. Further, ways in which the leaders associated with the successor regimes expressed interest and desire for the restorative justice values which the TRC-approach advances are also discussed.

\subsection{1: South Africa}

The negotiations between the NP and the ANC that produced the South African political transition resulted in agreement to provide blanket amnesty for gross human rights violations for persons associated with the apartheid regimes. The amnesty agreement, which was to be made part of the 1993 Interim Constitution, precluded any judicial approach to transitional justice policy. As already observed, victims of human rights abuses and human rights organizations assailed this amnesty deal as unfair and as disregarding the interests of the victims. Civil society organizations demanded retribution for apartheid crimes (Dugard, 1997; Fombad, 2002; Simpson, 2002). To avoid public uproar, the victims had to be brought into the process. To respond to civil society 
demands and, at the same time, to honour the amnesty agreement, the ANC devised a mechanism that transformed the unconditional amnesty into a conditional one. Amnesties were now to be granted only upon the full disclosure of the truth: a "quid pro quo for full disclosure" about the abuses (Simpson, 2002: 221).

The postscript of the 1993 Interim Constitution, titled "National Unity and Reconciliation", consequently provided for conditional amnesty for apartheid security operatives against egregious human rights violations. The placing of the postscript in the Constitution confirms Simpson's (2002) position that it was an eleventh-hour accord. The amnesty statute in the Interim Constitution made it illegal for the ANC government to formulate any transitional justice policy that aimed at prosecutions. Neither did the Constitution have any provision for the establishment of a truth and reconciliation commission for South Africa. In other words, while the Interim Constitution enabled the granting of amnesty for full disclosure of apartheid crimes, it did not specify how or by what means. Shea $(2000)$ observes that the precise mechanism for implementing the amnesty clause was left for the newly-elected parliament.

The TRC-approach was a creative response that met the amnesty obligation, brought the victims into the equation, and also came to terms with the past in order to facilitate national reconciliation. Simpson (2002) observes that the then ANC Minister of Justice, Dullah Omar, initiated the process of enacting a legislation that would create both a mechanism and a criterion for the granting of amnesty when the first post-apartheid democratic parliament was constituted. As discussed in the previous chapter, South Africa transferred the TRC-approach, which had essentially been non-retributive but still victim-centred, to transitional justice from foreign sources. Leading policy elites 
associated with the ANC were attracted to the TRC-approach because the format responded to the demands from human rights groups for equal attention to victims.

The TRC-approach provided a platform on which to address the fundamental questions of coming to terms with the past, facilitating healing and restoration of victims, and promoting national reconciliation: all of which South Africa urgently needed to stabilize its political transition. The ANC was attracted to the TRC-approach, not only because it had employed something similar while in opposition, but because it became convinced that the restorative justice outcomes that accompany it were what South Africa needed at that critical juncture of its political dispensation. Therefore, while a judicial policy approach to transitional justice was not permissible because of the amnesty clause, neither was a policy of amnesia, something the NP favoured (Christie, 2000), acceptable to the masses. Obviously, the desirability of the TRC-approach at that particular moment in the South African situation portrays the relationship between policy actors and the restorative justice ideas as informed by the structural conditions. It demonstrates the mutually constitutive nature of the TRC policy transfer with respect to the appeal to the restorative justice ideas, functionality of domestic agents, and the constraints of domestic structure.

The TRC-approach was considered the appropriate mechanism for a transitional justice policy because it could help South Africans put the past behind them and forge national reconciliation, and the needs of victims were to be given equal attention at the same time that perpetrators were given amnesties (Asmal, 1992; Sarkin, 1996; Asmal, Asmal and Roberts, 1997; Tutu, 1999; Boraine, 2000a). Asmal, for example, articulates this position well when he observes that South Africa could not ignore the past, and while 
the truth about the past needed to be officially acknowledged, victims and survivors of apartheid crimes needed to be satisfied to advance national reconciliation, and the TRCapproach offered such outcomes (Personal Interview, March 10, 2009). Exchanging truth for amnesty, it was expected, would offer healing to victims, and facilitate unity and national reconciliation, as captured in the postscript of the 1993 Interim Constitution. Through this format, a new post-apartheid South Africa built on democratic principles and respect for human rights would prevail.

\subsection{2: Nigeria}

The 1999 Nigerian political transition that brought the PDP government to political office was the replacement type, which encouraged a judicial approach to transitional justice. There was no room for negotiations between the outgoing military regime and the in-coming government that could have resulted in an amnesty deal as in the South African process. Nonetheless, the PDP government, headed by President Olusegun Obasanjo, employed the TRC-approach as a policy to address transitional justice demands. The weakness in the Nigerian judicial institution prevented the PDP government from formulating a judicial policy that led to a transitional justice process, which appears, as stated above, to have been favoured by many Nigerians.

In the several years of military rule, the judiciary had come to be associated with the military establishment. It deferred to force, and acquiesced before successive military regimes in the suspension and outright abrogation of the human rights of citizens (Yusuf, 2007; Oko, 2005). The judiciary had, in fact, since several years before the transition, lost credibility among Nigerians. According to one public official who was involved in the 
formulation of the policy on the TRC-approach, it was so compromised in the military regimes era, especially under General Abacha, that it was never trusted to deliver any meaningful criminal justice process (Personal Interview with Professor Akinseye George, February 2, 2009).

Oko observes that the judiciary, which should exemplify the nation's best and most just virtues, characterized the worst aspects of moral decadence in Nigeria (2005: 15). The extent to which it had lost public confidence and trust was reflected in the 1999 Afrobarometer study, which indicated that Nigerians (45\%) were distrustful of it (Lewis and Bratton, 2000; Logan and Machado, 2002). While this opinion did not mirror the majority view - 54 percent demonstrated some trust in the institution - public confidence in the judiciary was, however, minimal, to say the least. Public perception of and trust in the judiciary only worsened as the democratic experiment evolved. In a subsequent Afrobarometer survey, conducted in 2002,74\% of Nigerians expressed distrust for the judiciary. Furthermore, some $(48 \%)$ or most $(42 \%)$ saw their judges and magistrates as corrupt (Bratton et al., 2004). The judiciary thus screamed out for reform in the new democratic dispensation (Oko, 2005; Yusuf, 2008), and President Obasanjo's government earmarked it for such. Oko (2005) asserts that the legacies of military rule, especially corruption, executive control, and manipulation of the judiciary, undermined the ability of the courts to advance fair trial rights.

The decay in the judiciary was so grave that the purview of the truth-telling obligation in Nigeria should have included it, maintains Yusuf (2008). The public perception of the judiciary appears to have validated the view that it should not be used for the transitional justice process. Indeed, the ruling by the courts upholding the non- 
appearance of the three military generals before the HRVIC confirmed that perception. With a corrupt, inept and compromised judiciary, transferring the TRC-approach was deemed justified. Thus was the successor to the military regime prevented from adopting a retributive justice approach to transitional justice in Nigeria. The PDP government nevertheless did not consider any other available apparatus capable of advancing the retributive justice process. Certainly, there were no legal statutes like those in South Africa that prohibited the regime from undertaking criminal or retributive justice actions to account for historic human rights violations.

The notion of restorative justice appealed to the PDP leadership, and the PDP adopted the TRC-approach as a policy to achieve transitional justice. The South African experience inspired the government. President Obasanjo's conciliatory tone in the early stages of his presidency may have influenced his government to pursue a policy of nonretribution and, therefore, the TRC-approach to transitional justice. ${ }^{136}$ President Obasanjo saw himself as a victim of General Abacha's rule, and compared himself to the likes of Nelson Mandela, who eschewed vengeance and upheld the principle of reconciliation. Transferring the TRC-approach in Nigeria was not only informed by the perceived success of the South African TRC but, also, by the desire of President Obasanjo to mimic Nelson Mandela of South Africa. President Obasanjo's personal interest and his ego influenced the PDP to pursue the TRC-approach to the transitional justice process in response to demands from civil society.

Setting up the TRC, which was a voluntary act, was not only to respond to the demands of civil society for human rights accountability; it was also to position President

${ }^{136}$ While in prison (and condemned to death) under General Sani Abacha's rule for alleged subversive actions, President Obasanjo is said to have become a "born again" Christian, and it is argued that his new faith may have driven him to adopt the TRC approach, which offered him the opportunity to clear his name. 
Obasanjo as someone who has respect for, and seeks to promote, human rights, and who shuns retribution but desires reconciliation. The circumstance of the Nigerian case clearly demonstrates the mutually constitutive nature of agents-structure relationship--the manifestation of interest, identity and ideas--that characterized the policy transfer of the TRC-approach. President Obasanjo seized upon the demands of civil society to promote his identity at the world stage. His own interest in becoming an international personality, similar to that of Mandela, fitted well with the restorative justice ideas and therefore led him to promote the formulation of the TRC-approach as a transitional justice policy.

The TRC process helped him to distance himself from the previous military leaders and to project a new image for himself in the international community as a more human rights friendly president. ${ }^{137}$ One informant suggests that President Obasanjo was someone who was very much concern about his international prospects and image, and definitely the TRC process offered him such an opportunity to promote such image (Personal Interview with Priscilla Ankut, January 21, 2009). Chuwkuma observes, however, that President Obasanjo may have been sincere initially and may have set up the TRC to please nobody internationally. However, he saw a chance to "realize a political mileage both within and outside Nigeria" in formulating the policy on the TRC-approach to advance transitional justice in Nigeria (Personal Interview, February 5, 2009). This obviously reflects the constructive nature of the policy transfer and subsequent formulation of the TRC-approach in Nigeria. The circumstances leading to the policy

\footnotetext{
${ }^{137}$ When he assumed office, President Obasanjo was considered one of the few former military leaders who distinguished himself to the admiration of many, locally and internationally. He led his military regime in 1979 in supervising a peaceful and commendable transition to the second civilian regime. Upon leaving office, he transformed himself into a champion of anti-corruption and good leadership through NGO work in Africa. He was critical of General Abacha's human rights record. Through this advocacy body, he had become a notable figure in the Nigerian civil society community and in the international community.
} 
formulation of the TRC-approach in Nigeria reveal the appearance of a self-interest agenda, on the part of President Obasanjo, constructed in part by the attractiveness of the notion of restorative justice which informs the TRC-approach.

To sum up, the nationwide urgency for some response to historic egregious human rights abuses, the limitations, real or perceived, associated with adopting a judicial approach and the personal desire of the leadership of the PDP government, in particular the identity and interests of President Obasanjo, converged at an opportune time to pursue a policy of restorative justice inspired by the South African experience.

\subsection{3: Ghana}

Ghana's 2001 political transition was the replacement type. Its atypical choice of the restorative justice approach was the result of the blanket amnesty that had been added to the 1992 Constitution that began the earlier, 1993, democratic transition. Prior to the completion of the 2001 transition, it was apparent that a retributive justice approach to transitional justice was going to be difficult because of these blanket indemnity provisions. The self granted amnesty thus prevented any form of transitional justice that could advance any criminal or judicial policy approach. Since 1993 Ghana's judiciary had been powerless to entertain any civil or criminal hearings against previous military regimes for gross human rights abuses, or any policy decision taken by these regimes. ${ }^{138}$ Therefore, even if the courts in Ghana had been completely independent, and had not been compromised, as had happened in Nigeria, during the 19 years of Jerry Rawlings'

\footnotetext{
${ }^{138}$ It is on record that the courts in Ghana have thrown out, for lack of jurisdiction, cases brought by plaintiffs against the PNDC and other previous military regimes during the democratic dispensation. 
reign, they still would not have been able to follow a judicial approach to transitional justice because of these indemnity laws in Ghana's statute books.

Adopting a judicial policy approach meant a repeal of the indemnity provisions in the 1992 Constitution. Ghanaians appeared to support a repeal of these provisions and a transitional justice process that was judicial in nature. In an opinion survey, a majority of Ghanaians (69\%) did not know about the indemnity provisions in the Constitution, and a vast majority (82\%) opposed the granting of blanket amnesties to perpetrators of human rights abuses (CDD-Ghana, 2001a). The option of repealing the indemnity clauses was thus favoured by Ghanaians. The pursuit of the criminal justice approach to transitional justice, as noted earlier in this chapter, was also supported by them. The indemnity clauses, however, were entrenched in the 1992 Constitution. Amending or repealing them needed more than a simple majority vote in the legislature; it required a national referendum with half of eligible voters voting, and at least 75 percent voting in support of its repeal. That needed to be followed by two-thirds of members of Parliament voting to validate the referendum outcome.

The institutional and procedural requirements were an enormous obstacle. In other words, even though the NPP won the majority of seats in Parliament, it could not simply vote to repeal the indemnity provisions. If the NPP had attempted to test the popularity of the indemnity clauses by subjecting them to national referendum, it would probably have lost the votes to repeal them. The electoral strengths of the parties, the NPP and the NDC -- successor to the PNDC -- were almost equal. ${ }^{139}$ Even assuming that Ghanaians would

\footnotetext{
${ }^{139}$ The electoral votes for the NPP and the NDC following the 2000 elections suggested a close contest. While the NPP Presidential Candidate won with $56 \%$, as against $43 \%$ for the NDC Candidate following two rounds of polling, there were only eight seats separating the NPP (100) from the NDC (92) in Parliament.
} 
overwhelmingly vote to revoke the indemnity clauses from the Constitution, it was less certain that Parliament would validate the outcome of the national referendum. With a partisan Parliament, the possibility of getting the two-thirds majority required for the ratification was remote. The entrenched nature of the legal obstacle compelled the search for an alternative policy response to transitional justice demands.

The NPP government's choice of a non-judicial justice approach was thus by default, and not by design. The restorative justice option presented itself readily. Subsequently, the TRC-approach was identified as the appropriate alternative process based on the political context. The South African experience, with the global attention it received and its success seen around the world, would then offer the needed policy response to the transitional justice process in Ghana. The TRC-approach response to the demands of transitional justice appears to have characterized a 'quick fix' policy solution, which, as observed in chapter 3 , reflects the significant impact of globalization on the incidence of policy transfers. Coincidentally, most Ghanaians (89\%) endorsed the TRCapproach to transitional justice (CDD-Ghana, 2001a).

It must be said that while the legal obstacles created the context for the TRCapproach policy transfer, the restorative justice process that was associated with the approach also appealed to the leadership of the successor regime. The NPP political leadership saw the restorative justice process as responding to the needs of victims more quickly than the court process, and also as providing the opportunity to foster national reconciliation following the polarization of the Ghanaian state during the 19 years of Jerry Rawlings' rule. The pronouncement by then newly elected President, John Agyekum Kufuor, during his inauguration ceremony in early January 2001 , summed it 
up: "We have gone through turbulent times and we should not in any way down play or brush aside the wrongs that have been suffered. I do not ask that we forget, indeed we dare not forget, but I do plead that we try to forgive" (Government of Ghana, 2001: I). ${ }^{140}$

To be sure, the urgency on the part of the NPP government to address the needs of victims of human rights abuses was also politically motivated. The NPP sought to maintain its traditional image as a liberal and human rights friendly political party. ${ }^{141}$ Embarking on the TRC process expressed its desire to distance itself from the PNDC/NDC political tradition and, thereby, to project its public image locally and internationally.

\section{3: Analysis of Case Studies and Testing of Hypothesis One}

Concerns about and demands for transitional justice were central to the political transitions in South Africa, Nigeria and Ghana. The circumstances surrounding the political transitions suggested that the incumbent repressive regimes would be replaced with new political administrations. The political space was consequently ripe for the transitional justice process. By national and international norms and standards, as well as by the jurisprudence and ethics of human rights, South Africa, Nigeria and Ghana should have pursued criminal justice processes to achieve transitional justice. The replacement political transitions in Nigeria and Ghana presented clear cases for it.

\footnotetext{
${ }^{140}$ See also "Kuffour Urges All Hands" on Deck", a Ghanaweb news story, sourced on July 9, 2010 on http://www.ghanaweb.com/GhanaHomePage/NewsArchive/artikel.php?ID=12976

${ }^{141}$ The NPP traces its historical antecedent to the first political party in the Gold Coast (before Ghana was born), the United Gold Coast Convention (UGCC). The NPP is considered Ghana's liberal-conservative party, with respect for the human rights of individuals as its keynote. Its leadership includes prominent human rights and constitutional lawyers. Interviews with senior members of the party in Ghana in 2008 and 2009 confirmed this commitment to addressing historic human rights abuses as consistent with the party's philosophy of promoting and protecting individual human rights.
} 
Yet, although the political transitions in the three cases followed different paths, the countries all eventually pursued the non-criminal justice processes, in the form of the TRC-approach. The latter was formulated as the transitional justice policy to address citizens' concerns about and demands for human rights accountability with regard to previous regimes. Examination of the political transitions in the three cases demonstrates that there were clear varied institutional obstacles that disallowed the application of a judicial policy, informed by legalist and institutionalist principles, to transitional justice process.

In both South Africa and Ghana, the institutional constraints were occasioned by legal statutes -- amnesty and indemnity provisions in their constitutions. In South Africa the amnesty clauses were conditional; in Ghana, the indemnity provisions were not, and they were entrenched. In Nigeria, the limitation was institutional structure or organization, traced to a weak and compromised judicial institution. In both South Africa and Ghana, the obstacles were major ones. The legal prohibitions against criminal justice processes constrained the successor regimes in South Africa and Ghana from any attempt to design a transitional justice process that was purely judicial and criminal. In Nigeria, however, while the defects of the judicial institution were indisputable, that fact was not itself sufficient to compel exploration of other forms of criminal justice process. The motivations for a non-criminal justice process were strong, and so much preferred by the PDP leadership that the judicial institutional weakness strengthened the desire for, and hastened, the transfer of the TRC-approach. Indeed, the timing of the formulation of the TRC-approach, two weeks after the inauguration of President Obasanjo, tellingly indicates the government's predisposition to it. 
While in all cases the successor regimes were confronted with institutional prohibitions that precluded the use of judicial process to transitional justice policy, these proscriptions were less acute in Nigeria. It was those constraints that resulted in the policy transfer of the TRC-approach to transitional justice in South Africa, Nigeria and Ghana. Restorative justice ideas appealed to the leaderships of the successor regimes. They considered the restorative ideal not a second option, but an appropriate alternative policy response to the demands for transitional justice. As will be examined in chapter 7 , this ideal was also enabled by certain structural conditions in the domestic political systems.

Basing its views on the perceived necessity to respond to pressure from citizens, and also the desire to meet national and international obligations, and thereby bolster their own profile, the political leadership voluntarily drew lessons on the TRC-approach in order to advance restorative justice. Accordingly, the discussion here confirms the study's first proposition, that the notion of restorative justice associated with the TRCapproach informed its policy transfer to transitional justice in South Africa, Nigeria and Ghana. It did so at the instigation of the institutional constraints that prevented the application of prevailing judicial policy approaches.

Proposition one of the study, as stated in chapter 3, suggests that "ideas that informed the TRC-approach (restorative justice) to transitional justice in South Africa, Nigeria and Ghana were conditioned by institutional barriers that limited the application of existing judicial approaches to transitional justice". It further states particularly that "the entrenchment of institutional obstacles", where any of the following two scenarios occurs--“if there is a history of policies, including legal statutes, that outlaw or limit 
formal judicial inquiries into previous human rights offences, the more likely are restorative justice ideas (TRC-approach); and if the strength and capacity of the institution that undertakes judicial inquiries is evidently weak and compromised, then the more relevant is the restorative justice process; hence the policy transfer and subsequent application of the TRC-approach"--, will facilitate the policy transfer of the TRCapproach to transitional justice. The political contexts of South Africa, Nigeria and Ghana reflect these two scenarios.

In the South African and Ghanaian cases, the history of legal statutes, in the form of amnesty and indemnity informed by the dynamics of their respective (1994 and 1992) political transitions, presented these constraints, and created the space for the TRCapproach policy transfer. In Nigeria, deficit in institutional structure, resulting from the historical regimes' manipulation of the judiciary establishment that produced a weakened, compromised, and unreliable judiciary incapable of facilitating a criminal justice process, occasioned the TRC-approach policy transfer. Consequently, the significance of the appeal to the restorative justice ideas thrived in South Africa, Nigeria and Ghana when there were considerable institutional limitations to judicial policy approaches to transitional justice.

The discussion also reveals and confirms established arguments (Risse-Kappen, 1995; Lieberman, 2002; Hogan and Doyle, 2007) that suggest that ideas that inform policy change or transfer become relevant and flourish when there is a moment when political conditions favour their application to policy problems. Certainly, when such policy gaps and political conditions manifest, they create the space for alternative policy ideas or policy options, previously viewed as second best, to be fairly interrogated and 
their viability brought to the fore. Policy actors are able to investigate and draw lessons on such alternative policy ideas to inform policy change, in this context, to undertake policy transfer of the TRC-approach to transitional justice process.

In the current study the transmission of restorative justice ideas across borders became a reality when a policy gap appeared as a result of the institutional manifestations that prevented judicial approaches to transitional justice in the three cases. Yet, simultaneously, demands were urgent for some form of redress against human rights wrongs. The policy transfer of the TRC-approach in South Africa, Nigeria and Ghana was an effect of social learning processes (Ikenberry, 1990; Hall, 1993) on the restorative justice ideas by South Africa of the lessons of the South American experience, and also a consequence of the widespread information on the merits of the restorative justice process.

Further, observations from the cases reveal consistency with the propositions made by Dolowitz and Marsh $(1996 ; 2000)$ in their policy transfer model. Dolowitz and Marsh suggest that societies or policymakers engage in policy transfers based on voluntary lesson-drawing and on indirect or direct coercion to address urgent domestic policy needs and to meet domestic and international obligations. ${ }^{142}$ The findings from the three cases suggest that the policy transfer of the TRC-approach in the countries occurred against a background of lessons being voluntarily drawn in order to respond to pressures from domestic groups about meeting national obligations, and also in order to advance

\footnotetext{
${ }^{142}$ Voluntary transfer suggests deliberate lesson-drawing; indirect coercive transfer results from external pressures of competition among states, and pressure on states to meet domestic and international obligations; direct coercive transfer depends on externalities as a result of interdependence. They argue that policy transfers usually occur because domestic politicians attempt to implement policies that will meet international standards and give them a positive image in the international community.
} 
international and domestic recognition of the new regimes. The latter reason was more clearly manifested in Nigeria and Ghana than in South Africa.

Although the ANC, PDP and NPP governments intentionally and purposefully transferred the TRC-approach, they, however, did so under indirect coercion from domestic and international pressures. Domestically, pressure from victims' groups to address previous unattended human rights violations informed this coercion. Internationally, the desire to respect international standards and to be accepted into the community of pro-human rights nations provided the impetus. The policy transfer scenarios of the TRC-approach in the cases in question may therefore be described as a mixture of voluntary and indirectly coerced. The findings in this context corroborate the position by Dolowitz and Marsh that policy transfer cases are best understood to lie in the middle of a continuum that ranges from voluntary lesson-drawing to direct coercion (See Table 2 in Chapter 3).

The dynamics that were associated with the policy transfer of the TRC-approach in South Africa, Nigeria and Ghana represent social constructivism at work. In all the three cases, the mutuality of interests on the part of the political leaderships and their identities' promotion, as was seen with the Nigerian case, and the restorative justice ideas was apparent. Subsequent chapters examine in detail how these interests of the political actors manifested in drawing on the notion of restorative justice to transfer and formulate the policy on the TRC-approach. It will suffice to note that, while institutional obstacle created the political space for the policy transfer of the TRC-approach in South Africa, Nigeria and Ghana, the discussion in this chapter demonstrates that the policy transfer 
was characterized by human action informed by interests and the popularity of the restorative justice ideas.

\section{4: Summary and Conclusion}

The events that produced the political transitions and advanced the policy transfer of the TRC-approach to transitional justice in South Africa, Nigeria and Ghana display similarities, as well as significant differences. To begin with, in all the cases transitional justice concerns and demands from the citizenry featured prominently during the transition and post-transition phases. That citizens and, in particular, victims of human rights violations, prefer and support a criminal justice approach to transitional justice was also clearly apparent in all three cases. There were explicit institutional constraints that prevented the application of the existing judicial approach to the transitional justice process. In all instances, the newly installed regimes avoided (South Africa and Nigeria) or curtailed (Ghana) a policy of amnesia, and subsequently relied on the TRC-approach, which promotes restorative justice in addressing transitional justice concerns. The processes leading to the transfer of the TRC-approach to addressing the quest for transitional justice were voluntarily undertaken by the policymakers associated with the new political regimes, albeit in response to domestic citizens' pressure, and also to promote their own public image.

There were, however, significant differences across the cases. The political transitions in both South Africa and Nigeria were of the paradigmatic kind, where the countries were transiting from a non-democratic society to a democracy. In Ghana the political transition was within a democracy: a transition from one democratically-elected 
regime to another. Further, while both the Nigerian and Ghanaian political transitions, in which demands for transitional justice ensued, represented the replacement type, the South African process characterized the transplacement.

Moreover, while the transitional justice processes in all cases targeted gross human rights violations under previous undemocratic regimes, these undemocratic regimes differed in the systems that promoted abuses. In South Africa the regime under the microscope was the authoritarian apartheid system; in Nigeria and Ghana, the regimes for investigation were, primarily, military juntas. The dynamics of the institutional constraints that inhibited the application of the judicial approach also differed across the cases. In both South Africa and Ghana, these obstacles presented themselves in the form of legal provisions that could not be surmounted without dire political consequences. In Nigeria, the obstacle presented itself as a failure of the judicial institution to advance a consequential criminal transitional justice process.

This discussion and the analysis contained in this chapter addressed two main concerns of this study. First, it sought to demonstrate that the TRC-approach to transitional justice in South Africa, Nigeria and Ghana resulted from varied institutional limitations that confronted successors to the previous, undemocratic, regimes. Second, the chapter demonstrated that these institutional constraints created policy space that then facilitated the policy transfer of the TRC-approach. The transfer process was constructive in character. In all the three cases, the processes illustrated the interplay of actors (and identity promotion) on the restorative justice ideas--informed by interests--and structure. The TRC-approach became relevant and eventually preferred by the successor regimes because of the attraction of the restorative justice ideas that motivate the approach. 
Accordingly, the analysis in this chapter provided a context for validating the first hypothesis in this research, as well as establishing the functionality of ideas (Blyth, 1997; Adler, 1997; Campbell, 1998): in this instance, the restorative justice that informs the TRC-approach. What this chapter has not done is to identify the specific actors who were involved in the TRC-approach policy transfer process in the selected cases, examining the precise roles of these actors in the process, including the instrumentalities of domestic actors in formulating the policy on the TRC-approach in their respective domestic political environments, and locating the source from where the actors conducted the transfer. These broad questions, which also illuminate on the constructive nature of the policy transfer and formulation of the TRC-approach, are addressed in the following chapter. 


\section{Chapter 6: Actors and the TRC-Approach Policy Transfer and Formulation Processes}

\section{0: Introduction}

This chapter focuses on the functional and instrumental abilities ${ }^{143}$ of agents in the processes leading to the policy transfer of the TRC-approach and its subsequent formulation in the domestic political systems of South Africa, Nigeria and Ghana. The specific actors are identified and categorized as borrowers, carriers, and formulators. These categories of actors are found in both the domestic and international realms of agency, where they performed different roles. The borrowers and formulators of the TRC-approach were mostly domestic, while the carriers were international actors. The latter participated in the transfer process by providing necessary content information and best practices on the TRC-approach to the domestic borrowers and formulators. The relationship between the international and domestic actors constituted the process of social learning of the restorative justice ideas that inspire the TRC-approach. It manifested in the form of policy dialogues or what Apter (2006) calls discourse communities.

From where the TRC-approach policy transfers took place are found to have been combinations of in-country, multiple country and state-to-state lesson-drawing. The policy-making processes of the TRC-approach in the South African, Nigerian and Ghanaian political systems were led by the formulators. Borrowing the TRC-approach, the formulating actors advanced an argument for its positive effect on post-conflict or post-authoritarian accountability for human rights violations and subsequent

\footnotetext{
${ }^{143} \mathrm{By}$ this I mean the capabilities, role and influence of actors.
} 
contributions toward stability, peace, unity and development. They constructed the formulation process by appealing to the restorative justice ideas - the values of truth recovery, forgiveness, healing, reparations, and reconciliation - that inform the TRCapproach.

The actors therefore presented the restorative justice ideas from cognitive and normative perspectives (Campbell, 1998; 2002) in the domestic policy formulation settings. As a cognitive paradigm, the restorative justice ideas were articulated in terms of cause and effect relationships. In other words, the restorative justice paradigm that informs the TRC-approach policy program responds to the transitional justice demands and the consequent realization of the developmental needs of the post-transition societies. Normatively, restorative justice ideas were presented as consisting of values worth pursuing in societies whose histories were replete with divisions, distrust and animosities.

The chapter is divided into four sections. The first identifies the actors involved in the policy transfer processes of the TRC-approach in the selected cases. The three categories of actors noted above, described as both official and non-official and located in the domestic and international groups of agency, are delineated in each case. The platforms from where these actors transferred the TRC-approach and the specific roles played by these different categories of actors are examined.

The second section discusses the TRC-approach policy formulation processes -one of the fundamental roles of the domestic actors -- in the domestic political systems. Applying Campbell's analytical cognitive and normative scheme, which are elaborated on, and using process-tracing methods, the chapter demonstrates how the domestic actors in South Africa, Nigeria and Ghana promoted the restorative justice ideas resulting in the 
formulation of the TRC-approach as a transitional justice policy. The discussion thus illuminates the functional abilities of these actors in transforming the restorative justice ideas to shape the TRC public policy formulation.

The third section presents an analysis of the main findings from the case study discussions, which then provides the context for validating the second proposition of the study. The summary and conclusion follow in section four.

\section{1: Actors, Roles and Stages of the TRC-approach Policy Transfer Process}

The actors involved in the policy transfer processes of the TRC-approach in South Africa, Nigeria and Ghana were official domestic, non-official domestic and non-official international agents. The domestic official and non-official actors constituted the borrowers and formulators of the TRC-approach, while the international non-official actors were designated as carriers. The carriers identified in this study were mostly individuals, international non-governmental organizations and transnational transitional justice epistemic communities. ${ }^{144}$ The domestic official actors, identified as individuals and groups, included the elected and leading members of the ruling governments, the latter's hired consultants, and the ruling parties, the ANC in South Africa, the PDP in Nigeria, and the NPP in Ghana. The official actors were complemented by domestic nonofficial agents, sometimes referred to as non-state actors, who represented nongovernmental organizations, independent research organizations and policy think-tanks.

\footnotetext{
${ }^{144}$ In other words, they were transitional justice special knowledge or ideas producers. Epistemic communities are described as networks of professionals and experts with authoritative conclusions on policy-relevant knowledge, who share a set of normative beliefs, causal models, and notions of empirical validity, and who have a common policy enterprise (Campbell, 2002: 30).
} 
The most important role played by the domestic agents in the policy transfer process was the sourcing of the TRC-approach and its subsequent formulation in the domestic political systems. The specific roles played by the official and non-official actors were different because of the political and legal status separating the two groups of actors. ${ }^{145}$ Notwithstanding, they all acted as assimilators of the restorative justice ideas (policy content) that inform the TRC-approach. The international non-state actors, who were individual researchers and academics, TRC practitioners from countries in the South America region and from South Africa, the ICTJ, ${ }^{146}$ based in the USA, and the South African based CSVR, provided content of the TRC-approach policy transfer processes. They provided technical expertise to the domestic actors during the policy transfer process. This observation is consistent with what Roht-Arriaza acknowledges as the perceptible role played by the international and transnational actors in supporting domestic transitional justice processes, including truth commissions (2001: 40).

The international non-state actors acted as sources and spread of new information on the restorative justice process that the TRC-approach undertakes. They played the secondary role of making knowledge and best practices of the TRC-approach available to the domestic agents. Consequently, both the domestic and international actors were active in the social learning process of the restorative justice ideas that resulted in the policy formulation outcomes of the TRC-approach in South Africa, Nigeria and Ghana. This

\footnotetext{
${ }^{145}$ Official actors constitute the governing authorities, some of them duly elected and carrying the mandate of the people. They are the recognized agency that undertakes policy formulation process. Non-state actors do not have the legal mandate of the people and normally cannot initiate policy; their involvement in policy process is advisory.

${ }^{46}$ The ICTJ is the foremost global epistemic community in the transitional justice scholarship. It was formed in March 2001. Two of the three founding partners -- Alex Boraine and Paul van Zyl -- were leading figures in the South African TRC. The third partner, Priscilla Hayner, is a preeminent scholar on comparative truth commissions.
} 
confirms Haas' (1992) observation that without agents as carriers, ideas that inform policy designs -- in this case, restorative justice -- will be unproductive.

The different roles played by the domestic and international actors in the policy transfer process of the TRC-approach in the selected cases are thus consistent with the functions of agents in policy or social learning endeavours that produce policy designs or change. As Ikenberry (1990), Doern and Phidd (1992) and Hall (1993) all suggest, policy learning takes place when individuals or groups absorb new information or ideas based on experiences from elsewhere and borrow them to respond to their own circumstances. The assimilation processes can occur at both national and international levels by way of interactions. ${ }^{147}$ Certainly, the policy transfer and formulation processes of the TRCapproach in South Africa, Nigeria and Ghana reflected this social learning practice.

The domestic agents were the assimilators and the international actors were the content providers on the restorative justice process. As Haas (1992) further points out, transnational non-state actors, in particular the epistemic communities, have in the recent past played an important role in taking the various steps of the policy-making process, which include the introduction of policy alternatives, selection of policies and building national and international support for policies. The influences of international actors were apparent in all three countries; they were, however, more pronounced in Ghana and South Africa than in Nigeria.

The levels from which actors conduct the social learning process by way of interaction and sourcing of policy transfer -- in this instance, the TRC-approach -- vary. Three different platforms -- internal (in-country), outsourcing (state-to-state), and

\footnotetext{
${ }^{147}$ Through these interactions new ideas spread to produce policy choices, leading to policy formulation outcomes.
} 
regional/international - from which actors undertake policy transfers are identified in the policy transfer model developed by Dolowitz and Marsh (1996; 2000). The case studies in this study suggest that the domestic actors borrowed the TRC-approach from a combination of local and outside sourcing. While South Africa's policy transfer represents a combination of local and external multiple states sourcing, Nigeria and Ghana represent single external state sourcing.

To illustrate the specific actors in the policy transfer process, the diverse roles played by domestic and international actors, and the sources of the TRC-approach transfer in each case, the following pages examine the individual case studies.

\subsection{1: South Africa}

In the South African case, Kadar Asmal, an academic and then a leading member of the ANC, Dullah Omar, the first post-apartheid Justice Minister, and Albie Sachs and Johnny de Lange, both leading members of the ANC, were among the key individual official actors in the TRC-approach policy transfer process (Christie, 2000; VillaVicencio, 2009). In the main, the official group actors were the ANC as a governing political party and, in particular, the ANC National Executive Committee (NEC). Indeed, Boraine (2000a) argues that the ANC was the first to advocate the policy of a TRC for South Africa. ${ }^{148}$ These domestic official agents became the leading borrowers of the TRC-approach. They were complemented by domestic non-state actors led by Alex Boraine and his Justice in Transition Project, an NGO, the Institute of Democracy for

\footnotetext{
${ }^{148}$ It must be pointed out that the idea for a TRC was floated in the early $1990 \mathrm{~s}$ in a public lecture delivered by Kader Asmal (Asmal, 1992). The TRC idea, coming from a leading member of the ANC, was, contrary to the ANC earlier interests in a criminal justice approach if a political transition occurred (Boraine, 2000a). Significantly, the idea surfaced in the public space in the course of political negotiations toward the political transition.
} 
South Africa (IDASA), another policy research think-tank, and the CSVR. Boraine personally undertook travels to South America to learn and to understand the work of the TRCs established in the region and, also, to seek advice from TRC practitioners (Christie, 2000; Boraine, 2000a; Graybill, 2002).

Further, the non-state organization, the Justice in Transition Project, organized two conferences in $1994^{149}$ in which key international actors involved in the policy transfer process participated. Among the international actors at the conferences were: Patricio Aylwin, then President of Chile, under whose leadership the Chilean TRC was created; Pepe Jose Zalaquett, also from Chile; ${ }^{150}$ Catalina Smulovitz and Juan Mendez from Argentina; and Patricia Valdez and Roberto Canas of El Salvador (Boraine, Levy and Scheffer, 1997; Christie, 2000). Other international actors whose names feature prominently in the South Africa TRC process, and who took part in the domestic nonstate actors' organized meetings, are global transitional justice experts, authors and academics, including Aryeh Neier of the Open Society International (OSI), Lawrence Weschler, Adam Michnik, and Tina Rosenberg. ${ }^{151}$

These meetings constituted dialogue communities comprising domestic and international non-state actors who were drawing lessons from outside experiences to inform the policy formulation process and consequently shape the content of the policy

\footnotetext{
${ }^{149}$ The first conference was organized in February, prior to the April 1994 transitional election, and the second was in July.

${ }^{150}$ Zalaquett was a member of the Chilean TRC, and has since become one of the international individual agents promoting lessons drawn from the TRC approach.

${ }^{151}$ Aryeh Neier has been the President of Open Society Institute, a global NGO dedicated to building vibrant and tolerant democracies that promote accountable govemments, since 1993. A human rights activist, he was the founder of Human Rights Watch and its executive director for 12 years. Lawrence Weschler, Adam Michnik and Tina Rosenberg are famous authors with varied global experience whose writings have focused on violence and human rights crimes, among other subjects.
} 
that eventually emerged. It is instructive that at the time the South African TRC policy was being formulated there was no known reputable and global transitional justice epistemic community or NGO dedicated to these processes. Hence, many of the actors who were involved acted in their individual capacities.

The foremost role of these international actors was to offer lessons on transitional justice processes around the globe and, in so doing, demonstrate best practices to inform the policy discourse and formulation process. In addition to the organizers at these conferences, there were other domestic non-state groups, such as the South African Council of Churches, and the Khulumani victims' group, among whom discussions centred on the notion of restorative justice and its appropriateness for South Africa (Christie, 2000; Personal Interview with Hugo van der Merwe, October 6, 2008; Telephone Interview with Yasmin Sooka, March 16, 2009). For the most part, the presence and role of international actors was conditioned and facilitated by domestic nonstate actors. The domestic official actors were at the forefront of sourcing the TRCapproach and its subsequent policy formulation process. Villa-Vicencio (2009), for example, notes that Johnny de Lange ${ }^{152}$ was the architect of the TRC legislation.

The individual domestic official actors identified above, including Johnny de Lange, were ably supported by President Nelson Mandela, who strongly advocated a nonretributive transitional justice process for South Africa. In addition to these domestic ANC individuals were the South African Ministry of Justice and Parliament, which comprised other significant domestic official actors during the formulation process.

\footnotetext{
${ }^{152}$ Johnny de Lange was a member of the ANC negotiating team during the political transition and was a member of the first post-apartheid parliament. He had been a member of the ANC Parliamentary Study Group on Justice and of the Portfolio Committee on Justice and Constitutional Affairs of Parliament since 1994. He was one of the leading personalities that drafted the TRC Bill.
} 
Specifically, the Justice Committee of the Parliament was in charge of the TRC Bill. The involvement of Parliament in the formulation process was in accordance with the requirement in the 1993 Interim Constitution that the government would introduce a bill to activate the amnesty clause. The ANC ruling government was, however, responsible for developing the TRC bill and outlining its policy proposals. It was the Ministry of Justice, under Dullah Omar, that was charged with developing the draft bill for the review and approval of the Cabinet.

Accordingly, prominent individuals associated with the ANC party and the government, the ANC as a party and its NEC, were the principal TRC-approach policy transfer borrowers for South Africa. These actors, together with the Ministry of Justice and Parliament, were also the principal actors for the policy formulation process. In all of these processes -- borrowing and formulating -- the state actors were supported by domestic non-state actors, such as Boraine, the Justice in Transition Project, and IDASA. The domestic non-state actors formed partnerships with international non-state actors, a development that facilitated policy sourcing and formulation dialogues on the TRCapproach. Former TRC practitioners from Argentina, Chile, and El Salvador, human rights activists, and authors from around the world were the major actors who performed the function of carriers of the restorative justice process to South Africa.

There were two different platforms from which the South African TRC policy transfer occurred. The first platform, as established in the previous chapters, was the TRC experiences in South America: Chile, Argentina and El Salvador. For instance, Asmal (1992), in his professorial inaugural address, referred to the Argentinean and Chilean experiences as a potential source for South Africa in its grappling with the past. 
Moreover, in proposing a TRC for South Africa, the NEC of the ANC made references to the experiences in South America, especially the Chilean model (Boraine, 2000a). Zalaquett (2006), in a documentary on the proliferation of truth commissions, also affirmed that the South African TRC was informed by lessons from the South American experience. It is no surprise that the international actors who participated in the two conferences were mostly from South America.

While the first platform represented external political system or state-to-state (in this case, multiple) policy transfer sourcing, the second stage was internal lessondrawing. The TRC-approach for South Africa was informed by lessons from the ANC's own experiences while in opposition as a liberation movement of dealing with human rights violations in its camps in Angola, Tanzania, Uganda and Zambia. The ANC set up a series of prototype TRCs -- Commissions of Inquiry -- as part of its internal investigation in response to allegations of human rights violations perpetrated by some of its own members on its other members suspected of betraying the movement (Boraine, 2000a; Christie, 2000). Three of these inquiries -- the Stuart, Skweyiya, and Motsuenyane -- are worth mentioning. The Motsuenyane Commission in 1993 is described as the most credible of all.

During the review and discussion of the Motsuenyane report in August and September 1993, the NEC recommended the establishment of a Commission of Inquiry or a Truth Commission for South Africa (Boraine, 2000a; Shea, 2000; Sachs, 2009). Sachs specifically observes that in the process of discussing the findings from the Motsuenyane report, a political decision was taken that if an ANC government came to power after the transitional elections, a truth commission would be set up that would 
examine all abuses of human rights from all quarters (2009: 69). Lessons from within South Africa were thus another source for the policy transfer of the TRC-approach. The local or in-country sourcing of policy ideas and innovations is usually the rational base for actors to begin from. As Dolowitz and Marsh point out in their model, internal sourcing helps actors both explore what has worked well and avoid repeating what has not.

As with the 1994 political transition, it is not too surprising that the TRCapproach policy transfer in South Africa was evidence more of domestic initiative and engineering and less of international influence. The leading role of state actors and, to a greater degree, the members of the domestic civil society community in the sourcing and formulating of the TRC-approach was obvious. The official actors, led by the Ministry of Justice and the Presidency, developed and formally initiated the formulation process. Domestic non-state actors played a considerable role by complementing the sourcing and by shaping the content of the policy proposals. The domestic non-state actors partnered and collaborated with transnational actors who participated in the transfer and formulation processes by sharing knowledge of the restorative justice process and of lessons from and best practices on the TRC-approach.

The international actors participated at the instigation of domestic actors: an example of a productive collaboration between national and transnational actors in domestic policy formulation processes, especially when the policy approach under consideration is partly informed by externally generated ideas. To buttress the observation made in this study, and as was demonstrated in Chapter 4, the processes leading to the policy formulation of the South African TRC was an activity of policy 
transfer informed by locally and externally generated sources of ideas and lessondrawing. Both the domestic and international actors identified in this chapter were active in different capacities during the transfer process.

\subsection{2: Nigeria}

In Nigeria, the individual official actors responsible for the policy transfer and the borrowing and formulation processes were found to be located in the Executive arm of government. They included the elected President, General (retired) Olusegun Obasanjo, his policy advisers, the Minister of Justice, Godwin Kanu Agabi, and consultants attached to the Ministry of Justice. The ruling PDP party was the corresponding official group actor identified in these processes. On the side of non-state domestic actors, two main NGOs, the Center for Democracy and Development (CDD) and the Legal Resource Consortium (LRC), played significant roles in the policy transfer process and, also, in the development of the TRC policy content. The participation of domestic non-state actors was limited because of the nature of the TRC policy formulation process adopted in Nigeria -- that is, the executive decree, rather than legislative process, and the short period for the enactment of the decree. Moreover, unlike in South Africa, the role for non-state actors occurred very late, after the first decree was promulgated on June 7 , 1999. The domestic CSOs therefore had less political opportunity to influence the TRC policy content.

In the same context, the participation and the role of international actors were also restricted and short-lived. At the time the policy formulation process of the Nigerian TRC unfolded, in addition to individual actors, few organized international non-state groups 
worked in the transitional justice field. The individual actors who participated in the policy transfer process came from South Africa, many of whom were associated with the South African TRC (Personal Interview with Clement Nwankwo, January 27, 2009). Among them were Dumisa Ntsebeza, a commissioner, who flew in to offer lessons from and experiences of the South African process. The CDD also organized several conferences that brought international experts on the TRC-approach to provide lessons and best practices on the TRC-approach to Nigerians. These conferences, which were attended by members of the TRC, took place after the June 7, 1999 enactment and after the inauguration of the TRC. Participants at these conferences represented international TRC practitioners from South Africa, Chile and Guatemala (Nwogu, 2007; Personal Interview with Nwankwo, January 27, 2009; Personal Interview with Informant \# 7 , February 2, 2009).

Apart from the individual actors, the two notable international non-state groups that were involved in the policy transfer and formulation processes were the Swedenbased transnational NGO, IDEA, which provided global knowledge on transitional justice processes, and the ICTJ. The ICTJ, which was formed in 2001, got involved in the Nigeria policy transfer process when it was already in its dying phase. On the invitation of the CDD, the ICTJ went to Nigeria to impart best practices and lessons on how TRCs develop meaningful final reports (ICTJ Internal Document, 2001; CDD, 2001). As one former senior official at ICTJ revealed, "at the end, our role was very much providing little bits and pieces of comparative advices." (Personal Interview with Louis Bickford, 
May 21, 2008). ${ }^{153}$ The participation of international actors in the policy transfer process manifested in the form of partnership building with domestic non-state actors. Thus, as the ICTJ was invited to Nigeria by the CDD to assist it in giving technical advice to the Commission, the CDD and the International IDEA also jointly organized one of the international conferences that brought foreign TRC practitioners to inform the domestic policy discourse in October 1999.

Just as the sourcing of the TRC-approach was spearheaded by the presidency, the formulation phase was also engineered by the executive arm of government. There was no involvement of Parliament and, as observed before, civil society engagement in the entire transfer and formulation process was generally very limited. The Ministry of Justice was the principal formulator of the TRC executive order, Statutory Instrument Number 8 of 1999. Through the work of the domestic non-state actors and, in particular, the CDD operating in partnership with international non-state actors, however, the formulation process benefited from non-state inputs. Consequently, in the Nigerian policy transfer process, the borrowers and formulators of the TRC-approach were the individual policy advisers located at the Presidency and the Ministry of Justice. They were assisted by a limited section of the domestic civil society community: in the main, the CDD and the LRC. A limited presence of international non-state individual actors and groups, representing carriers of the approach, participated in the process through their partnerships with domestic NGOs.

The South African TRC model became the primary stage for policy transfer in Nigeria (Nwogu, 2007; Yusuf, 2007; Personal Interviews with Father Kukah, January 28,

\footnotetext{
${ }^{153}$ The ICTJ, for example, submitted samples of TRCs' final reports, including those of Argentina, Chile and Guatemala, to the Commission. Two of the ICTJ senior staff, Louis Bickford and Priscilla Hayner, travelled to Nigeria to provide content knowledge.
} 
2009; Olawale Fapohunda, January 31, 2009; Akinseye George, February 2, 2009; Innocent Chukuma, February 5, 2009). Therefore the Nigerian experience with the TRCapproach policy transfer was on the level of state-to-state. As observed in the previous chapter, the perceived success of the South African experience inspired the formulation of a TRC for Nigeria. According to Professor Akinseye George, a leading consultant for the Ministry of Justice during the formulation of the TRC policy, he personally travelled to South Africa to learn lessons with which to inform the domestic policy formulation process (Personal Interview, February 2, 2009).

Indeed, the entire body of commissioners of the Nigerian TRC (the Human Rights Violations Investigation Commission) undertook a study tour of South Africa, and interacted with their counterparts once the Commission had been constituted (Personal Interview with Father Kukah, January 28, 2009). The majority of the international TRC practitioners and experts who participated in policy dialogues, facilitated by the domestic non-state actors, were South Africans. The policy transfer source of the TRC-approach thus occurred at the level of outsourcing beyond the borders of Nigeria.

The policy transfer and formulation processes of the TRC-approach in Nigeria were led predominantly by the domestic elected officials located within the executive arm of government. The Presidency was the leading force in the processes. In fact, it has been suggested that President Olusegun Obasanjo was a significant actor in sourcing and formulating the TRC-approach in Nigeria. Some informants argue that his craving to become the "Mandela of Nigeria" led him and his associates to conduct the policy transfer of "Mandela's TRC" to Nigeria (Focus Group Discussion \# 2, February 12, 2009). Other elected official actors, such as members of parliament, were absent from 
participation, and the role of domestic non-state actors and international actors was minimal. The minimal roles played by both the domestic and international non-state actors in these processes were in the areas of providing content information on the TRCapproach and its associated expected restorative justice outcomes.

\subsection{3: Ghana}

The leading domestic individual official actors in the policy transfer of the TRCapproach in Ghana were the elected President, John Agyekum Kufuor, the Attorney General and Minister of Justice, Nana Akufo-Addo, individual government-hired consultants, and Professor Mike Oquaye, a leading member of the ruling NPP party, who was also a member of the party's election 2000 Manifesto Committee. Accompanying these individuals was the NPP as the governing political party. Prominent associates of the domestic non-official actors were the Ghana Center for Democratic Development (CDD-Ghana), a policy and research think-tank, and the Legal Resource Center (LRC), an NGO. The international non-state actors were represented by academics, TRC practitioners, the ICTJ and the CSVR. Among the academics who participated in the policy transfer process were Douglass Cassel and Jan Perlin, ${ }^{154}$ who had been associated with the El Salvador and the Guatemala TRCs, respectively. The South African presence in Ghana was also noticed, with two of its TRC Commissioners, Alex Boraine and Yasmin Sooka, participating.

For the ICTJ, Ghana was perhaps one of the pioneer countries with which it was deeply engaged in assisting by providing content and lessons sharing on transitional

${ }^{154}$ Cassel and Perlin were professors from Northwestern and the American Universities respectively. 
justice processes. In 2001, when Ghana's TRC policy formulation process began, the ICTJ had just been formed, with its headquarters in New York. Several of its staff visited Ghana on multiple occasions to advise on the policy transfer, the emerging transitional justice policy discourse and formulation processes. Some of the prominent people involved were Boraine, Priscilla Hayner, ${ }^{155}$ Eric Okyere Darko, Mark Freeman, and Louis Bickford. The ICTJ, for example, established a working relationship with CDDGhana, through which it channelled its technical assistance. It gave information and best practices on the restorative justice process and the TRC-approach to the CDD-Ghana. ${ }^{156}$ The ICTJ also formed a partnership with the Ministry of Justice upon invitation, advising on the draft policy content. As a former employee of the ICTJ disclosed, the ICTJ contributed to the draft bill produced by the government before it was submitted to Parliament (Personal Interview with Eric Okyere Darko, May 25, 2008).

The policy formulation process was driven by the domestic official actors. As observed in chapters four and five, the elected President led the argument for a restorative justice process in Ghana. His Minister of Justice, Nana Akufo-Addo, then led the formulation process by introducing a draft bill on the TRC-approach to Parliament. Similar to the South African process, these events took place after the Cabinet had reviewed and approved of it. Parliament, through its Committee on Constitutional, Legal and Parliamentary Affairs, was therefore another official actor in the formulation process. Accordingly, just as the borrowing of the TRC-approach was led by domestic official actors, they equally directed the formulation aspect of the transfer.

\footnotetext{
${ }^{155}$ Hayner records her involvement in the Ghana TRC policy formulation processes in her latest book on TRCs (2011).

${ }^{156}$ The international actors' intervention in the Ghanaian case occurred at the invitation of the domestic actors. For instance, the CDD invited the ICTJ and the CSVR to participate at conferences held in June and October 2001 as part of the public discourse on the TRC policy formulation process.
} 
Nevertheless, domestic and international non-state actors played significant roles in the formulation stage as well. The CDD-Ghana, for example, was one of the few domestic non-state actors with which the Ministry of Justice shared its draft TRC bill for review, comments, and contributions before presenting it to the Cabinet for approval (Personal Interview with a Senior Official at CDD-Ghana, August 25, 2008). Further, and as has been stated, the ICTJ submitted advisory commentaries on draft proposals presented to it by the Ministry of Justice. ${ }^{157}$

Despite the fact that throughout the course of the policy transfer process several sources of the TRC-approach were explored by the Ghanaian domestic official and nonofficial agents, South Africa became the sole platform from which the policy transfer was conducted. The participation of South African TRC practitioners, including Boraine and Sooka, the presence on several occasions of CSVR staff in Ghana, and the references to the South African model in media presentations suggest that Ghana's was a state-to-state policy transfer. As was observed in chapter 4 , the policy goals formulated and the administrative structure established for the Ghana TRC were extensions of the South African model. The Minister of Justice set up a team in his office to draw lessons from South Africa with which to inform Ghana's particular TRC policy; the outcome of this initial scoping resulted in the Bill that was introduced in Parliament. The public generally believed that the South African experience was a significant source for Ghana (Focus Group Discussion \# 1, January 15, 2009). Thus, similar to Nigeria, the policy transfer origins of the TRC-approach in Ghana was outsourced.

\footnotetext{
${ }^{157}$ The ICTJ gave the NPP government materials on experiences of TRCs from other systems to help it design its own preferred policy on the TRC approach.
} 
In Ghana, the TRC-approach policy transfer and formulation processes were undertaken primarily by domestic official and non-official actors. The principal borrowers were the President, the Minister of Justice, the Cabinet, the NPP, and party officials. These actors and Parliament were all equally the principal formulators of the TRC-approach. The official actors were supported by domestic and international nonstate actors in the transfer and formulation processes. The domestic non-official actors secured a cordial partnership with the official actors that enabled them to contribute significantly in the transfer and formulation processes by way of content development.

The international non-state actors' principal role was in the area of transmitting knowledge, information and best practices on the TRC-approach to their partners in the domestic political environment. The partnerships that these international agents struck with domestic official and non-official agents made it possible for them to share lessons drawn from around the world on the TRC-approach, and especially from the South Africa experience, to inform the Ghana TRC policy formulation. Their carrier role was not limited to spreading and providing information on the TRC-approach; it extended to influencing policy formulation by contributing to the draft bill.

\section{2: Formulating the TRC-approach: Actors and the Restorative Justice Ideas}

The foregoing examination of the cases reveals that the domestic actors, particularly the official ones, were the principal formulators of the TRC-approach. Formulating the policy on the TRC-approach in the political systems of South Africa, Nigeria and Ghana required the domestic actors to frame the policy debate and discourse around the notion of restorative justice. Because the TRC-approach to transitional justice 
resulted from policy transfers, the formulating actors needed to construct the formulation process in ways that would attract broad support from the intended beneficiaries. For the domestic actors, the restorative justice concept itself dictated the articulation of the policy debate and directed the policy discourse in their respective political systems. Hogan and Doyle (2007), for example, suggest that once actors coalesce around a set of ideas that offer an alternative response to a persistent policy gap, they attempt to inject those ideas into their political systems. They do so by uniting around specific aspects of and values inherent in that particular policy approach, and infuse them into the policy discourse to seek public support for and endorsement of the formulation process.

In many instances the actors present these alternative policy responses by invoking the attributes and values associated with them as collectively held beliefs that are integral to the shared social, political and economic structures. Formulating agents employ languages, words, symbols and concepts connected to these alternative policy programs that resonate with societal norms, cultural identities and beliefs to provoke debate in the domestic policy formulation discourse (Campbell, 1998; 2002). In so doing actors seek to promote the contents of the policy option, and to identify them with domestic social and political systems in order to generate public acceptance and support.

The conditions that promoted the policy transfer of the TRC-approach in the political systems of the cases under study suggest that the processes were engineered by the domestic official actors. The formulating actors, already identified, appealed to the values of truth discovery or recovery, forgiveness, restoring victims' dignity in society by way of healing, reparations, and reconciliation, which are all associated with the restorative justice process in the policy discourse on the TRC-approach. Thus, the 
domestic official actors argued for the TRC-approach as the platform on which to deliver restorative justice outcomes that are treasured by each of the three countries' citizens.

Campbell $(1998 ; 2002)$ devises an analytical scheme to explain how agents use alternative policy ideas to formulate public policies to address urgent domestic policy needs. On the one hand, Campbell suggests that alternative policy ideas can be the fundamental and, sometimes, presumed assumptions in the foreground or background of policy debates. As foreground assumptions, these policy ideas are concepts and theories that are openly articulated by actors in the public discourse on the proposed policy programs. As background assumptions, they are the underlying policy prescriptions for solving policy problems in the minds of political elites and policymakers. These assumptions, whether in the foreground or the background, are employed by actors to inform the policy design phase. On the other hand, these alternative policy ideas can be deployed to play an instrumental role either cognitively, as descriptions and theoretical analysis, or normatively, consisting of standards and attitudes.

These two levels can be incorporated to understand fully how actors can promote alternative policy ideas that result in policy formulation processes. At one level, Campbell incorporates the alternative policy ideas as cognitive foreground and background assumptions, and labels them program and paradigm, respectively. At another level, he integrates alternative policy ideas at the normative level as foreground and background assumptions, and calls them, respectively, frames and public sentiments. Campbell's scheme thus defines the cognitive program and normative frames as the foreground assumptions of policy debates, while the cognitive paradigm and normative public sentiments are designated background assumptions. 
Campbell suggests that the foreground assumptions provide the alternative programmatic ideas as policy recommendations that allow political elites and policymaking actors to address specific policy problems. Campbell suggests that through policy briefs, position papers, or advisory memos to policymakers and congressional (parliamentary) testimonies, programmatic ideas are articulated by formulating actors. Further, actors deploy the normative values and attitudes inherent in the policy programmatic ideas by way of symbols, concepts and language; by using these solutions, policy solutions may be found and the policy programs legitimized for public acceptance.

The background assumptions constrain the actions of policy-making actors and political elites in terms of the range of policy alternatives permitted and perceived as worth pursuing, acceptable and legitimate to the public. On the one hand, paradigms offer implicit theoretical and ontological assumptions that inform actors about the kind of policy program that would work well under the particular political and contextual conditions. Campbell (1998) suggests that paradigmatic assumptions are insightful because they define the terrain for policy discourse. When programmatic assumptions fit the prevailing paradigm they appear natural and recognizable, and the result is that these programs are more likely to appeal to policy actors than alternatives that do not. On the other hand, the support of the targeted policy beneficiaries among the public is sought by appealing to their emotions.

Determining public sentiments, however, can be challenging for actors during policy formulation processes. It is usually difficult to decide incontrovertibly what the public desires and hopes for, because public sentiments do not constitute a logical, coherent and reliable set of issues and positions. Campbell (1998) suggests that public 
sentiments cover a wide range of issues, and broad-based sentiment in one issue area may contradict another. ${ }^{158}$ Campbell's scheme provides the model for understanding the specific ways the domestic actors in the three cases pursued the formulation of the transferred TRC-approach in the domestic political systems. The table below demonstrates Campbell's analytical scheme.

Table 5: Types of ideas and their effects on policy-making Sourced from Campbell (1998)

Concepts and theories in the foreground of the policy debate
Underlying assumptions in the background of the policy debate
Programs

Cognitive level that help policy makers to chart a clear and specific course of policy action.

\section{Frames}

Normative level Ideas as symbols and concepts that help policy makers legitimize policy solutions for the public.

\section{Paradigm}

Ideas as elite assumptions that constrain the cognitive range of useful solutions available to policymakers.

\section{Public sentiments}

Ideas as public assumptions that constrain the normative range of legitimate solutions available to policymakers.

\footnotetext{
${ }^{158}$ The popular means by which policy actors detect public sentiments are through public opinion polls, focus groups and other forms of citizens' feedback.
} 
Through varied processes the formulating actors in the cases under study promoted the TRC-approach formulation at the cognitive and normative levels. The TRC-approach was proposed as the alternative transitional justice program. The elected agents in the three countries devised the TRC-approach as the course of policy action to meet the transitional justice demands. The TRC-approach was presented by the domestic actors as the only option available in the range of alternative policy solutions to address transitional justice needs. They presented the TRC-approach as the best alternative policy solution available for the country. The restorative justice values of truth discovery, forgiveness, healing, reparations, and reconciliation were expressed as goals worth pursuing during the policy formulation process. These normative values associated with the restorative justice process allowed the actors to present the TRC-approach goals as comprising a limited range of policy objectives that satisfied societal and public emotions. They were expressed in ways calculated to attract public sentiment for general acceptance by the populace of the program.

\subsection{1: Actors and Foreground Assumptions in South Africa, Nigeria and Ghana}

In South Africa, Nigeria and Ghana the domestic official actors proposed the TRC-approach as the transitional justice program for implementation. Basing their attitude on the prevailing political dynamics, the official actors intentionally and voluntarily chose the TRC-approach as the most appropriate program to meet transitional justice policy needs and, therefore, as the program most likely to yield the desired objectives -- peace, unity, stability, progress and development. The TRC-approach was presented as the alternative to the criminal justice approach to transitional justice, and one 
that would advance the restorative justice outcomes that the respective post-transitions circumstances needed. Consequently, the TRC-approach became the supply-side (Campbell, 1998) to the transitional justice demands. By way of parliamentary bills and presidential decree, the official actors announced the alternative TRC-approach as a policy program to achieve transitional justice. The official actors equally expressed publicly the five broad normative values -- truth discovery, forgiveness, healing, reparations and reconciliation -- associated with the restorative justice process the TRCapproach seeks to achieve.

In all three cases the actors variously argued for the TRC-approach by emphasizing the normative values as the path to a meaningful transitional justice process. The domestic actors constantly asserted that the five related principal attributes and values associated with the restorative justice process were fulfilled by the TRC-approach policy program. The framing was deliberately crafted by these actors who presented those values as the essence of the policy on transitional justice, so as to make the TRCapproach politically and legitimately acceptable to the public. The framing process took the form of stressing these normative words and concepts in public statements, pronouncements and campaigns, as well as in formal speeches made by the leading official actors.

The framing process also manifested in commentaries by the actors and their aides, and through public releases, all in an effort to garner public support for the TRCapproach program. The domestic actors in South Africa, Nigeria and Ghana developed these foreground assumptions by placing at the forefront of the policy debates in their 
respective countries the programmatic ideas in the form of a TRC-approach and framing the policy discourse on the restorative justice values as worth embracing.

Significantly, this study found that while the domestic actors framed the policy discourse on the restorative justice ideals by publicly articulating support for the TRCapproach, across the three cases, however, there was little empirical evidence observed where the actors publicly offered a critique of the criminal or retributive justice process. In other words, the foreground assumptions developed by the domestic actors to shape the public discourse in South Africa, Nigeria and Ghana placed more emphasis on the values associated with the restorative justice and benefits to be gained by formulating the TRC policy program than attempting to contrast the chosen policy program with other transitional justice policy programs, particularly the criminal justice approach.

\subsubsection{1: South Africa}

The proposal of the TRC-approach as a policy program for transitional justice began with a policy decision by the ANC National Executive Committee. In its meeting held in 1993 to review the report of the Motsuenyane Commission, it took a policy decision to set up a TRC to investigate all acts of human rights violations during the apartheid rule should it assume political office following the conclusion of the political transition. Subsequently, in late May 1994, a policy advisory memo in the form of a bill was introduced to the South African Parliament by the new, democratically elected, ANC government. The bill articulated in detail the programmatic ideas on the TRC-approach that the actors intended to implement toward meeting transitional justice demands in South Africa. 
The TRC program for a transitional justice policy was intended to transform the post-apartheid society toward a peaceful co-existence and development opportunities. The 1993 South African Interim Constitution articulated the need for a bridge between, on one hand, the past of the society deeply divided by racial strife, conflict, and human rights injustices, and, on the other, a future harmonious South Africa for all and the reconstruction of the society (Republic of South Africa, 1993). The TRC program was thus promoted as the policy proposal to keep this future promise.

The values of the restorative justice process -- a quest to satisfy the need for the truth about apartheid human rights crimes, for forgiveness, healing and compensation to victims, and for reconciliation - were the values the TRC program sought to promote. Certainly, they were desires expressed by leading official policy actors. Consequently, the policy discourse on the TRC-approach was articulated around these restorative justice values. These values and concepts were evident not only in public documents, but in the speeches, public statements and pronouncements of leading proponents of the TRCapproach, including President Nelson Mandela, Kader Asmal, and Dullah Omar. For instance, apart from its title -- 'National Unity and Reconciliation' -- the epilogue of the 1993 Interim Constitution specifically used the words understanding (truth), nonvengeance, and reconciliation, and spoke of the need for reparation to chart the course of policy response to transitional justice process. In his inaugural speech in May 1994, President Mandela stated, "[W]e must therefore act together as a united people, for national reconciliation, for nation building, for the birth of a new world" (Mandela, 1994:3). 
Following the inaugural address, President Mandela again reflected on these restorative justice attributes as part of his government policy document to the South African Parliament in his state of the nation address. In this address, given two weeks after his inauguration, President Mandela specifically asked for the nation to come to terms with its past (truth-seeking) in the spirit of forgiveness, reparation and healing (Villa-Vicencio, 2009: 98). The Minister of Justice, Omar, in a submission made in Parliament on proposals towards transitional justice, remarked that the policy course of action to be taken by the ANC government sought to "create a process which will make it possible for us -- all South Africans -- to come to terms with our painful past with dignity and in the spirit of forgiveness, but with due consideration to acknowledgment and to the need to provide reparation or compensation for the victims" (Minister of Justice, 1994: 190). Thus, the rhetoric of the domestic official actors was suffused with the restorative justice values of truth recovery, forgiveness, restoring victims' dignity, reparation, and reconciliation, and this was apparent in government documents, in the speeches, and in parliamentary debates.

\subsubsection{2: Nigeria}

The idea of a TRC-approach came in the form of a broad policy statement that President Obasanjo gave in his inaugural address in May 1999. In this statement, the President, while identifying many other policy challenges facing Nigeria, pledged to promote public reconciliation as a measure for addressing the transitional justice demands (Obasanjo, 1999). President Obasanjo emphasized that his programmatic ideas (policy) towards transitional justice sought unity, progress, reconciliation and the social-political 
well being of the Nigerian people. In a follow up address to the inaugural session of the Nigerian Parliament (the National Assembly) in June 1999, on the theme 'National ReAwakening', President Obasanjo again described his policy program as answering the pressing need of Nigerians to seek the truth about the past in order to promote national forgiveness and reconciliation. The policy on the TRC-approach program was unveiled in the presidential statutory decree, Number 8, enacted in June 1999. The forecast result of the TRC program would be a united Nigeria and a developmental path towards improvement in the political and economic well-being of all Nigerians.

Similar to South Africa, the restorative justice process presented the domestic official actors with the best means of achieving these end results. Therefore, the policy discourse on the TRC program was based on the normative values associated with this process. Unlike South Africa, however, the official actors chose to pattern the discourse around four of the standard five normative values associated with the restorative justice process. The policy formulation discourse was patterned on truth-seeking, forgiveness, healing and reconciliation. Reparation remained unbroached. In statements and speeches that articulated the policy content of the TRC-approach, these four priorities were stressed. As captured in one of his speeches, the lead proponent of the TRC program approach, President Obasanjo, emphasized the searches for truth and reconciliation as the priority issues for the country. He noted Nigeria's "determination to heal the wounds of the past, and quickly put the ugly past behind us so as to continue to stretch our hands of fellowship and friendship to all Nigerians for complete reconciliation based on truth and knowledge of the truth in our land" (Obasanjo, 1999). 
It is instructive, however, that the domestic non-state actors advocated reparations for victims of human rights abuses as part of the restorative justice process (Onyegbula, 2004). ${ }^{159}$ As Onyegbula (2004) points out, on the few occasions that the language of reparation came up during the policy discourse, President Obasanjo dismissed it as irrelevant, and argued that no amount of money could replace the loss of life that had resulted from human rights violations. ${ }^{160}$ Thus, for Nigeria, truth-seeking, forgiveness, healing and reconciliation were the main references for that the actors who formulated the policy discourse on the TRC policy program.

\subsubsection{3: Ghana}

The programmatic ideas on the TRC-approach for Ghana were first expressed in a campaign manifesto of the NPP. In it, the NPP pledged to create a policy that would address lingering transitional justice demands by setting up a "National Reconciliation Committee" (New Patriotic Party, 2000). President John Agyekum Kufuor re-affirmed his party's position to fulfil this manifesto promise by stating, in his inaugural address in January 2001 , the desire of his government to undertake an exercise to investigate historic human rights violations as an active policy to heal wounds and promote national reconciliation. In his policy statement to the inaugural session of Parliament the following

\footnotetext{
${ }^{159}$ The TRC -- the Oputa Commission -- did respond to the demands, and made proposals for reparations in its final report.

${ }^{160}$ President Obasanjo's affirmation of and preference for forgiveness and reconciliation over reparations are believed to have been bome out of his spiritual renewal during his incarceration (Onyegbula, 2004; reflections from interviews with cross section of Nigerians in 2009). Onyegbula (2004) suggests further that President Obasanjo's discomfort with reparations may be innate, because he showed his disdain for them when he became one of the leading political figures, in contrast with many of his African colleagues. He opposed demands by people of African descent for any form of reparation for years of colonialism and slavery at a global summit held in South Africa in 2001.
} 
month, he noted that the NPP government would introduce the policy program on the TRC-approach for approval. Then, in July, the Minister of Justice, Nana Akufo-Addo, presented to Parliament a bill that contained the policy proposals for the establishment of the NRC as a transitional justice program for Ghana. The TRC-approach program was conceived as a transitional justice policy that would facilitate conditions for economic development, peace, and the consolidation of democracy.

Public statements by leading official actors and official documents reflected these expectations. The President, for example, in his January 2001 address said, "Our greatest enemy is poverty. And the battle against poverty starts with reconciling our people and forging ahead in unity" (Government of Ghana, 2001: 1); meanwhile the Minister of Justice, in the memorandum accompanying the TRC bill, emphasized that "The consolidation of democracy and the promotion of constitutional rule demand that we deal with some of the issues from our turbulent past that risk compromising the forward march of democracy and peace in the country" (Government of Ghana, 2001: II). Achieving these outcomes necessitated the pursuit of the restorative justice process through the TRC-approach. Consequently, the domestic actors invoked concepts and words of truth, forgiveness, healing, reparations and reconciliation, similar to the South African case, in determining the policy discourse on the TRC program. In the NPP campaign manifesto, the restorative justice values of healing, reparations, and reconciliation were endorsed.

As detailed in the manifesto, the NPP stated that the proposed "National Reconciliation Committee" would help to heal the festering sores within the body politic, compensate victims and promote genuine reconciliation (New Patriotic Party, 2000: 37). Furthermore, President Kufuor, in his first public pronouncement on the policy direction 
for a transitional justice process, called for knowledge of the truth about historic human rights violations, healing and reparation for victims, forgiveness and reconciliation as desired values that were significant for the nation (Government of Ghana, 2001; New Africa, 2001). Nana Akufo Addo, in introducing the bill to Parliament, emphasized that the rationale behind the TRC policy program was the need for reconciliation and not vendetta, truth and not amnesia, healing, and restoration of victims. These normative values associated with the restorative justice process, and that the TRC-approach claims to promote, featured in the public pronouncements, speeches and statements of the leading official actors during the public debate.

In all the three cases analysed above, the domestic official actors conceptualized the programmatic ideas on the TRC-approach in terms of cause and effect relationships. Thus, the application of the TRC-approach as a policy program towards transitional justice was espoused as promoting economic and political development outcomes. As observed in Chapter 5, preference for the criminal justice process to transitional justice was obvious in all three cases. The institutional limitations, however, made such a policy approach untenable. The domestic official actors instead proposed the restorative justice process, to be realized through the TRC-approach program. The alternative restorative justice process to transitional justice was presented by the actors as the appropriate program that would advance the desired unity of purpose, peace and stability, and forge the national reconciliation that was required for political, social and economic transformations.

The restorative justice attributes of truth discovery, healing, forgiveness, reparations and reconciliation were thus articulated as admirable values the societies 
should embrace as transitional justice process outcomes. The domestic actors subsequently deployed these words and concepts in their speeches and statements to frame the policy formulation discourse on the TRC-approach. Leading the discourse in the formulation process, the elected presidents in all the three cases presented these values at the forefront of the policy debates and as positive assumptions behind the TRCapproach program. For instance, in all their inaugural speeches the presidents did not specifically mention the policy program names (that is, the TRC), but the inherent normative values associated with the program were expressed. In other words, the broad assumptions of cause and effect of the policy proposals were outlined in these inaugural speeches. The speeches were used to make public the policy intent of the official actors, and thus initiate public debate on the alternative policy options being proposed.

To actualize these broad assumptions, the official actors followed up with a specific programmatic course of policy action in the form of bills to parliament (South Africa and Ghana) and a decree (Nigeria) that detailed the concrete policy programs for addressing the transitional justice demands and, accordingly, for achieving the desired outcomes. As cognitive and normative foreground assumptions, then, the official actors articulated the TRC-approach as the policy program to address transitional justice demands and legitimized the program for public acceptance by emphasizing the restorative justice values that the TRC-approach advances.

The TRC-approach was presented as the transitional justice program that would offer the platform for the recovery of the truth about past human rights violations and, in so doing, create the forum for both victims and perpetrators to confront one another in an effort to promote healing of victims and their restoration in society, and forgiveness for 
reconciliation. The pursuit of this program approach to transitional justice process will, therefore, lead to peace, stability, progress, economic development, and democratic consolidation. The domestic actors deployed these foreground assumptions to facilitate the TRC policy design and formulation phase of the policy transfer process.

As was demonstrated in the examination of the three cases above, there was little to no observable proof to suggest that the negative critique of the criminal justice policy program, and for that matter any other policy mechanisms of transitional justice process, informed the cognitive and normative foreground assumptions. To put it differently, the foreground assumptions that were openly presented by the domestic actors in support of the TRC program as a transitional justice policy did not explicitly contrast the preference of the approach to the downsides of the criminal justice policy program. This does not, however, suggest that the impracticality of the criminal justice approach, as a result of the institutional obstacles as discussed in the previous chapter did not make up the views and perspectives of the domestic actors in proposing the TRC-approach. In reality, it, in addition to other informed critiques of the criminal justice approach, formed part of the cognitive and normative background assumptions that constrained actions of the official actors in ways that promoted public legitimacy and acceptance of the alternative restorative justice process and its TRC program towards transitional justice. These background assumptions are examined next.

\subsection{2: Actors and Background Assumptions in South Africa, Nigeria and Ghana}

The restorative justice norms that support the TRC-approach gave the domestic official actors background assumptions during the policy formulation processes in South 
Africa, Nigeria and Ghana. These background assumptions were construed as paradigms; they appealed to public sentiments that were articulated as compelling the domestic policy actors, the victims of human rights abuses and the citizenry as a whole to accept the alternative TRC policy program that was initiated to address transitional justice demands. As a paradigm, the notion of restorative justice was understood in a conceptual premise that informs the TRC-approach program as the specific course of action. Therefore, while the TRC-approach was the specific program consciously and publicly expressed as the policy solution to the transitional justice problem, the restorative justice paradigm of the transitional justice process was the implicit assumption of the TRCapproach, making it a politically and contextually viable policy program.

In the current study, the assumptions associated with the restorative justice paradigm informed the choice of the TRC-approach by permitting its program design to address the transitional justice dilemmas in South Africa, Nigeria and Ghana. These assumptions were elevated by the impossibility of formulating a retributive or criminal justice policy program. Other negative assessments of the criminal justice policy program also informed these background assumptions that promoted the restorative justice paradigm. The restorative justice normative values and attributes of knowledge of truth, forgiveness, healing, reparations and reconciliation were presented as 'collectively shared expectations'. Consequently, the formulating actors appealed to the public's sentiments by expressing these values in ways that not only legitimized the choice of the TRCapproach but, also, influenced public desirability.

Public sentiments, Campbell (1998) suggests, play two significant roles in shaping public policies. First, they influence the constituent pressures to which policy- 
making actors respond. Second, formulating actors themselves may possess sentiments that then determine the range of policy options they consider normatively tolerable. Public sentiments project the normative range of policy responses that are seen to be suitable and appropriate for formulation and implementation. As a result, public sentiments present actors with background assumptions that constrain them but, at the same time, liberate them to choose normative values that are politically and socially tolerable. For instance, Campbell observes that "even if a solution is deemed instrumentally effective, it may not receive serious consideration if it lacks political legitimacy" (1998: 392).

While it may be difficult to assess society's public sentiments, the fact remains that profoundly held public sentiments do influence how actors conduct public policy transfer and formulation processes, especially when such policy is doubted. To a greater extent, drawing on citizens' sentiments by basing the policy discourse on the restorative justice attributes helped the domestic actors formulate the policy on the TRC-approach in the three cases under study. There were, however, challenges that manifested as well.

\subsubsection{1: South Africa}

The statement by Dullah Omar, the South African Justice Minister, during the tabling of the TRC bill in Parliament captured the underlying restorative justice paradigm that motivated the choice of the TRC-approach for a transitional justice process. Omar observed that the substance of the 'Promotion of National Unity and Reconciliation Bill' was "on the basis that there is a need for understanding but not vengeance, a need for 
reparation but not retaliation, a need for 'ubuntu' ${ }^{161}$ but not for victimization" (Minister of Justice, 1995: 1340). The objectives of the TRC bill, as stated in chapter four, were to seek the truths behind apartheid human rights crimes, offer compensation as reparations to victims of these abuses and restore their dignity in society, and forge national reconciliation. It is these objectives that constitute the essence of the restorative justice paradigm that informed the policy formulation of the TRC-approach.

The restorative justice process to transitional justice took on special meaning for South Africa in part because of the nature of the political and democratic transition that occurred and because of the associated amnesty deal, but also because of the leadership role of President Nelson Mandela. President Mandela, for example, articulated values like reconciliation and nation-building in his campaign messages for the April 1994 elections (Lemarchand, 1994). Following his victory, he reiterated his dedication to a transitional justice policy that was informed by restorative justice outcomes. In his inaugural speech in May 1994, President Mandela stressed a policy process that would promote national reconciliation, peace and unity. Other leading official actors involved in the policy transfer and formulation processes of the TRC-approach followed President Mandela in affirming these underlying background assumptions.

Although it is difficult to doubt the sincerity of some leading personalities of the ANC party, particularly President Mandela, in their preference and support for the restorative justice process as a transitional justice mechanism, it is also, however, the case that at the back of the minds of some of the leading official actors, a retributive justice policy program was unsustainable. Not only was the amnesty deal contained in the 1993

\footnotetext{
${ }^{161}$ Cultural and religious beliefs that project humanity or the commonality of humanity. The concept will be examined in chapter seven.
} 
Interim Constitution sufficient obstacle to formulating such a policy program, but also the inherent challenges associated with implementation constituted background assumptions for these official actors in opting for the restorative justice policy program. As Howard Varney suggests, informing the choice of the TRC-approach in South Africa was the recognition by the official actors that "there was little prospect of going down the road of one criminal trial after the next, and there were also some practical considerations around systems, just something you wouldn't be able to deal with" (Personal Interview, October 10, 2008).

The potential consequences of formulating and implementing a retributive justice policy program on the national unity and stability of post-apartheid South Africa also informed the fundamental background assumptions that promoted the notion of restorative justice. Such a policy program, it was assumed, typified a revenge action on the part of the ANC, which did not promote reconciliation but rather a divisive process that could undermine the stability of the democratic transition that had just taken place. As was observed by Yasmin Sooka, the TRC policy program certainly fitted with the notion of robust reconciliation rather than a policy of retribution (Telephone Interview, March 16, 2009).

Undoubtedly, the restorative justice values appealed to the sentiments of the leading official actors, thus compelling them to argue for the TRC-approach to transitional justice as the most appropriate. By way of speeches and rhetoric, as demonstrated in Chapters 4 and 5 and already in this chapter, the restorative justice paradigm to transitional justice was emphasized. The formulating actors attempted to project these normative values by appealing to citizens' sentiments in an effort to 
legitimize the TRC policy alternative. The policy discourse was framed by these leading actors using the five standard restorative justice attributes.

The South African public appeared to have responded positively to the official actors and embraced the TRC-approach, thereby resulting in the latter's policy formulation outcomes (Villa-Vicencio, 2009). The Judeo-Christian religious beliefs of forgiveness and reconciliation are situated well in relation to the restorative justice paradigm and, therefore, generated the capacity for the official actors to harvest public sentiment and support for the TRC program. These religious values coincided with the African concept of 'Ubuntu' which was also invoked to draw the sentiments of South Africans in support of the TRC-approach policy program. As will be examined in the next chapter, the actors employed these belief systems in the discourse on the TRCapproach policy formulation process, and were among the contributory structural factors that facilitated public acceptance of the approach to transitional justice.

\subsubsection{2: Nigeria}

In Nigeria, the official actors formulated the policy on the TRC-approach in terms of giving voice to the victims of human rights abuses, restoring them to political society, and advancing reconciliation between victims and perpetrators. President Obasanjo observed, "[W]e want the injured and seemingly injured to be reconciled with their oppressors or seeming oppressors" (Obasanjo, 1999: 50). The foundation for the TRCapproach program was thus premised on the restorative justice paradigm. The pronouncements and speeches of the leading official actors, in particular President Obasanjo, confirm the restorative justice leanings of the actors. 
President Obasanjo's new-found Christian faith, it appears, was reflected in his public pronouncements, which included words like "forgiveness" and "reconciliation" (Focus Group Discussion \# 2, February 12, 2009). As the leading supporter of the nonretributive justice process in the policy transfer and formulation process, his penchant for the TRC-approach swayed the other official actors who were involved in the formulation process. The official policy actors sincerely believed that the notion of restorative justice and the corresponding TRC-approach policy-specific course of action held much promise for Nigeria (Personal Interview with Professor Akinseye George, February 2, 2009).

Transitional justice in Nigeria was, therefore, conceived of by the official actors as providing a forum for victims and perpetrators to make public grievances over human rights abuses, and as a step towards repairing the broken social relationship. As Nwogu suggests, the Nigerian TRC was established to "sooth the hurt of victims and society" (2007:24). Acknowledgment, forgiveness and reconciliation, and not reparations, however, were the primary objectives that informed the background assumptions of the formulating actors. These cognitive background assumptions, derived from the restorative justice principles, constrained the official actors in selecting the TRC-approach program.

It was explained in the previous chapter that weaknesses in the judiciary limited the PDP government's ability to exercise the criminal justice apparatus. This resulted in the TRC-approach policy transfer. It was also argued that this obstacle was less significant than in the South African and Ghanaian cases. The PDP could have explored other options to promote criminal justice policy, yet did not because of its principal desire and belief in the restorative justice paradigm for the transitional justice process. The view that a criminal justice policy program was undeniably slow in delivering the expected 
transitional justice objectives was apparent. Further, formulating a policy program with a criminal justice objective was conceived as a source of deepening the already divided Nigerian society. As one informant observed, "our criminal justice system is like a snail, people will have to go to court every time, but when you take me to court and come back, we can never be friends again" (Personal Interview with Godwin Aidenagbon, January 27, 2009). These assumptions were significant that limited the official actors in advocating for the TRC-approach program.

Informing the PDP's aspiration for a restorative justice policy program to transitional justice was for a post-transition Nigeria that was reconciled and victims of human rights abuses healed through truth-telling process. If a criminal justice policy program was proposed, the perceptions, it was feared, would be created that the PDP, and in particular President Obasanjo, wanted to use the process to seek revenge but not genuine justice and accountability for previous human rights violations. As Innocent Chukwuma suggests, formulating a criminal justice policy, which to him was the right transitional justice policy required for Nigeria, "people could say, ah, the only reason why he is doing this is because he (President Obasanjo) is after those from the North" (Personal Interview, February 5, 2009). In other words, sections of the Nigerian populace would have interpreted the PDP's criminal justice policy program as an attempt by President Obasanjo to get at his enemies--those leaders of the military regime that kept him in prison (Personal Interview with Chukwuemeka Eze, February 9, 2009). Such a polarized national discourse would have jeopardized any sincere effort to formulate any meaningful transitional justice policy program and created conflict. 
Consequently, in the Nigerian case, developing a policy program with the notion of retributive justice as the expected goal was viewed as producing unconstructive transitional justice outcomes which would not appeal to the citizenry and would not meet the expected national reconciliation agenda. These understandings were very much considered by official actors when they advocated for the TRC policy program. The inherent normative values of truth recovery, forgiveness, healing and reconciliation associated with the restorative justice paradigm morally appealed to the leading official actors. Nevertheless, the extent to which the formulating actors sought to verify public sentiments about the restorative justice process was not evident. Positive public sentiment on restorative justice ideas notwithstanding, not much was done by the domestic official actors to engage the public in this regard, particularly the religious community ${ }^{162}$ during the formulation process.

The omission may have been the fault of the policy formulation style -- the presidential decree -- adopted by the Nigerian formulating actors, which allowed scant opportunity for public discourse. Except for the few occasions when President Obasanjo specifically referred to forgiveness and reconciliation in policy statements and speeches on the TRC-approach, there is little evidence that the actors consciously sought to validate these background assumptions among victims of human rights violations and, more broadly, citizens in general.

\footnotetext{
${ }^{162}$ Views of participants in a focus group discussion held on February 12, 2009 in Lagos. Ninety (90\%) of Nigerians claim to be religious (50\% Islam; 40\% Christianity). Information sourced on August 12,2010 from Research Marketing Service on facts on Nigeria from http://www.rms-africa.com/nigeria.htm
} 


\subsubsection{3: Ghana}

In Ghana the policy on the TRC program was expressed in the context of rehabilitating victims. It was construed as a forward looking exercise, where the program would help reveal the truths about historic human rights violations and bring about the victim reparation and restitution and thereby restore broken relationships. These normative values, associated with the restorative justice paradigm, formed the background assumptions for the formulating actors in justifying the choice of the TRC program. Similar to South Africa and Nigeria, the domestic formulating actors were inspired by the restorative justice paradigm.

The pronouncements, statements and speeches of leading official actors, including President John Agyekum Kufuor and the Minister of Justice, Nana Akufo-Addo, evidenced these background assumptions. For example, the memorandum to the bill on the TRC made them apparent. Nana Akufo-Addo stated in the memorandum that "those who have been wronged need to be acknowledged, and where it is beyond human capability that those wrongs can be reversed as in the loss of dear ones, for example, the least we can do is to publicly apologize and help in whatever way we can, with their rehabilitation" (Government of Ghana, 2001: I).

As was the case in South Africa, the domestic formulating actors were also compelled by the restorative justice paradigm, and subsequently projected it in the form of a TRC policy program because of the indemnity provisions that had blocked any judicial policy response to transitional justice. The restorative justice process came naturally and thus limited the policy formulators in the range of policy alternatives that would address transitional justice concerns. It is helpful to point out that in Ghana these 
background assumptions had been formed in the minds of some of the actors, particularly those who belonged to the NPP, several years before the resulting election 2000 manifesto promise of the NPP. In that manifesto the NPP stated that it would establish a "National Reconciliation Committee to consider all surviving cases of human rights abuses and award appropriate compensation for victims"(New Patriotic Party, 2000: 37).

It is thus comprehensible that the restorative justice paradigm of transitional justice constrained the Ghanaian official actors in the range of policy options available, and that it was thought appropriate in the political circumstances. A policy program that advanced a criminal justice outcome was conceived as not in the interest of the country, and as a policy program that would further polarize the society. As one Member of Parliament disclosed "We thought that adopting the reconciliation (approach) was better than the criminal justice system where the people (alleged perpetrators) had to be tried for the crimes they committed; we would have opened wounds, divided the society further and the end results would have been unimaginable"(Personal Interview with Cletus Avoka, July 31, 2008). Therefore, although the indemnity clauses prohibited any transitional justice policy program that was criminal or retributive, the Ghanaian official actors were rationally informed by the possible consequences of formulating a criminal justice policy program.

In addition to the observation made above by Avoka, it was also felt that a criminal justice policy program did not allow for a fully and well documented record of human rights violations that took place during the past years; it was limited to exacting punitive sanctions against those found to be guilty of these crimes and for the most part did not address the material needs of victims. As Mike Oquaye recalls "the decision was 
that, let us establish a body to hear people's complaints whatever in public, to know the truth, and offer compensation to those who deserve" (Personal Interview, May 8, 2009). Thus, as part of the background assumptions of the official actors, the criminal justice paradigm did not promote these objectives, instead the restorative justice process did.

The official actors thus consciously crafted the TRC policy debate in ways that would harness public emotions about the norms of restorative justice and thereby attract national support for the selected TRC program approach to transitional justice policy. The policy formulation process on the TRC-approach seems to have benefited from patterning the discourse around the restorative justice values. Efforts were made by the official actors to locate the policy discourse in the context of Ghana's religious life. Being aware of Ghanaians' religious beliefs and public opinion (CDD-Ghana, 2001a), which were receptive to concepts such as forgiveness and reconciliation, the official actors focused the policy discourse on the TRC program in ways that would arouse the sentiments of Ghanaians to legitimize it. In one of his speeches, President Kufuor appealed to Ghanaians to forgive the human rights wrongs committed in the past. He remarked that the past could not be brushed away, and Ghanaians dared not forget, but asked that they try to forgive. ${ }^{163}$

The religious community found itself arguing for the TRC-approach and speaking in terms that were akin to the restorative justice attributes. This was done not because the NPP government asked them to, but because the religious leaders saw the TRC policy proposals as containing objectives that were consistent with the beliefs of their religion and the aspirations of the people. As one prominent religious leader disclosed, he,

\footnotetext{
${ }^{163}$ See Ghanaweb news story sourced on July 17, 2011 on: http://www.ghanaweb.com/GhanaHomePage/NewsArchive/artikel.php?ID=12976
} 
together with others in the religious faiths, welcomed the government's initiative mainly because they had themselves been calling for such a restorative process of healing and reconciliation in the body politic since the return to democracy in 1993 (Personal Interview with Archbishop Palmer Buckle, May 14, 2009). ${ }^{164}$

In the three cases just examined, the process of formulating the TRC-approach as a policy for transitional justice in the domestic political systems suggests that the official actors were influenced by the restorative justice paradigm. Their statements and pronouncements, in particular those of the chief policy formulators (that is, the elected presidents), contained attributes of the restorative justice paradigm. As chief formulators, their beliefs and policy intents reflected the positions of other official actors. It is apparent from the foregoing discussion that the formulating actors were inspired by the restorative justice paradigm, which thereby compelled them to advocate the TRCapproach as the most appropriate and legitimate policy option available to address transitional justice demands.

It follows, then, that the values and attributes associated with the restorative justice paradigm appealed to the sentiments of the official actors, thus making it possible for them to promote the TRC-approach as the transitional justice policy most likely to work. These assumptions led to the policy discourse debate being formulated in terms of promoting the restorative justice values. The official actors recognized the shortcomings of the retributive justice policy program if that was applicable. At the core of this recognition was which of the two held promise for the respective countries. It is significant that while these actors appeared to have been compelled to embrace and, therefore, project the TRC-approach by their interests to the inherent attributes of ${ }^{164}$ Archbishop Buckle served on the Ghana National Reconciliation Commission. 
restorative justice and the promise it held for reconciliation and stability, it is also the case that the constraints to opt for restorative justice policy approach to transitional justice process were enabled by the institutional limitations to the criminal or judicial policy approach as concluded in Chapter 5.

The personal attachments to the normative values of the restorative justice paradigm gave these actors models for policy discourse of a kind that inspired the sentiments of the victims of human rights violations and the public at large. They allowed the actors to promote the TRC-approach as the suitable policy program for transitional justice demands. The normative values also compelled the targeted policy beneficiaries to accept the program as legitimate. The use of words, language and norms, such as the right to truth, healing, forgiveness, reparation, and reconciliation, which had become world views associated with transitional justice processes, became powerful tools for the actors in constructing and formulating the TRC policy debate in their respective countries.

To be able to inspire public approval, the formulating actors situated the restorative justice values within the societal belief systems. In all three cases the official actors consciously crafted the policy discourse using these attributes and values as references that were parallel to the societies' structural feasibilities. In this context, arousing favourable public sentiments became the means of facilitating the policy formulation process of the TRC-approach. The actors needed to demonstrate why the TRC-approach, rather than any other, was the appropriate policy towards the transitional justice process. In many ways, the restorative justice values appealed to the societies' public sentiments. It is, however, obvious from the discussion that the formulating actors 
in South Africa and Ghana conducted such a purposeful policy formulation discourse better than in Nigeria.

The cases, as just discussed, indicate that the restorative justice paradigm to transitional justice and its associated normative values presented the formulating actors with the background assumptions that controlled the range of policy solutions, in this instance the TRC-approach, that the actors recognized as functionally and instrumentally compelling to address transitional justice demands. The extent to which the domestic structural conditions responded to this restorative justice paradigm and its normative values is examined in the next chapter.

\section{3: Analysis of Case Studies and Testing of Hypothesis Two}

The study hypothesized in Chapter 3 that "both domestic (elected officials and domestic CSOs) and international (transitional justice expert groups) agents were active in the policy transfer processes that resulted in the formulation of the TRC-approach to transitional justice in the domestic politics of South Africa, Nigeria and Ghana". And that the precise roles played by the two categories of agency were different, and depended on the following: "If the policy transfer of the TRC-approach is sourced voluntarily by domestic actors, and in particular by elected political officials, the probability is high that they will be the leading policy actors to guide its policy discourse, content development and formulation process in the domestic political environment; and If the policy transfer of the TRC-approach is voluntarily initiated by domestic policy actors, the transnational transitional justice policy epistemic communities only play a limited role as providers of content-- that is the restorative justice-- on the approach and its legitimization". The 
discussion of the case studies, though on different trajectories, reflects these assumptions, and thereby corroborates the study's second hypothesis.

The previous chapter revealed that the policy transfer of the TRC-approach in the three cases, although driven by citizens' pressures for past human rights wrongs accountability, and although an opportune act by the successor regimes to promote a credible national and international image, was nonetheless a voluntary act. In this chapter, examination of the actors involved in the policy transfer process demonstrates that the domestic actors -- elected governments (ANC, PDP and NPP) and their associated public officials -- were the main conductors of the voluntary policy transfer of the TRCapproach to effect transitional justice processes. They were the lead borrowers of the TRC policy program, and were assisted by domestic non-official actors, such as the various NGOs and research and policy think-tanks. As borrowers, the official actors in the respective cases were also the principal formulators of the TRC-approach as a policy to address transitional justice demands. As demonstrated above, the formulating actors, the chief policy formulators particularly, consciously devised the path of policy discourse and its formulation in their respective political systems.

The official actors were supported by the domestic non-state actors, who provided content information on the restorative justice process to enrich the policy discourse for formulation. For example, in Ghana the domestic NGOs participated in the process from the start of the transfer and formulation processes, to the extent that some of them established a cordial working arrangement with Ghana's Ministry of Justice, which enabled them to contribute directly to the official actors. While the domestic actors were principally the borrowers and formulators in the sourcing and shaping of the domestic 
policy discourse and the formulation process, the international actors -- in particular, the individual transitional justice experts, TRC practitioners, and transitional justice epistemic communities -- were carriers of content information and knowledge of best practices of the restorative justice process and the associated TRC-approach instrument. Thus, both the domestic and international actors were functional and instrumental in the policy transfer and related formulation in South Africa, Nigeria and Ghana.

The levels of agency, however, played different roles, with domestic actors leading in sourcing and formulating the policy program, and the intemational actors complementing as providers of required information. As repository of knowledge and information on the TRC-approach to transitional justice, the international actors' vital role in this instance was not to advocate and project one approach over another, but to service the domestic actors by imparting to them the necessary information on a transitional justice policy approach, which they themselves had voluntarily sourced and transferred. As argued elsewhere, transnational actors do play a useful role in the sharing of experiences of the difficulties faced by and options available to governments that are seeking to confront the history of human rights abuses (Roht-Arriaza, 2001; 2006; OHCHR, 2006).

This limited role for the international actors of providing content information was consistent with how in all cases they were formally invited by the domestic actors in their individual capacities and/or as organizations. The TRC-approach policy transfer was obviously an initiative of the domestic actors. It was not driven by outside forces that might have necessitated international actors to engage deeply in the policy process at their own invitation, as shown in Chapter 2 with respect to the history of economic 
policy-making in Africa. In this context, the extent to which international actors will be engaged in the policy discourse depends on how well they are able to develop policy discourse communities with domestic groups.

As the cases suggest, the mode of transmitting of these international actors, as in the case of the ICTJ in Nigeria and Ghana, for example, was in the form of policy dialogue communities with domestic non-state agents ${ }^{165}$ to facilitate information sharing on the TRC-approach. The collaboration that the international actors, in particular the ICTJ, formed with domestic actors was beneficial to both. For example, on the one hand, the relationship allowed the ICTJ the flexibility to disseminate knowledge of the TRCapproach processes across borders; on the other hand, it strengthened the capacity of domestic actors to engage in the TRC policy discourse having relevant information and best practices.

The significant role played by the non-state actors in the formulation process is an indication that the act of formulating public policies is ever less the sole responsibility of the state or its official agents. ${ }^{166}$ The role of non-state actors reflecting the TRC-approach policy transfer process as revealed by the three cases substantiates the observations by Dobrowolsky and Saint-Martin (2003) that civil society and the third sector are clearly part and parcel of the new state reconfiguration by way of policy advocacy and formulation.

The discussion of the cases also confirms the Dolowitz and Marsh policy transfer model that there are several and different levels and groups of actors, both domestic and

\footnotetext{
${ }^{165}$ In Ghana, however, the ICTJ also formed a dialogue partnership with state actors during the content development stage.

${ }^{166}$ I use the notion of the state to refer to the political authority: government and its apparatus of governance.
} 
international, all involved in policy transfers at various stages. As demonstrated, the actors who participated in the TRC-approach policy transfer and formulation processes were, in the main, domestic actors identified as elected governments, political parties, leading officials in the government and in the political parties, selected consultants, the Ministry of Justice and the Parliaments, all located in the realm of state or official actors. There were also identified domestic non-state actors in the forms of NGOs and thinktanks. In the realm of international actors were individuals identified as former heads of states, academics, former TRC practitioners - as commissioners and senior staff - and a few INGOs and transitional justice epistemic communities.

These identified levels and groups of agents were of different citizenships, and played different roles as borrowers, formulators and carriers. Accordingly, the cases examined here conform to the received wisdom that actors involved in policy transfers and their roles are always limited depending on the particular policy being considered and the nature of the policy transfer taking place. Furthermore, some of these categories of actors may not have known or seen each other. For example, many of the elected official actors, particularly the elected presidents, did not have any personal encounters with some of the domestic and international non-state actors, yet the roles played by them influenced the policy thoughts and directions of these actors in the transfer and succeeding formulation processes.

Boraine (2008), for example, recalls ICTJ's involvement in the policy formulation process of the TRC-approach to transitional justice in Ghana when he observes that he received a telephone call from Nana Akufo-Addo, the then Ghanaian Minister of Justice and Attorney General on one Monday morning in 2001, requesting him to comment on a 
draft bill developed for the formation of a TRC. He remarks as follows: "I had never met him and it was a strange situation to discuss a country that I didn't know a great deal about" (Boraine, 2008:244). The significance of this observation is that actors in the policy transfer domain may be of different citizenships, and may be unknown to one another in the transfer process, but are connected by way of policy networks and epistemic communities.

The levels from which the domestic actors transferred the TRC-approach are also consistent with what Dolowitz and Marsh identify in their model. The observations from the cases suggest that the TRC-approach policy transfer sourcing in all cases indicated external beyond the countries' borders. The domestic actors in South Africa, Nigeria and Ghana drew lessons on the TRC-approach from other political systems: for South Africa, from multiple countries in South America; and for Nigeria and Ghana from South Africa. As was shown, however, in addition to outsourcing, South Africa borrowed from past experiences within the ANC's own use of commissions of inquiries. The Nigerian and Ghanaian single state-to-state lesson-drawing or the bilateral policy exchange is the most common in the policy transfer discourse: what Dolowitz and Marsh refer to as the national level policy transfer. The recognition in this chapter of the multiple lessondrawing of the South African experience, which is less common in the literature, illuminates the policy transfer discourse as not exclusively a state-to-state affair. In other words, policy transfers do occur at the level of multiple state-to-states outsourcing.

Finally, this chapter brings out the constructivist insight into the dynamics surrounding the policy transfer process of the TRC-approach. The chapter reveals how actors in South Africa, Nigeria, and Ghana purposefully deployed the notion of 
restorative justice in the respective policy settings to facilitate the policy formulation process. They did so, not only in drawing upon the restorative justice ideas that inform the TRC-approach as the desired policy response to transitional justice demands, but also by exhibiting genuine interest and belief in the worth of the restorative justice process. Consequently, the examination of the cases in this chapter demonstrates the interactive nature of ideas and interests. At the center of this interaction are agents-- both domestic and international--and their actions that reflect their different capacities and roles.

\section{4: Summary and Conclusion}

This chapter addressed two fundamental research questions relating to agency in the TRC-approach policy transfer and formulation processes in the three selected cases. First, it identified the specific agents in these processes; second, it examined the specific and divergent roles played by these actors in these processes. In all three cases there were similarities in the identifiable domestic actors who functioned as borrowers and formulators in the processes. In South Africa, Nigeria and Ghana, these actors were, principally, the elected political parties -- the ANC, the PDP, and the NPP -- respectively; their leaders, including the elected heads of states; the respective Ministers of Justice; government-hired consultants; and leading officials associated with the ruling political parties.

In South Africa and Ghana, however, the institution of Parliament was involved at the formulating stage, while in Nigeria it was not: there, the formulation phase was limited to the same actors as the borrowers in the other two. An important observation from these cases is the seeming absence of civil servants and bureaucrats as borrowers or 
formulators in the policy transfer process. ${ }^{167}$ Perhaps, when it comes to transitional justice policy formulation processes -- in this case, the policy transfer of the TRCapproach -- elected politicians are the most salient actors.

In all cases the elected official actors were complemented by non-official ones, particularly domestic NGOs, during the borrowing and formulating phases of the process. There were significance nuances, though, in the involvement of non-state domestic actors in the policy transfer process. In both South Africa and Ghana, from the beginning of the transfer and during the subsequent formulation process they were more active, in terms of levels of engagement with the sourcing and content development, than in Nigeria. The formulating agents, who were mostly the domestic official actors, promoted the TRC policy approach using its restorative justice philosophical underpinnings as both foreground and background enabling assumptions.

In Nigeria, however, the notion of reparation was consciously excluded from the standard normative frames referenced in constructing the policy discourse. Moreover, while in all instances the normative values connected to the restorative justice process were projected in ways intended to excite the sentiments of the citizenry so as to produce public support for the TRC policy program, in South Africa and Ghana, more than in Nigeria, the formulating actors deliberately emphasized the normative values to ensure that the citizenry responded favourably.

With regard to international actors, who were the carriers of the TRC-approach and its content, the same types of specific actors were identified across all the three cases. These groups of actors included individual transitional justice and TRC-approach experts,

\footnotetext{
${ }^{167}$ It was observed during the investigations, however, that senior bureaucrats at the respective ministries of justice were helpful in the design of the draft legislations (South Africa and Ghana) and of the statutory decree (Nigeria).
} 
TRC practitioners, academics and authors, INGOs, and transitional justice epistemic communities. The levels of engagement of the international actors, however, were deeper in South Africa and Ghana than in Nigeria. As noted, in South Africa, for example, the influence of TRC practitioners from South America was apparent; in Nigeria, while some individual TRC practitioners from South Africa and the ICTJ were identified as participants in the process, they only came in after the first stage of the policy content formulation had been completed by the official actors; and in Ghana, individual TRC practitioners and NGOs from South Africa and the ICTJ played roles from the inception phase.

To sum up, the chapter makes clear that the domestic official actors were at the forefront of the policy transfer and formulation processes of the TRC-approach in South Africa, Nigeria and Ghana. The role of non-state actors, locally and internationally, in facilitating the policy transfer process in all cases was also apparent, although secondary. The discussion in this chapter thus emphasizes the significance of agency in policy formulation discourse, especially when new policy ideas are involved and the policy design promotes policy change or innovation. It also validates proposition two of this study. The reality is that policy ideas, however appealing, cannot assure generation of domestic policy transfer and its formulation. In all instances, policy ideas, just like the restorative justice that informs the TRC-approach, necessitate actors to transport and develop them in the domestic political environment. Thus, the character of policy transfer and formulation process of the TRC-approach was an act of mutual construction involving agents, ideas/interest and an enabling structure, and is therefore a phenomenon of social constructivism. 
Further, as demonstrated in Chapter 2 of this study, contrary to the received wisdom about the dominance of international actors in economic policy formulation processes in African countries, this chapter reveals that when it comes to formulating the TRC-approach to transitional justice policy, domestic actors, not transnational actors, were in the vanguard position.

Despite these insights into the functional and instrumental abilities of agents, it remains a fact that agents do not exist in a vacuum. In other words, there are certain structural constraints that affect how actors conduct policy formulation processes and that determine whether the formulation will succeed. The extent to which domestic structures in the three cases responded to the restorative justice paradigm that informs the TRCapproach as formulated by the identified domestic actors is examined in the next chapter. 


\section{Chapter Seven: Domestic Structures and TRC-Approach Policy Transfer}

\section{0: Introduction}

The chapter addresses two broad questions: what factors facilitate or restrict the TRC-approach policy transfer; and, how do we explain the TRC-approach policy transfer success or failure in the three cases? In chapter 4 of this study, it was concluded that both South Africa and Ghana recorded a blend of successes and partial successes, and that Nigeria recorded success, partial failure, and failure in the policy transfer and formulation processes. These diverse outcomes, it was suggested, are explainable by referring to the relationships between domestic structures and the processes of the TRC-approach policy transfers as undertaken by the domestic official actors. Accordingly, this chapter puts forward the notion that domestic structures of the political systems in South Africa, Nigeria and Ghana were significant factors in determining the TRC-approach policy transfers and their subsequent formulation process.

Furthermore, the domestic structure -- conceptualized in this study as cultural receptiveness and enabling political platforms - in South Africa and Ghana were more obvious, amenable and responsive to the TRC-approach policy transfers than they were in Nigeria. The underlying reason for the assertion just made is that the domestic agents engaged in the policy transfers in South Africa and Ghana were more informed on the TRC-approach and the associated administrative technique for implementation than those in Nigeria; they learned lessons on the domestic formulation process; and the political contexts in those two countries were acutely appropriate for the TRC-approach to transitional justice. 
The domestic official actors in South Africa and Ghana, unlike those in Nigeria, were particularly influential in using the normative values associated with restorative justice to frame the TRC-approach policy formulation discourse. This was done in ways that coincided with certain religious beliefs of their respective citizenries. Moreover, the legislative process adopted for the policy formulation in South Africa and Ghana, unlike the executive decree format used in Nigeria, allowed the public to participate in and contribute to the policy discourse, thereby promoting a perception of ownership of the policy process. These observations suggest that structural constraints or feasibilities were important considerations in the TRC policy transfer processes in the selected cases. In other words, any of the structural and/or institutional elements identified in the Dolowitz and Marsh $(1996 ; 2000)$ policy transfer model ${ }^{168}$ can hold back or make possible policy transfers and their successive formulation in the domestic political systems.

This study then suggests further that the manifestations of these structural constraints or feasibilities during policy transfer processes depend on: how well informed agents of policy transfers, particularly domestic actors, are about the policy being transferred; the comprehensiveness of the transfer process, in terms of the essential conditions that enabled the successful formulation of the policy in the originating country; and the suitability of the transferred policy in the domestic politics. These conditions are also presented in the Dolowitz and Marsh policy transfer model which the authors identify as uninformed, incomplete, and inappropriate policy transfers. Any of

\footnotetext{
${ }^{168}$ On the list of structural and institutional constrains or feasibilities that Dolowitz and Marsh identify in their policy transfer model are ideology, culture, bureaucracy, history of past policies, and policy complexities. See Chapter 3 of this dissertation.
} 
these factors alone or in combination, the authors suggest, may inform policy transfer success or failure.

Following the introduction is an examination of the cultural strand of the domestic structure that constrained or facilitated the TRC-approach policy transfers in South Africa, Nigeria and Ghana. The discussion centres on how certain societal values, particularly religious beliefs of the citizenry, invoked by the formulating actors to construct the policy formulation discourse, were received and supported the TRCapproach. Next is an examination of the political format employed in the policy formulation processes of the TRC-approach in the selected cases. The discussion extends Risse-Kappen's (1995a; 1995b) concept of domestic structure to examine the political setup in analysing the degree to which citizens and other non-state actors, apart from the formulating actors, were involved in the policy formulation discourse.

The third section of the chapter analyses the case studies by referencing the third research hypothesis, and also underscoring other findings from the case studies. The summary and conclusion of the chapter follows. Using the findings from the case study analysis, the summary and conclusion section addresses the factors that account for TRCapproach policy transfer success or failure outcomes. It explains why there were variations in the outcomes in the three cases as examined in Chapter 4.

\section{1: Domestic Structure: Cultural (Religious) Beliefs}

There is no gainsaying the fact that cultural manifestations and belief systems do affect the world views of their adherents and those of the people who live with them. In the context of this study, religious beliefs and practices have a significant impact on the 
conduct and actions of people who subscribe to them. They do shape people's behaviour, and also do influence their support, or absence thereof, of certain courses of action. Max Weber's suggestion that Calvinist doctrine created a unique frame of mind that promoted a rational and ascetic behaviour of individuals, for example, demonstrates how culture, in this instance Protestant Ethic, was invoked to explain capitalism -- rational capitalist economic behaviour. ${ }^{169}$

Religious beliefs may not possess a causal connection in the form of a single explanatory power. Like other forms of culture, though, religious beliefs and practices do shape people's behaviour in either restraining or supporting ways. In such circumstances, culture may play a unique underlying role at a certain critical moment in an individual's life. As Swidler observes, "culture has an independent causal role because it shapes the capacities from which such strategies of action are constructed" (1986: 276-277). In this study, without suggesting that the religious beliefs presented a causal explanation, certain pathways of the religious beliefs of the targeted policy beneficiaries had significant effects on their degree of receptiveness to the TRC-approach policy transfer and formulation processes. These pathways shaped the way the public responded to the TRCapproach to the transitional justice process, judging it appropriate or otherwise as a policy program.

For the most part, the citizenries in the selected cases were predisposed to endorse the TRC-approach to transitional justice because its restorative justice values were familiar to their own cultural settings -- their religious beliefs, values and understandings. Certainly, the leading domestic formulating actors, particularly in Nigeria, appear to have also brought their religious beliefs to bear in advocating the TRC-approach to the

${ }^{169}$ See Max Weber's The Protestant Ethic and the Spirit of Capitalism (1958). 
transitional justice process. ${ }^{170}$ This resonance enabled the actors to mobilize societal sensitivity to the TRC-approach policy program by calling upon rooted religious convictions and principles.

The normative values associated with the restorative justice paradigm, which it was argued in the previous chapter to have appealed to the domestic official formulating actors, overlapped with some of the principal religious tenets of the citizenry. In particular, the values of truth-telling, forgiveness, and reconciliation embedded in the restorative justice process corresponded to Judaeo-Christian, and also, to a degree, to Islamic, religious beliefs. In these religious faiths, truth-telling, likened to confession and pilgrimage to Mecca in the Christian and Islamic faiths respectively, forgiveness, and reconciliation, both embraced by these faiths as well, were paramount behaviours expected from believers. It was incumbent upon practitioners to express, advance and promote them at all times as dictated by both the Christian and Islamic faiths. ${ }^{171}$

At a time that the TRC-approach was considered for a transitional justice process by the successor regimes in all the three cases, and its policy formulation process was

\footnotetext{
${ }^{170}$ In addition to President Obasanjo of Nigeria, whose religious beliefs were openly expressed, it is instructive that President Kufuor of Ghana is a devout Catholic, and Alex Boraine, who was instrumental in the policy transfer and formulation process in South Africa, is an ordained Methodist clergyman, and once practised as a preacher.

${ }^{171}$ The majority of the South African population identify with the Christian religion. In $199180 \%$ of the population was identified with the Protestant Christian faith. According to the 2001 census data, $79 \%$ of the South African population were identified as Christians, $1.5 \%$ as Muslims, $4.5 \%$ were identified with other religious faiths, and the remaining $15 \%$ of the population had no religion. Information sourced on July 28 , 2011 from http://countrystudies.us/south-africa/52.htm; and http://www.southafrica.info/about/people/population.htm. In Nigeria the breakdown of the religious groups is as follows: $50 \%$ Islam; $40 \%$ Christianity; and $10 \%$ indigenous faiths. Information sourced on August 12 , 2010 from http://www.rms-africa.com/nigeria.htm; and on July 28, 2011 from http://www indexmundi.com/nigeria/demographics profile.html. In Ghana the 2000 population census had Christians constituting $68.8 \%$ of the population with Muslims occupying $15.6 \%$; the remaining $15.6 \%$ represented indigenous beliefs, other religions and no religion. Information sourced on July 28,2011 from http://www.newsfromafrica.org/newsfromafrica/articles/art 7902.html; and http://www. factrover.com/people/Ghana people.html
} 
characterized by a policy transfer activity, appealing to such principal religious values that were consistent with the restorative justice process was a strategic measure to invoke societal sympathy and agreement. In Chapter 6 it was shown that the formulating actors drew upon the values and attributes associated with restorative justice to appeal to the public sentiments of their respective citizenries, and thereby invite their approval in the policy formulation process of the TRC-approach to transitional justice. The policy discourse phase of the formulation process was infused with these religious doctrines from which naturally flowed not only the need to know the truth about historic human rights violations, but also the necessity of forgiveness by the victims after acknowledgment of errors on the part of the perpetrators, and demands for reconciliation.

This policy formulation process was intended to align the values associated with the restorative justice process with these avowed religious beliefs to which the majority of the population, including the victims of human rights violations, subscribed. The extent of this appeal on the part of the formulating actors, and the matching response on the part of the citizenry, more evidently manifested in South Africa and Ghana than in Nigeria. The three cases are examined in sequence.

\subsection{1: South Africa: Significance of the Judaeo-Christian Religious Beliefs}

To a considerable degree, Judaeo-Christian beliefs and values contributed to the receptiveness of the TRC-approach in South Africa. Invoking and appealing to the religious faiths and situating the TRC process in this context at the time of the TRCapproach policy formulation process enabled the public, particularly those who may, ideologically and for selfish reasons, have opposed the non-retributive process, to consent 
to it. Graybill (2002) suggests that South Africa is a Christian country to the degree that Christianity is the central ideological frame of reference. She argues further that "biblical language and Christian discourse resonate powerfully, and theological discourse on political matters is taken seriously" (Graybill, 2002: 25). It is therefore not surprising that the South African formulating actors, as noted in the previous chapter, succeeded in utilizing these religious beliefs to promote the TRC-approach to transitional justice and, thereby, facilitated its policy transfer process.

The considerable role of the South African Council of Churches (SACC) in the public discussions on the TRC-approach, and in mobilizing support for it, was apparent. One Member of Parliament at the time of the formulation process, for example, had this to say: "the churches and Tutu and people like that, they will always talk about reconciliation, peaceful path, forgiveness and so on" (Personal Interview with Professor Ben Turok, March 10, 2009). The Christian community had for a long time -- since 1968 -- been interested in and supported the themes of truth, reconciliation, confession, guilt and forgiveness for South Africa (Graybill, 2002: 25-26). These were processes the TRC had to deal with subsequently. Indeed, the extent to which the Christian religious tenets of forgiveness and reconciliation shaped, informed, and enabled the TRC policy approach is also traceable to an observation by Tutu (1999) on the impact of the church mission schools. He recalls that most of the black community leaders who were associated with the ANC had told him that their desire for reconciliation and forgiveness had been attributable to influence and witness of the Christian Churches (Tutu, 1999: 43).

The church teachings and subsequent involvement in the policy discourse contributed to facilitating the formulation process. As Graybill further observes, the 
cultural matrix within which the TRC operated was "heavily influenced by Christian thought and tradition" (2002: 25). This view is acknowledged by Andre du Toit, an academic and a keen observer of the genesis and the work of the South African TRC, who notes that a range of civil society actors with the Council of Churches "drove the proposal for a truth commission" for South Africa (Personal Interview, September 16, 2008). The idea is also emphasized by Piers Pigou, who suggests that the western Christian interpretation of forgiveness was significantly infused into the policy formulation discourse (Personal Interview, September 16, 2008). Therefore, one of the enabling structural conditions that facilitated the policy transfer of the TRC-approach was the inherent Judaeo-Christian religious beliefs of confession (truth-telling), forgiveness and reconciliation.

Significantly for the South African case, these religious values resonated well with the African belief system of ubuntu. The notion of ubuntu, the philosophical antecedents of which are traceable to African rooted human identity, and was captured in the postscript to the South African Interim Constitution of 1993, resounded well with the Judaeo-Christian religious values to serve as the necessary feasible basis for the policy formulation of the TRC-approach. The concept of ubuntu essentially connotes humanism, or humanity to one another, with an emphasis on empathy, sympathy, harmony, compromise, and peace (Wilson, 2000; 2001; Villa-Vicencio, 2009). ${ }^{172}$ It is literally translated as 'human beings or persons are human beings or persons because of other human beings or other persons'. Villa-Vicencio argues that "the underlying principle of

\footnotetext{
${ }^{172}$ Ubuntu is a Bantu word, a language the majority of whose speakers are in the Southern and Eastern regions of Africa. Nonetheless, the concept is understood in large parts of Africa, with different references and names. The philosophy of ubuntu also suggests sharing with and caring for one another, and its underlying objective is to build and strengthen relationships.
} 
ubuntu is that human existence is interconnected and communal" $(2009: 114) .{ }^{173}$ Its inclusion in the post-amble to the Constitution constrained the South African political leaders to explore a non-retributive transitional justice process.

As Villa-Vicencio (2009) observes, the South African transitional justice process was one of a restorative justice paradigm and ubuntu. The latter's meanings thus dovetailed with the restorative justice values of transitional justice. The ubuntu viewpoint epitomizes capacity for understanding and compassion, and therefore focuses on how to restore broken relationships collectively. Thus, underlying ubuntu is the capacity to forgive and reconcile, which are both essential to the Christian doctrine and faith. The fundamentals of ubuntu match the core principles and beliefs of the Judaeo-Christian religion -- with which the majority of the South Africans are identified. ${ }^{174}$ This unity allowed the TRC-approach policy formulating actors to construct the policy discourse in ways that would appeal to large proportions of the population so as to encourage receptiveness to the TRC-approach.

These cultural frames were consciously appealed to by the leading formulating actors to garner public support for the policy process. As Wilson (2001) observes, the ANC often appealed to pan-African identity -- in this case, ubuntu -- to mobilize support for its policies. Significantly, this identity perspective coincided with the faiths of the

\footnotetext{
${ }^{173}$ Villa-Vicencio was the director of research at the South African TRC. A theologian by profession, he was one of the non-state individual actors who participated in the policy formulation process.

${ }_{174}$ Archbishop Desmond Mpilo Tutu is considered to be one person who contributed considerably in identifying the synergies between ubuntu and the Christian religion (Wilson, 2001; Villa-Vicencio, 2009). Desmond Tutu, although not identified in this study as one of the actors in the policy transfer process in South Africa, has been viewed as one of the civil society voices that argued for the restorative justice process to transitional justice during the policy formulation discourse. (Findings from cross-section of personal interviews conducted in South Africa for this study in 2008 and 2009). Desmond Tutu ended up chairing the TRC. Ubuntu profoundly influenced the operational phase of the TRC and its outcomes, as reflected in the opening pages of the TRC final report (Tutu, 1999; Graybill, 2002; Boraine, 2008).
} 
religious community that led to the citizenry responding favourably to the appeal on that decisive occasion. To be sure, it was the Judaeo-Christian religious values that were appealed to by the formulating actors during the TRC-approach policy transfer and formulation process and the ubuntu concept was readily present to facilitate these religious values.

\subsection{2: Nigeria: Promising Religious Beliefs Unutilized}

Nigeria, similar to South Africa, is a heavily religious society. Ninety percent (90\%) of the population claim to be religious, with the Islamic and Christian faiths dominating. Both religions and their followers aspire to and affirm the principles of confession, forgiveness and reconciliation. It has been suggested that religion is central in political power legitimization with God seen as the source and pinnacle of the political process. Abogunrin (1984), for example, observes that in Nigeria politics and religion are viewed together as complementary institutions in the social consciousness. The broad attractiveness of the restorative justice process to transitional justice is unsurprising. A considerable number of informants agreed with the suggestion that the Nigerian religious setting and the fact that its people ardently profess their religious faiths may have constituted an enabling condition for the TRC-approach to transitional justice being accepted and supported at the initial stages (Focus Group Discussion \# 2, February 12, 2009).

The normative values of truth-telling, forgiveness and reconciliation resonated well with the religious duties of many Nigerians. Unlike South Africa, in Nigeria there was no evidence of efforts by the formulating actors to appeal to the religious beliefs of 
the citizenry. Neither was there evidence of receptiveness to the TRC-approach as a transitional justice policy on the basis of the religious beliefs of the people. As was observed in the previous chapter, observers point out that there was no attempt to locate the policy transfer process within any known Nigerian cultural frame, including religion, during the policy formulation discourse. ${ }^{175}$ As one informant remarked, "the formulation process was not invested in the kind of being more deliberative and contextualizing it in the local system" (Personal Interview with Chidi Odinkalo, February 10, 2009).

Thus, even though there was no conscious effort on the part of the formulating actors to situate the TRC-approach in any identified cultural resemblance during the formulation process, some observers believe that the religious beliefs of the Nigerian people may, on the whole, have contributed positively to the public's receptivity to the TRC-approach at the time the policy program was announced by President Obasanjo. As one informant remarked, entrenchment of religion in Nigerian society may have made it easy for people to accept the TRC-approach, especially if one considers the surprising nature of the announcement by President Obasanjo of his intention to set up a TRC (Personal Interview with Father Matthew Kukah, January 28, 2009).

Certainly, the language of forgiveness and reconciliation that was used on several occasions by President Obasanjo -- coming as an appeal from someone who, for many reasons (such as his incarceration), could have been vindictive-- may have encouraged Nigerians' receptiveness. It is significant to point out that the vast majority of Nigerians may have viewed the TRC process as something compatible with their religious practices, but may not have endorsed it as the appropriate policy response to transitional justice.

\footnotetext{
${ }^{175}$ With the exception of the chief policy formulator in the person of President Obasanjo, who by his own spiritual transformation in Christianity, it is suggested, strongly influenced, among other reasons, Nigeria's choice of a TRC approach.
} 
The investigations of the Nigerian case revealed no deliberate effort by the TRCapproach policy formulators to indigenize the policy transfer process in the domestic cultural settings by appealing to the Nigerian religious faith community. The absence of convincing empirical evidence for the receptiveness or otherwise of this cultural strand of the Nigerian domestic society to the TRC-approach was also apparent.

\subsection{3: Ghana: Explicit Support from the Religious Community}

Ghana, similar to South Africa and Nigeria, can be considered a deeply religious society, with the main groupings being Christian and Muslim. It can also be argued that to an extended degree and similar to South Africa, religious conversations in Ghana reverberate significantly through daily political issues. Nonetheless, unlike South Africa, the basis for establishing the TRC was not heavily embedded with religious thoughts (doctrines) and traditions. Ghana is a case of the leadership of the religious groups seizing an opportunity to argue for a transitional justice process that resonated acceptably with their own beliefs and practices. As disclosed elsewhere, the clergy in Ghana, together with other civil society groups, had since 1993 called for a national process of forgiveness and reconciliation with reference to the history of gross human rights violations (Sarpong, 1996; Palmer-Buckle, 1998; Mensa-Bonsu, 2005); and, as was revealed in the previous chapter, the leadership of the Ghanaian religious community was seen to have supported the TRC-approach process.

The support from the clergy was made obvious when the domestic formulating actors, citing the normative values associated with the restorative justice process, appealed to the sentiments of Ghanaians. The clergy spoke favourably of the TRC- 
approach and, while urging the government to speed up the process, also carried their membership along to embrace the chosen policy program for transitional justice. For example, at one point during the policy debate on the TRC-approach, the head of the Muslim community in Ghana (the Chief Imam), Sheikh Osmanu Nuhu Sharabutu, urged President John Agyekum Kufuor to speed up the full implementation of the government's policy proposal of national reconciliation. The Chief Imam is reported to have argued that the proposal was an imperative tool for national unity and integration (The Ghanaian Times, 2001).

The formal announcement by the Ghanaian government to set up the TRC process to promote reconciliation, among other objectives, was therefore viewed as consistent with what the religious community had stood for, and it thus warranted their explicit support. Consequently, the domestic formulating actors, unlike their Nigerian counterpart, consciously inculcated in the policy discourse the restorative justice values of truth-telling, forgiveness and reconciliation that fitted well into the religious mood of the country in order to ensure positive reception of the TRC-approach policy transfer. For instance, while the majority of Ghanaians (89\%) supported some form of national reconciliation, support from citizens within the two main religious persuasions $-.90 \%$ of Muslims and $88 \%$ from Christian faiths -- was emphatic (CDD-Ghana, 2001a). This background societal view, informed by religious persuasions, no doubt provided indicators of how receptive the Ghanaian religious disposition could be to the TRCapproach policy transfer. The Ghanaian temperament of forgiveness, love of peace, and desire for harmony may have played a role in the acceptance of the TRC-approach as an alternative process to transitional justice (Focus Group Discussion \# 1, January 15, 2009). 
Indeed, views from Ghanaians with religious affiliation, particularly Christianity and Islamic, rated peace, forgiveness and reconciliation, in that order, as the three most important goals for any transitional justice process (CDD-Ghana, 2001a). Ghanaian cultural forms, and in particular religious beliefs, thus synchronized well with the TRCapproach processes (Personal Interviews with Professor Joseph Ayee, July 30, 2008; Professor George Hagan, August 11, 2008; Kwadwo Appiagyei-Atua, August 20, 2008; Maulvi Wahab Adam, January 15, 2009). Professor Ayee, for example, had this to say: "If you look at the Ghanaian context, if you wrong somebody, you go with somebody, you go and then beg the person, and I think the truth and national reconciliation commission was cast in that way."

By detecting these aspects of the TRC-approach that were consistent with the religious beliefs and practices, and by bringing them to the fore of the policy debates, the receptiveness of the peoples' religiousness facilitated the policy transfer and formulation process. The religious communities -- Christian and Muslim -- played pivotal roles by emphasizing the aspects of forgiveness and reconciliation in the indigenization of the TRC policy approach to transitional justice. The interventions in the policy discourse of the clergy manifested in a way that projected the values to be derived from the TRC policy approach as not unfamiliar to the Ghanaian way of life. Accordingly, their religious beliefs and practices constrained many Ghanaians to endorse the TRC-approach. 


\section{2: Domestic Structure: Political Platform for Citizen Engagement}

In addition to cultural forms, the political platforms that foster state-society relations ${ }^{176}$ in policy discourse also make possible the policy transfers of the TRCapproach. As policy transfers represent the domestic formulation of new or alternative policy responses to societal problems, the degree to which beneficiaries and citizens are able to participate in the policy discourse is critical to the transfer process. By accessing the policy formulation process through making contributions, channelling views, and submitting comments and critiques on the proposed policy programs, the public is able to demonstrate its responsiveness to the policy process. This demonstration creates a sense of public ownership of the policy process, and thus facilitates policy transfers. The manifestation of this responsiveness on the part of the public depends on an enabling political arena that promotes state-society relations.

Sometimes the immediate history of political processes that promote state-society relations can also encourage (or discourage) public participation and facilitate the policy transfer process. The policy formulation style adopted by policy-making actors will either create the space for public participation or suppress citizen participation. As McGregor observes, most often the national policy prescriptions towards the transitional justice process fail to take into account the rights, interests and needs of key stakeholders,

\footnotetext{
${ }^{176}$ The term state-society relations is generally understood to mean the interactions between state institutions and societal groups to discuss, bargain over and redefine political society, political space, and how public power or authority is managed, and how it can be influenced by non-state actors and citizens generally. These exchanges are focused on issues that include rights and obligations of state and society, how public resources are allocated and expended, representation, transparency and accountability, and economic reforms and management, among others. See, for example, Boone (1998) and Migdal (2001) for discussion on this subject. Migdal, whose seminal work on the state in society looks at how states are fragmented and face crowds of social organizations that seek to maintain and compete for the power to regulate societal behaviour, is very insightful.
} 
including victims (2008: 55). Such exclusive policy processes generate a sense of detachment from the policy process on the part of citizens.

In the current study, the policy formulation styles adopted by the successor regimes in the selected cases towards the TRC-approach policy transfer were significant factors accounting for how responsive to and engaged with the policy dialogue and discourse the public were. Different political systems and their accompanying institutional arrangements for policy dialogues have varied impacts on the effectiveness of non-state actors and citizens generally in policy formulation process. Drawing on Risse-Kappen's notion of domestic structures, particularly of the societal structure and state-society structure, to examine the extent of citizens' participation in the TRCapproach formulation processes in South Africa, Nigeria and Ghana makes it clear that the political platforms observed in the cases manifested differently and accounted for varied degree and level of citizen involvement during the time of the TRC policy transfer processes.

On one hand, the societal structure intensifies citizens' participation in the policy discourse, their awareness and interventions, and civil society configuration into the policy process. It symbolizes the expressions of political attitudes, ideological positions and shared beliefs that are articulated by the citizenry during the policy process that result in the formulation of a particular policy. On the other hand, the state-society structure features in a more organized form of public participation in policy process. It suggests institutional arrangements that cultivate the participation of organized non-state actors displayed as policy networks, research and policy think-tanks and non-governmental organizations, among others. These organized groups serve the intermediary function by 
mobilizing inputs from citizens and channelling them on their behalf into the policy formulation process. Both structures, Risse-Kappen suggests, are signs of the expression of political culture in the political systems.

In South Africa and Ghana the legislative policy process style adopted by the respective successor regimes for the formulation of the TRC-approach provided the avenues for both societal structure and state-society structure forms of public participation to emerge. In Nigeria, the executive decree style employed by the government in the formulation process restricted the degree of public participation. The style impacted negatively on any meaningful opportunities for wider citizen participation in the policy process. There was no observed direct intervention by ordinary citizens. The Nigeria case, however, demonstrates a limited manifestation of organized non-state actors' participation in the policy formulation process. Nonetheless, the examination of the three cases demonstrates the significance of forms of political processes around statesociety relations that existed prior to the ensuing transitional justice policy debates.

\subsection{1: South Africa: Legislative Process}

The level of openness in the consultative process and of the broad public participation in the policy formulation processes resulting in the TRC in South Africa has been described as one of the greatest assets of the transitional justice process (Simpson, 2002; Backer, 2007; Center for Conflict Resolution, 2007; Sachs, 2009). Boraine (2000a), for example, cites a very robust civil society in South Africa as one of the favourable conditions for the formation of the TRC process. The legislative framework adopted by the ANC for the TRC-approach formulation process created opportunities for 
civil society, either in their individual capacities or in the form of organized groups, to engage in the policy discourse, make contributions, and produce a sense of ownership. Not only did the institution of Parliament, which enacted the legislation, constitute the elected representatives of the people, but the deliberative process adopted by the institution allowed for extensive civil society involvement in the policy process.

The extended period for the gestation of the law meant that ordinary South Africans had the opportunity to contribute to the draft bill by examining it, making additions, and, even, rejecting it. As one Member of Parliament who was involved in the process disclosed, "There was a huge public discourse around the process of the TRC, everybody had gotten involved, so it was a national event, it went on too long in my view" (Personal Interview with Sheila Camerer, October 23, 2008). This view of extensive and extended civil society participation is corroborated by civil society activists familiar with the process (Personal Interviews with Carnita Ernest, October 5, 2008; Hugo van der Merwre, October 6, 2008). Civil society participation represented all sides of the debate, including those in support of and against the truth commission approach to the transitional justice process (Dugard, 1997; Simpson, 2002). As parliamentary member Camerer suggests further, lots of submissions from interested parties were received, and some of the submissions agreed to the TRC proposals, and others objected to it (Personal Interview, October 23, 2008).

The pervasiveness of South African civil society during the TRC-approach policy formulation process can be traced to the nature of the political processes prior to the 1994 political transition. Although apartheid South Africa was undemocratic, apartheid governance exhibited certain democratic principles and practices. Participatory 
democracy was respected even if it was limited to the white minority. The parliamentary process of policy-making was the norm to the extent that apartheid legislations went through the formal parliamentary processes where opposition was recognized. Civil society involvement in the governance process, particularly by sections of the religious community, was tolerated as well. Thus, some degree of state-society relationship was fostered prior to the demise of apartheid rule -- except that it was not inclusive. The then political environment and processes formally excluded the majority black population.

Moreover, the opposition struggle and challenges against apartheid rule resulted in an expanded civil society activism outside of the formal democratic structures. Certainly, the aftermath of the 1976 Soweto massacre changed the face of non-state popular mobilization against apartheid rule. The formations and intensity of several organized groups in political activism and engagement increased. By the time the political transition unfolded in the early 1990 s, the space available for civil society mobilization and engagement in political process was unparalleled in the rest of Africa. The 1994 political transition brought with it formal, fully fledged and inclusive democratic practices and processes. The new political environment expanded the role of civil society and, building on the limited state-society relationship prior to the 1994 transition, the political space was ripe for vigorous and elaborate citizen participation in decision-making processes on policies and programs that affected their lives.

When it came to the TRC-approach policy formulation process, from the time the draft bill (the Promotion of National Unity and Reconciliation Bill) was published in November 1994 until the tabling of it for debate and passage in Parliament on May 17, 1995, citizens' involvement was noticeable at two levels. To start with, the legislative 
deliberative process allowed ordinary South Africans to make direct contributions to the policy process (Graybill, 2002). ${ }^{177}$ The public hearings conducted by the Portfolio Committee on Justice, the legislative body that was in charge of the draft bill, facilitated this process of direct citizen participation. The individual citizen participation was in addition to that of CSOs. On the list of CSOs that made submissions before the committee were the Catholic Bishops' Conference, the Black Sash, Amnesty International, the South African Bar Council, and Lawyers for Human Rights (Boraine, 2008: 175$).{ }^{178}$

Second, the legislative platform and the long period for the deliberative process allowed for organized non-state actors to mobilize constituency inputs and submit them to the justice committee. The conferences organized by Boraine's Justice in Transition NGO in 1994, as noted in Chapter 6, and subsequent ones in $1995^{179}$ presented such occasions when policy networks and groups played the intermediary role of mobilizing civil society inputs to inform the policy discourse and formulation process on the TRCapproach. For instance, the second conference held in 1994 drew representation from about 150 people, including academics, the South African Defence Force, the National Party, and the Conservative Party, in addition to some foreign participants (Christie, 2000). The two conferences organized in 1994, as Boraine (2008) argues, were to generate public discussion and debate on the emerging policy proposal for a TRCapproach to transitional justice. Boraine (2008) further recalls that he presented, on behalf

\footnotetext{
${ }^{177}$ This was confirmed in consensus findings from personal interviews conducted with a cross-section of stakeholders in South Africa in 2008 and 2009.

${ }^{178}$ It has been stated elsewhere that the committee on justice listened to more than 20 hours of submission (Graybill, 2002: 2).

${ }^{179}$ One particular conference organized by the NGO was the two-day history conference that brought 24 leading South African historians to deliberate on the TRC approach to transitional justice (Boraine, 2008).
} 
of 21 NGOs, to the Justice Committee views and comments on the TRC draft Bill following a two-day deliberative workshop that his NGO organized.

It is on record that several NGOs, including CSVR and the Khulumani Support Group, ${ }^{180}$ submitted memoranda to Parliament that reflected opinions mobilized from their respective constituencies (Christie, 2000). Not all of these intermediary representations were supportive of the TRC-approach, however. Some of the contributions of the non-state organized actors were critical of the process (Boraine, 2008). Graybill (2002) also notes that the NGO sector, for example, recommended against conducting the amnesty hearings in private. The legislative process for formulating the policy on the TRC-approach promoted different formations of the civil society community. Representations by citizens, as well as by advocacy groups, interest groups, and pressure and policy networks, which are all part of the policy subsystems (See Chapter 2), represented different attitudes, ideological and interest positions, ${ }^{181}$ and beliefs (such as religious ones) regarding matters of human rights justice and accountability. The assertion by the chair of the Justice Committee as recorded by Graybill (2002:2) that "what makes this piece of legislation so unique is that it really is a patchwork of all the viewpoints of the country" is very correct.

The process created the space for policy formulating actors, especially those who were behind its production, to interact with the wider citizenry in order to seek their endorsement and contributions to enrich the content. In other words, the political platform for policy formulation in the form of the legislative process that was apparent

\footnotetext{
${ }^{180}$ This is a group composed of victims of gross human rights abuses. It was quickly formed during the advent of the transitional justice policy discourse as a stakeholder and a pressure group. It made significant inputs into the process.

${ }^{181}$ Interest groups that strongly opposed the TRC approach included the IFP, Freedom Front (FF) and the South African Police Force (Graybill, 2002; Boraine 2008).
} 
fostered a strong sense of a state-society relationship that contributed to facilitating the policy transfer process in South Africa. Consequently, even though not all South Africans supported the TRC-approach to transitional justice as demonstrated by the record of final voting in Parliament, ${ }^{182}$ what eventually emerged as the policy legislative model for the TRC reflected the views and preferences of the majority of South Africans. The legislative process produced the political environment needed to facilitate citizens' participation in the policy formulation process.

The openness, transparency and consultative nature of this political setting encouraged public debate on the goals, form and modus operandi of the truth commission that was to be set up. The conclusion that the policy formulation consultations with the wider South African civil society were thus adequate and inclusive is affirmed by many witnesses to the formulation process, including Members of Parliament at the time of the policy process, academics, representatives of CSOs, and individuals (Personal Interviews with du Toit, September 16, 2008; Ernest, October 5, 2008; der Merwre, October 6, 2008; Camerer, October 23, 2008; Turok, March 10, 2009; Written Responses to Email Interview with Thapalo Mokushane, November 10, 2008). ${ }^{183}$

\footnotetext{
${ }^{182}$ The IFP and FF, the two political parties in Parliament, voted against the bill (Graybill 2002)

${ }^{183}$ Nonetheless, there were some few individuals who felt the public consultations were not enough. For example, Trevor Ngwane, a human rights activist who describes himself as a former member of the ANC, suggests that the TRC approach was good for the elites but not for the masses, and that the policy formulation process was inadequate. He argues that there was concerted effort on the part of the ANC to get its members and the masses to agree to the process. He concedes that it is possible that most South Africans were receptive, but cautioned that it is wrong to assume that because a large number people voted for the ANC in 1994, the people endorsed the TRC process (Written Response, October 24, 2008).
} 


\subsection{2: Nigeria: Executive Decree Process}

The executive decree style adopted by the Nigerian government and the shortness of the policy formulation process towards the TRC-approach influenced the degree to which civil society engaged with the policy discourse on the policy transfer process. The policy formulation style controlled the extent to which ordinary citizens could directly participate in the process. It also affected how quickly organized civil society actors meaningfully engage with the formulation process, notwithstanding their efforts to liberate the policy process from executive dominance. When queried about citizens' participation in the policy formulation process that led to the establishment of the TRC in Nigeria, one informant had this to say: "There was no engagement of the National Assembly; there was no engagement of the civil society" (Personal Interview Chukwuemeka Eze, February 9, 2009). Certainly, this response represents the views of a cross-section of ordinary Nigerians who were familiar with the process (Focus Group Discussion \# 2, February 12, 2009).

This apparent exclusive policy formulation process occurred at the expense of any meaningful political platform that could facilitate state-society relations. The executive decree format adopted by the PDP government to formulate the policy on the TRCapproach restricted citizens' engagement and involvement in the policy discourse. Typically, executive decree policy-making is administrative-driven, and unlike the legislative process, it limits the direct participation of citizens. Furthermore, the executive decree style of policy-making is often swift, and usually comes as a surprise to many of the intended beneficiaries and the public generally. These two features associated with 
the executive decree format to policy formulation manifested in the TRC-approach policy transfer in Nigeria.

The Nigerian government decided to opt for the executive decree style, instead of the legislative, to formulating the policy on the TRC-approach. The results of this method of TRC-approach policy formulation were a weak public policy discourse and limited involvement of Nigerians in the process. As one informant emphatically remarked, "There were no consultations with individuals" in the policy process (Personal Interview with Chino Obiagwo, February 9, 2009). It is instructive that the declaration by President Obasanjo of his wish to set up a TRC for Nigeria, and the subsequent promulgation of the executive order, the Statutory Instrument Number 8, which outlined the TRC framework, followed his swearing in as President. As Father Kukah says, the TRC initiative "caught everyone by surprise; it came barely two weeks after the inauguration of the government, and then, of course, there was a total air of secrecy, if you like, around it" (Personal Interview, January 28,2009$)$. Obviously, the pace of the formulation came as a shock to many Nigerians, and its executive-centred process left only a short period for Nigerian citizens to make any substantial contributions to the policy content.

Further to the alacrity with which the TRC-approach to transitional justice was announced, the non-participation of the Nigerian National Assembly (Parliament) in the formulation process was another missed opportunity to broaden stakeholder participation in the policy formulation process. Although a new representative National Assembly had been elected and installed at the same time as President Obasanjo, the PDP government did not allow the National Assembly to partake in the policy formulation process. The decision generated political and legal contestations between the two arms of government 
as to which body had the mandate to formulate a policy on the TRC-approach (Fombad, 2002). Anyanwu (2001), who was then a member of the national legislature, for example, suggests that it was critical that the National Assembly exercise legislative powers to secure an enabling context for the TRC to achieve its objectives.

Indeed, the absence of an enabling legislative model has been cited as the reason for the operational difficulties that the TRC faced during its lifetime and the subsequent lack of follow up action on its final report as observed in Chapter 4. For example, both Ikhariale (2002) and Yusuf (2007) suggest that the TRC was never equipped, in a policy sense, to fully and significantly undertake its mandate. ${ }^{184}$ The controversy that surrounded whether to use the executive or the legislature in formulating the TRCapproach policy is not the focus of this discussion. It is sufficient to point out that there were concerns regarding how significant the National Assembly could be in the formulation process if it was involved. Some observers of the TRC-approach policy formulation process suggest that adopting the legislative style would have slowed the policy formulation process. Not only could the divisive nature of the National Assembly - in terms of party representation -- make the body dysfunctional; but similar to the judiciary institution, the legislature had already been bastardized following years of military rules. Any history of quality and robust legislative processes was thus weak or nonexistent.

\footnotetext{
${ }^{184}$ For instance, some of these observers recall the inability of the Commission to subpoena three former military heads of states who refused to appear before it upon invitation (and rather took the Commission to court and won). They argue that if the policy formulation process had created space for citizens' participation and public inputs, some of these gaps in the model that negatively affected the work of the TRC might have been addressed, and efforts made to strengthen the status of the TRC.
} 
A newly installed legislature with little to no experience in legislation making, it was argued, would have slowed down the transitional justice process and, also, undermined the process. As one civil society activist, Innocent Chukwuma, observes, as much as he agreed that the formulation process lacked popular participation, allowing the National Assembly to be involved would have resulted in a more polarized debate, if not a defeat of the bill. Moreover, many of the members of the National Assembly were appendages of, and were sponsored by, some powerful political individuals who stood to lose considerably if the transitional justice process was implemented (Personal Interview, February 5, 2009). This kind of public opinion invariably fitted well into the objectives of the presidency when it came to the TRC-approach. As a leading consultant to the Ministry of Justice acknowledged, not only did the executive have the legal authority to formulate the TRC-approach policy; it was also unnecessary to go through the legislature to formulate the TRC policy (Personal Interview with Professor Akinseye George, February 2, 2009).

It is important to point out that the rationale for not going through the legislature and for the executive going alone in the TRC-approach policy formulation has roots in the lack of democratic practices, especially when it comes to state-society relationships, and in inclusive policy-making processes. As was stated in Chapter 2, the history of military dominance in Nigerian politics, at the expense of civilian democratic governance, had rendered public policy-making a state-centred process. Several years of military rule had weakened the capacity for civil society participation in governance. The military itself saw civil society as hostile to the development of public policy, and instead 
relied on senior bureaucrats and strategically identified societal elites (Koehn, 1983; Adamolekun, 1986; Aborisade and Mundt, 2002).

Thus, effective state-society engagement in policy-making had been feeble. In other words, although Nigerian civil society had been loudly critical of military regimes during all the years of undemocratic rule, and had been persistent in urging a return to a democracy, its experience in policy-making process was limited. As a consequence, prior to the 1999 democratic transition, the history of the Nigerian body politic around political processes that promoted state-society relations in policy process was not favourable to civil society. Preceding the new democratic dispensation, which followed 16 continuous years of military rule, disregard for a participatory approach to policy-making was entrenched. To make matters worse, the elected president, Olusegun Obasanjo, had been a military ruler, and therefore was accustomed to a quick and state-centred approach to the policy-making process.

It was therefore unsurprising when there was no attempt by the new regime to expand the frontiers of the policy formulation process by cultivating civil society participation in the TRC-approach policy transfer. In this regard, Chino Obiagwo, a human rights lawyer, had this to say: "That is not surprising because that has been the method of governance inherited from the military" (Personal Interview, February 9, 2009). The lack of any meaningful formal political stage to facilitate public participation in the TRC-approach policy formulation made the process non-inclusive, and also limited the degree to which non-state actors could get involved. Specifically, the use of the executive decree style and the lack of a legislative process limited avenues for direct citizen participation. 
Nonetheless, Nigerian organized civil society groups found avenues to mobilize public opinion and the views of their respective constituencies to further enrich the terms of reference for the TRC that had been established following the promulgation of Statutory Instrument Number 8 . As was observed in Chapter 6, the involvement of the Center for Democracy and Development (CDD) and the Legal Resource Consortium (LRC) in the policy transfer process manifested in the sourcing and formulation stages. Although the two groups got involved once the Statutory Instrument Number 8 had been enacted on June 7,1999 , they managed to engineer a revision to the instrument that resulted in the amended version of it on October 4, 1999. Through series of conferences and workshops the CDD in particular galvanized other NGOs and the civil society community to review the Statutory Instrument Number 8 and to contribute to it.

These conferences generated public discussions on the TRC-approach, and brought public attention to the policy formulation process. A former staff member of the CDD who worked closely on the TRC process, Dauda Garuba, recalls how the organization intervened following the June 7, 1999 promulgation of the TRC Statutory Instrument to mobilize civil society contributions and produced an amended version that significantly altered the initial framework (Personal Interview, February 2, 2009). ${ }^{185}$ The contributions of the CDD in helping to expand the public space on the discourse on the policy formulation process of the TRC-approach were acknowledged. Its involvement helped to extricate, to a degree, the policy process from the state-centred approach adopted by the government (Personal Interviews with Olawale Fapohunda, January 31, 2009; Innocent Chukwuma, February 5, 2009). Chukwuma, for instance, sums up the

\footnotetext{
${ }^{185}$ Dauda mentions the Civil Liberty Organization (CLO) and the Committee for the Defence of Human Rights (CDHR) as other NGOs contributing significantly to the formulation process.
} 
CDD's involvement by suggesting that if the CDD had not mobilized relevant information on the TRC-approach and engineered non-state contributions to the policy framework, the TRC would not have gone as far as it did.

While acknowledging the role played by these organized NGOs in mobilizing public contributions to inform the formulation process, however, some observers still viewed the process as lacking wider citizen participation. Obiagwo, for example, opined: "There was no grassroots mobilization, there was no participation in regard to grassroots civil society, it was only the city based NGOs that were there, you know we (NGOs) are not the voice of the people, the people are out there, and so there was no consultation" (Personal Interview, February 9, 2009). The Nigerian TRC-approach policy formulation process lacked an enabling political platform that could foster an elaborate and deeper non-state participation in order to facilitate the policy transfer and formulation process. As was stated before, civil society was utterly shocked at the speed with which the new government announced the setting up of the TRC. The executive decree method of policy-making adopted by the government also made it difficult for civil society to organize and effectively engage with the policy discourse and in so doing to submit contributions to enhance the policy design.

The democracy and human rights advocacy groups, particularly the $\mathrm{CDD}$, found ways to mobilize citizens' inputs into the design of the policy after it was enacted. Yet, the consensus view of informants is that this was limited, and that the views and interests of ordinary Nigerians were left out in the formulation process (Focus Group Discussion \# 2, February 12, 2009). The reflection by Priscilla Ankut, a former staff member at LRC, to the effect that "Nigerians did not have the opportunity to input in the process and to 
decide what it was they wanted as an outcome" (Personal Interview, January 21,2009 ) is, therefore, accurate.

\subsection{3: Ghana: Legislative Process}

Ghana's adoption of the legislative method for the policy formulation process of the TRC-approach provided a political structure to facilitate public participation. Public discourse on the TRC-approach through media discussion had generally emerged in early 2001. The installation in government of the NPP and the subsequent official announcement of intention to establish a TRC to address previous human rights wrongs generated this public debate. The laying down of the draft bill in Parliament on July 6 , 2001, however, signalled the NPP government's intention to make the formulation process consultative and inclusive. During the next six months, when the draft bill was debated in Parliament and enacted into law in December 2001, Ghana's Parliament became the formal arena for public engagement on the policy discourse and the formulation process on the TRC-approach.

It is generally held that the policy formulation style of legislative process fostered citizens' participation in the policy content development of the TRC-approach (Personal Interviews with Professor Joseph Ayee, July 30, 2008; Ayi Koi Otoo, August 20, 2008; Professor Mike Oquaye, May 8, 2009). Oquaye, for example, said, "Yes, it generally did" when asked if the legislative process promoted citizens' participation in the policy formulation of the TRC-approach. Yet, others, while acknowledging the openness of the consultative process, are of the opinion that the policy process was short, not elaborate and non-inclusive (Personal Interviews with Cletus Avoka, July 31, 2008; Francis 
Agbotsi, August 20, 2008; Amos Safo, May 12, 2009; Albert Salia, May 18, 2009). For example, Avoka, who was a Member of Parliament then, responded as follows: "It was terrible, it was passed in such a hurried manner that we did not do proper research."

The different views expressed by informants above present two significant reflections on the policy formulation process of the TRC-approach in Ghana. First, there is no dispute over the fact that the legislative process allowed for direct citizens' involvement in the policy formulation process of the TRC-approach to transitional justice. This political platform gave unhindered access for citizens to directly submit contributions to the formulation process. To be sure, the Committee on Constitutional, Legal and Parliamentary Affairs (CLPA), which was responsible for the draft bill, took the consultative process to citizens. It conducted country-wide public hearings on the draft bill in October 2001. In addition, the CLPA also invited submissions from 21 specific public stakeholder organizations, NGOs, and the general public (Parliament of Ghana, 2001). ${ }^{186}$

In its report, the CLPA stated that it received 10 memoranda from individuals and organizations that informed its report on the review of the draft bill and the recommendations it made for passage. ${ }^{187}$ These Parliamentary public hearing formats embarked afforded Ghanaians -- individuals and groups - the political space and opportunity to participate in the formulation process. This view of public participation in the policy formulation process is shared by some informants and observers of the policy

\footnotetext{
${ }^{186}$ Among the groups invited by the Committee were the Ghana Bar Association, the Ghana Medical Association, the National Commission, registered political parties, retired military, police and prisons associations, the Trades Union Congress and religious bodies.

${ }^{187}$ Memoranda were received from among the following non-state actor groups: the Ghana Center for Democratic Development; the Ghana National Association of Teachers; the Regional House of Chiefs; the Civil Servants Association; and the Legal Resource Center.
} 
formulation process. For example, when asked whether the use of legislative framework created the enabling platform for citizens to participate in the TRC-approach policy formulation process, Ayee said, "I thought so", although he felt that there were not enough consultations among Parliamentarians themselves; while Otoo remarked that "it (the bill) was more debated, it took a long time but they (citizens) were" able to participate.

Apart from the stage that provided direct access to individuals and groups to contribute to the legislative debate, non-state actors, such as policy and research thinktanks, as well as NGOs, also mobilized public participation through workshops, focus group discussions and conferences. Prior to the presentation of the draft bill in Parliament, the Ghana Center for Democratic Development, for example, through a civil society coalition it created in March $2001,{ }^{188}$ began to collect opinions and views from citizens across the country. The CDD-Ghana and its Civil Society Coalition partners organized a two-day national conference in June 2001 that brought over 100 participants - Ghanaian stakeholders and non-Ghanaian experts--to formulate a civil society agenda for the TRC policy process. The conference produced a 12-point declaration to serve as the model for the transitional justice process (CDD-Ghana, 2001b; CDD-Ghana Internal Document, 2003; Okyere-Darko, 2005). The group further undertook nation-wide focus group discussions in August 2001 once the draft bill had been presented in Parliament.

These activities implemented by CDD-Ghana aimed at widening public consultations on the legislative process in order to generate strategic public inputs into the TRC-approach policy formulation process. The product of these public consultations

\footnotetext{
${ }^{188}$ The civil society coalition was an umbrella group of about 20 NGOs that was set up to mobilize nonstate actors' views and opinions to inform and advise on the TRC process.
} 
undertaken by CDD-Ghana was a memorandum that was submitted by CDD-Ghana to the CLPA as reflecting views of Ghanaian civil society. Further to that, the CDD-Ghana sponsored a three-day retreat for the members of the CLPA in early December 2001, which local and international experts attended in order to critically review and refine the draft bill clause by clause. This was to enable the members of the CLPA to shape the draft bill according to the contributions from the public and, in so doing, to prepare it for tabling in the full House of Parliament for passage.

The interventions by CDD-Ghana and other non-state organized actors ${ }^{189}$ in mobilizing opinions of Ghanaians to influence the public debate on the TRC-approach policy formulation process were duly recognized by my respondents (Personal Interviews with Papa Owusu Ankomah, August 5, 2008; Maulvi Wahab Adam, January 15, 2009; Mohammed Affum, April 20, 2009). Mohammed Affum, for example, sums it up in this manner: "But I also want to say that CDD-Ghana, even though the NPP government had this as a manifesto issue, played a pivotal role in sensitizing Ghanaians on the relevance of the truth commissions in this country, and the role it (CDD-Ghana) played in the course of (policy formulation) proceedings -- the national conference triggered off a lot of discussion -- is very noteworthy." There is no doubt, therefore, that the legislative fashion provided an enabling political platform to encourage state-society engagement with the policy formulation process of the TRC-approach. It helped in making the governmentinitiated policy response to the transitional justice demands available for citizens' scrutiny and contributions, which strengthened the perception of public ownership of the entire policy formulation process.

\footnotetext{
${ }^{189}$ In addition to the CDD-Ghana, the Legal Resource Centre was another notable non-state actor that mobilized citizens' inputs on the draft bill and presented them to Parliament.
} 
Ghana's use of legislative policy formulation process for the TRC-approach was not by an unusual design for this particular public policy, but a matter of course. Political processes that promoted state-society relations dated back to 1993 , when Ghana made the democratic transition. At the time the transitional justice policy debate ensued, Ghana had been a practising democracy for close to eight years, with three successive democratic elections. ${ }^{190}$ Ghana's democratic processes were deepening, with a vibrant media and a robust civil society. Parliamentary deliberations on public policies and legislative means of generating them have become norms embraced by both political actors and the citizenry. In other words, and as was demonstrated in Chapter 2 , since the mid-1990s public consultations for government policy initiatives have become accepted (Ohemeng, 2005; Amoako-Tuffour, 2008; Kpessa, 2011). The political processes at the time the TRC-approach was being debated thus supported citizens' participation in the policy processes. Such a history of political processes and political structures for public participation also permitted the free expression of divergent views.

Consequently, it was not a surprise that the members of the main opposition party, the NDC, walked out of the Legislature in protest against the refusal of the majority NPP to accede to its request for an additional amendment to one clause in the bill during the parliamentary vote. This particular proposed amendment in question related to the period of investigations to be conducted by the TRC. The NDC party therefore did not vote on the final bill. ${ }^{191}$ This incident polarized the policy debate, and introduced partisanship

\footnotetext{
${ }^{190}$ The 2000 general elections had produced, for the first time in Ghana, a peaceful power alternation by way of democratic process, and not by the familiar barrel of the gun.

${ }^{191}$ It must be pointed out that the NDC, as a matter of principle, had from the onset endorsed the TRC process to transitional justice. Its members serving on the CLPA had participated fully in all the activities, workshops and conferences on the TRC draft bill. Their refusal to boycott the bill at the last stage was therefore at variance with what they had done before.
} 
into the concluding phase of the formulation process. It is for this reason that some observers argue the policy formulation process on the TRC-approach was exclusive and short. The polarized vote informs the second important reflection arising from Ghana's TRC-approach policy formulation process. The observers, including Ayee (Personal Interview, July 30,2008 ), assert that with such an important public policy ( with political undertones), a deeper consultative process, particularly between the Members of Parliament from opposing parties were warranted to avoid what did occur with the boycott during the final legislative vote.

The Ghanaian case raises two important general questions around policy formulation processes, especially if it is informed by transfer. To start with, what is the appropriate time frame for elaborate public consultations; and second, at what level can policy actors conclude that the contributions from the public are enough to formulate a public policy? Although these questions are beyond the scope of this research, it will be enough to point out that when it came to the TRC-approach policy formulation process in Ghana, some observers believe that the public consultations process could have benefitted from an extended legislative process and a deeper engagement by civil society. Francis Agbosti, then a Member of Parliament remarked, "Oh I will say no, it ended up not being a full parliamentary act", when asked to assess citizen participation and legislative consultations in the policy formulation process.

The views of the parliamentarians (including the one of Avoka, already stated above), while they may be informed by partisan considerations, ${ }^{192}$ do reflect the opinions of others as well. For example, Safo, a media practitioner, argues that citizens'

\footnotetext{
${ }^{192}$ The two members represented the NDC
} 
participation was not intense, and that the government assumed that going through the legislative format was enough because the institution of Parliament was the representative of the people. He remarked rhetorically, "If the MPs agreed that the law should be passed, then it means that the people agreed".

The foregoing expressions notwithstanding, the views of ordinary Ghanaians on the policy process show that an enabling political structure in the form of the legislative process promoted varied levels of citizens' involvement and participation in the policy formulation process of the TRC-approach (Focus Group Discussion \# 1, January 15, 2009). The legislative process towards the formulation of a model for the TRC-approach created public and political spaces for interactions between policy actors and the wider citizenry. The organized non-state actors also contributed by stimulating the public awareness and mobilizing contributions from the citizenry. They thus acted as an intermediary source of civil society contribution to the formulation process. Accordingly, the TRC-approach policy formulation process was open, consultative and, generally, inclusive.

\section{3: Analysis of Case Studies and Testing of Hypothesis Three}

The preceding discussion of the three cases, exploring the relationships between TRC-approach policy transfers and domestic structures, reveals that the latter mattered significantly in the domestic policy formulation processes. Where domestic realities -cultural affinity for the values of the notion of restorative justice, and political platforms that promote opportunities for citizens to be involved in the policy discourse and 
formulation process -- are receptive and responsive, policy transfers of the TRC-approach are likely to succeed, and the policy formulation process will record successful outcomes.

As suggested by Dolowitz and Marsh in their policy transfer model, cultural proximity is a structural condition that can constrain or facilitate policy transfers. In policy process, this cultural proximity is expressed by actors, particularly the domestic ones, who use it to appeal to the citizenry. The latter identify their cultural beliefs and values with the particular policy being proposed and, consequently, embrace it. This process contributes to facilitating the policy formulation process. The South African, Nigerian and Ghanaian cases demonstrate that collective and shared meanings reflected in religions presented useful cultural references for agents - both policy formulating actors and the citizenry - to formulate the policy transfer of the TRC-approach. The normative values associated with the notion of restorative justice resonated well with some basic principles of the religious practices of the residents of the three societies under study.

It therefore made it somewhat easier for the policy formulating actors to draw upon the culture and to associate the proposed alternative TRC policy program with these religious beliefs and practices. The formulating actors, as demonstrated in the previous chapter, and the leaders of the religious communities in South Africa and Ghana used these religious belief systems to shape and to localize the restorative justice process that the TRC-approach seeks to advance. These processes of strategically indigenizing the policy transfers of the TRC-approach in the domestic political systems were evidently observed more in South Africa and Ghana than in Nigeria. In other words, while the TRC policy formulation actors in these two countries utilized the religious beliefs of their 
people to draw public support for the TRC-approach, their peoples were equally receptive to it.

The processes that took place in South Africa and Ghana also demonstrate one form of the constitutive nature of agents and structures in the production of social action: in this instance, the TRC-approach policy formulation drawing on the restorative justice ideas. In other words, in both the South African and Ghanaian situations, the policy actors deployed social practices, systems and resources, in this instance, religious beliefs, to reproduce a social action by way of the formulation of the TRC-approach. The two cases reveal how agent-structure relationship is constructed. The domestic policy actors in the two countries consciously deployed the restorative justice ideas and drew upon the societies' enabling social practice, in the form of religious beliefs. This interaction provided a receptive political setting for the TRC policy to be formulated. Certainly, the cases make obvious the duality of agent-structure relationship--how the thoughts, intentions and motives of actors are shaped by the cultures and social systems in which they live.

Dolowitz and Marsh further identify in their model political systems, arrangements or platforms as other domestic structure or institutions that may constrain or facilitate policy transfers. The authors, for example, cite how political institutional arrangements, such as federal or unity systems of governance, may constrain or facilitate policy transfers (Dolowitz and Marsh, 1996). Taken from this model, this study suggests further that the type of political platform that restricts or encourages public participation in the formulation process could constrain or facilitate policy transfers and, therefore, the policy formulation process. In this chapter, the two different styles -- legislative and 
executive decree -- employed by the formulating actors in formulating the TRC-approach produced different outcomes regarding public participation.

As the case study discussions above show, the legislative method used in South Africa and Ghana fostered civil society participation more than the executive decree technique adopted in Nigeria. The case studies illustrate that where the political platforms exhibited an open and consultative policy process, including the use of legislative process, to formulate the policy on the TRC-approach, the citizens were more responsive to the policy transfer process. This was more evident in South Africa and Ghana than in Nigeria, which used the executive decree format. The latter instance was characterized by a top-down form of the transitional justice policy formulation process, which may have unfortunately facilitated a 'one-size fits all' approach to transitional justice (McEvoy, 2008).

Taken together, the religious beliefs and political platforms, whether by way of legislative process or executive decree, constituted the domestic structures. They either constrained or facilitated policy transfers and the subsequent formulation of the TRCapproach to transitional justice in South Africa, Nigeria and Ghana. The domestic structures were more favourable in South Africa and Ghana than in Nigeria. These structural elements both shaped citizens' behaviour in ways more supportive of the TRCapproach and created an enabling political environment for beneficiaries of the TRC policy approach to participate in the formulation process to promote a feeling of ownership. The discussion in this chapter as reflected in the case studies is therefore consistent with the study's third hypothesis. 
The study hypothesized in Chapter 3 that "there is a relationship between domestic structures (culture and political) and a policy transfer process of the TRCapproach to transitional justice, such that if there is an approximation in cultural beliefs of the restorative justice ideas, the TRC-approach policy transfer and formulation process is likely to succeed; and if the domestic political arrangements allow for and support victims of human rights abuses, and the more complete citizens' participation in the policy discourse during the formulation process, the more successful will be the TRC policy transfer process." As the foregoing case studies revealed, the approximation in cultural beliefs of the restorative justice process was demonstrated in the expressions of the religious beliefs of the people in South Africa and Ghana.

In the case of Nigeria, as was observed above, it is unclear how this approximation in cultural beliefs could have resonated with the restorative justice process as there was no attempt to deploy religious beliefs during the policy formulation discourse. Further, the political platforms that promoted citizens' participation in the TRC-approach policy formulation processes were demonstrated more by the legislative process used in South Africa and Ghana than the executive decree method used in Nigeria.

These outcomes suggest that hypothesis three is not equally demonstrable across the three cases. The Nigerian case constitutes an outlier. In the case of Nigeria, it was obvious that religious beliefs may have had a positive impact on people's receptiveness to the TRC-approach at the initial stage of the formulation process. Yet the research could not empirically and convincingly prove this appearance and impact. This is because, and as was discussed above, the policy actors failed to utilize this resource as part of the 
policy formulation discourse. In both the South Africa and Ghana cases, the research empirically demonstrated the proximity of the religious beliefs and the restorative justice process, and the functional abilities of agents in the receptiveness of the TRC-approach.

The two cases, particularly the Ghanaian case, further show that demonstrating how the religious beliefs, and indeed culture, affect policy formulation process is not so clearly observable because of the instinctive character of cultural beliefs. In South Africa the cultural value of ubuntu, which was the underlying philosophy for the TRC process, appeared to have resonated positively with the Judaeo-Christian religious beliefs that many South Africans follow and practice. In Ghana, the mood of the majority of the population connected with the religious beliefs of the citizenry in ways that were supportive of the TRC-approach policy transfer. This was furthered by the central role played by the leadership of the religious faith -- both Christian and Muslim -- in the policy formulation discourse in affirming the TRC-approach's reconciliatory motive. This made the religious setting supportive of the policy transfer process. Nonetheless, empirically testing the certainty of this independent role presented a rather challenging task.

While religion appeared to resonate well with the notion of restorative justice, this study does not, however, conclude that religious values are the only possible cultural system that might correspond well with the restorative justice process. At best, what this chapter confirms with respect to the functional role of culture in the policy process is that religion has the potential to influence the behaviour of people by shaping their thought processes in facilitating the acceptance and endorsement of a particular policy proposal during policy formulation process. This is true of the situations in South Africa and 
Ghana. Calling upon these beliefs at the precise time the TRC-approach policy transfer was being conducted was helpful in procuring general acceptance from the public of the TRC-approach as a transitional justice policy. Therefore, culture provides a context during the discursive process in policy formulation discourse.

Consequently, successful policy transfers generally need to consider critically how cultural realities may be exploited to support the process of domestic policy formulation endeavours. In the case of the TRC-approach to transitional justice process, there may be certain indigenous societal values, apart from religion, that correspond with the notion of restorative justice. The import from this study is that the TRC-approach policy transfer and the related domestic formulation process is facilitated by the abilities of policy actors being able to detect and to draw on specific societal cultural values that match the normative values associated with the restorative justice process. In other words, domesticating the policy transfer of the TRC-approach will require that domestic policy actors identify societal cultural belief systems, whatever they may be, that parallel the notion of restorative justice that underlie the TRC-approach to transitional justice.

Certainly, political platforms that promote state-society relations in ways that encourage citizens and other organized non-state actors to participate in policy dialogues, and in the discourse on the domestic policy formulation processes, are means of detecting how cultural themes could be helpful in the policy transfer process. These platforms provide domestic references for the public to channel views that are informed by different perspectives, including ideologies, cultural beliefs, and personal preferences. It is this enabling political stage fostering citizens' participation with which the Nigerian case presents yet another inconsistency (hypothesis 3). The executive decree format adopted in 
Nigeria constrained effective public participation and, therefore, impacted negatively the TRC policy transfer and formulation outcomes. Both the South African and Ghanaian cases suggest that the legislative process to formulating the TRC-approach provides sufficient means of public participation, and hence facilitates its policy transfers.

The executive decree format by its nature is restricted to actors in the executive branch of government, and it does not encourage public engagement with the process that could verify, among other things, that citizens can bring their cultural beliefs and preferences to bear on the policy processes. The executive decree method used in Nigeria made the TRC-approach policy formulation process largely non-inclusive, and therefore made it impossible, for example, to assess the specific functions that religious beliefs and other locally contextual relevant factors may have played in the policy discourse narratives. Undoubtedly, the policy formulation process in Nigeria failed, to paraphrase McEvoy (2008), to resonate with and embed itself in the local context.

The examination of the three cases also helps this study to illuminate the contributions of domestic CSOs to the TRC-approach policy formulation processes. Although all the three cases demonstrate the significant roles played by organized nonstate actors in stimulating public discussions and mobilizing citizens' inputs to inform the policy discourse and formulation process, these contributions were, however, observed in South Africa and Ghana more than in Nigeria. This observation reflects an outcome of the nature of the political platforms that were in place to cultivate public participation in the TRC-approach policy formulation process. The legislative method encouraged an open, decentralized and pluralistic policy formulation process, as was seen, for example, in the public hearings conducted by committees of Parliament in South Africa and Ghana. 
The executive decree style did not promote such a level of open, decentralized and pluralistic policy formulation process, because its institutional make-up is typified by a closed and centralized process.

To be sure, the foregoing insight from this chapter complements Risse-Kappen's $(1995 \mathrm{a} ; 1995 \mathrm{~b})$ conclusion that transnational actors are more likely to have access to decentralized and pluralistic societies than closed ones. Because this chapter focuses on domestic actors, it contributes to shedding light on what makes it possible for domestic non-state actors to access domestic structures in policy formation processes. Without looking broadly at political systems of societies, as Risse-Kappen does, the chapter examined political platforms within societies that allow for citizen participation in policy process, and concludes, using the TRC-approach policy transfer process, that a legislative style of domestic policy formulation process provides a more highly structured institutional stage to promote domestic non-state actors access to policy process than a executive decree format.

\section{4: Summary and Conclusion}

The observations from the case studies presented in this chapter lead us to return to the findings made in Chapter 4 regarding the successes, partial successes, partial failure and failure outcomes of the TRC policy transfers in South Africa, Nigeria and Ghana. It was noted in that chapter that to be able to explain the variations in the outcomes, investigation into the relationship between domestic structures and policy transfer process was vital. The discussions of the case studies in this chapter point to the fact that both South Africa and Ghana, more than Nigeria, learned considerably from the 
political systems from which the transfer of the TRC-approach was drawn. It is obvious that South Africa thoroughly learned lessons, as was demonstrated in Chapter 4, from the TRC experiences in South America, including what were the positives and the negatives of the processes. One significant lesson from the South American experiences, from which the South African policy actors departed, was the absence of public participation in the policy formulation process (Boraine, 2000a; 2008; Personal Interview with Kader Asmal, March 10, 2009).

Backer (2007), for example, suggests that the South Africans departed from the top-down approach of original TRCs that made the policy process non-inclusive and, also, made victims the subject, rather than the participants, in the investigation process. In South Africa, the policy process in search for a policy response to address human rights violations was broad and inclusive, and also allowed for a bottom-up approach to the policy formulation discourse. The use of the legislative format to formulating the policy on the TRC-approach created space and opportunities for victims' groups to participate and to influence the policy debate. In Chile, however, where South Africans drew substantial lessons from, the executive decree format adopted for the policy formulation process reflected a top-down process which, instead of making victims participants in the policy search, rather made them subjects.

Similarly, the Ghanaian policy actors appeared to have learned the positive lessons associated with the South African experience, and therefore transferred to the domestic political system the enabling building blocks that made the TRC policy formulation process inclusive and participatory. The legislative method, together with the extended period for formulating the TRC-approach in domestic politics following the 
transfer process, was therefore significant in the entire policy process. Thus, the domestic formulating actors in South Africa and Ghana were highly informed about the policy transfer process and, to a large degree, made their respective transfer processes comprehensive in order to inform the domestic policy process. Moreover, the policy actors, being exceedingly informed and drawing complete lessons from the source political systems, were enabled to situate the TRC-approach policy transfer in an appropriate domestic context, including by consciously crafting the policy discourse to draw on the cultural values (in this instance religious beliefs) and sentiments during the policy formulation process. This was purposefully done in order to attract public support for the transferred TRC policy approach.

The Nigerian case exemplified the opposite of what was observed in South Africa and Ghana regarding the TRC policy transfer processes. Although the Nigerian TRCapproach policy transfer was inspired by the success story of the South African experience, as noted in Chapter 4 , the role of the formulating actors in the domestic policy formulation process, as explained in Chapter 6 and in this chapter, however, indicates that the policy actors did not fully transfer the associated lessons that made the South African process successful. For example, the executive decree format used to formulate the TRC-approach was at variance with the legislative style that was used in South Africa. Moreover, the format did not allow considerable time for the formulating actors strategically to conduct the policy discourse by making the best use of the milieu from the point of view of its relevance to the TRC-approach, including the religious beliefs of the people. 
In the same way, the opportunities for non-state actors and citizens to contribute to the policy formulation process, as occurred in South Africa, were very limited. Insufficient political space for public participation in the policy formulation process affected the desirable content of the TRC policy model, which inevitably had huge implications for the efficacy of the overall TRC process and outcomes. The experience of the Nigerian TRC policy transfer is typical of an uninformed and incomplete policy transfer process. The uninformed and incomplete policy transfer made the TRC-approach inappropriate for the domestic political system at the time the TRC-approach was proposed to address the transitional justice demands. The Nigerian TRC policy transfer and formulation process thus recorded a combination of success, partial failure and failures, unlike South Africa and Ghana, which recorded a combination of successes and partial success across the six phases of the study's policy transfer success or failure outcomes.

Without a doubt, the outcome of the Nigerian case does not in any way suggest that the TRC-approach to transitional justice was unsuitable in 1999 , or that it will not be appropriate in the near future. It is simply an indication that the policy transfer process fell short of the standard and acceptable ways for undertaking policy transfers. 


\section{Chapter Eight: Conclusion}

\section{0: Research Problem Revisited}

This study has suggested that the policy formulation of the TRC-approach to addressing transitional justice demands in South Africa, Nigeria and Ghana was characterized by policy transfer processes. The policy transfer process that occurred followed that path of social constructivism. At the onset, two main research questions were asked: what explains the reproduction of the TRC-approach across borders in Africa; and what factors and/or forces determine the policy establishment of the TRCapproach, shape its mandate and condition its success or failure? Accordingly, the research proceeded on two broad assumptions. First, the study put forward that each case of the TRC-approach policy formulation resulted from lesson-drawing from other political systems following institutional blockade against the use of criminal justice processes to achieve transitional justice. Second, the domestic policy formulation processes of the TRC-approach in each case was a consequence of interaction of domestic and transnational policy actors with components of domestic structures informed by the restorative justice ideas that motivate the TRC-approach.

Employing a comparative method, featuring the 'most similar systems', the 'controlled structured focused comparison', and the process-tracing techniques, the study examined the functional abilities of different types of actors -- individuals, organizations, local and foreign -- and the interactions among them by way of 'social learning' practices in the formulation of the TRC-approach to, servicing transitional justice needs. The study investigated the production of the TRC policy program--its policy transfer, and its subsequent development as a transitional justice policy in each of the cases. In other 
words, the study focused on how the TRC policy program became the policy response to the quest for transitional justice in South Africa, Nigeria and Ghana, and on how the respective domestic societal beliefs and political structures contributed to shaping the policy discourse to the purpose of formulating the TRC-approach policy.

To reaffirm, then, the research designated two variables of outcomes: degrees of success and failure of policy transfer; and formulation processes. None of the cases achieved full success in all of the six defined phases. The South Africa and Ghana cases were identified as having achieved successes and partial successes, while the Nigerian case recorded success, partial failure and failure. Thus, the outcomes of these cases differ. In many respects, however, the cases have similarities in terms of their experiences of political history, social demographics, and political and economic systems. As was stated in Chapter 1, the three cases were all at one time under British colonial authority; they all experienced forms of undemocratic rule; they share a multiplicity of ethnic and linguistic groups; they all practise the executive presidential system of government; and they all champion the neo-liberal paradigm for economic policies.

Therefore, the fundamental questions that arise from the cases examined in this study are: why did the TRC-approach emerge as the preferred transitional justice policy in all the cases, and why did the policy transfer and formulation process outcomes record successes in South Africa and Ghana, but failures in Nigeria? A summary of the findings from the three cases are presented next to address these fundamental questions. 


\section{1: Summary of Findings and Relevance to the Study}

Throughout this study, it has been shown that the TRC-approach to addressing transitional justice demands in South Africa, Nigeria and Ghana was formulated as a policy transfer activity. In Chapter 4, it was established that the TRCs in the three cases were the results of borrowing and lesson-drawing from different political jurisdictions and experiences of this approach to transitional justice. While South Africa learned from the experiences of countries in South America, particularly Chile, as well as by drawing on experiences of the use of commissions of inquiry by the ANC, both Nigeria and Ghana borrowed from the South African experience. Significantly, all the case study countries transferred both the policy goals and administrative machinery that are associated with the TRC-approach. As was noted in Chapter 4, there were, however, some noteworthy differences in terms of the manner in which these administrative techniques were structured and operated across the three cases.

The TRCs became the preferred policy approach to transitional justice across the three cases as a result of the need to overcome institutional obstacles of different kinds. These institutional barriers made it impossible for the successor governments to utilize the originally favoured and publicly supported criminal justice approach. Nonetheless, it is significant that the TRC-approach, rather than any of the remaining transitional justice policy options, was viewed by the successor regimes as the most appropriate process in light of the peculiar political and social circumstances of the countries during the transition period. In other words, while the institutional barriers may have acted as the impetus and created the political space to facilitate the policy transfer, the domestic formulating actors -- particularly the elected presidents, as Chapter 6 reveals -- 
demonstrated high levels of approval of the notion of restorative justice that the TRCapproach advances.

The normative values of truth recovery, victims' healing and national reconciliation associated with the restorative justice process appealed to the domestic policy actors and, thus, informed the transfer process. The findings from this study thus cast doubt on the frequently expressed generalization to the effect that the TRC-approach is weak and second best, or a 'soft option', as a transitional justice process just because it does not offer criminal or retributive justice (Nesiah, 2006). Consequently, this study urges scholars and researchers to reassess other factors that motivated the policy actors in these three countries to voluntarily employ the TRC-approach to the transitional justice process. These considerations must apply to the study of other, previous and future, TRC endeavours. Chapters 6 and 7 of the study make known the motivations of actors in the TRC-approach policy transfer processes. The specific roles played by domestic and international actors and the relationships between the domestic actors and domestic structures in the political systems that facilitated or constrained the policy formulation processes across the three cases are also discussed in those chapters.

An important disclosure from this study is the role of political parties and elected politicians as the principal domestic actors at the forefront of the TRC-approach policy transfer processes. The manifestations in the three cases of the prominent domestic state actors in the TRC-approach policy transfer process run contrary to observations elsewhere, such as in the case of Sierra Leone, where the formulation of the TRCapproach appears to have been externally instigated, with the role of international actors significantly on display in the policy formulation and implementation processes. In this 
study, the role of international actors across the three cases was secondary to that of the domestic actors. The former acted as carriers of content information pertaining to the restorative justice process and best practices of the TRC-approach.

What this finding suggests is that when it comes to policy transfer processes that are informed by a voluntary act on the part of domestic actors, at least with respect to transitional justice policy, international actors have less influence in determining the direction of the formulation process. The power of international actors is limited to supplying content information, and even that is subject to invitation by domestic partners. Thus, although the impact of globalization has been to reduce the emphasis on the tightness of the territorial boundaries of the nation-state, thereby opening its political and policy spaces for the infiltration of global knowledge, policy innovations, and transnational actors, the simplistic notion that domestic actors have no control over preferences and directions is untrue, as this study shows, when it comes to domestic policy formulation processes of the TRC-approach to transitional justice.

The state and its agents are still the gatekeepers of the policy formulation processes. They still command, as noted by Haas (1992), a wide degree of latitude in policy processes. Domestic actors play a crucial role in facilitating or constraining policy formulation processes, especially when the policy in question is transferred. This is because without domestic actors, international actors alone cannot successfully engineer the successful formulation process of a transferred policy.

The accessibility of the domestic structure, in this instance cultural proximity and enabling political system, to externally generated policy ideas is very critical to policy transfer processes, which obviously have undertones of the forces of globalization. In 
order to provide a fuller understanding of the TRC-approach policy formulation process in South Africa, Nigeria and Ghana, Chapter 7 recognizes the degree to which the religious beliefs of the citizenry were brought to bear on, and the ability of the public to participate in, the policy discourse, and to make contributions to the policy content. In other words, although the TRC-approach policy program was informed by a policy transfer activity, the receptiveness and responsiveness of the domestic structures were critical to the degree of success of the policy formulation outcomes across the three cases.

The South African and Ghanaian cases demonstrate how actors consciously invoke the religious beliefs of the citizenry, which then resonate appropriately with the restorative justice process to draw public awareness to and arouse sentiments regarding, as well as support for, the TRC-approach. The two cases show how an enabling political platform that promotes state-society relations, in this instance the legislative format to policy formulation, fosters citizens' involvement and promotes a sense of ownership of the policy formulation process. The manifestations of these two components of domestic structures in the two cases facilitated the policy transfer process of the TRC-approach and the success of the formulation outcomes, in which the significance of agents in constructing these events was apparent.

The accessibility of the Nigerian domestic structures differed from that of South Africa and Ghana regarding the TRC-approach policy transfer. The case study shows how not to conduct a policy transfer process of the TRC-approach. In the Nigerian case, because there was no conscious attempt by the domestic actors to call upon the religious beliefs of the public, or to draw parallels between the restorative justice process and those religious beliefs, even though that potential existed, it limited the degree to which the 
preferences of the Nigerian people informed the TRC-approach policy transfer process. Further, the executive degree format and its differences from the legislative style used in South Africa and Ghana meant that the extent to which the views of Nigerians informed the policy transfer process was narrow. The inability of the Nigerian domestic actors to locate the TRC-approach policy transfer process in domestic social and political structural contexts was the cause of the degrees of failures in the policy formulation outcomes.

The lesson derived from this contrasting outcome is that elements of domestic structures, particularly cultural and/or political arrangements, are critical for the successful formulation of the TRC-approach as a policy transfer activity in domestic political systems. A permitting domestic structure that facilitates a successful policy transfer of the TRC-approach is, however, dependent upon agency: that is, the extent to which the capability (voices and perspectives) of agents is factored into the discourse on the TRC-approach policy process and its outcomes. Through the manifestations of inherent social beliefs and preferences, and the course of actions that they consciously conduct, such capabilities are brought forth. In this study, more so in South Africa and Ghana than in Nigeria, agency is expressed in the role of CSOs in mobilizing opinions of the citizenry to inform and shape the policy content of the TRC policy framework. It is observed for example, that in Nigeria, where the political space was limited and short, and followed a state-centred policy process, limited efforts were made by non-state organized actors to engage with the policy formulation process.

The findings from the comparative analysis of the South Africa, Nigeria and Ghana cases give an in-depth understanding of the proliferation of the TRC-approach 
across borders in Africa. Not only is the spread of the TRC-approach informed by institutional barriers to the criminal justice approach; the attraction to the restorative justice ideas has also promoted the choice to the TRC-approach to the transitional justice process in Africa. This is not to suggest that the TRC-approach is the only option available on the menu of transitional justice approaches. The findings also illuminate how political decisions are made by actors, and the significant but also divergent roles played by both domestic and international actors in the policy transfer and formulation processes of the TRC-approach. They shed light on how social and political structures in the domestic political systems are vital conditional factors in facilitating the policy transfer process of the TRC-approach, and also in accounting for the success or failure outcomes.

Collectively, these findings explain why the TRC-approach emerged as the transitional justice policy in South Africa, Nigeria and Ghana, and also why the policy transfer and formulation process outcomes recorded successes in South Africa and Ghana, but failures in Nigeria. These findings from the three cases together enable the corroboration of the three stated propositions of this study. To begin with, the findings confirm that the restorative justice ideas that inform the TRC-approach to the transitional justice process in South Africa, Nigeria and Ghana were made possible by institutional limitations in the forms of entrenched legal statutes in South Africa and Ghana and the weaknesses of the judicial institution in Nigeria. These limitations encouraged the policy transfer processes of the TRC-approach to transitional justice in the three cases.

Second, the findings substantiate the proposition that both domestic and international agents were active in the policy transfer and subsequent formulation processes of the TRC-approach to transitional justice in the domestic political systems 
across the three cases. The findings from the cases uphold the thesis put forward in this study that if the TRC-approach was voluntarily sourced by domestic actors, particularly the elected political officials, they would also be the leading policy formulating actors guiding the policy discourse and content development of the formulation process. In this context, the domestic actors become the borrowers and formulators in the realm of the TRC-approach policy transfer process.

In the same circumstance, while the domestic actors were the borrowers and formulators, the study also put forward the idea that the international actors would be the carriers in the policy transfer process, playing the limited and secondary role of providing content knowledge around restorative justice. The role these carrier actors play is to complement the domestic actors in legitimizing the TRC-approach to the transitional justice process. Therefore, as already stated, both the domestic and international actors were instrumental in the TRC-approach policy transfer process; the roles they played, while different, were complementary.

Third, the findings from the three cases support the hypothesis that there is a relationship between the cultural and political components of domestic structures and a policy transfer process of the TRC-approach to transitional justice. The findings from the three cases demonstrate that where, as in the South African and Ghanaian cases, there was an approximation of the religious beliefs of the citizens to the restorative justice ideas, the policy transfer and formulation of the TRC-approach were easily received; and when the domestic political set-up allowed for and supported citizens' participation in the policy discourse and formulation, as with the legislative format in South Africa and Ghana, the citizenry were positively responsive. Both the South African and Ghanaian 
TRCs registered successes and partial successes in the policy transfer and formulation process, a consequence of the presence of favourable domestic structures.

The affirmation of the three hypotheses that guided this study constitutes the context in which to persuasively articulate the factors accounting for the reproduction of the TRC-approach across borders in Africa. The recent policy formulation processes of the TRC-approach in Africa are best understood as encompassing political processes that include a dialectical relationship between political and other non-political actors and domestic structures with the notion of restorative justice at the center of this discourse. The political processes involve ongoing conversations among political policy actors and domestic social and political activities, such as citizens' participation in the policy discourse on the TRC-approach. These conversations are informed by the domestic political and social conditions, which then open up the political space to learn from the knowledge produced at the global level on the restorative justice process. In short, the political processes in the recent policy formulation of the TRC-approach are constructive in course.

The findings from the South African, Nigerian, and Ghanaian cases are that in spite of the differences in their paths, they followed similar patterns. The nature of the construction also enables this study to determine, as already revealed, the factors that facilitate the shaping of the mandate of TRCs, and to condition its success or failure. The conclusions drawn from the findings of the three cases and the corresponding confirmation of the study's hypotheses yield certain policy implications, recommendations and insights into future policy formulation processes of the TRC- 
approach and, for that matter, transitional justice policy options, in Africa. Certainly, these prescriptions and insights affect general policy formulation processes there.

\section{2: Policy Implications and Recommendations}

The comparative case studies, showing degrees of success and failure of policy transfer and formulation outcomes, in this dissertation hold useful lessons for policy formulation processes of TRCs in Africa. As was stated in Chapter 4, the appeal to the TRC-approach, not only in Africa but across the globe, is on the rise, and insights from this study provide positive guides to future policy formulation processes. First, formulating a TRC-approach to transitional justice requires purposeful efforts on the part of official policy actors to engage the public in the policy discourse. Domestic official actors need to locate the normative values of the restorative justice process that inform the TRC-approach in the national context. Policy actors should aim to draw a course parallel to these societal cultural systems and beliefs with the restorative justice process so as to avoid the perception that the TRC-approach is foreign and, therefore, not welcome.

In the recent past researchers and observers of transitional justice processes in Africa have called for indigenous African traditional and cultural practices and restorative processes, rather than Western inspired criminal justice processes, to inform policy solutions to transitional justice demands (Kende, 2007; Villa-Vicencio, 2009). As was observed in Chapter 4, however, many victims of gross human rights abuses in Africa appear to support criminal justice methods to transitional justice processes. Nonetheless, substantial elements of these African traditional and cultural practices, observers suggest, 
are consistent with objectives and modus operandi of the TRC-approach to transitional justice. Indeed, a recent study exploring traditional justice and reconciliation processes in Africa is very insightful, and contributes to this debate (Huyse and Salter, 2008).

The findings from this study regarding cultural receptiveness to the TRCapproach to transitional justice contribute to this growing body of literature on African transitional justice discourse. This study suggests that there should be a systematic process to integrate and indigenize the normative values to be gained from the TRCapproach in the domestic social and cultural contexts. The current study specifically identified religious beliefs, which are universal but not restricted to Africa, as the feasible cultural belief system that resonated well with the TRC-approach in the selected countries. The potential is there in Africa for such an integration process. Across Africa, religion (including indigenous African religious practices) is held in high esteem by the majority of the population, and religious orientation significantly informs state affairs.

The pervasiveness of religious faith in African society is reflected in the recent Afrobarometer survey, which recorded $81 \%$ of respondents in 19 African states indicating that religion was a very important factor in their lives (McCauley and GyimahBoadi, 2009). ${ }^{193}$ The survey also, among other factors, identifies how the religiosity of Africans affects support for democracy. Those who valued religion also demonstrated support for democratic processes. The fact remains that religion is one of the central markers in the socio-political lives of many Africans. Appealing to religious faiths and practices in shaping policy discourse and formulation processes can contribute to public receptiveness and support. When it comes to the TRC mechanism for the transitional

\footnotetext{
${ }^{193}$ Although the survey interviewed over 26,000 individuals, it must be noted that the 19 countries referred to in this study do not necessarily represent the entire continent. The findings do, however, present some indicators of the levels of religiosity in African societies.
} 
justice process, such a conscious appeal coming from domestic policy actors will contribute to letting the public feel connected to the TRC-approach and its associated restorative justice values, because the restorative justice values appear to resonate well with religious beliefs and practices of many Africans.

It must be noted, however, that whereas religious ethics and values may have potential resonance for the TRC-approach policy formulation process in Africa, this study does not necessary endorse the view that it is only the religious aspect of culture that need to be appealed to by policy actors. One of the central arguments in this study is that structural context matters when it comes to TRC-approach policy transfer and its related formulation process. In this study, the findings suggest that certain religious values corresponded appropriately with the normative values associated with the restorative justice process. This match made the TRC-approach to transitional justice more appealing to the citizenry at the precise time that policy formulation occurred. In other contexts, it may be other societal beliefs and values that may matched perfectly with the restorative justice values. The reality, and which this study emphasises, is that for a TRC-approach policy transfer and its formulation to be successful, domestic policy actors have to ensure that the restorative justice values parallel certain societal cultural values--whatever they may be.

Second, formulating a policy on the TRC-approach must follow an inclusive process. Policy actors, particularly from the official levels, should develop a broad-based approach to public policy discourse. This will require adopting a political institutional structure that will afford citizens opportunities to engage with the policy discourse and to submit contributions, and will promote a feeling of ownership of the process. Doing so 
will also solicit continuous support from the public for the work of the TRC. Undoubtedly, the legislative structure for formulating the policy on the TRC-approach holds much promise for such an effective state-society relationship. Admittedly, the executive decree context of the policy formulation process fosters a top-down and exclusive institutional arrangement. Nonetheless, if an executive decree, in the form of presidential statutory instrument, is to be used to develop the TRC policy, as in Nigeria, then it is strongly recommended that the duration of the development be longer to allow the public to debate the policy program.

Indeed, it would be helpful if official actors strategically partnered with domestic non-state organized actors and used these groups as conduits to consult citizens and mobilize their opinions to inform the content of the TRC policy model. The consultations process must, of course, be broad, and not limited to residents in the urban centres. A bottom-up policy formulation process that involves grassroots participation is critical for an inclusive TRC-approach policy formulation process. As a political process, it is imperative that a policy transfer-informed TRC-approach policy formulation process be an inclusive so as to minimize partisanship undertones, as well as to avoid creating the perception or feeling that some sections of the society have been left out of the process.

Certainly, the three cases showcased how non-state actors have been active in policy processes in Africa. The experiences of NGOs during the TRC-approach policy formulation process characterize the increasing participation of civil society in public policy processes in Africa, which began during the late twentieth century. The NGOs have linked the state apparatus with the citizenry. They have played the intermediary role of mobilizing citizens' contributions and channelling them to inform government public 
decision-making institutions. In some instances, as the South Africa and Ghana cases exemplify, non-state actors have been invited and welcomed by state actors to engage with the policy formulation process. Through the establishment of cordial and constructive working relationships, state actors now view civil society as partners, and not as hostile to policy and national development.

In other situations non-state actors have on their own, uninvited, involved themselves in the policy formulation process in order to influence policy content by mobilizing civic contributions. The Nigerian case illustrated such an occasion when it was demonstrated that the domestic non-state actors came into the TRC-approach policy discourse and formulation arena after the government had already, in June 1999, promulgated the Statutory Instrument that set up the TRC. Although their interventions came late in the process, the result of their involvement was an amendment to the Statutory Instrument published in October 1999.

Although these observations are encouraging in as much as they reveal a changing political attitude on the part of African state policy actors to collaborating with CSOs in the policy process, it is not clear, however, whether state actors welcome and work with CSOs because the policy options supported by them resonate with their own objectives, beliefs and aspirations. Will the state actors still be amenable to the course proffered by the non-state actors if the latter's agenda does not coincide with theirs? In this circumstance, non-state actors can do very little to advance the course of policies they advocate if state actors refuse to engage with them. Further, while these observations regarding CSOs' interventions in the policy formulation process of the TRC-approach signal the expansion of citizens' involvement in policy issues that affect their lives, there 
is, however, still a concern that the absence of a favourable institutional arrangement can inhibit levels of citizens' participation in policy formulation processes. Once again, the Nigerian case exemplifies such limitations.

Third, it is critical that domestic policy actors constructively engage transnational actors in the policy formulation processes of the TRC-approach. There is no doubt that international actors, particularly transitional justice epistemic communities, possess relevant and current information on experiences of the TRC-approach around the world. The positions these actors occupy make them vital partners in domestic policy processes of the TRC-approach. Not only do they come with expert advice and documentary materials to inform and strengthen the debate in domestic policy discourse; their involvement in the policy formulation process also brings some legitimacy to the process. Because some of these individual actors and groups are respected globally as experts in the transitional justice process, when state officials seek partnerships and request assistance from them they bring international attention to the domestic political systems and promote local and international recognition. The policy dialogue communities they form with domestic non-state actors also strengthen the capacity of local groups to leverage on the policy formulation discourse and create a local ownership process. In addition, their presence can persuade financial assistance from donors.

Fourth, focusing on the object of this research, a general recommendation for states in Africa who intend to learn from others is that policy actors be well informed about the policy formulation process that took place in the political system from which the transfer is being conducted. The TRC-approach appears to have become a ubiquitous policy response to transitional justice processes in Africa. The opposition expressed by 
the AU to the ICC may signal the preparedness of societies in Africa to employ other transitional justice approaches besides criminal trials. It appears that the TRC-approach is more favoured by the AU. While some TRCs established in the past decade, like the Liberian, have recently wound up, new ones were created on the eve of the present decade. The Togo and Kenya TRCs formed in 2008 and 2009 respectively are notable, Cote d'Ivoire has recently (2011) set up a TRC, and discussions for yet another TRC for Uganda are still being held.

It is reasonable to conjecture that TRCs have not seen the end of their policy formulations in Africa if one considers the complex nature of recent political transitions from conflict, dictatorship, and electoral disputes to peace, democracy and stability on the continent. The South African TRC remains a source of inspiration for many African societies contemplating a transitional justice process, despite the fact that in South Africa resentment over the impact of the TRC continues to emerge. Whether drawing on the South African experience is good practice or not is not the underlying object of this study. A well-informed policy transfer process not only helps in comprehensive understanding of the political process that resulted in the policy formulation process in the source country; it will enable the domestic actors to appropriately situate the formulation discourse in the domestic contextual relevant conditions.

Because the TRC-approach, unlike the judicial process, is more of a whole community process, the work and outcomes of the TRC process do not directly affect only the victim and perpetrator. Truth and reconciliation commissions have ramifications for the entire society as they seek to promote reconciliation for the entire community, unlike the narrow focus of the judicial process. Consequently, the TRC operates 
differently from the judicial process. Each instance of formulating the TRC-approach to transitional justice policy is unique, and contextual relevance is crucial due to context differentials. An informed TRC-approach policy transfer process that comes with identifying the positive and negative lessons from the source political system is therefore indispensable for successful domestic policy formulation outcomes.

Finally, the findings from the study offer insights into current political and policy processes of the African state. The case studies demonstrate that governments in Africa do formulate policies based on contextual needs. Certainly, the study, at least the South Africa and Ghanaian cases, evidently demonstrates good efforts by new democracies in Africa to institutionalize domestic public policy-making processes. Contrary to the pessimistic view that states in Africa do not possess the relevant capacity to formulate public policy, the case studies reveal that governments consciously devise policy programs by way of lesson-drawing to address similar policy challenges at home. Thus, when it comes to transitional justice policy processes, the TRC-approach has become popular in Africa as a result of nations learning from one another.

In a continent with a common political history, concerns for transitional justice have also permeated across the states. Drawing from one another, in a manifestation of south-south policy transfer, to formulate transitional justice demands has merit; yet it also requires a locally-driven process to produce the policy objectives envisaged. Obviously, the cases examined in this study reveal a changing phenomenon where the development of public policy in Africa no longer rests with the neo-patrimonial political state (centralization of power), in that the policy formulation process reflects some levels of citizen-government engagement. Perhaps, it is this gradual institutionalization of the 
policy process that requires in-depth investigations in understanding new ways of looking at the policy capacity needs of African states.

\section{3: Theoretical Implications of the Study and an Agenda for Future Research}

At its outset this study aimed to challenge the prevailing theoretical understanding of the policy formulation of the TRC-approach to transitional justice programs. In Chapter 2 the study suggested that the legalist or institutionalist typology, the transition to democracy typology, and the instrumentalist models were not useful in explaining recent policy formulation processes of the TRC-approach in domestic politics. Moreover, none of them could account for why the TRC-approach was being reproduced in societies. It was demonstrated in that chapter that the policy formulation processes of the TRCapproach in South Africa, Nigeria and Ghana defied expectations when they attempted to interrogate the policy processes within these models. Certainly, one of the central themes of this study was the theory corroboration objective.

While not completely discarding the existing models, this study, by extending the social constructivism framework, argued that a more plausible paradigm for explaining recent country cases, as well as the reproduction of the TRC-approach beyond borders, was a social constructivist account of policy transfers. This alternative paradigm was expanded upon in Chapter 3 of the study. Drawing from the three cases, this study has, in the conclusions of the previous three chapters $(5,6,7)$, advanced modest generalizations in support of this claim. All through this study it has been established that the policy formulation of the TRC-approach in the three cases was an activity of policy transfer. The study acknowledges agency in this policy transfer process of the TRC-approach. As was 
stated before, the TRC-approach policy formulation is a political process that involves human behaviour and actions to respond to transitional justice policy challenges.

At the centre of the TRC-approach policy formulation processes are agents of different capacities acting as borrowers, carriers and formulators of the TRC-approach. Agents are drawn to ideas on the restorative justice process that inform the TRCapproach; agents become the producers, transporters and circulators of the TRC-approach and its underpinning restorative justice normative values; and agents assimilate and draw from components of domestic structure to embed these ideas in the form of a policy program in the domestic political systems. Definitely, the revelations from this study of the considerable role of agents in the TRC-approach policy formulation process affirm observations made by Dobrowolsky and Saint-Martin (2005) where they demystify the argument that accounting for policy change in societies is largely the result of path dependency and institutionalism. Thus, the TRC-approach policy formulation process becomes a social construction that involves actors, restorative justice ideas, and elements of domestic structure. There are two levels of the manifestations of this social construction affecting the TRC-approach policy formulation.

At one level, the social construction is informed by the interaction between agents in the domestic and international realms of agency. Through social learning and the creation of discourse communities, agents in the international arena supply new forms of understanding, knowledge and best practices on the restorative justice process and the TRC-approach. Agents from the domestic sphere take on board these restorative justice innovations, and transform them into TRC policy programs. This form of interaction results in the production and reproduction of the TRC-approach in domestic political 
systems; hence its policy transfer dynamic. In other words, agents coalesce around the notion of restorative justice to produce the TRC-approach across borders. The set of eight questions that revolve around the Dolowitz and Marsh policy transfer model bring to light this dynamic interplay between agents from the domestic and international arenas in the global production of the TRC-approach.

At the second level, the social construction of the TRC-approach occurs in the domestic political systems where official actors attempt to localize the restorative justice ideas in formulating the TRC policy program. In the domestic political systems, formulating actors interact with the citizenry during the policy discourse on the TRCapproach, and also situate these ideas in the domestic social and political structures. Relying on discourse analysis and discursive processes, through using expressions like 'right to truth-seeking', 'healing', 'restoration of victims', and 'reconciliation', domestic formulating actors construct the policy formulation process of the TRC-approach by appealing to public sentiments. The three cases examined in this study were such situations. Thus, by way of interactions between domestic agents and structure, the TRCapproach as a social and political phenomenon is produced as a policy response to transitional justice demands.

This study demonstrates how the TRC-approach to transitional justice policy in South Africa, Nigeria and Ghana resulted from a policy transfer activity that was socially constructivist in nature. In this way, the study has argued that a convincing method of explaining why the TRC-approach has proliferated globally and how this proliferation is being conducted is through the lens of policy transfers accounted for by social constructivism. In this age of globalization, where policy ideas and innovations are easily 
produced, communicated and transported, with human endeavours at the centre of these activities, this alternative theoretical and analytical model is a useful tool with which to investigate the proliferation of the TRC-approach to the transitional justice process. It becomes all the more significant when one considers that transitional justice processes in recent times have moved away from the paradigmatic notion of transitions from authoritarian regimes to democracy.

Transitional justice processes, particularly the TRC-approach, have become more political issues than legal imperatives. They no longer apply to the exclusive moment of political democratic transition, such as the Ghana example shows. Indeed, more nontransitional examples are manifesting in Africa, including Kenya, Cote d'Ivoire and potentially in Uganda. What is more interesting is that the TRC-approach to addressing a history of gross human rights abuses has also surfaced in developed societies, such as Canada.

Undoubtedly, although transitional justice processes have become largely political processes, their conceptual foundation is still underpinned by legal imperatives and the jurisprudence of human rights. In other words, although transitional justice processes have become globalized, and their manifestations extend beyond the conventional norms, including the paradigmatic transitions, that were associated with the first and second phases of the field's genealogy, they remain an exercise inspired by legalism, rooted in international law, and towards human rights wrongs accountability. To a large extent, they also remain processes oriented to deepening democratic development in emerging democracies. 
Nevertheless, this study concludes that a more credible theoretical and analytical approach for understanding the recent policy formulation processes of the transitional justice mechanism, particularly TRCs, across territorial borders in Africa, is by way of a social constructivist explanation of policy transfers. The theoretical and analytical model has been successfully extended in South Africa, Nigeria, and Ghana. It does not, however, tell all the stories to be told on this subject in the whole of Africa. To deepen understanding of it and of how actors involved in TRC policy formulation processes are motivated and engaged with it, the model will require further interrogation in other political contexts in Africa that are similar or dissimilar to the cases investigated in this study. For instance, it will be useful to deploy this model to investigate the recent policy formulation of the TRC-approach in Kenya, Togo and Cote d'Ivoire. Kenya's case, particularly its political context, as noted before, is, to a degree, similar to the Ghanaian case.

Furthermore, while the cases studied here involved voluntary transfer and formulation of the TRC-approach to transitional justice, extending this model to cases of the TRC-approach to transitional justice that emerged as part of internationally supervised post-conflict peace agreements and/or coercively informed, such as in Sierra Leone and Liberia, could yield additional insights into the usefulness of this alternative model to understanding transitional justice policy formulation processes. Beyond Africa, applying this model in other political jurisdictions will be helpful in deepening understanding of policy processes in the ever growing field of transitional justice. This study views the understanding of the dynamics of policy formulation processes as critical 
to conducting impact and other evaluation studies on the transitional justice mechanisms, and particularly the TRC-approach, that have aroused scholarly interest in recent years.

The conclusions drawn in this study also demand further research and testing of the hypothesis confirmed here: particularly, the cultural receptiveness of the TRCapproach in the formulation process and its consequent feasibility for its policy transfers are subjects the understanding of which will benefit from future investigations. There is the need to better understand whether and how cultural factors influence people's views and behaviour regarding the reproduction of the TRC-approach in domestic political systems. This study also demonstrates the varying degrees of influence that different actors possess during the policy transfer and formulation process. It is also necessary to examine, in addition to domestic actors, the reasons external actors, in particular transitional justice policy communities, have proliferated around the world and contribute to transitional justice and TRC knowledge.

It will be useful to investigate further how collaboration between domestic and international actors is being fostered to generate and disseminate transitional justice knowledge globally. This study has contributed to a fraction of this policy discourse debate by looking at three cases in Africa. Further studies, using the social constructivist model, to investigate policy transfers of transitional justice programs will strengthen our understanding of contemporary public policy-making in Africa during this epoch of globalization. Evidently, this study demonstrates that it is worthwhile to study public policy formation in Africa. The TRC-approach policy formulation process to the quest for transitional justice in South Africa, Nigeria and Ghana resulted from the initiatives of domestic policy actors. The findings from the cases show how political decisions were 
made to formulate the policy on the TRC-approach. The assumptions that African societies do not make policies but implement externally generated policies, and that the policy settings in Africa are in disarray are unmeritorious in this era. This study confirms that there is an African public policy to be studied.

Having successfully deployed the Dolowitz and Marsh policy transfer model in the three cases, this study has contributed to understanding policy formation processes in twenty-first century Africa. As was observed in Chapter 3, the model has been less used for research outside of the developed societies. This study validates its viability in studying policy-making processes in developing societies. Definitely, there is a strong perception that a substantial portion of public policy developments in developing societies, Africa included, are informed by a policy transfer activity. African countries tend to learn from one another in their social, political and economic policies. For example, a trend towards the formulation of a national health insurance policy is gaining momentum in Africa. Indications are that its policy formulation process is triggered by lessons-learning from fellow African states. To a large extent, this study reveals this pattern of lesson-drawing in confirming this indigenous institutionalization of policymaking process in Africa. The study clearly departs from past studies that failed to recognize this pattern of originality, and still maintains that Africa continues to exhibit weakness in policy-making capacity.

It is imperative that scholars and researchers investigate these activities to draw both academic and practical lessons from them to guide future countries. This study points out that applying a social constructivist account of policy transfer models is a useful research tool to conduct such investigations. Perhaps, it may be the lens to 
interrogate policy sciences in Africa. Certainly, social constructivism explanation of policy transfers of the TRC-approach to transitional justice in Africa, as this study has demonstrated, is helpful in understanding the proliferation of the TRC-approach to transitional justice, and how the domestic policy formulation processes of the approach is manifesting, in the African continent. Not only does such a theoretical and analytical model elucidate on human actions in the production, circulation and assimilation of transitional justice policy ideas around the globe, but it also liberate the discourse from the dominance of legal perspectives and brings to the fore the language of policy analysis. 


\title{
Appendices
}

\section{Appendix A: Ethics Approval Information}

\author{
Letter of Information \\ (Individual Interviewees)
}

January 12,2009

Dear Participant,

Ph.D Dissertation Research Project:

Transitional Societies, Democratic Accountability and Policy Responses: The Formulation of the Oputa Human Rights Commission Approach to Transitional Justice Policy in Nigeria

\section{Researcher}

Franklin Oduro, Doctoral Candidate, Political Science Department, Carleton University. Contact Information: Telephone: 0249-777788; Email: foduro@connect.carleton.ca

Research Supervisor

Dr. Chris Brown, Associate Professor, Political Science Department, Carleton University. Contact Information: Telephone: (+1) 613-851-6674; Email: cbrown6156@hotmail.com

As part of my doctoral degree requirements, I am undertaking a research on transitional justice processes in Africa. In particular, I am seeking to understand and explain the processes surrounding the policy formulation of the Human Rights Violations Investigations Commission, popularly known as the Oputa Commission, in Nigeria in 1999. The study aims at establishing the policy transfer and its associated policy formulation dynamics in African states. The study seeks to illuminate recent policy discourse in African states in the face of globalization. It also adds to the academic literature on TRCs, transitional justice and policy analysis. On a more practical level, it will highlight how to make policy transfers more acceptable to domestic social structures and, thus, successful in their implementation.

I am seeking to interview you in order to assist me in collecting individual, academic and organization experiences and views on the subject. I would very much appreciate it if you could consider granting me this interview. The interview will take between forty-five minutes and one hour. A mutually acceptable place and time depending on your availability and willingness will be agreed for the interview. Thus, the interview may take place at your office or at any other central place for your convenience. During the interview, you may end the interview session at any time, reschedule the interview for a later date, or request to not answer a particular question.

Your permission to audio record (tape record) the interview will be sought. You may accept or decline this permission. If you decline the audio recording, hand-written notes 
will be taken during the interview. Hand-written notes taken during interviews will be destroyed using shredder following transcription into electronic format. This will take place shortly after the interview. All electronic data, including notes and audio files (tape recording) will be stored and accessed only by myself and my supervisor. Since this is an academic research, which may later be used to publish articles in academic journals, make presentations at academic conferences and/or be used as the basis for future research, the data will be kept by me as a password protected file on a personal computer that is used only by myself. Files will also be kept on a back-up disk with further password protection and in a secure location.

The audio tapes from the discussion will be stored in a secure place under lock. However, you may accept or decline the request to use the information obtained in the discussion in future research. In that case, the audio-taped interview will be destroyed when the research project is finished. In addition, in all cases where the interview is requested to be anonymous, any responses will be attributed to an anonymous source in all future publications, including this research project. Please note that although I will keep your responses confidential if requested, the small number of interviewees means that I may not be able to guarantee anonymity in terms of your participation.

All efforts will be made to conduct interviews in person. Furthermore, where there is a need on my part or yours to have another session for clarification on earlier interview granted, the necessary arrangements will be made to make sure this takes place. Please note that your consent will be sought again for any future interviews or research. I appreciate your participation in granting me this interview.

The project has been reviewed and received ethics clearance by the Carleton University Research Ethics Committee. Should you have any concerns, please contact the ethics committee chair:

Professor Antonio Gualtieri, Chair

Carleton University Research Ethics

Committee

Carleton University

1125 Colonel By Drive

Ottawa, Ontario K1S 5B6

Tel: 613-520-2517

E-mail: ethics@carleton.ca

Yours sincerely

Franklin Oduro

(Student Researcher) 


\section{Letter of Information \\ (Focus Group Discussion)}

January 12, 2009

Dear Participant,

Ph.D Dissertation Research Project:

Transitional Societies. Democratic Accountability and Policy Responses: The Formulation of the Oputa Human Rights Commission Approach to Transitional Justice Policy in Nigeria

Researcher

Franklin Oduro, Doctoral Candidate, Political Science Department, Carleton University. Contact Information: Telephone: 0249-777788; Email: foduro@connect.carleton.ca

Research Supervisor

Dr. Chris Brown, Associate Professor, Political Science Department, Carleton University. Contact Information: Telephone: (+1) 613-851-6674; Email: cbrown6156@hotmail.com

As part of my doctoral degree requirements, I am undertaking a research on transitional justice processes in Africa. In particular, I am seeking to understand and explain the processes surrounding the policy formulation of the Human Rights Violations Investigations Commission, popularly known as the Oputa Commission, in Nigeria in 1999. The study aims at establishing the policy transfer and its associated policy formulation dynamics in African states. The study seeks to illuminate recent policy discourse in African states in the face of globalization. It also adds to the academic literature on TRCs, transitional justice and policy analysis. On a more practical level, it will highlight how to make policy transfers more acceptable to domestic social structures and, thus, successful in their implementation.

I am seeking to invite you to attend and participate in a focus group discussion in order to assist me in collecting individual as well as collective experiences and views on the subject. I would very much appreciate it if you could consider participating in the discussion. The focus group discussion will last for two hours. It will bring together between fifteen and twenty participants drawn from policy makers, representatives of local civil society organizations (CSOs), elected and unelected politicians from identifiable political groupings, opinion leaders and ordinary citizens. The discussion will take place at the premises of the ...VENUE...AND..............TIME. During the discussion, you may excuse yourself at any time if you no longer want to continue, or request not to discuss a particular question.

Your permission to audio record (tape record) the discussion will be sought. You may accept or decline this permission. If you decline the audio recording, hand-written notes will be taken during the discussion. Hand-written notes taken during interviews will be destroyed using a shredder following transcription into electronic format. This will take 
place shortly after the discussion. All electronic data, including notes and audio files (tape recording) will be stored and accessed only by myself and my supervisor. Since this is an academic research, which may later be used to publish articles in academic journals, make presentations at academic conferences and/or be used as the basis for future research, the data will be kept by me as a password protected file on a personal computer that is used only by myself. Files will also be kept on a back-up disk with further password protection and in a secure location.

The audio tapes from the discussion will be stored in a secure place under lock. However, you may accept or decline the request to use the information obtained in the discussion in future research. In that case, the audio-taped interview will be destroyed when the research project is finished. In addition, in all cases where the discussion is requested to be anonymous, any responses will be attributed to an anonymous source in all future publications, including this research project. Please note that although I will keep your responses confidential if requested, the small number of participants and the nature of the focus group discussion may make it impossible for me to be able to guarantee anonymity in terms of your participation. Where there is the need for further clarification in your response after the discussion, I shall arrange to make myself available for this purpose. Please note that your consent will be sought again for any future interviews or research

Furthermore, I do recognize that revisiting these issues may bring back painful memories to some of you. Should you require any need for counselling (for psychological/emotional support) following the interview. I will be glad to facilitate such counselling support.

I appreciate your participation in this discussion. To cover your transportation expense, a travel allowance ...... will be provided. Snacks will also be served during the discussion.

The project has been reviewed and received ethics clearance by the Carleton University Research Ethics Committee. Should you have any concerns, please contact the ethics committee chair:

Professor Antonio Gualtieri, Chair

Carleton University Research Ethics

Committee

Carleton University

1125 Colonel By Drive

Ottawa, Ontario K1S 5B6

Tel: 613-520-2517 E-mail: ethics@carleton.ca

Yours Sincerely

Franklin Oduro

(Student Researcher) 


\section{Consent Form}

Research Project Title:

Transitional Societies, Democratic Accountability and Policy Responses: The Formulation of the Oputa Human Rights Commission Approach to Transitional Justice Policy in Nigeria

I agree to participate in an academic research study being conducted by Franklin Oduro of the Department of Political Science, Carleton University, Canada. I understand that the study is under the supervision of Dr. Chris Brown also of the same department and university. I have made this decision based on the information I read in the letter of information. I am participating in this study voluntarily and I may refuse participation or end the interview at any time. I may also request to not answer a particular question, or to reschedule the interview for a later date at any time. I may request for confidentiality of responses that I give. I can make this request before, during or after the interview. Although I must make this request before the final report is completed. The completion date of this research project is end of June 2010. I understand that I may make this request of confidentiality on or before end of June 2009. I may be able to contact the researcher directly on (+1)613-265-2681 or on email: foduro@connect.carleton.ca if I have any questions or concerns before, during or after the interview.

If I choose to end the interview entirely, I may ask that the final report and related articles and/or presentations will not use my responses in any way and all my notes and audio (tape) recording will be destroyed. As a participant in this study, I realize that I will be granting an interview to the researcher lasting anywhere between one hour thirty minutes and two hours at my convenience. I understand that all the audio tapes and electronic data will be kept in secure manner by the researcher, who, together with his supervisor, has sole access to the data. Furthermore, I understand that the interviewer will facilitate for me to have counselling support, if it becomes necessary during the interview.

Signing this consent form signifies that I agree that the researcher may openly use my responses as quotations or restatements in the final dissertation document, conference presentations, classroom presentations, and academic publications related to the dissertation research, unless otherwise specified as outlined above. I understand that my consent will be sought at all times for the present interview and any future research. By

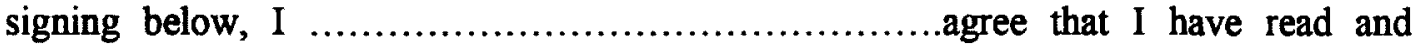
understood the above information regarding my role and rights as an interviewee.

I confirm that I have explained the nature and complications of the research project to the participant.

(Researcher) Date:


I understand that this project has been reviewed and has received clearance from the Carleton University Ethics Committee and that I may contact the office regarding any concerns at:

Prof. Antonio Gualtieri,

Carleton University Research Ethics Committee

Carleton University

1125 Colonel By Drive

Ottawa, Ontario K1S 5B6

Tel: 613-520-2517

E-mail: ethics@carleton.ca.

\begin{tabular}{ll}
\hline (Signature of research participant) Date & Date
\end{tabular}

This consent form will be retained by me; a copy will be provided to you. 


\section{Oral Consent}

\section{Introduction}

My name is Franklin Oduro, Doctoral Candidate, Political Science Department, Carleton University, Ottawa-Canada.

\section{Purpose of Study}

I am undertaking a research on transitional justice (how societies confront past abuses that haunt them in a way to build a more just and democratic future) processes in Africa. In particular, I am seeking to understand and explain the processes surrounding the policy formulation of the truth and reconciliation commissions (TRCs) in South Africa, Nigeria and Ghana. The study aims at establishing the policy transfer and its associated policy formulation dynamics in African states. I am seeking to interview you in order to assist me in collecting individual, academic and organization experiences and views on the subject. I would very much appreciate it if you could consider granting me this interview.

\section{Duration}

The interview will take between one hour thirty minutes and two hours.

\section{Research Benefits}

The study seeks to illuminate on recent policy discourse in African states in the face of globalization. It also adds to the academic literature on TRCs, transitional justice and policy analysis. On a more practical level, it will highlight on how to make policy transfers more acceptable to domestic social structures and, thus, successful in their implementation.

\section{Confidentiality and Anonymity}

Your permission to audio record (tape record) the interview will be sought. You may accept or decline this permission. If you decline the audio recording, hand-written notes will be taken during the interview. Hand-written notes taken during interviews will be destroyed immediately following transcription into electronic format.

In addition, in all cases where the interview is requested to be anonymous, any responses will be attributed to an anonymous source in all future publications, including this research project. I may, however, not be able to guarantee anonymity in terms of your participation, because of the small number of interviewees/particular the nature of your organization in this study.

\section{Access to Data}

All electronic data, including notes and audio files (tape recording) will be stored and accessed only by myself and my supervisor. Since this is an academic research, which may later be used to publish articles in academic journals, make presentations at academic conferences and/or be used as the basis for future research, the data will be kept by me as a password protected file on a personal computer that is used only by myself. Files will also be kept on a back-up disk with further password protection and in a secure location. The audio tapes from the discussion will be stored in a secure place under lock. 
However, you may accept or decline the request to use the information obtained in the discussion in future research.

\section{Voluntary Participation}

Your participation in this interview is voluntary and therefore you may end the interview session at any time, reschedule the interview for a later date, or request to not answer a particular question.

\section{Feedback}

Feedback from this research will, first and foremost, be a complete dissertation document. Other forms will be in the form of academic publications, conference presentations and roundtable discussions.

\section{Ethics Approval}

The project has been reviewed and received ethics clearance by the Carleton University Research Ethics Committee. Should you have any concerns, please contact the ethics committee chair:

Professor Antonio Gualtieri, Chair

Carleton University Research Ethics

Committee

Carleton University

1125 Colonel By Drive

Ottawa, Ontario K1S 5B6

Tel: 613-520-2517

E-mail: ethics@carleton.ca

\section{Consent}

Do I understand that I have explained the nature of my research and the purpose of the study to you and that you are prepared to participate in this interview voluntarily?

Yes

No 


\section{Appendix B: $\quad$ STANDARD QUESTIONNAIRE INSTRUMENTS FOR INTERVIEWS}

\section{A. For Domestic Actors (individuals-elected politicians, party officials, policymakers, members of parliament)}

1. Why did you/government/party choose TRC-approach instead of trials to promote democratic accountability?

2. Were you/your government under pressure to adopt a policy program of redress?

3. Ghana/Nigeria: Don't you think you chose to address human rights abuses because you wanted to build a new image different from your predecessor in the 'eyes of the international community?

4. How did you get to know about TRCs? What motivated you to go for this approach?

5. Did the SATRC model influence your decision in any way?

6. Which aspects (policy goals or program) of the SATRC-approach informed your choice?

7. What kind of benefits did you enjoy from local NGOs/Think Tanks?

8. Did you/your government receive any assistance from International Organizations/Supra national organizations (both governmental and nongovernmental)?

9. If yes, what was the nature of the assistance?

10. How do you rate the level of citizens' participation/involvement in the formulation stage? Did you get the sense that the TRC policy outcome reflected the general interest of the citizenry, particularly the direct beneficiaries?

11. What is your general level of assessment of the outcome of the TRC-approach?

12. Do you/your party/government feel vindicated in your role in the TRC process?

13. Is there a particular local factor/social norms/structure that made it possible for the TRC to be accepted or not?

14. South Africa: What about Tutu's 'Ubuntu's philosophy. Do you think it played a crucial role in the choice of TRC in South Africa?

15. Did Parliament feel that the TRC-approach was wholly driven from within the country or it was a borrowed policy? What makes you feel this way? 
16. Did the parliamentary process allow for deeper public consultations and citizens input before the passage of the law?

17. What would you consider as the critical factors that facilitate/constrain successful policy formulation of TRC-approach borrowed from elsewhere?

18. How can Ghana/South Africa/Nigeria strengthen local processes in the design and formulation of public policies that results from policy transfers?

\section{B. For Domestic Actors (Non-Governmental (organizations/individuals-pressure groups, Think Tanks, NGOs, CSOs, experts, consultants, policy entrepreneurs)}

1. Which ideological/partisan position/image does your Think Tank promote?

2. What are the specifics of your organization in policy discourse in Ghana/Nigeria/South Africa?

3. How do you define your research/policy engagement agendas? Do you promote policy change? How?

4. Why do you think the TRC-approach was adopted and not any other transitional justice policy options?

5. Why did you decide to get involve and what role did you play?

6. How did you/your organization get involved in the TRC process in Ghana/Nigeria/South Africa?

7. Did you/your organization play any role during the formulation stage?

8. What was the nature of your involvement?

9. Were you consulted by the government to assist in formulating the TRC policy approach?

10. Did the process (e.g. parliamentary debate) of formulating the TRC model allow for public consultations and citizens input?

11. Do you feel your role impacted heavily on the TRC process?

12. Do you think the TRC achieve its aims?

13. What might have gone wrong in the TRC process?

14. What is your source of knowledge in TRCs / Transitional justice processes?

15. Does your organization have an external partner in this field of activity? 
16. What is the nature of relationship with this external partner?

17. Would you say that there was a particular social norm that made the TRC-approach receptive to the society? What was it?

18. South Africa: What about Tutu's 'Ubuntu's philosophy. Do you think it played a crucial role in the choice of TRC in South Africa?

19. How would you describe the nature of public policy making process in Ghana/Nigeria/South Africa?

20. What would you consider as the critical factors that facilitate/constrain successful policy formulation of TRC-approach borrowed from elsewhere?

21. How can Ghana/South Africa/Nigeria strengthen local processes in the design and formulation of public policies that results from policy transfers?

22. Has transitional justice become a global industry? What is your role in this industry?

C. For International Agency (individuals/organizations-Think Tanks, INGOs, consultants, experts, policy entrepreneurs)

1. How would describe your core mandate?

2. Do you/your organization have a clear ideological/image that you seek to promote?

3. Why did you choose to operate/work in the transitional justice field?

4. Where do you work?

5. How do you get to work in the countries that you choose to work? Is it by invitation or other by means of entry?

6. Is your mission to market ideas/expertise on transitional justice around the world?

7. What does your organization do specifically with domestic public policy on transitional justice programs? /How do you define your research/policy engagement agendas in the countries you work in?

8. You/your organization work(ed) on the TRCs in Ghana/South Africa/Nigeria? Right?

9. What was the nature of your work in these countries?

10. Did you/your organization play any role during the policy formulation stage? 
11. Did you feel that the internal/domestic policy process of the countries (Ghana/South Africa/Nigeria) provided adequate space for local inputs?

12. Did you work directly with Government or with local NGOs/Think Tanks?

13. How did you establish this relationship/partnership?

14. Do you think the TRC worked well in Ghana/Nigeria/South Africa?

15. What worked/What did not work?

16. What made it work?

17. A lot of emphasis has been placed on Tutu's 'Ubuntu's philosophy. Do you think it played a crucial role in the choice of TRC in South Africa?

18. Why do you think the TRC model was adopted in these countries (South Africa/Ghana/Nigeria) and not the criminal justice approach for example?

19. Why do you think the SATRC has become the best international model for replication? Do you subscribe to this view?

20. How would you describe the impact of your involvement in the TRC processes in Ghana/South Africa/Nigeria?

21. Do you want to attempt an assessment on how these TRCs performed?

22. How do you fund your activities in the countries you work, including Ghana/South Africa/Nigeria?

23. Do your funders ask specifically to channel the funds towards a particular agenda/ideology/specific country? Any idea on why such specificity?

24. How do you build on your knowledge in transitional justice processes?

25. It is argued these days that transitional justice has become a global industry? How would you respond to that: globalization of transitional justice?

26. What is your/organization role in this global industry?

27. What would you consider as the critical factors that facilitate/constrain successful policy formulation of TRC-approach borrowed from elsewhere?

28. How can we strengthen local processes in the design and formulation of public policies that results from policy transfers? 


\section{Design for Focus Group Discussions}

\section{Part 1: On Public Policy Making}

1. Does this country make policies? Or perhaps, it only implements policies?

a) How would you describe public policy-making in Ghana (the process?)

2. Why do most of the country's public policies fail to achieve their intended objectives?

3. Do you agree that globalization has impacted on the way this country makes public policy? If yes, how?

\section{Part 2: On TRC Policy Formulation}

4. How did the government come by the TRC policy?

a) Do you think it was indigenously created or borrowed from elsewhere?

b) Did the process follow the normal/standard process of public policy-making?

5. What motivated the government to embark on a transitional justice?

a) Why did it choose TRC-approach and not any other approach?

6. Do you have a sense that the policy process was influenced from outside? From where and whom do you think the influence came from?

7. Is there a particular social norm that made the TRC-approach receptive or hostile to the society?

8. Did the process allow for deeper public consultations and citizens input before the passage of the law?

9. What is your assessment of the TRC process in this country?

a) Was it a success or failure? How? Why?

10. What would you consider as the critical factors that facilitated/constrained the successful policy formulation of TRC-approach?

\section{Part 3: Recommendations for Policy Process}

11. How can we strengthen local processes in the design and formulation of public policies that results from policy transfers? 


\section{Appendix C: Interviews}

\section{$\underline{\text { I. South Africa }}$}

Interview 1: Associate Professor, Anthony Butler, University of Cape Town, South Africa, Wednesday, September 10, 2008.

Interview 2: Professor Emeritus Andre du Toit, University of Cape Town, South Africa, Tuesday, September 16, 2008.

Interview 3: Piers Pigou, Director of South Africa History Archives (SAHA), NGO based in Johannesburg, former investigative staffer of the SATRC, Tuesday, September 16, 2008.

Interview 4: Tim Hughes, Programme Head: Governance of Africa's Resources Programme, South African Institute of International Affairs (SAIIS), Friday, September 26, 2008.

Interview 5: Professor Robert Mattes, University of Cape Town, South Africa, October 2, 2008.

Interview 6: Carnita Ernest, former manager, Transitional Justice Project at CSVR and currently at the school of Public Health, University of Western Cape, Sunday, October 5 , 2008.

Interview 7: Dr. Hugo van der Merwre, Director of the Cape Town office of CSVR, Monday, October 6, 2008.

Interview 8: Howard Varney, former staffer of the SATRC and also former international staffer of the Sierra Leone TRC, currently Director of Truth-Seeking at the Cape Town office of ICTJ, Friday, October 10, 2008.

Interview 9: Hon. (Dr.) Sem Pheko, Member of Parliament (PAC), Friday, October 10, 2008.

Interview 10: Hon. J.T. Delport, Member of Parliament (Democratic Alliance), Tuesday, October 14, 2008.

Interview 11: Dr. Fannie du Toit, Executive Director of IJR, Tuesday, October 14, 2008.

Interview 12: Hon. (Mrs.) Sheila M. Camerer, Member of Parliament (Democratic Alliance), Thursday, October 23, 2008. 
Interview 13: Thapelo Mokushane, Former SABC reporter and currently a staff (Deputy Media Liaison officer) at Department of Justice and Constitutional Development (Written Email Response)

Interview 14: Trevor Ngwane, Former member of the ANC and a Human Rights Activist based in Johannesburg, South Africa, (Written Email response)

Interview 15: Prof. Ben Turok, Member of Parliament (ANC), Tuesday, March 102009.

Interview 16: Prof. Kadar Asmal, Former Member of Parliament (ANC, former Minister of Education, Tuesday, March 102009.

Interview 17: Cyril Adonis, Senior Researcher at CSVR (Johannesburg Office), Thursday, March 12, 2009.

Interview 18: Yasmin Sooka, Member/Commissioner of the SATRC, one of the external commissioners of the Sierra Leone TRC, Monday, March 16, 2009 (Telephone Interview)

\section{Nigeria}

Interview 1: Ms. Priscilla Ankut, Former Staff for LRC and currently the Govemance Adviser for the European Commission Delegation in Nigeria, Wednesday, January 21, 2009.

Interview 2: Clement Nwankwo, Human Rights Lawyer, former staff of Constitutional Rights Project, currently Deputy Director, NDI-Nigeria, Tuesday, January 27, 2009.

Interview 3: Mr. Godwin Aidenagbon-Head, Research and Development, Yakubo Gowon Centre, Tuesday, January 27, 2009.

Interview 4: Father Matthew Kukah, Member of the HRVIC (Oputa Commission), Wednesday, January 28, 2009.

Interview 5: Dr. Sam Amadi, Human Rights Lawyer, Director, CPPR (Lagos) and also Director of Research and Programs for KNC (Abuja), Thursday, January 29, 2009.

Interview 6: Mr. Olawale Fapohunda, Human Rights Activist, Managing Partner, LRC, Saturday, January 31, 2009.

Interview 7: Anonymous, Representative of an NGO, February 2, 2009.

Interview 8: Dauda Garuba, Former Senior Programs Officer of CDD, currently, Nigeria Country Coordinator for Revenue Watch Institute, Monday, February 2, 2009. 
Interview 9: Professor Yemi Akinseye George, a Legal Practitioner/Academic and Consultant/Adviser to the Ministry of Justice, Monday, February 2, 2009.

Interview 10: Dr. Olatunji Abayomi, Human Rights Lawyer/Activist, Monday, February 22009.

Interview 11: Professor Julius Ihonvbere, Academic and former Special Advisor to President Olusegun Obasanjo (Programs and Policy Monitoring), Tuesday, February 3, 2009.

Interview 12: Innocent Chukwuma, Criminologist/a civil and human rights activist, currently Executive Director, CLEEN Foundation, Thursday, February 5, 2009.

Interview 13: Chukwuemeka B. Eze, National Coordinator, WANEP, Nigeria, Monday, February 9, 2009.

Interview 14: Chino Obiagwu, Human Rights Lawyer/ National Coordinator, LEDAP, Monday, February 9, 2009.

Interview 15: Nosike Ogbuenyi, a Journalist/Media Practitioner, Group Politics Editor, This Day Newspaper, Tuesday, February 10, 2009.

Interview 16: Bamidele Aturu, Legal Practitioner/Human Rights Lawyer, Tuesday, February 10, 2009.

Interview 17: Chidi Odinkalo, Human Rights Activist/OSJI, Tuesday, February 10, 2009.

Interview 18: Professor John Ayoade-Academic, Former chair of the political science, Ibadan University/Served as a Director in the Nigerian Presidency (1990-1995), currently professor of African politics at the University of Pennsylvania, USA, Saturday, April 25, 2009.

\section{Ghana}

Interview 1: Justice V.C.R.A.C. Crabbe, Statue Law Revision Commissioner/Chairman of CDD-Ghana/Civil Society Coalition/Member of Attorney General's Reparation Implementation Committee, Thursday, July 24, 2008.

Interview 2: Prof. J.R.A. Ayee, Professor of Political Science/Dean, Faculty of Social Studies, University of Ghana, Wednesday, July 30, 2008.

Interview 3: Hon. Cletus Avoka, Former Member of Parliament (NDC, 20012004)/Member of CLPA/Minister of Environment, Science and Technology during the NDC last regime (1996-2000), Thursday, July 31, 2008. 
Interview 4: Hon. Papa Owusu-Ankomah, Former Majority Leader in Parliament (NPP)/Minister of Parliamentary Affairs (2001-2003), former Minister of Justice and Attorney General (2003-2004), currently Minister of Trade, Industry \& Presidential Special Initiatives, Tuesday, August 5, 2008.

Interview 5: Prof. George Panyin Hagan, a Professor of Cultural Anthropology, University of Ghana, currently Chairman of NCC, Monday, August 11, 2008.

Interview 6: Mrs. Regina Apotchie, Former Chief Director at the Ministry of Justice and Attorney General (2002-2004), currently retired public servant, Friday, August 15, 2008.

Interview 7: Dr. Yaw Owusu-Frempong, Senior Lecturer, Department of Public Administration, University of Ghana Business School, Legon, Monday, August 18, 2008.

Interview 8: Dr. Kwadwo Appiagyei-Atua, Senior Lecturer, Faculty of Law, University of Ghana, Legon, Wednesday, August 20, 2008.

Interview 9: Hon. Francis Agbotsi, Member of Parliament (NDC, 2001-2008)/Deputy Ranking Member of Committee on CLPA (2001-2004), currently Chairman of the Subsidiary Legislation Committee, Wednesday, August 20, 2008.

Interview 10: Hon. Ayi koi Otoo, Minister of Justice and Attorney General (20052006)/Legal Practitioner, Wednesday, August 20, 2008.

Interview 11: Hon. Joseph Yileh Chireh, Member of Parliament (NDC, 2005-2008), former Chairman of the PNDC constituted Confiscation of Assets Committee (19861993), Monday, August 25, 2008.

Interview 12: Anonymous (Senior Official at CDD-Ghana), August 25, 2008.

Interview 13: Dr. Kwesi Aning, Head of CPMRD at KAIPTC, Wednesday, September 3 2008.

Interview 14: Mr. Joe D. Issachar, Senior Civil Servant, currently the Head of Ghana Civil Service, Thursday, September 4, 2008.

Interview 15: Maulvi Wahab Adam, Ameer of the AMM in Ghana/Commissioner of the NRC, Thursday, January 15, 2009.

Interview 16: Mr. Mohammed Affum, Deputy Director, Public Affairs Directorate of NRC, Monday, April 202009.

Interview 17: Professor Mike Oquaye, Senior Official of the NPP/Member of the NPP's 2000 Election Manifesto Committee, currently Second Deputy Speaker of Parliament, Friday, May 8, 2009. 
Interview 18: Mr. Amos Safo, Managing Editor, Public Agenda Newspaper, Wednesday, may 12, 2009.

Interview 19: Archbishop Palmer-Buckle-Catholic Bishop/Commissioner of the NRC, Thursday, May 14, 2009.

Interview 20: Mr. Albert Salia, a Journalist/Senior Staff Writer of the Daily Graphic Newspaper, Monday, May 18, 2009.

Interview 21: Mrs. Tina Aforo-Yeboah, Victim of Human Rights Abuses who also testified before the NRC, currently Foreign Desk Editor, Ghanaian Times Newspaper, Tuesday, May 19, 2009.

\section{United States of America (Think Tanks/NGOs)}

Interview 1: Dr. Scott Worden, Adviser, Rule of Law Program and Co-Director, International Network to promote the Rule of Law, USIP, May 15, 2008.

Interview 2: Dr. Christina Jones-Pauly, Customary Law Advisor, USIP, May 16, 2008.

Interview 3: Dr. Dorina Bekoe, Senior Research Associate, Center for Conflict Analysis and Prevention, USIP, May 16, 2008.

Interview 4: Kelli Muddell, Gender Specialist, ICTJ, May 21 and 23, 2008.

Interview 5: Dr. Louis Bickford, Director, Policymakers and Civil Society Unit; Director, Memory, Museums and Monuments Program ICTJ, May 21, 2008.

Interview 6: Dr. Suliman Baldo, Africa Director, ICTJ, May 22, 2008.

Interview 7: Ana Paltel, Deputy Director, Policymakers and Civil Society Unit, ICTJ, May 22, 2008.

Interview 8: Samar Al-Bulushi, Consultant, ICTJ May 22, 2008.

Interview 9: Priscilla Hayner, Co-Founder; Director, Peace and Justice Program; Director, Geneva Office, ICTJ, May 22, 2008.

Interview 10: Graeme Simpson, Director, Thematic Programs, ICTJ, May 23, 2008.

Interview 11: Paige Arthur, Deputy Director, Research, ICTJ, May 23, 2008.

Interview 12: Eric Okyere-Darko, former Documentation Officer, ICTJ, May 25, 2008. 


\section{Appendix D: Participants at Focus Group Discussions}

\section{Focus Group Discussion \# 1: Accra. Ghana January 15, 2009}

1. Richard Apronti, Program Officer, Committee on Human and Peoples Rights, Accra.

2. Otu Ayittah, Victim/Complaint of Human Rights Violations, Ada/Accra.

3. Ofotsu Apronti, Victim/Complaint of Human Rights Violations, Ada/Accra.

4. Nathan Nyamedor, Victim/Complaint of Human Rights Violations, Ada/Accra.

5. Vincent Adzahlie-Mensah, Board Chairman, Amnesty International (Ghana), Accra.

6. Samuel Opoku Agyarkwa, Former Staffer, NRC, Accra.

7. Ruby Quantson, Researcher, Institute of Democratic Governance, Accra.

8. Adolf Awuku Bekoe, Lecturer; former Staffer, NRC, Accra.

9. Eric Carbonu, Regional Chairman, National Association of Graduate Teachers, Accra.

10. Sheikh Armiyawo Shaibu, Regional Manager, Islamic Education Unit, Accra.

II. Focus Group Discussion \# 2: Lagos. Nigeria. February 12, 2009

1. Kelechi Godson, Conveyner, The Redeemers Project, Lagos.

2. Samuel M. Sunday, Student, Lagos.

3. Chinidu Opara, Student, Lagos.

4. Reebelle Wisdom, Technical Director, Ejotor Enterprise, Lagos.

5. Ekeh Emma, Economist, Ossy Motors, Lagos.

6. Constance Matthew, Missionary, Gospel Saints, Lagos.

7. Nwachukwu Chibiyo, Proprietor, Eldad Nursery and Primary School, Lagos.

8. Atuma Ken, Marketing, Dynamite Creations, Lagos.

9. Olaitam David, Pastor, First Gospel Bearers Assembly International, Lagos.

10. Ify Eze, Evangelists, First Gospel Bearers Assembly International, Lagos. 
11. Agu Stanley, Student, Lagos.

12. Ossi Chinazo, IT Consultant, Win Matrix Solution, Lagos.

13. Nkwocha Fabian, Photographer, Lagos.

14. Godwin Amadi, Public Relations Officers, Godek Foundation, Lagos. 


\section{Works Consulted/Bibliography}

Abogunrin, S.O. 1984. "Towards a Unifying Political Ideology and Peaceful Coexistence in Nigeria: A Christian View." In Religion, Peace and Unity in Nigeria, ed. J.O. Onaiyekan. Ibadan: NACS.

Aborisade, Oladimeji and Robert Mundt. 2002. Politics in Nigeria, $2^{\text {nd }}$ Edition. New York: Longman

Adamolekun, Ladipo. 1986. Politics and Administration in Nigeria. Ibadan: Spectrum Books Limited.

Adedeji, John L. 2001. "The Legacy of J.J. Rawlings in Ghanaian Politics, 1979-2000". African Studies Quarterly, Vol. 5: Number 2.

Adeshida, Emma. 2000. "Truth commission' reconciles enemies". West Africa, Issue No. 4253. 20-26 November 2000.

Adler, Emmanuel. 1997. "Seizing the Middle Ground: Constructivism in World Politics". European Journal of International Relations, Vol. 3: Number 3. pp. 319-363.

African Union. 2009. The Assembly of the African Union: Decisions and Declarations, Thirteenth Ordinary Session, July 1-3. Assembly/AU/Dec.243-267(XIII), Assembly/AU/Decl. 1-5(XIII).

Agbaje, Adigun. 2004. "Nigeria: Prospects for the Fourth Republic." In Democratic Reform in Africa: The Quality of Progress, ed. E. Gyimah-Boadi. Colorado: Lynne Rienner Publishers.

Agyeman-Duah, B. 2008. "Introduction: Fifty Years in Perspective". In Ghana: Governance in the Fourth Republic, ed. Baffour Agyeman-Duah. Accra: Digibooks Ghana Ltd.

Agyeman-Duah, B. 2002. Civil-Military Relations in Ghana's Fourth Republic, Critical Perspective: Number 9 (Monograph). Accra: CDD-Ghana.

Akeredolu, Alero. ed. (undated). Constitutional Law Classics Vol. 1. Law Reports, Abuja.

Akokpari, John. 2004. "Ghana: Economic dependence and marginalized foreign policymaking." In Diplomacy and Developing Nations: Post-Cold War foreign policy-making structures and processes, eds. Justin Robertson and Maurice A. East. London: Routledge

Alexander, Jane. 2003. A Scoping Study of Transitional Justice and Poverty Reduction. Final Report for the UK Department for International Development (DFID). 
Ameh, Robert K. 2006a. "Doing Justice After Conflict: The Case for Ghana's National Reconciliation Commission." Canadian Journal of Law and Society, Vol. 21 : Number 1. pp. 85-109.

Ameh, Robert K. 2006b. "Uncovering Truths: Ghana's National Reconciliation Excavation of Past Human Rights Abuses." Contemporary Justice Review, Vol. 9: Number 4. pp. 345-368.

Amnesty International. 2010. Commissioning Justice. Truth Commissions and Criminal Justice. London: Amnesty International Publications

Amoako-Tuffour, Joe. 2008. "Public Consultations, Bureaucrats and Development Partners in Ghana's Poverty Reduction Strategy." In Poverty Reduction Strategies in Action: Perspectives and Lessons from Ghana, eds. Joe Amoako-Tuffour and Bartholomew Armah. New York: Lexington Books

Anderson, James. 1984. Public Policy-Making: An Introduction, $3^{\text {rd }}$ Edition. Boston: Houghton Mifflin.

An-na'im, Abdullahi A. 2005. "September 11 and the Search for Justice and Accountability." In Roads to Reconciliation: Conflict and Dialogue in the Twenty-First Century, eds. Amy Benson Brown and Karen M. Poremski. New York: M.E. Sharpe.

Anyanwu, Tony. 2001. "Still on Oputa Panel". Thisday Newspaper. http://www thisdayonline,com/archive/2001/08/19/20010819com01/html. Sourced on March 30, 2010.

Apter, D. 2006. "Duchamp's Urinal: Who says What's Rational When things Get Tough?" In The Oxford Handbook of Contextual Political Analysis, eds. Robert E. Goodin and Charles Tilly. Oxford: Oxford University Press.

Arnold, G. 2000. The New South Africa. London: Macmillan Press.

Arthur, Paige. 2009. "How "Transitions" Reshaped Human Rights: A Conceptual History of Transitional Justice." Human Rights Quarterly, Vol. 31: Number 2. pp. 321-367.

Asare, Abena A. 2008. "The Ghanaian National Reconciliation Commission: Reparation in a Global Age". The Global South, Vol. 2: Number 2. pp. 31-53.

Asmal, K., Louise Asmal and Ronald S. Roberts. 1997. Reconciliation through Truth: A Reckoning of Apartheid's Criminal Governance, Second Edition. Cape Town: David Philip Publishers.

Asmal, Kader. 1992. "Victims, Survivors and Citizens-Human Rights, Reparations and Reconciliation". Inaugural Lecture. University of Western Cape. 
Attafuah, Ken A. 2004. “An Overview of Ghana's National Reconciliation Commission and its Relationship with the Courts". In Truth Commissions and Courts. The Tension Between Criminal Justice and the Search for Truth, ed. William A. Schabas and Shane Darcy. Dordrecht: Kluwer Academic Publishers.

Ayee, Joseph, R.A. 2006. "Political Leadership and Democratic Consolidation". In Voting for Democracy in Ghana: The 2004 Elections in Perspectives, Thematic Studies, Vol. 1, ed. Kwame Boafo-Arthur. Accra: Freedom Publications.

Ayee, Joseph R.A. 2000. Saints, Wizards, Demons and Systems: Explaining the Success or Failure of Public Policies and Programmes. Accra: Ghana Universities Press.

Backer, David. 2007. "Victims' response to truth commissions: Evidence from South Africa". In Security, Reconstruction, and Reconciliation. When the wars end, ed. Muna Ndulo. London: University College London Press.

Backer, David. 2006. "Book Review: Overcoming Apartheid: Can Truth Reconcile a Divided Nation? by James L. Gibson (2004), New York: Russell Sage" Comparative Politics, Vol. 39: Number 9. pp. 1157-1168.

Bates, Robert H, ed. 1988. Toward a Political Economy of Development: A Rational Choice Perspective. Berkley: University of California Press.

Bates, Robert H. 1981. Markets and States in Tropical Africa: The Political Basis of Agricultural Policies. Berkley: University of California Press.

Bates, Robert H and Michael F. Lofchie. eds. 1980. Agricultural Development in Africa: Issues of Public Policy. New York: Praeger Publishers.

Bell, Christine. 2009. "Transitional Justice, Interdisciplinarity and the State of the 'Field' or 'Non-Field'." The International Journal of Transitional Justice, Vol. 3: Number 1. pp. 5-27.

Bennett, C.J. 1991. "What is Policy Convergence and What Causes it?" British Journal of Political Science, Vol. 21: Number 2. pp. 215-233.

Berat, Lynn. 1995. "South Africa: Negotiating Change". In Impunity and Human Rights in International Law and Practice, ed. Naomi Roht-Arriaza. New York: Oxford University Press.

Berry, F.S. and W.D. Berry. 2007. "Innovation and Diffusion Models in Policy Research". In Theories of the Policy Process, $2^{\text {nd }}$ Edition, ed. Paul A. Sabatier. Colorado: Westview Press. 
Berry, F.S. and W.D. Berry. 1999. "Innovation and Diffusion Models in Policy Research". In Theories of the Policy Process, ed. Paul A. Sabatier. Colorado: Westview Press.

Bickford, Louis. 2007. "Unofficial Truth Projects". Human Rights Quarterly, Vol. 29. pp. 994-1035.

Bickford, Louis. 2004. "Transitional Justice." Macmillan Encyclopaedia of Genocide and Crimes Against Humanity, Vol. 3. pp. 1045-1947. Sourced from: http//www.icti.org/en/ti (November 15 2009).

Blaikie, Norman. 2006. Designing Social Research: The Logic of Anticipation. Cambridge: Polity Press.

Bloomfield, David. 2006. On Good Terms: Clarifying Reconciliation. Berghof Report No. 14.

Blyth, M.M. 1997. “"Any more Bright Ideas?" The Ideational Turn of Comparative Political Economy". Comparative Politics, Vol. 29: Number. 2. pp. 229-250.

Boafo-Arthur, Kwame. 2006. "The Quest for National Reconciliation in Ghana: Challenges and Prospects". In Voting for Democracy in Ghana: The 2004 Elections in Perspectives, Thematic Studies, Vol. 1, ed. Kwame Boafo-Arthur. Accra: Freedom Publications.

Boafo-Arthur, Kwame. 2005. "National Reconciliation or Polarisation? The Politics of Ghana's National Reconciliation Commission." In The Crisis of the State and Regionalism in West Africa: Identity, Citizenship and Conflict, eds. W. Alade Fawole and Charles Ukeje. Dakar: Codesria Book Series.

Boahen, Albert A. 1995. "A Note on the Ghanaian Elections". African Affairs, Vol. 94: Number 375. pp. 277-280.

Bond, Patrick. 2000. Elite Transition: From Apartheid to Neoliberalism in South Africa. London: Pluto Press

Boone, Catherine. 1998. " "Empirical Statehood" and Reconfigurations of Political Order." In The African State at a Critical Juncture, eds. Leonardo A. Villalon and Phillip A. Huxtable. London: Lynne Rienner Publishers.

Booysen, Susan. 2006. "Public policy-making in South Africa" In Government and Politics in the new South Africa, $3^{\text {rd }}$ Edition, eds. Albert Venter and Chris Landsberg. Pretoria: Van Schaik Publishers.

Boraine, Alex. 2008. A Life in Transition. Cape Town: Zebra Press. 
Boraine, Alex. 2006. "Defining Transitional Justice: Tolerance in the search for justice and peace." In Transitional Justice and Human Security, eds. Alex Boraine and Sue Valentine. Cape Town: International Center for Transitional Justice.

Boraine, Alex. 2000a. A Country Unmasked: Inside South Africa's Truth and Reconciliation Commission. Oxford: Oxford University Press.

Boraine, Alex. 2000b. "Truth and reconciliation in South Africa: The Third Way". In Truth v. Justice. The Morality of Truth Commissions, eds. Robert I. Rotberg and Dennis Thompson. Princeton: Princeton University Press.

Boraine, Alex, Janet Levy and Ronel Scheffer. eds. 1997. Dealing with the Past. Truth and Reconciliation in South Africa. Cape Town: IDASA.

Borer, Tristan A. 2004. "Reconciling South Africa or South Africans? Cautionary Notes from the TRC". African Studies Quarterly, Vol.8: Issue 1. pp. 19-38.

Bosire, Lydiah. 2006. Overpromised, Underdelivered: Transitional Justice in SubSaharan Africa. Occasional Paper Series. New York: ICTJ.

Brahm, Eric. 2009. "Judging Truth: The Contributions of Truth Commissions in PostConflict Environments". In Negotiating Sovereignty and Human Rights: Actors and Issues in Contemporary Human Rights Politics, eds. Noha Shawki and Michaelene Cox. Surrey: Ashgate.

Brahm, Eric. 2007. "Uncovering the Truth: Examining Truth Commission Success and Impact". International Studies Perspectives, Vol. 8. pp. 16-35.

Bratton, M., C. Logan, W. Cho and P. Bauer. 2004. Afrobarometer Round 2: Compendium of Comparative Results from a Fifteen-Country Survey, Afrobarometer Working Paper 34. Afrobarometer Working Papers: Afrobarometer Network.

Burton, Mary. 2004. "Reparations-It is Still Not Too Late". In To Repair the Irreparable. Reparation and Reconstruction in South Africa, eds. Erik Doxtader and Charles VillaVicencio. Claremont: New Africa Books (Pty).

Busia Jr., Nana K.A. 2003 "Ghana: Competing Visions of Liberal Democracy and Socialism". In Human Rights Under African Constitutions: Realizing the promise for Ourselves, ed. Abdullahi Ahmed An-Na'im. Philadelphia: University of Pennsylvania Press.

Butler, Anthony. 2004. Contemporary South Africa. New York: Palgrave Macmillan.

Call, Charles. 2004. "Is Transitional Justice Really Just?" Brown Journal of World Affairs, Vol. XI: Issue 1.pp. 101-113. 
Campbell, J.L. 2002. "Ideas, Politics and Public Policy". Annual Review of Sociology, Vol. 28. pp. 21-38.

Campbell, J.L. 1998. "Institutional analysis and the role of ideas in political economy". Theory and Society, Vol. 27: Number 3. pp. 377-409.

Carothers, Thomas. 2002. "The End of Transition Paradigm." Journal of Democracy, Vol.13: Number 1. pp. 5-21.

Carpenter, R.S. 2007. "Setting the Advocacy Agenda: Theorizing Issue Emergence and Nonemergence in Transnational Advocacy Networks". International Studies Quarterly, Vol. 51: Issue 1. pp. 99-120.

Carranza, Ruben. 2008. "Plunder and Pain: Should Transitional Justice Engage with Corruption and Economic Crimes?" International Journal of Transitional Justice, Vol. 2: Issue 3. pp. 310-330.

Carroll, B.W., T. Carroll and F. Ohemeng. 2007. "A Comprehensive Approach to Third World Policy Making Process: Evidence from Botswana, Ghana and Mauritius". Research Working Paper (unpublished).

Carroll, B.W., T. Carroll and F. Ohemeng. 2003. "Is there a distinctive Third World Policy Making Process"? Paper presented at the annual meeting of the Canadian Political Science Association, Halifax, Canada.

Carroll, B.W., and T. Carroll. 1999. "Civic Networks, Legitimacy and the Policy Process." Governance: An International Journal of Policy and Administration, Vol. 12: Number 1. pp. 1-28

Center for Conflict Resolution. 2007. Peace Versus Justice? Truth and Reconciliation Commissions and War Crimes Tribunal in Africa. Policy Advisory Group Seminar Report. Cape Town: Center for Conflict Resolution.

Center for Democracy and Development (CDD). 2001. Deepening Democracy to prevent conflict and entrench sustainable development. Annual Report. Lagos: CDD

Chapman, Audrey R. 2009. "Truth Commissions and Intergroup Forgiveness: The Case of the South African Truth and Reconciliation Commission". Peace and Conflict: Journal of Peace Psychology, Vol. 13: Number 1. pp. 51-69.

Cherry, Janet. 2000. "Historical truth: something to fight for". In Looking Back Reaching Forward: Reflections of the Truth and Reconciliation Commission of South Africa, eds. Charles Villa-Vicencio and Wilhelm Verwoerd. Cape Town: University of Cape Town.

Chinapen, Rhiana and Richard Vernon. 2006. "Justice in Transition." Canadian Journal of Political Science, Vol. 39: Number 1.pp. 117-134. 
Christie, Kenneth. 2000. The South African Truth Commission. Hampshire: Macmillan Press Ltd.

Cloete, J.J.N. 1998. South African Public Administration and Management. Pretoria: JL van Schaik Publishers.

Cohen, Michael D., James G. March, and Johan P. Olsen. 1972 . "A Garbage Can Model of Organizational Choice". Administrative Science Quarterly, Vol. 17: Number. 1. pp. 125.

Common, Richard. 1998. "The new public management and policy transfer: the role of international organizations". In Beyond the New Public Management: Changing Ideas and Practices in Governance. eds. Martin Minogue, Charles Polidano and David Hulme. Cheltenham: Edward Elgar.

Conteh, Charles and Frank L.K. Ohemeng. 2009. "The Politics of Decision-Making in Developing Countries: A comparative analysis of privatization decisions in Botswana and Ghana". Public Management Review, Vol. 11: Issue 1. pp. 57-77.

Corkery, Joan, Anthony Land, and Jean Bossuyt. 1995. The Process of Policy Formulation. Institutional Path or Institutional Maze? A Study based on the introduction of cost-sharing for education in three African countries. Policy Management Report 3. European Centre for the Development Policy Management.

Daily Dispatch. 2001. Lessons from South Africa's Truth and Reconciliation. Vol. 4: No. 82 (Friday Edition). June $29^{\text {th }}$ - July 5

Daily Dispatch. 2001. Truth and Reconciliation:-A Typical South African Example. May 4-10 (Edition)

Daily Graphic. 2008. Kutu, Others to get Assets Back. Issue No. 17939. October 16.

David, Roman. 2003. "Lustration Laws in Action: The Motives and Evaluation of Lustration Policy in the Czech Republic and Poland (1989-2001)." Law and Social Inquiry, Vol. 28: Number 2. pp. 387-439.

Davis, S.M. 1987. Apartheid's Rebels: inside South Africa's hidden war. New Haven and London, Yale University Press.

Daye, Russell. 2004. Political Forgiveness: Lessons from South Africa. New York: Orbis Books.

De Brito, Alexandra Barahona, Carmen Gonzalez-Enriquez and Paloma Aguilar. 2001. "Introduction." In The Politics of Memory: Transitional Justice in Democratizing Societies, eds. Alexandra Barahona De Brito, Carmen Gonzalez-Enriquez and Paloma Aguilar. Oxford: Oxford University Press. 
De Brito, Alexandra Barahona et al, eds. 2001. The Politics of Memory: Transitional Justice in Democratizing Societies. Oxford: Oxford University Press.

Deleon, Peter. 2006. "The Historical Roots of the Field." In The Oxford Handbook of Public Policy, eds. Michael Moran, Martin Rein and Robert Goodin. New York: Oxford University Press.

Deleon, Peter. 1999. "The Stages Approach to the Policy Process: What Has It Done? Where Is it Going?" In Theories of the Policy Process, ed. Paul A. Sabatier. Colorado: Westview Press.

Dessler, David. 1999. "Constructivism within a positivist social science". Review of International Studies, Vol. 25. pp. 123-137.

Di Palma, Giuseppe. 1990. To Craft Democracies: An Essay on Democratic Transitions. Berkeley: University of California Press.

Dobrowolsky, A. and Denis Saint-Martin. 2005. "Agency, Actors and Change in a ChilFocused Future: 'Path Dependency' Problematised". Commonwealth \& Comparative Politics, Vol. 43: Number 1.pp. 1-33.

Doern, G.B. and R. W. Phidd. 1992. Canadian Public Policy: Ideas, Structure, Process, $2^{\text {nd }}$ Edition. Scarborough: Nelson Canada.

Dolowitz, P. David and David Marsh. 2000. "Learning from Abroad: the Role of Policy Transfer in Contemporary Policy-Making." Governance: An International Journal of Policy and Administration, Vol. 13: Number 1. pp. 5-24.

Dolowitz, P. D., S. Greenwold and D. Marsh. 1999. "Policy Transfer: something old, something new, something borrowed, but why red, white and blue?" Parliamentary Affairs, Vol. 52: Issue 4. pp. 719-730.

Dolowitz, P. David and David Marsh. 1998. "Policy Transfer: a framework for comparative analysis". In Beyond the New Public Management: Changing Ideas and Practices in Governance. eds. Martin Minogue, Charles Polidano and David Hulme. Cheltenham: Edward Elgar.

Dolowitz, P. David and David Marsh. 1996. "Who Learns What from Whom: a Review of the Policy Transfer Literature" Political Studies, XLIV: pp. 343-357.

Du Toit, Andre. 1997. 'No Rest Without the Wicked: Assessing the Truth Commission". Indicator SA, Vol. 4. pp. 7-12.

Dugard, John. 1997. "Retrospective Justice: International Law and the South African Model". In Transitional Justice and the Rule of Law in New Democracies, ed. A. James McAdams. Notre Dame: University of Notre Dame Press. 
Dugard, J. 1972 "The Legal Framework of Apartheid", in N.J. Rhoodie, South Africa Dialogue: contrasts in South African thinking on basic race issues. New York: McGrawHill Book Co.

Doxtader, Erik and Philippe-Joseph Salazar. 2007. Truth and Reconciliation in South Africa. The Fundamental Documents. Cape Town: Institute of Justice and Reconciliation.

Dye, Thomas. 1972. Understanding Public Policy. Englewood Cliffs, NJ: Prentice-Hall.

Edigheji, Omano and Abubakar Momoh. 2005. "Nigerian Human Rights Civil Society Organizations: Contestations and Engagements with the State (1987-2003)". Research Report. Center for Civil Society: University of KwaZulu-Natal.

Elliot-Teague, Ginger L. 2008. "Coalition lobbying in Tanzania: the experiences of local NGOs." Journal of Public Affairs, Vol. 8. pp. 99-114.

Ellis, S. 1998. "The Historical Significance of South Africa's Third Force". Journal of Southern African Studies, Vol. 24: Number 2, pp. 261-299.

Elster, Jon. 2004. Closing the Books: Transitional Justice in Historical Perspective. Cambridge: Cambridge University Press.

Evans, Mark. 2006. "At the Interface between Theory and Practice-Policy Transfer and Lesson-Drawing". Public Administration, Vol. 84: Number 2. pp. 479-515.

Evans, Mark. 2004a. "Introduction: is Policy Transfer Rational Policy-making?" In Policy Transfer in Global Perspective, ed. Mark Evans. Aldershot: Ashgate Publishing Limited.

Evans, Mark. 2004b. "Understanding Policy Transfer". In Policy Transfer in Global Perspective, ed. Mark Evans. Aldershot: Ashgate Publishing Limited.

Evans, Mark and Jonathan Davis. 1999. "Understanding Policy Transfer: A Multi-level, Multi-Disciplinary Perspective". Public Administration, Vol. 77: Number 2. pp. 361-385.

Evans, Peter, D. Rueshemeyer and Theda Skocpol, eds. 1985. Bringing the State Back In. Cambridge: Cambridge University Press.

Fatic, Aleksander. 2000. Reconciliation via the War Crimes Tribunal? Aldershot: Ashgate.

Fierke, Karin, M. 2001. "Critical Methodology and Constructivism". In Constructing International Relations: the next generation, eds. Karin M. Fierke and Knud Erik Jorgensen. New York: M.E. Sharpe. 
Finnemore, Martha and Kathryn Sikkink. 2001. "Taking Stock: The Constructivist Research Program in International Relations and Comparative Politics". Annual Review of Political Science, Vol. 4: Issue 1.pp. 391-416.

Finnemore, Martha. 1996. National Interests in International Society. Ithaca: Cornell University Press.

Fletcher, E. Laurel, Harvey M. Weinstein and Jamie Rowen. 2009. "Context, Timing and the Dynamics of Transitional Justice: A Historical Perspective." Human Rights Quarterly, Vol. 31: Number 1. pp. 163-220.

Fombad, Charles M. 2002. "Prospects for Peace Building through Truth Commissions in Africa". In The Quest for Peace in Africa: Transformation, Democracy and Public Policy, ed. Alfred Nhema. Addis Ababa: OSREA.

Freeman, Mark. 2006. Truth Commissions and Procedural Fairness. Cambridge: Cambridge University Press.

Freeman, Mark and Priscilla B. Hayner. 2003. "Truth-Telling." In Reconciliation after Violent: A Handbook, eds. David Bloomfield, Teresa Barnes and Luc Huyse. Stockholm: International IDEA.

Freeman, Richard. 2006. "Learning in Public Policy". In The Oxford Handbook of Public Policy, eds. Michael Moran, Martin Rein and Robert E. Goodin. Oxford: Oxford University Press.

Friedman, Steven. 2004. "South Africa: Building Democracy After Apartheid." In Democratic Reform in Africa: The Quality of Progress, ed. E. Gyimah-Boadi. Colorado: Lynne Rienner Publishers.

Geertz, Clifford. 1973. The Interpretation of Cultures: Selected Essays. New York: Basic Books

George, Alexander L. and Timothy J. McKeown. 1985. "Case Studies and Theories of Organizational Decision Making." In Advances in Information Processing in Organizations, eds. Lee S. Sproull, Patrick D. Larkey, Robert F. Coulam and Richard A. Smith. London: Jai Press Inc.

Ghana Center for Democratic Development (CDD-Ghana). 2006. Opinions of Victims of Past Human Rights Abuse in Ghana after the National Reconciliation Commission's Public Hearings. Accra: CDD-Ghana.

Ghana Center for Democratic Development (CDD-Ghana). 2003. Interim Report on the National Reconciliation Commission. CDD-Ghana Internal Document. 
Ghana Center for Democratic Development (CDD-Ghana). 2001a. Public Opinion on National Reconciliation in Ghana: Survey Evidence, Research Paper: Number 10. Accra: CDD-Ghana.

Ghana Center for Democratic Development (CDD-Ghana). 200lb. National Conference: International Perspectives. Report of Conference Proceedings on National Reconciliation in Ghana. Accra: CDD-Ghana.

Ghanaian Times. 2001. Make National Reconciliation a Reality: Muslims urge President. No. 13499, June 11.

Gibson, James L. 2004. Overcoming Apartheid: Can Truth Reconcile a Divided Nation? New York: Russell Sage Foundation.

Giddens, Anthony. 1993. New Rules of Sociological Method: a positive critique of interpretative sociologies, $2^{\text {nd }}$ Edition. Stanford: Stanford University Press.

Giddens, Anthony. 1984. The Constitution of Society: Outline of the Theory of Structuration. Cambridge: Polity Press.

Giddens, Anthony. 1981. A Contemporary Critique of Historical Materialism. Volume 1: Power, Property and the State. London: Macmillan.

Gill, Graeme. 2000. The Dynamics of Democratization: Elites, Civil Society and the Transition Process. New York: St. Martin's Press.

Gloppen, Sri. 2002. Reconciliation and Democratization: Outlining the Research Field. CMI Report: 5. Bergen: Chr. Michelsen Institute.

Goldfinch, Shaun. 2006. "Rituals and Reforms, Policy Transfer and the National University Corporation Reforms of Japan". Governance: An International Journal of Policy, Administration and Institutions, Vol. 19: Number 4. pp. 585-604.

Goldstone, Judith and Robert O. Keohane. 1993. "Ideas and Foreign Policy: An Analytical Framework". In Ideas and Foreign Policy: Beliefs, Institutions and Political Change, eds. Judith Goldstein and Robert $\mathrm{O}$. Keohane. Ithaca: Cornell University Press.

Goodin, Robert, Martin Rein and Michael Moran. 2006. "The Public and its Policies." In The Oxford Handbook of Public Policy, eds. Michael Moran, Martin Rein and Robert Goodin. New York: Oxford University Press.

Government of Ghana. 2006. Ghana Government Budget Statement and Economic Policy and a Supplementary Estimate. Presented by the Minister of Finance to Parliament on Thursday, July 13. 
Government of Ghana. 2002. .National Reconciliation Act (Act 611), 2002. Accra: Government Printer Assembly.

Government of Ghana. 2001. The National Reconciliation Commission Bill. Accra: Government Printer Assembly.

Government of Ghana. 1992. The 1992 Constitution of Ghana. Accra: Government Press.

Government of Kenya. 2008. Kenyan Transitional Justice and Reconciliation Commission Act (Act 2008).

Government of Nigeria. 1999. The 1999 Constitution of the Federal Republic of Nigeria.

Government of Nigeria. 1966. Tribunals of Enquiry Act.

Government of South Africa. 1996. The Constitution of the Republic of South Africa.

Government of South Africa. 1995. The Promotion of National Unity and Reconciliation Act (No 34), 1995.

Graybill, Lyn S. 2002. Truth and Reconciliation in South Africa. Miracle or Model. London: Lynne Rienner Publishers.

Green, Daniel, M. 2002. "Constructivist Comparative Politics: Foundations and Framework." In Constructivism and Comparative Politics, ed. Daniel M. Green. London: M.E. Sharpe.

Grindle, Merilee S. and John W. Thomas. 1991. Public Choices and Policy Change: The Political Economy of Reform in Developing Countries. Baltimore: The John Hopkins University Press

Grindle, Merilee S and John W. Thomas. 1989. "Policy makers, policy choices, and policy outcomes: The political economy of reform in developing countries." Policy Sciences, Vol. 22: Number 3-4. pp. 213-248.

Grindle, Merilee, ed. 1980. Politics and Policy Implementation in the Third World. Princeton, NJ: Princeton University Press.

Gyimah-Boadi, E. 2007. "Taking Account of Past Legacies: Reflections on Military Rule in Ghana". In Ghana at 50: Government, Politics and Development, ed. Joseph R.A. Ayee. Accra: Friedrich Ebert Stiftung and University of Ghana.

Gyimah-Boadi, E. 2006. "Ghana Transitional Justice Experience”. In Transitional Justice and Human Security, eds. Alex Boraine and Sue Valentine. Cape Town: International Center for Transitional Justice. 
Gyimah-Boadi, E. ed. 1993. Ghana Under PNDC Rule, 1982-1989. Dakar: Codesria Book Series.

Haas, M. Peter. 1992. "Introduction: Epistemic Communities and International Policy Coordination". International Organization, Vol. 46: Number 1. pp. 1-35.

Hacking, Ian. 1999. The Social Construction of What? Cambridge: Harvard University Press.

Hall, P.A. and Rosemary C.R Taylor. 1996. "Political Science and the Three Institutionalisms". Political Studies, Vol. 44: Issue 5. pp. 936-957.

Hall, P.A. 1993. "Policy Paradigms, Social Learning and the State: The Case of Economic Policy-making in Britain". Comparative Politics, Vol. 25: Number 3. pp. 275296.

Halliday, Fred. 2001. "The Romance of Non-state Actors". In Non-state Actors in World Politics, eds. Josselin and William Wallace. New York: Palgrave.

Hamber, Brandon. 2002. " 'Ere their Story Die': Truth, Justice and Reconciliation in South Africa". Race and Class, Vol. 44: Issue 1.pp. 61-79.

Handley, Antoinette'. 2007. "Business, Government, and the Privatization of the Ashanti Goldfields Company in Ghana." Canadian Journal of African Studies, Vol. 41: Number 1.pp. 1-37.

Harbeson, John. W. 1999. "Rethinking Democratic Transitions: Lessons from Eastern and Southern Africa". In State, Conflict, and Democracy in Africa, ed. Richard Joseph. Boulder: Lynne Rienner Publishers.

Hayner, Priscilla B. 2011. Unspeakable Truths: Transitional Justice and the Challenge of Truth Commissions. Second Edition. New York: Routledge.

Hayner, Priscilla B. 2001. Unspeakable Truths: Confronting State Terror and Atrocity. New York: Routledge.

Hayner, Priscilla B. 2000. "Same Species, different animal: how South Africa compares to truth commissions worldwide". In Looking back Reaching Forward: Reflections of the Truth and Reconciliation Commission of South Africa, eds. Charles Villa-Vicencio and Wilhelm Verwoerd. Cape Town: University of Cape Town.

Hayner, Priscilla. H. 1995. "Fifteen Truth Commissions-1974 to 1994: A Comparative Study". In Transitional Justice: How Emerging Democracies Reckon with Former Regimes Vol. 1., ed. Neil Kritz. Washington D.C: United States Institute of Peace Press. 
Hayner, Priscilla B. 1994. "Fifteen Truth Commissions- 1974-1994: A Comparative Study". Human Rights Quarterly, Vol. 16: Number 4. pp. 597-655.

Haynes, J. 1991. "Human Rights and Democracy in Ghana: The Record of the Rawlings' Regime." African Affairs, Vol. 90: Number 360. pp. 407-425.

Herz, John. 1995. "From Dictatorship to Democracy: Coping with the Legacies of Authoritarianism and Totalitarianism." In Transitional Justice: How Emerging Democracies Reckon with Former Regimes, Vol. 1, ed. Neil Kritz. Washington DC: United States Institute of Peace Press.

Higley, John, Jan Pakulski and Wlodzimierz Wesolowski. 1998. Postcommunist Elites and Democracy in Eastern Europe. London: Macmillan Press Ltd.

Hogan, John and David Doyle. 2007. "The Importance of Ideas: An A Prior Critical Juncture Framework". Canadian Journal of Political Science, Vol. 40: Number 4. pp. 883-910.

Houghton, Patrick, David. 2007. "Reinvigorating the Study of Foreign Policy Decision Making: Toward a Constructivist Approach". Foreign Policy Analysis, Vol. 3. pp. 24-45.

Howlett, Michael, M. Ramesh and Anthony Perl. 2009. Studying Public Policy: Policy Cycles and Policy Subsystems, Third Edition. Oxford: Oxford University Press.

Howlett, Michael and M. Ramesh. 2003. Studying Public Policy: Policy Cycles and Policy Subsystems, Second Edition. Oxford: Oxford University Press.

Hughes, Tim. 2004. "Composers, conductors and players: Harmony and discord in South African foreign policy making." Occasional Paper. Johannesburg: Konrad-AdenauerStiftung

Human Rights Violations Investigation Commission (HRVIC). 2002. Human Rights Violations Investigation Commission Final Report, Volume 1-7. Abuja: HRVIC.

Huntington, Samuel P. 1995. "The Third Wave: Democratization in the Late Twentieth Century". In Transitional Justice: How Emerging Democracies Reckon with Former Regimes, Vol. 1, ed. Neil Kritz. Washington D.C: United States Institute of Peace Press.

Huntington, Samuel P. 1991.The Third Wave: Democratization in the Late Twentieth Century. Norman and London: University of Oklahoma Press.

Huyse, Luc and Mark Salter. (eds.) 2008. Traditional Justice and Reconciliation after Violent Conflict: Learning from African Experiences. Stockholm: International IDEAS.

Huyse, Luc. 2003a. "Justice". In Reconciliation after Violent Conflict: a handbook, eds. David Bloomfield, Teresa Barnes and Luc Huyse. Stockholm: International IDEA. 
Huyse, Luc. 2003b. "The Process of Reconciliation". In Reconciliation after Violent Conflict: $a$ handbook, eds. David Bloomfield, Teresa Barnes and Luc Huyse. Stockholm: International IDEA.

Huyse, Luc. 1995. "Justice after Transitions: On the Choices Successor Elites Make in Dealing with the Past." In Transitional Justice: How Emerging Democracies Reckon with Former Regimes, Vol. 1, ed. Neil Kritz. Washington DC: United States Institute of Peace Press.

Idowu, A.A. 2008. "Human Rights, Democracy and Development: The Nigerian Experience". Research Journal of International Studies, Issue 8. pp. 27-41.

Ignatieff, Michael. 1996. “Article of Faith.” Index of Censorship, Vol. 5. pp. 110-122.

Thonvbere, Julius O. 1996. "Are Things Falling Apart? The Military and the Crisis of Democratization in Nigeria". The Journal of Modern African Studies, Vol. 34: Number 2. pp. 193-225.

Ikelegbe, Augustine. 2001. "The Perverse Manifestation of Civil Society: Evidence from Nigeria". The Journal of Modern African Studies, Vol. 39: Number 1. pp. 1-24.

Ikenberry, G. J. 1990. "The International Spread of Privatization Policies: Inducements, Learning, and Policy Bandwagoning". In The Political Economy of Public Sector Reform and Privatization, eds. Ezra N. Suleiman and John Waterbury. Oxford: Westview Press.

Ikhariale, Mike. 2002. "The Oputa Reports: An Unfinished Job". http://www.nigerdeltacongress.com/oarticles/oputa reports.htm. Sourced on Monday, April 6, 2009.

International Center for Transitional Justice (ICTJ). 2008a. What is Transitional Justice? New York: ICTJ. Sourced from ICTJ Webpage on February 11, 2010: http://www.ictj.org/en/tj/138.html

International Center for Transitional Justice (ICTJ). 2008b. The Canadian Truth and Reconciliation Commission. New York: ICTJ.

International Center for Transitional Justice (ICTJ). 2008c. Reparations in Ghana: Implementing the National Reconciliation Commission (NRC) Recommendations, a Preliminary Assessment. ICTJ Internal Document.

International Center for Transitional Justice (ICTJ). 2001. Nigeria Trip Report, October 22-26, 2001. ICTJ Internal Document.

James, Oliver and Martin Lodge. 2003. "The Limitations of 'Policy Transfer' and 'Lesson-Drawing' for Public Policy". Political Studies Review, Vol.1: Issue 2. pp. 179193. 
Jenkins, William. 1978. Policy Analysis: A Political and Organizational Perspective. London: Martin Robertson

John, Peter. 1998. Analysing Public Policy. London: Continuum.

Jones, Trevor and Tim Newburn. 2007. Policy Transfer and Criminal Justice: Exploring US Influence over British Crime Control Policy. Berkshire: Open University Press.

Jones, Trevor and Tim Newburn. 2002. "Learning from Uncle Sam? Exploring US Influences on British Crime Control Policy" Governance: An International Journal of Policy, Administration and Institutions, Vol. 15: Number 1. pp. 97-119.

Joseph, Richard, Scott D. Taylor and Adigun Agbaje. 1996. "Nigeria". In Comparative Politics at the Crossroads, eds. Mark Kesselman, Joel Krieger and William A. Joseph. Massachusetts: D.C. Heath and Company.

Josselin, Daphne and William Wallace. 2001. "Non-state Actors in World Politics: a Framework". In Non-state Actors in World Politics, eds. Josselin and William Wallace. New York: Palgrave.

Keck, Margaret and Kathryn Sikkink. 1998. Activities Beyond Borders; Advocacy Networks in International Politics. Ithaca: Cornell University.

Keeley, James and Ian Scoones. 2000. "Knowledge, Power and Politics: The Environmental Policy-Making Process in Ethiopia". Journal of Modern African Studies, Vol. 38: Number 1. pp. 89-120.

Kende, Mark S. 2007. "Truth commissions versus prosecutions". In Security, Reconstruction, and Reconciliation. When the wars end, ed. Muna Ndulo. London: University College London Press.

King, Gary, Robert Keohane and Sidney Verba. 1994. Designing Social Inquiry: Scientific Inference in Qualitative Research. Princeton, NJ: Princeton University Press.

Kingdon, John, W. 1995. Agendas, Alternatives, and Public Policies. Second Edition. New York: Longman

Klotz, Audie. 2002. "Transnational Activism and Global Transformation: The AntiApartheid and Abolitionist Experiences". European Journal of International Relations, Vol.8: Number 1.pp. 49-76.

Klotz, Audie. 2000. "Migration after apartheid: deracialising South African foreign policy." Third World Quarterly, Vol. 21: Number 5. pp. 831-847.

Koehn, Peter. 1983. "The role of public administrators in public policy making: practice and prospects in Nigeria." Public Administration and Development, Vol.3. pp. 1-26. 
Kottak, P.C. 1996. Mirror for Humanity: A Concise Introduction to Cultural Anthropology. New York: McGraw-Hill, Inc.

Kottak, P.C. 1974. Cultural Anthropology. New York: Random House.

Kpessa, W. Michael. 2011. "The Politics of the Public Policy in Ghana. From Closed Circuit Bureaucrats to Citizenry Engagement." Journal of Developing Societies, Vol. 27: Number 1. pp. 29-56.

Kratochwil, Friedrich. 2001. "Constructivism as an Approach to Interdisciplinary Study". In Constructing International Relations: the next generation, eds. Karin M. Fierke and Knud Erik Jorgensen. New York: M.E. Sharpe.

Kriesberg, Louis. 2004. "Comparing Reconciliation Actions Within and Between Countries". In From Conflict Resolution to Reconciliation, ed. Yaacov Bar-Siman-Tov. Oxford: Oxford University Press.

Kritz, Neil. 2002a. "Keynote Address". In Empirical Research Methodologies of Transitional Justice Mechanism. Conference Report: Organized by the American Association for the Advancement of Sciences (AAAS), Stellenbosch-South Africa. (November 18 to 20, 2002)

Kritz, Neil. 2002b. "Where We Are and How We Got Here: An Overview of Developments in the Search for Justice and Reconciliation". In The Legacy of Abuse: Confronting the Past, Facing the Future, ed. Alice Henkin. Washington D.C: The Aspen Institute.

Kritz, Neil, ed. 1995. Transitional Justice: How Emerging Democracies Reckon with Former Regimes, Vol.1. Washington DC: United States Institute of Peace Press.

Kubalkova, Vendulka, Nicholas Onuf and Paul Kowert. 1998. "Constructing Constructivism". In International Relations in a Constructed World, eds. Vendulka Kubalkova, Nicholas Onuf and Paul Kowert. New York: M.E. Sharpe.

Kukah, Matthew. 2010. "Peace versus Justice". In Peace versus Justice? The Dilemma of Transitional Justice in Africa, eds. Chandra Lekha Sriram and Suren Pillay. Woodbridge: James Currey.

Kukah, Matthew H. 2004. "Transitional Justice: Interrogating the Paradigms". Unpublished Conference Paper. Conference organized by the International Center for Transitional Justice on the theme: 'Transitional Justice in Africa: Future Directions' in Bellagio, Italy March 25-29.

Ladi, Stella. 2005a. Globalization, Policy Transfer and Policy Research Institutes. Cheltenham: Edward Elgar. 
Ladi, Stella. 2005b. "The Role of Experts in the Reform Process in Greece". West European Politics, Vol. 28: Number 2.pp. 279-296.

Larmour, Peter. 2002. "Policy Transfer and Reversal: Customary Land Registration from Africa to Melanesia". Public Administration Development, Vol. 22. pp. 151-161.

Lasswell, Harold D. 1951. "The Policy Orientation." In The Policy Sciences: Recent Developments in Scope and Method, eds. Daniel Lemer and Harold D. Lasswell. Stanford: Stanford University Press.

Lederach, Paul. 1997. Building Peace: Sustainable Reconciliation in Divided Societies. Washington D.C: United States Institute of Peace Press.

Lehman, Howard P. 2008. "The emergence of civil society organizations in South Africa." Journal of Public Affairs, Vol. 8. pp. 115-127.

Lemarchand, Rene. 1994. "Managing Transition Anarchies: Rwanda, Burundi, and South Africa in Comparative Perspective". The Journal of Modern African Studies, Vol. 32: Number 4. pp. 581-604.

Lewis, P. and Bratton, M. 2000. Attitudes to Democracy and Markets in Nigeria, Afrobarometer Working Paper 3. Afrobarometer Working Papers: Afrobarometer Network.

Lieberman, Robert. 2002. "Ideas, Institutions, and Political Order: Explaining Political Change". American Political Science Review, Vol. 96: Number 4. pp. 697-712.

Linz, Juan. 1995. "The Breakdown of Democratic Regimes: Crisis, Breakdown, and Reequilibration." In Transitional Justice: How Emerging Democracies Reckon with Former Regimes, Vol. 1, ed. Neil Kritz. Washington DC: United States Institute of Peace Press.

Llewellyn, Jennifer J. 2006. "Restorative Justice in Transitions and Beyond: The Justice Potential of Truth-Telling Mechanisms for Post-Peace Accord Societies". In Telling the Truths: Truth Telling and Peace Building in Post-Conflict Societies, ed. Tristan Anne Borer. Notre Dame: University of Notre Dame Press.

Llewellyn, Jennifer J. 2004. "Doing Justice in South Africa: Restorative Justice and Reparation". In To Repair the Irreparable. Reparation and Reconstruction in South Africa, eds. Erik Doxtader and Charles Villa-Vicencio. Claremont: New Africa Books (Pty).

Llewellyn, Jennifer J. and Robert Howse. 1999. "Institutions of Restorative Justice: The South African Truth and Reconciliation Commission". The University of Toronto Law Journal, Vol. 49: Number 3.pp. 355-388. 
Lodge, Martin. 2003. "Institutional Choice and Policy Transfer: Reforming British and German Railway Regulation". Governance: An International Journal of Policy, Administration and Institutions, Vol. 16: Number 2. pp. 159-178.

Logan, Carolyn and Fabiana Machado. 2002. Afrobarometer Round 1: Compendium of Comparative Data from a Twelve-Nation Survey, Afrobarometer Working Paper 11. Afrobarometer Working Papers: Afrobarometer Network.

Longman, Timothy. 2006. "Justice at the grass roots? Gacaca trials in Rwanda." In Transitional Justice in the Twenty-First Century: Beyond Truth versus Justice, eds. Naomi Roht-Arriaza and Javier Mariezcurrena. Cambridge: Cambridge University Press.

Majone, Giandomenico. 2006. "Agenda Setting" In The Oxford Handbook of Public Policy, eds. Michael Moran, Martin Rein and Robert Goodin. New York: Oxford University Press.

Makhalemele, Oupa. 2004. Still not talking. Government's exclusive reparations policy and the impact of the $R 30000$ financial reparations on survivors. Research Report. Brammfontein: Center for the Study of Violence and Reconciliation.

Malamud-Goti, Jaime. 1996. Game without end: state terror and the politics of justice. Norman: University of Oklahoma Press.

Malamud-Goti, Jaime. 1990. "Transitional Governments in the Breach: Why Punish State Crime?” Human Rights Quarterly, Vol.12: Number: 1. pp.1-16.

Mamdani Mahmood, 2000. "The Truth According to the TRC". In The Politics of Memory: Truth Healing and Social Justice, eds. Ifi Amadiume and Abdullahi An-Na'im. London: Zed Books.

Mandela, R. Nelson. 1994. Statement of the President of the African National Congress at his Inauguration as President of the Democratic Republic of South Africa. May 10. Union Buildings, Pretoria

Mani, Rama. 2008. "Editorial- Dilemmas of Expanding Transitional Justice, or Forging the Nexus between Transitional Justice and Development." The International Journal of Transitional Justice, Vol. 2: Number 3. pp. 253-265.

Marais, H. 1998. South Africa Limits to Change: The Political Economy of Transition. London: Zed Books.

Mayer-Rieckh, Alexander and Pablo de Greiff. 2007. Justice as Prevention: Vetting Public Employees in Transitional Societies. New York: Social Science Research Council. 
Mbeki, Thabo. 2003. Statement by President Thabo Mbeki to the National Houses of Parliament and the Nation on the occasion of the Tabling of the Report of the Truth and Reconciliation Commission. Cape Town, April 15.

McCauley, F. John and E. Gyimah-Boadi. 2009. Religious Faith and Democracy: Evidence from Afrobarometer Surveys. Afrobarometer Working Paper No. 113. Afrobarometer Working Papers: Afrobarometer Network.

McEvoy, Kieran. 2008. "Letting Go of Legalism: Developing a 'Thicker' Version of Transitional Justice." In Transitional Justice from Below: Grassroots Activism and the Struggle for Change, eds. Kieran McEvoy and Loma McGregor. Portland: Hart Publishing.

McGregor, Lorna. 2008. "International Law as a 'Tiered Process': Transitional Justice at the Local, National and International Level. In Transitional Justice from Below: Grassroots Activism and the Struggle for Change, eds. Kieran McEvoy and Loma McGregor. Portland: Hart Publishing.

Mendeloff, David. 2004. "Truth Seeking, Truth-Telling, and Postconflict Peacebuilding: Curb the Enthusiasm?" International Studies Review, Vol. 6: Issue 3. pp. 355-380.

Mendez, Juan. 1997. "In Defence of Transitional Justice." In Transitional Justice and the Rule of Law in New Democracies, ed. A. James McAdams. Notre Dame and London: University of Notre Dame Press.

Mensa-Bonsu, Henrietta. 2005. "Reconciliation and National Integration." In Public Forum on Reconciling the Nation, a compilation of presentations in a national symposium organized by the Ghana Academy of Arts and Sciences (GAAS) and the Friedrich-Ebert Foundation (FES). Accra: FES.

Migdal, S. Joel. 2001. State in Society. Studying How States and Societies Transform and Constitute One Another. Cambridge: Cambridge University Press.

Minister of Justice. 1995. "Debates of the National Assembly on the Promotion of the National Unity and Reconciliation Bill". Hansard, May 17, pp. 1339-1348.

Minister of Justice. 1994. "Debates of the National Assembly on the Promotion of the National Unity and Reconciliation Bill". Hansard, May 27, pp. 187-190.

Minow, Martha. 1998. Between Vengeance and Forgiveness. Boston: Beacon Press.

Molenaar, Arthur. 2005. Gacaca: Grassroots justice after genocide. Research Report 77 Leiden: African Studies Center. 
Morris, M. 1991. "State, capital and growth: the political economy of the national question". In South Africa's Economic Crisis, ed. Stephen Gelb. Cape Town: David Philip.

Mulder, C.P.. 1972. "The Rationale of Separate Development". In N.J. Rhoodie, South Africa Dialogue: contrasts in South African thinking on basic race issues. New York: McGraw-Hill Book Co.

Murithi, Tim. 2010. Sequencing the Administration of Justice to Enable the Pursuit of Peace. Can the ICC play a role in complementing restorative justice? Policy Brief, No.1. Cape Town: Institute of Justice and Reconciliation.

Murray, M. 1994. The Revolution Deferred. London: Verso.

Mustapha, Abdul, R. 1999. "The Nigerian Transition: Third Time Lucky or More of the Same”. Review of African Political Economy, Vol. XXVI: Number 80. pp. 277-291.

Nagy, Rosemary. 2008. "Transitional Justice as Global Project: critical reflections." Third World Quarterly, Vol. 29: Number 2. pp. 275-289.

National Reconciliation Commission. 2004. National Reconciliation Commission Report: Executive Summary. Accra: Inter-Particpations Agency.

National Reconciliation Commission. 2004. National Reconciliation Commission Final Report, Volume 1-5. Accra: Inter-Particpations Agency.

NEPAD Secretariat. 2001. The New Partnership for Africa's Development Framework.

Nesiah, Vasuki. 2006. "Truth vs. Justice? Commissions and Courts". In Human Rights and Conflict. Exploring the Links between Rights, Law, and Peacebuilding, eds. Julie A. Mertus and Jeffrey W. Helsing. Washington D.C.: United States Institute for Peace.

New Africa. 2001. Ghana: A new order cometh (Cover Story). Issue No. 391, February, pp. 16-17.

New Patriotic Party (NPP). 2000. Agenda for Positive Change: Manifesto 2000 of the New Patriotic Party. Accra: NPP.

Nhema, Alfred. 2004. "Introduction." In The Quest for Peace in Africa: Transformation, Democracy and Public Policy, ed. Alfred Nhema. Addis Ababa: OSREA.

Ní Aoláin, Fionnuala and Colm Campbell. 2005. "The Paradox of Transition in Conflicted Democracies." Human Rights Quarterly, Vol. 27: Number 1. pp. 172-213.

Nino, Carlos. 1996. Radical Evil on Trial. New Haven and London: Yale University Press. 
Nino, Carlos. 1991. The Ethics of Human Rights. Oxford: Clarendon Press.

Ninsin, K. A. (ed). 1998. Ghana: Transition to Democracy. Dakar: Codesria Book Series.

North, Douglass C. 1990. Institutions, Institutional Change and Economic Performance. Cambridge: Cambridge University Press.

Nwogu, Nneoma V. 2007. Shaping Truth, Reshaping Justice: Secretarian Politics and the Nigerian Truth Commission. New York: Rowman \& Littlefield Publishers, Inc.

Obasanjo, Olusegun. 1999. A New Dawn: Selected Speeches by Olusegun Obasanjo Vol.1. Abuja.

Obiagwu, Chinoye and Chidi A. Odinkalu. 2003. "Nigeria: Combating Legacies of Colonialism and Militarism". In Human Rights under African Constitutions: Realizing the promise for Ourselves, ed. Abdullahi Ahmed An- $\mathrm{Na}$ 'im. Philadelphia: University of Pennsylvania Press.

O' Donnell, G and P. C. Schmitter. 1986. Transition from Authoritarian Rule: Tentative Conclusions about Uncertain Democracies. Baltimore: Johns Hopkins University Press.

Office of the United Nations High Commissioner for Human Rights. 2006. Rule-of- Law Tools for Post-Conflict States. Vetting: An Operational Framework. New York: United Nations.

Office of the High Commissioner for Human Rights. 2006. Rule-of- Law Tools for PostConflict States. Truth commissions. New York: United Nations.

Ohemeng, F.L.K. 2010. "The new Charter System in Ghana: the 'holy grail' of public service delivery". International Administrative Review Science, Vol. 76: Number 1, pp. 115-136.

Ohemeng, Frank. 2005. "Getting the state right: think tanks and the dissemination of New Public Management ideas in Ghana." Journal of Modern African Studies, Vol. 43: Number 3. pp. 443-465.

Ojo, Emmanuel O. 2006. "Human Rights and Sustainable Democracy in Nigeria (19992003". Journal of Social Science, Vol. 13: Number 1. pp. 15-29.

Okafor, Victor O. 2006. A Roadmap for Understanding African Politics: Leadership and Political Integration in Nigeria. New York: Routledge.

Oko, Okechukwu. 2005. "Seeking Justice in Transitional Societies: An Analysis of the Problems and Failures of the Judiciary in Nigeria". Brooklyn Journal of International Law, Vol.31: Number 1. pp. 9-82. 
Okyere-Darko, Eric. 2005. The Ghana National Reconciliation Commission: Looking Back and the way Forward. A monograph (unpublished)

O'Meara, D. 1996. Forty Lost Years: The Apartheid State and the Politics of the National Party, 1948-1994. Athens: Ohio University Press.

Omotola, J.S. 2007. "Democratization, Good Governance and Development in Africa: The Nigerian Experience". Journal of Sustainable Development in Africa, Vol. 9: Number 4. pp. 247-274.

Onuf, N. 1998. “Constructivism: A User's Manual”. In International Relations in a Constructed World, eds. Vendulka Kubalkova, Nicholas Onuf and Paul Kowert. New York: M.E. Sharpe

Onyegbula, Sonny C. 2004. "Reparation Policy in Nigeria". In To Repair the Irreparable. Reparation and Reconstruction in South Africa, eds. Erik Doxtader and Charles VillaVicencio. Claremont: New Africa Books (Pty).

Oquaye, Mike. 2004. Politics in Ghana, 1982-1992: Rawlings, Revolution and Populist Democracy. Accra: Tornado Publications.

Oquaye, Mike. 1995. "Human Rights and the Transition to Democracy under the PNDC in Ghana". Human Rights Quarterly, Vol. 17: Number 3. pp. 556-573.

Oquaye, Mike. 1980. Politics in Ghana, 1972-1979. Accra: Tornado Publications.

Orentlicher, Diane F. 2007. “'Settling Accounts' Revisited: Reconciling Global Norms With Local Agency." International Journal of Transitional Justice, Vol. 1: Issue 1. pp. 10-22.

Orentlicher, Diane F. 1995. "Settling Accounts: The Duty to Prosecute Human Rights Violations of a Prior Regime." In Transitional Justice: How Emerging Democracies Reckon with Former Regimes, Vol. 1, ed. Neil Kritz. Washington DC: United States Institute of Peace Press.

Orr, Wendy. 2000. "Reparation delayed is healing retarded". In Looking back Reaching Forward: Reflections of the Truth and Reconciliation Commission of South Africa, eds. Charles Villa-Vicencio and Wilhelm Verwoerd. Cape Town: University of Cape Town.

Pal, Leslie A. 2006. Beyond Policy Analysis: Public Issue Management in Turbulent Times. Third Edition. Toronto: Thomson and Nelson.

Palmer-Buckle, Charles. 1998. Sermon for the Celebration of the $16^{\text {th }}$ Martyrs Day Service. A paper presented at the $16^{\text {th }}$ day remembrance service delivered at the Ebenezer Presbyterian Church, Osu-Accra, Ghana. 
Parliament of Ghana. 2001. Report of the Committee on Constitutional, Legal and Parliamentary Affairs on the National Reconciliation Bill. Accra: Parliament of Ghana

Pedersen, Jon. 2005. "Ideas, think-tanks, commissions, and global politics". In International Commissions and the Power of Ideas, eds. Thakur, Ramesh, Andrew F. Cooper and John English. Tokyo: United Nations University Press.

Pham, Phuong and Patrick Vinck. 2007. "Empirical Research and the Development and Assessment of Transitional Justice Mechanisms". International Journal of Transitional Justice, Vol. 1. pp. 231- 248.

Pham, Phuong et al. 2005. Forgotten Voices. A Population-Based Survey of Attitudes about Peace and Justice in Northern Uganda. Research Report. Berkeley: International Center for Transitional Justice and Human Rights Center, University of California.

Pietkiewicz, Igor. 2008. Culture, Religion, and Ethnomedicine: The Tibetan Diaspora in India. Lanham, Maryland: University Press of America, Inc.

Posel, Deborah and Graeme Simpson. 2002. "The Power of Truth: South Africa's Truth and Reconciliation Commission in Context". In Commissioning the Past. Understanding South Africa's Truth and Reconciliation Commission, eds. Deborah Posel and Graeme Simpson. Johannesburg: Witwatersrand University Press.

Posel, Deborah. 2002. "The TRC Report: what Kind of History? What Kind of Truth? In Commissioning the Past. Understanding South Africa's Truth and Reconciliation Commission, eds. Deborah Posel and Graeme Simpson. Johannesburg: Witwatersrand University Press.

Price, Richard and Christian Reus-Smit. 1998. "Dangerous Liaisons?: Critical International Theory and Constructivism". European Journal of International Relations, Vol. 4: Number 3. pp. 259-294.

Przeworski, Adam and Cheibub, A. Jose. 1998. "Culture and Democracy". In World Culture Report: Culture, Creativity and Markets. Paris: UNESCO

Przeworski, Adam and Henry Teune. 1970. The Logic of Comparative Social Inquiry. New York: Wiley-Interscience.

Quainoo, Samuel E. 2000. Transitions and Consolidation of Democracy in Africa. New York: Binghamton University.

Quinn, R. Joanna. 2009. "Chicken and Egg? Sequencing in Transitional Justice: The Case of Uganda." International Journal of Peace Studies, Vol. 14: Number 2. pp. 35-53. 
Radaelli, C. M. 2000. "Policy Transfer in the European Union: Institutional Isomorphism as a Source of Legitimacy". Governance: An International Journal of Policy and Administration, Vol. 13: Number 1. pp. 25-43.

Republic of Liberia. 2009. The Liberian Truth and Reconciliation Commission Final Report.

Republic of South Africa. 1995. "Debates of the National Assembly on the Promotion of the National Unity and Reconciliation Bill". Hansard, May 3, pp. 795-802.

Republic of South Africa. 1993. The 1993 Interim Constitution of the Republic of South Africa.

Riker, William H. 1985. "Comments on "Case Studies and Theories of Organizational Decision Making'." In Advances in Information Processing in Organizations, eds. Lee S. Sproull, Patrick D. Larkey, Robert F. Coulam and Richard A. Smith. London: Jai Press Inc.

Risse-Kappen, Thomas. 1995a. "Ideas Do not Float Freely: Transnational Coalitions, Domestic Structures, and the End of Cold War". In International Relations Theory and the End of the Cold War, eds. Richard Ned Lebow and Thomas Risse-Kappen. New York: Columbia University Press.

Risse-Kappen, Thomas. 1995b. "Bringing transnational relations back in: introduction". In Bringing transnational relations back in: Non-state actors, domestic structures and international institutions, ed. Thomas Risse-Kappen. Cambridge: Cambridge University Press.

Risse, Thomas. 2002a. "Constructivism and international institutions: towards conversations across paradigms". In Political Science: State of the Discipline, eds. Ira Katznelson and Helen V. Milner. New York: W.W. Norton \& Company.

Risse, Thomas 2002b. "Transnational Actors and World Politics". In Handbook of International Relations, eds. Walter Carlsnaes, Thomas Risse and Beth A. Simmons. London: Sage Publications.

Roht-Arriaza, Naomi. 2006. "The new landscape of transitional justice." In Transitional Justice in the Twenty-First Century: Beyond Truth versus Justice, eds. Naomi RohtArriaza and Javier Mariezcurrena. Cambridge: Cambridge University Press.

Roht-Arriaza, Naomi. 2001. "The Role of International Actors in National Accountability Processes". In The Politics of Memory: Transitional Justice in Democratizing Societies, eds. A.B. De Brito, Gonzalez-Enriquez, and P. Aguilar. Oxford: Oxford University Press.

Roht-Arriaza, Naomi. ed. 1995. Impunity and Human Rights in International Law and Practice. New York: Oxford University Press. 
Rose, Richard. 2005. Learning from Comparative Politics: A Practical Guide. London: Routledge.

Rose, Richard. 1993. Lesson-drawing in Public Policy: A Guide to Learning Across Time and Space. Chatham, $\mathrm{NJ}$ : Chatham House Publishers, Inc.

Rose, Richard.1991. "What Is Lesson-Drawing?" Journal of Public Policy, Vol. 11: Number 1. pp. 3-30.

Ross, M.H. 1997. "Culture and Identity in Comparative Political Analysis". In Comparative Politics: Rationality, Culture and Structure, eds. Mark I. Lichbach and Alan S. Zuckerman. Cambridge: Cambridge University Press.

Rotberg, Robert I. 2000. "Truth Commissions and the Provisions of Truth, Justice, and Reconciliation". In Truth $v$. Justice. The Morality of Truth Commissions, eds. Robert I. Rotberg and Dennis Thompson. Princeton: Princeton University Press.

Rushton, Beth. 2006. "Truth and reconciliation? The experience of Truth Commissions". Australian Journal of International Affairs, Vol. 60: Number 1. pp. 125-141.

Saasa, Oliver. 1985. "Public policy-making in developing countries: the utility of contemporary decisions-making models." Public Administration and Development, Vol.5: Number 4. pp. 309-321.

Sabatier, Paul A and Christopher Weible. 2007. "The Advocacy Coalition Framework: Innovations and Clarifications." In Theories of the Policy Process, Second Edition, ed. Paul A. Sabatier. Colorado: Westview Press.

Sabatier, Paul A and Hank Jenkins-Smith. 1999. "The Advocacy Coalition Framework: An Assessment." In Theories of the Policy Process, ed. Paul A. Sabatier. Colorado: Westview Press.

Sabatier, Paul A. 1988. "An Advocacy Coalition Framework: Revisions and Relevance for Europe." Journal of European Public Policy, Vol. 5: Issue 1. pp. 98-130.

Sachs, Albie. 2009. The Strange Alchemy of Life and Law. Oxford: Oxford University Press.

Salazar, Philippe-Joseph. 2004. "The Joint Sitting of Parliament, 15 April 2003: A Rhetorical View of the Reparation Debate". In To Repair the Irreparable. Reparation and Reconstruction in South Africa, eds. Erik Doxtader and Charles Villa-Vicencio. Claremont: New Africa Books (Pty).

Sarkin, Jeremy. 1996. "The Trials and Tribulations of South Africa's Truth and Reconciliation Commission". Africa Journal of Human Rights, Vol. 17. pp. 617-640. 
Sarpong, K. Peter. 1996. The Role of Religious Bodies in the Search for Peace and Reconciliation in Ghana. A paper presented at a National Forum on Peace and Reconciliation at Golden Tulip Hotel, Accra, Ghana.

Saul, J. 2004. "Postwar and Post-Apartheid: The Costs and Benefits of PeaceBuilding, South African Style". In Challenges for Peacebuilding in Africa, eds. Taisier M. Ali and Robert O. Matthews. Toronto: University of Toronto Press.

Secretary-General. 2004. The Rule of Law and Transitional Justice in Conflict and PostConflict Societies. Report by the Secretary-General: UN Security Council S/2004/616. August 232004.

Shea, Dorothy. 2000. The South African Truth Commission: The Politics of Reconciliation. Washington D.C: United States Institute of Peace.

Shillington, K. 1992. Ghana and the Rawlings Factor. London: Macmillan Press.

Sikkink, Kathryn and Carrie Booth Walling. 2007. "The Impact of Human Rights Trials in Latin America." Journal of Peace Research, Vol. 44: Number 4. pp. 427-445.

Sikkink, Kathryn and Carrie B. Walling. 2006. "Argentina's contribution to global trends in transitional justice". In Transitional Justice in the Twenty-First Century: Beyond Truth versus Justice, eds. Naomi Roht-Arriaza and Javier Mariezcurrena. Cambridge: Cambridge University Press.

Sikkink, Kathryn. 1993. "Human Rights, Principled-Issue Networks, and Sovereignty in Latin America”. International Organization, Vol. 47: Number 3. pp. 411-441.

Simpson, Graeme. 2002. "Tell No Lies, Claim No Easy Victories: A Brief Evaluation of South Africa's Truth and Reconciliation Commission". In Commissioning the Past. Understanding South Africa's Truth and Reconciliation Commission, eds. Deborah Posel and Graeme Simpson. Johannesburg: Witwatersrand University Press.

Skaar, Elin. 1999. "Truth commissions, trials-or nothing? Policy options in democratic transitions". Third World Quarterly, Vol. 20: Number 6. pp. 1109-1128.

South African Truth and Reconciliation Commission (SATRC). 1998. South African Truth and Reconciliation Commission Final Report, Volume 1-7. Cape Town: SATRC.

Sriram, Chandra L. 2007. "Justice as Peace: Liberal Peacebuilding and strategies of transitional justice". Global Society, Vol. 21: Issue 4. pp.571-591.

Stan, Lavinia. 2009. "Introduction: post-communist transition, justice, and transitional justice." In Transitional Justice in Eastern Europe and the Former Soviet Union, ed. Lavinia Stan. London: Routledge. 
Stanley, Elizabeth. 2001. "Evaluating the Truth and Reconciliation Commission". Journal of Modern African Studies, Vol. 39: Number 3. pp. 525-546.

Stone, Diane. 2004. "Transfer agents and global networks in the 'transnationalization' of policy". Journal of European Public Policy, Vol. 11: Number 3. pp. 545-566.

Stone, Diane. 2001. "Learning Lessons, Policy Transfer and the International Diffusion of Policy Ideas". CSGR Working Paper No. 69/01. Center for the Study of Globalization and Regionalization, University of Warwick.

Stritch, Andrew. 2005. "Power Resources, Institutions and Policy Learning: The Origins of Workers' Compensation in Quebec". Canadian Journal of Political Science, Vol. 38: Number 3. pp. 549-579.

Surty, Enver (MP). 2008. Input by Mr. Enver Surty, Member of Parliament and the Minister of Justice and Constitutional Development at a Conference on the Recommendations of the Truth and Reconciliation Commission (TRC). Cape Town, October 29.

Susskind, Lawrence. 2006. "Arguing, Bargaining, and Getting Agreement." In The Oxford Handbook of Public Policy, eds. Michael Moran, Martin Rein and Robert Goodin. New York: Oxford University Press.

Swidler, Ann. 1986. "Culture in Action: Symbols and Strategies." American Sociological Review,Vol. 51: Number.2. pp. 273-286.

Tamuno, Tekena N. 1989. "The Search for Viable Policies." In Nigeria Since Independence: The First 25 Years, Vol. IV (Government and Public Policy), eds. Tekena N. Tamuno and J.A. Atanda. Ibadan: Heinemann Educational Books (Nigeria Ltd).

Tarrow, Sidney. 2001. "Transnational Politics: Contention and Institutions in International Politics". Annual Review of Political Science, Vol. 4: Issue 1. pp. 1-20

Tavits, Margit. 2003. "Policy Transfer and Uncertainty: The Case of Pension Reform in Estonia and Latvia". The Policy Studies Journal, Vol. 31: Number 4. pp. 643-660.

Teitel, Ruti G. 2008. "Editorial Note-Transitional Justice Globalized." The International Journal of Transitional Justice, Vol. 2: Number 1. pp. 1-4.

Teitel, Ruti. G. 2003a. "Transitional Justice Genealogy." Harvard Human Rights Law Journal, Vol. 16. pp. 69-94

Teitel, Ruti G. 2003b. "Theoretical and International Framework: Transitional Justice in New Era." Fordham International Law Journal, Vol. 26: Issue 4. pp. 893-906.

Teitel, Ruti G. 2000. Transitional Justice. Oxford: Oxford University Press. 
Teitel, Ruti G. 1995. "How are the New Democracies of the Southern Cone Dealing with the Legacy of Past Human Rights Abuses?" In Transitional Justice: How Emerging Democracies Reckon with Former Regimes, Vol. 1, ed. Neil Kritz. Washington DC: United States Institute of Peace Press.

The Chronicle Newspaper, 2004. NDC will set up own NRC. Vol. 13. No. 12. September 27.

Thelen, Kathleen. 1999. "Historical Institutionalism in Comparative Politics". Annual Review of Political Science, Vol. 2. pp. 369-404.

Thelen, Kathleen and Sven and Steinmo. 1992. "Historical Institutionalism in Comparative Politics". In Strucuturing Politics: Historical Institutionalism in Comparative Analysis, eds. Sven Steinmo, Kathleen Thelen, and Frank Longstreth. Cambridge: Cambridge University Press.

Thomas, Caroline. 2004. "The international financial institutions' relations with Africa: Insights from the issue of representation and voice." In Africa in International Politics: External involvement on the Continent, eds. Ian Taylor and Paul Williams. London and New York: Routledge

Thoms, Oskar, James Ron, and Roland Paris. 2008. "The Effects of Transitional Justice Mechanisms: A Summary of Empirical Research Findings and Implications for Analysts and Practitioners." Working Paper. Centre for International Policy Studies. University of Ottawa.

Tungaraza, Felician S.K. 2004. "Social Policy Formulation in Tanzania." In The Quest for Peace in Africa: Transformation, Democracy and Public Policy, ed. Alfred Nhema. Addis Ababa: OSREA.

Turner, Mark and David Hulme. 1997. Governance, Administration and Development: Making the State work. Connecticut: Kumarian Press.

Tutu, Desmond. M. 1999. No Future Without Forgiveness. New York: Doubleday.

United Nations. 2006: Handbook on Restorative Justice Programmes. Criminal Justice Handbook Series. Vienna: United Nations Office on Drugs and Crime.

Uvin, Peter. 2003. "The Gacaca Tribunals in Rwanda." In Reconciliation after Violent: $a$ handbook, eds. David Bloomfield, Teresa Barnes and Luc Huyse. Stockholm: International IDEA.

Valji, Nahla. 2006. Ghana's National Reconciliation Commission: A Comparative Assessment. New York: ICTJ. 
Villa-Vicencio, Charles. 2009. Walk with Us and Listen. Political Reconciliation in Africa. Washington D.C.: Georgetown University Press.

Villa-Vicencio, Charles. 2004. "Restorative Justice". In Pieces of the Puzzle: Keywords on Reconciliation and Transitional Justice, eds. Charles Villa-Vicencio and Erik Doxtader. Cape Town: Institute of Justice and Reconciliation

Vinck, Patrick et al. 2008. Living in Fear. A Population-Based Survey on Attitudes about Peace, Justice and Social Reconstruction in Eastern Democratic Republic of Congo. Berkeley: Human Rights Center, University of California, Payson Center for International Development, Tulane University, and International Center for Transitional Justice.

Walaza, Nomfundo. 2000. "Insufficient healing and reparation". In Looking Back Reaching Forward: Reflections of the Truth and Reconciliation Commission of South Africa, eds. Charles Villa-Vicencio and Wilhelm Verwoerd. Cape Town: University of Cape Town.

Weber, Max. 1958. The Protestant Ethic and the Spirit of Capitalism. New York: Charles Scribner and Sons.

West Africa. 2003. Ghana: Long road to reconciliation (Cover Story) Discord over reconciliation. Issue No. 4375, May 12-18. pp. 8-9.

West Africa. 2001. Cover Story: Rights Inquiry divides Nigeria (Cover Story). Issue No. 4295, October 1-7.

Wilson, Richard A. 2001.The Politics of Truth and Reconciliation in South Africa. New York: Cambridge University Press.

Wilson, Richard A. 2000. "Reconciliation and Revenge in Post-Apartheid South Africa. Rethinking Legal Pluralism and Human Rights". Current Anthropology, Vol. 41: Number 1. pp. 75-87.

Wight, Colin. 2006. Agents, Structures and International Relations. Cambridge: Cambridge University Press.

Worden, Nigel. 1994. The Making of Modern South Africa, Third Edition. Oxford: Blackwell Publishers.

Yusuf, Hakeem O. 2008. "Calling the Judiciary to Account for the Past: Transitional Justice and Judicial Accountability in Nigeria". Law and Policy, Vol. 30: Number 2. pp. 194-226.

Yusuf, Hakeem. O. 2007. "Travails of Truth: Achieving Justice for Victims of Impunity in Nigeria". International Journal of Transitional Justice, Vol.1. pp. 268-286. 
Zalaquett, Jose. 2006. Interview on Truth Commissions. In Confronting the Truth: Truth Commissions and Societies in Transition. A documentary on Truth Commissions. DVD, a production of YORK Zimmerman Inc and the United States Institute for Peace. Washington D.C.

Zalaquett, Jose. 1995. "Confronting Human Rights Violations Committed by Former Governments: Principles Applicable and Political Constraints." In Transitional Justice: How Emerging Democracies Reckon with Former Regimes, Vol. 1, ed. Neil Kritz. Washington DC: United States Institute of Peace Press.

Zunes, Stephen. 1999. "The Role of Non-Violent Action in the Downfall of Apartheid". The Journal of Modern African Studies, Vol. 37: Number 1. pp. 137-169.

Zyl, Paul V. 2005. "Promoting Transitional Justice in Post-Conflict Societies". In Security Governance in Post-Conflict Peacebuilding, eds. Alan Bryden and Heiner Hanggi. Geneva: Geneva Center for Democratic Control of Armed Forces.

Zyl, Paul V. 2002. 'Unfinished Business: The Truth and Reconciliation Commission's Contribution to Justice in Post-Apartheid South Africa". In Post Conflict Justice, ed. M. Cherif Bassiouni. New York. Transnational Publishers, Inc. 